Max-Planck-Institut für demografische Forschung

Max Planck Institute for Demographic Research

Konrad-Zuse-Strasse 1 - D-18057 Rostock - GERMANY

Tel +49 (0) 3812081 - 0; Fax +49 (0) 3812081 - 202;

http://www.demogr.mpg.de

MPIDR WORKING PAPER WP 2003-030

SEPTEMBER 2003

\title{
The late life legacy of very early life
}

Gabriele Doblhammer (doblhammer@demogr.mpg.de)

This working paper has been approved for release by: James W. Vaupel (jwv@ demogr.mpg.de)

Head of the Laboratory of Survival and Longevity.

(C) Copyright is held by the authors.

Working papers of the Max Planck Institute for Demographic Research receive only limited review.

Views or opinions expressed in working papers are attributable to the authors and do not necessarily reflect those of the Institute. 


\section{Contents}

of Birth

Cohort studies

Ecological studies and place of birth $\quad 11$

The fetal origins hypothesis of adult disease $\quad 14$

$\begin{array}{ll}\text { Life-course factors } & 16\end{array}$

$\begin{array}{ll}\text { Month of birth } & 17\end{array}$

II Differences in Life Span by Month of Birth in Austria, 19

Denmark, Australia, and Hawaii

Data and method $\quad 21$

$\begin{array}{ll}\text { Results } & 24\end{array}$

Seasonal distribution of deaths 32

Social differences in the seasonal distribution of births - $\quad 37$

the procreational habits hypothesis

The deadline hypothesis $\quad 40$

Selective survival in the first year of life or debilitation 43

$\begin{array}{ll}\text { in-utero or in infancy } & \\ \text { Conclusion } & 46\end{array}$

III Differences in Life Span by Month of Birth in the United 49

States

Data $\quad 54$

Method $\quad 55$

Results $\quad 56$

Latitude and temperature $\quad 56$

Education, race, marital status $\quad 57$

Region of birth $\quad 60$

Conclusion 64

IV Month of Birth and Causes of Death $\quad 69$

$\begin{array}{ll}\text { Malignant Neoplasms } & 69\end{array}$

Diseases of the circulatory system $\quad 74$

Diseases of the respiratory system and infectious disease $\quad 78$

$\begin{array}{ll}\text { Non-natural causes of death } & 80\end{array}$

Diseases of the nervous and mental system 83

Conclusion $\quad 84$

V Does the Mortality Advantage of the Fall-born Exist at All $\quad 89$

Ages

$\begin{array}{ll}\text { Data and Method } & 91\end{array}$ 
Results 94

Comparison Danish register data \& Danish twin data $\quad 94$

Danish register data 96

Danish twin data $\quad 99$

Us census data $\quad 103$

$\begin{array}{ll}\text { Conclusion } & 109\end{array}$

VI The Month-of-Birth Pattern of Migrants and Farmers 110

$\begin{array}{ll}\text { Data and Method } & 114\end{array}$

Results 114

British Migration to Australia 116

Internal US Migration 121

The month-of-birth pattern of farmers, non-farmers and 123

$\begin{array}{ll}\text { Conclusion } & 125\end{array}$

VII Do the Differences in Life Span by Month of Birth Persist 127 among Cohorts Born Today?

$\begin{array}{ll}\text { Birthweight } & 129\end{array}$

Current weight 130

Length at birth and height gain during the first year of 131

life

Current height 137

Data and Method 139

Results $\quad 145$

$\begin{array}{ll}\text { Conclusion } & 149\end{array}$

$\begin{array}{llr}\text { VIII Summary } & 169\end{array}$

Appendix $\quad$ Three Methods of Smoothing Seasonal Data 181

$\begin{array}{ll}\text { References } & 177\end{array}$ 


\section{ONE}

\section{THE DEMOGRAPHIC AND EPIDEMIOLOGICAL CONTEXT OF THE MONTH OF BIRTH}

When is a person's lifespan determined? At conception through genes, in-utero, during childhood and adolescence, or at adult ages through environmental factors? Different opinions prevailed at different times in the course of the $20^{\text {th }}$ century and are still hotly debated. Infancy and childhood were seen as the critical phase in the first thirty years of the twentieth century. Since then the emphasis has turned on life-style factors and, thus, adult ages. However, since the 1970s new evidence has been emerging that chronic disease is rooted in infancy and childhood. In the last decade an influential theory traces the antecedents of heart disease and diabetes back to the womb. The theory claims that nutrition and infectious disease during pregnancy of the mother is responsible for an increased susceptibility of the child to heart disease and diabetes once it reaches adult ages. The interpretation of this recent research, however, has been challenged. Deprivation in-utero and during childhood may simply be the starting point of deprivation throughout life. The increased susceptibility later in life may, thus, be the result of the life-long accumulation of detrimental effects.

In this debate - whether chronic disease at adult ages is determined by "programming" in-utero or in childhood or whether early-life factors are mediated through the lifelong accumulation of detrimental effects - the month of birth fits in. To contribute to the debate an indicator of the environment early in life is needed which does not have any life course interpretation. Starting with the work of Ellsworth Huntington (1934) a large body of epidemiological research (see Chapter 4) proposes that month of birth is such an indicator. This monograph takes up this idea and explores the month-ofbirth pattern in survival and causes of death. An extensive part of this monograph, however, is devoted to the question whether month of birth is indeed free of social confounding and of life course interpretation. 
If month of birth is a measure of the seasonal changes in the environment early in life and independent from life course factors then the differences by month of birth indicate that the very first period of life influences late life mortality and the susceptibility to chronic disease.

This chapter follows the debate about the critical age at which adult mortality is determined from the first articles that were published at the beginning of the $20^{\text {th }}$ century to the most recent research today. A better understanding of this research will allow the reader of the monograph to put the results of the following chapters, which mainly deal with the differences in life span by month of birth, into a broader perspective.

Cohort analysis from the 1920s and 1930s for England and Wales and Scotland (Derrick 1927, Kermack, McKendrick and McKinley, 1934) suggested that up until 1925, year of birth was more important than year of death in predicting mortality. In 1927, Derrick plotted age-specific mortality rates of the period 1716 to 1916 against year of birth, rather than year of death, and found that the curves were strikingly parallel. The parallel curves imply that the relative mortality decline of successive birth cohorts is the same in all age groups. Derrick rightly interpreted the parallel curves as indicating that each succeeding cohort experienced a lower mortality risk at all ages. This is contrary to period effects, which would affect different age groups in different birth cohorts and would thus distort the parallelism of the mortality trajectories.

Derrick had excluded child mortality under the age of ten because he was interested in the general law of mortality. He argued that the environmental improvements that had resulted in the reduction of child mortality would disturb this general law. Seven years later Kermack, McKendrick and McKinley postulated that it is the level of child mortality that determines the mortality of the cohorts at older ages. In their 1934 article, which has been recently reprinted (Kermack et al. 2001), they used the same data as Derrick but included child and infant mortality. They took the age-specific mortality in the year 1845 for England and Wales as their base year and calculated the relative mortality of the same age groups in the period 1855 to 1925 relative to that base year. They found the general pattern that cohorts carried with them the same relative mortality throughout life. At each age, each succeeding cohort had a lower relative mortality than the previous cohort. However, infant mortality did not follow this general 
pattern and only started to decline after the turn of the century, well after mortality at later ages. The authors argue

"It has been observed that the improvement in the infantile death-rate became apparent only after 1901. If we remember that before birth and during its first year of life, the child is dependent of its welfare to a very large degree upon the general health and vitality of the mother, then it would be expected that a substantial improvement in the health of the latter would show itself in a reflected improvement in the infantile deathrate. The mothers of 1901 would on the average be born about 1870 or possibly a little later, and, ( ), the health offemales born at that date has so far improved that the deathrate was improved by about 30 per cent in the case of Scottish and by about 40 per cent in the case of English mothers. It is suggested that this may constitute at least one of the factors conducive to the improvement of infantile mortality in the present century. "

(p. 681, Kermack, McKendrick \& McKinley 1934, 2001)

As an explanation for the regularity of the relative mortality-rates at other ages than infancy and childhood they remark that "the figures behave as if the expectation of life was determined by the conditions which existed during the child's earlier years." And they postulate

"..the health of the child is determined by the environmental conditions existing during the years $0-15$, and (...) the health of the man is determined by the physical constitution which the child has built up."

(p. 680, Kermack, McKendrick \& McKinley 1934, 2001)

The latter two statements obviously contradict the first statement about the onset of the decrease in infant mortality. Since the onset of the decrease in infant mortality is delayed as compared to the onset of the decrease in adult mortality, it can hardly determine the mortality of the survivors of each cohort.

Despite this contradiction (see also Harris 2001) their paper was a landmark in the analysis of birth cohort influences on adult disease risk since it was the first to formulate 
hypotheses regarding early-life exposures and their influence on later disease (Davey Smith and Kuh 2001).

Kermack et al. (1934, 2001) did a similar analysis for Sweden calculating relative mortalities to the base year 1755. For Sweden the cohort decline is not as clear as for England and Wales. The authors argue that a rectangular block dating from 1855 onwards, and affecting the age groups 10 to 30 years primarily causes the disturbances in the cohort decline. If the block is omitted a cohort decline is observed. This result, however, could not be replicated by a study of Swedish mortality between 1778 and 1993 by Vaupel et al. (1997). The authors calculate probabilities of death relative to agespecific levels from 1778 to 1799 and plotted them in form of a shaded contour map. They come to the conclusion that "the pattern is clearly more complex than a pure cohort-effect model would suggest"(Vaupel et al. 1997, page 63). Further studies that took death rates relative to a period earlier than 1870 and that found a pattern which suggests a cohort decline of adult mortality were conducted by Preston and van der Walle (1978) and Coale and Kisker (1990) .

In their review (Kuh and Davey Smith 1993) of the historical debate on the question when the mortality risk is determined, Kuh and Davey Smith show how these early studies influenced public health policies in Great Britain. However, soon public health interest in early-life determinants of adult mortality dissipated. One reason for this was that the year of birth lost its predictive power in terms of mortality prediction by 1925 and period factors became more and more important. Davey Smith and Kuh (2001) updated the table of relative mortality-rates for England and Wales from the Kermack paper and showed that there are dramatic differences between observed and predicted mortality rates. At younger ages, mortality rates fell faster than predicted on the basis of birth cohort regularities, whereas at older ages, mortality declined at a much slower rate than predicted.

Elo and Preston (1992) point out that these early studies were probably so successful in demonstrating cohort effects because they were based on mortality data from a time period before the process of mortality decline on a period level had begun. Once both cohorts and periods have begun to show mortality improvements it became more difficult to separate the two. Period factors of mortality gained importance as the 
mortality spectrum shifted from infectious disease towards chronic disease. In Britain, in the middle of the nineteenth century over a third of the deaths in the 15-55 year age group and 15 per cent of the deaths at ages 45-64 were due to respiratory tuberculosis (Davey Smith and Kuh 2001). In the United States, TB remained the second leading cause of death at the turn of the century when it accounted for approximately 11 per cent of all deaths (Elo and Preston 1992 citing Mason and Smith, 1985). Respiratory tuberculosis is the major cause of death in which childhood conditions are implicated in cohort mortality and has received extensive treatment in the analysis of cohort effects on mortality. Davey Smith and Kuh (2001) mention John Brownlee (Brownlee 1916) and the report of the British General registrar in 1921 (Greenwood 1936) as the first studies that dealt with cohort effects in respiratory tuberculosis. The most frequently referenced article is the one of Frost (1939) who pointed out that the changes in mortality from tuberculosis were more consistent on a cohort than a period basis. Mason and Smith (1985) came to the same conclusion when analyzing the trend in respirator tuberculosis in Massachusetts from 1880 to 1970 . Each following cohort had a lower mortality than the previous one while period coefficients showed little trend with the exception of the advent of successful chemotherapy after 1950 (Elo and Preston 1992). Tuberculosis in late adulthood is believed to originate in infections during childhood, thus, improvements in earlier life conditions should be reflected in a lower incidence of tuberculosis later in life.

Davey Smith and Kuh (2001) mention stroke, stomach cancer and bronchitis as other important contributors to adult mortality that declined between the mid $19^{\text {th }}$ century and today. For all of them evidence of important early-life influences, or birth cohort pattern in decline does exist. With the shift from infectious to chronic disease in the course of the $20^{\text {th }}$ century coronary heart disease and lung cancer dominated adult mortality. Coronary heart disease initially shows period-specific rather than cohortspecific increases, lung cancer shows cohort specific increases, which reflects the uptake of smoking by successive groups of young adults (Davey Smith and Kuh 2001). Additionally, the introduction of antibiotics for the treatment of infectious disease, which became increasingly effective from the end of the 1930s, influenced mortality at a periodspecific rather than a cohort-specific way. Taking all these factors together - 
“...the change in the cause-of-death profile (and thus of particular aetiological agents) and the development of medical therapeutics led to change in the relative importance of birth cohort and period effects on all-cause mortality. This change coincided with a shift in focus of public health and epidemiological thinking, from the importance of childhood environment (in particular childhood nutrition) to the importance of adult lifestyles, as major determinants of population health." (p. 696: Davey Smith and Kuh 2001).

It took until the end of the 1970s before the idea of early-life influences on mortality was taken up again. In 1973, Forsdahl published his first paper out of a series of five about the effect of very poor living conditions in childhood and adolescence on adult mortality (Forsdahl 1973). Originally this paper was written in Norwegian and has been reprinted recently in English (Forsdahl 2001). Forsdahl observed that ever since the registration of county mortality in Norway has started, the mortality of the county of Finnmark has been higher than for the rest of the country. Current socioeconomic differences or current differences in life-style behavior like smoking or diet could not explain the difference in mortality. He concluded that the 25 per cent higher mortality rates than in other parts of Norway must be the result of events during childhood and adolescence. To test this hypothesis he gathered data about infant mortality and adult mortality for the municipality of Sør -Varanger which is part of Finnmark and is the most remote municipality in Norway situated between the northern parts of Russia and Norway.

Forsdahl writes in his commentary to the reprint of his paper (Fohrsdahl 2001a) that he was particularly qualified to do the investigation of this region since he grew up in this municipality, where his father was a district doctor and where later, from 1963 to 1974, he became the district doctor. He found that infant mortality in Sør-Varanger was consistent with the infant mortality pattern in Finnmark and that in the past, both had been more than twice as high as in Norway. Only in the most recent years of his analysis did the infant mortality rates of Norway as a whole and of Finnmark and Sør -Varanger converge. When he divided the population of Sør -Varanger into those of Finnish and non-Finnish origin he found that both infant mortality and adult mortality are higher for 
the Finnish population than for the non-Finnish. He observes that in the past the Finnish part of the population was generally employed in the more vulnerable branches of the economy such as farming and fishing. Sør-Varanger had suffered twice in the beginning of the $20^{\text {th }}$ century from famine, particularly in region dominated by the Finnish population. In addition, fertility of the Finnish population had been higher and they had lived in more crowded environments than the rest of the population. Since the 1950s these differences have disappeared and at the time when he wrote his paper he did not find any difference in current socio-economic and current life style behaviors between the two groups. He concluded his article by observing that

"This study may suggest an association between very poor living conditions in childhood and adolescence and high mortality in adulthood so that the worse the living standards, the higher the later mortality. Thus, one should not expect that the difference in mortality between Finnmark and the rest of the country will disappear until the generation that grew up under these adverse conditions are gone."

(page 307, Forsdahl 2001).

Already in his first paper he mentions that the difference in the mortality between the Finnish and the non-Finnish population is mainly due to arteriosclerotic heart disease. Four years later (Forsdahl 1977) he confirmed in an article the hypothesis that poor living conditions in childhood are positively correlated with the risk of dying from arteriosclerotic heart disease. He compares the twenty county rates of all-cause mortality among adults aged 40 to 69 in the period 1964 to 1967 with county infant mortality during the period of their childhood and youth (1896 to 1925). He finds a positive correlation of 0.93 for men and a somewhat weaker correlation of 0.75 for females. This implies that in countries where infant mortality was high the same generation had high mortality later in life. The correlation was particularly high and highly significant for arteriosclerotic heart disease and for lung cancer. When he compared adult death rates at county level to current levels of infant mortality the correlations disappeared. In his next paper he reports a positive correlation between infant mortality and serum cholesterol levels of the same generation at ages 34 to 49 (Forsdahl 1978). In this paper he further 
develops the explanation given above and suggests "poverty in childhood and adolescence, followed by later prosperity, results in high cholesterol levels."

Forsdahl's analyses have been subject to criticism because he did not control for current socio-economic circumstances, current life-style factors or any other current or historical characteristics. He, therefore, cannot exclude the possibility, that what he observed were the indirect effects of childhood environment mediated through current life-course conditions. Despite this valid criticism his studies stand out insofar, as they reintroduced the idea that the critical period that determines adult mortality is in childhood and adolescence. His analyses are the first in a long series of ecological studies that investigated the relationship between infant and childhood mortality, and adult mortality of the same generation by geographical area.

The 1980s saw a resurgence of the interest in the effects of early-life conditions on late life mortality that continues until today. Researchers mainly applied three approaches to demonstrate the importance of early-life conditions. Following the approach of Derrick and Kermack they tried to separate period and cohort effects, they undertook ecological analysis following Forsdahl's ideas, and they studied the relationship of anthropometric measures, particularly height, to adult mortality. Elo and Preston (1992) extensively reviewed these studies.

\section{Cohort studies}

Since the 1930s both cohort and period effects simultaneously influence old-age mortality. Thus, more sophisticated models were needed to separate the two. Caselli and Capocaccia (1989) studied trends in Italian mortality during the twentieth century and tried to shed light on the effects of mortality decline in infancy and childhood on a cohort's mortality at older ages. They used age-specific probabilities of dying between the ages 29 and 79 for the time period 1907 to 1978. These cohorts were born between 1882 and 1953. The cohorts had experiences very different patterns of early mortality for example, for men the probability if survival to age 15 had increased from 68 per cent in 1918 to 82 per cent (Caselli 1990). They estimated logistic regression models of agespecific probabilities of dying including age, period and a cohort's infant mortality or a cohort's probability of dying during the first 15 years of life as independent variables. 
Introducing an interaction effect between the latter two variables and age allowed them to study which ages later in life were most affected by changes in early-life mortality. They found that for both sexes a higher mortality between ages 0 and 15 was associated with a higher mortality between ages 25 and 45 . At older ages, they found the opposite effect, although slightly weaker.

A large series of studies (Horiuchi 1983, Wilmoth 1986, Caselli et al. 1987, Vaupel et al. 1987, Wilmoth et al. 1989) took advantage of abrupt changes to identify cohort effects. During the $20^{\text {th }}$ century the two major wars constituted such abrupt changes that affected different cohorts at different ages. A number of these studies found elevated mortality for cohorts who were either born during the two World Wars or were in their adolescence. Both male and female children born during World War I in Italy, in France and in the Former Soviet Union have subsequently experienced higher mortality. Cohort mortality was elevated for German male cohorts who were adolescents during World War I. Elevated cohort mortality after World War II has been found for Japanese male cohorts and cohorts of both sexes from the former Soviet Union who were adolescents during war. Both wars affected the subsequent mortality of adolescent cohorts in France and in Italy. Generally the effect was somewhat stronger for males than females, which suggests that the effects on male cohorts may be due to their participation in the wars at very young ages rather than to nutritional deprivation or poor health conditions.

One example from epidemiological research in which a cohort effect had been originally attributed to World War I and is now believed to be rooted in poor living conditions during childhood is peptic ulcer morbidity

Susser and Stein (1962 )observed:

"the timing of the first world war, and the unemployment of the 1930s, roughly fit the fluctuations, and the cohorts with the highest peptic-ulcer death-rates were also the chief victims of the first world war. The immediate effects of war are evident in the rise in perforations and deaths from peptic ulcer which followed air-raids and the stress of war. Perhaps in a chronic condition such as this acute events might precipitate prolonged effects". 
(Susser and Stein (1962) cited by Davey Smith and Kuh (2001))

In 1985 Sonnenberg and colleagues demonstrated that birth cohort dependency of peptic ulcer morbidity could be seen in many countries and that the causative factors became effective before age 15 (Sonnenberg, Mueller and Pace, 1985; Sonnenberg 1987). The probably explanation of the cohort effects today is $\mathrm{H}$ pylori infection, occurring during childhood, and influencing peptic ulcer many years later (Susser 2001). The most recent study analysis peptic ulcer morbidity and mortality in Iceland (Thors et al, 2002) and cites twelve studies that had demonstrated a cohort pattern previously. The authors find that in Iceland for all manifestations of peptic ulcer the disease risk was particularly high in individuals born after the turn of the century and it was lower in previous and subsequent cohorts. At that time in Iceland the industrial revolution created the fish industry, which lead to overcrowd and poor living conditions. The same cohorts that experienced the highest risk of peptic ulcer disease were also the cohorts with the maximum prevalence of $\mathrm{H}$ pylori antibodies.

Influenced by the fetal origin's hypothesis - which suggests that nourishment before birth and during the individual's infancy programs the development of risk factors for several important diseases of middle and old age - several studies have investigated the effect of famine on cohort mortality. Between 1866 and 1868 a severe famine hit Finland. Kannisto et al. (1997) analyzed the cohort mortality of more than 600.000 individuals born 5 years before and after the famine and of about 160.000 individuals born during the famine. They found that survival in childhood and adolescence was significantly lower for cohorts born before and during the famine. However, at subsequent age, including old age, mortality for those born during famine did not differ from the mortality of those born before or after the famine. Similar results were obtained in a study of prenatal exposure to the Dutch famine in 1944-1945 (Rosenboom et al 2001). Mortality up to age 18 was higher for those born before the famine and those exposed to the famine in the third trimester. Between ages 18 and 50, however, no effect of prenatal exposure to the famine could be demonstrated. This result is supported by a study of Bengtsson et al. (2001) who analyzed the effect of environmental stress in old age mortality in Sweden during the period 1760-1894. They used infant mortality of an 
individual's cohort to measure the disease load early in life and rye prices to account for nutritional changes. They did not find a significant effect of rye-prices during the first years of life on late life mortality, and also rejected the hypothesis that the disease load on the mother during pregnancy affects the adult mortality of her child. They found, however, a significant effect of the crude death rate in the first year of life on later life mortality. The authors concluded that the disease environment in the first year of life rather than nutrition in-utero is the critical factor that influences late life mortality.

\section{Ecological studies and place of birth}

Barker and colleagues (Barker and Osmond 1986a, 1986b, 1987, Barker et al. 1989a, Barker et al. 1990, Osmond et al. 1990) performed the most extensive series of ecological analysis. Basically, all these studies follow one general research design. They compare adult death rates of specific age groups with infant mortality rates of the same generation on the basis of local authority areas in England and Wales. In their initial paper (Barker and Osmond 1986a) they found high positive correlations between infant mortality in 1921-1925 and standardized mortality ratios for chronic bronchitis, ischemic heart disease, stomach cancer, and rheumatic heart disease among adults in 1968-1978. For lung cancer and stroke the associations were lower. They did not correct for any other current or historical conditions. In their next paper - using the same data - they studied the relationship between geographical distributions of infant mortality from bronchitis and pneumonia and current distributions of mortality at ages 35-74 from chronic bronchitis. They found that infant mortality from bronchitis and pneumonia were more closely related with adult mortality from chronic bronchitis in the periods 1959-1967 and 1968-1978 than with any other major cause of death. They controlled for smoking behavior by including lung cancer death rates in their regression model, since smoking is one of the established risk factors for lung cancer. The authors concluded that pulmonary infections in infancy may have persistent effects and raise the risk of death from chronic bronchitis in adulthood. In their next study (Barker and Osmond 1987) they use maternal mortality as an indicator of intrauterine environment and demonstrate a positive correlation between maternal mortality rates in 1911-1915 and mortality from stroke among people aged 55-74 in 1968-1978. 
The next article further develops the idea that the increased susceptibility to cardiovascular disease and chronic bronchitis originates from the intrauterine and early postnatal environment (Barker and Osmond 1989). Barker refers to this study as the first that showed that coronary heart disease primarily results from poor condition in-utero (Barker 2002). Using 212 local authority areas by age at death the authors found that the geographical distribution of the death rates of stroke at ages 35-74 between 1968 and 1978 are more closely related to neonatal mortality of the same generation (mortality in the first month) than to post-neonatal mortality (mortality between ages 2 months and one year). The reverse is true for ischemic heart disease and bronchitis. This study may thus be seen as the founding study of the fetal origins hypothesis, which states that chronic disease later in life is caused by programming of the infant in-utero. It suggests to Barker, that

“..research should be directed towards the intrauterine environment rather than the environment of late childhood - housing, family income, diet, and other influences" (p1111, Barker 1990)

The above statement explains why he writes in his commentary to the reprint of Forsdahl's 1993 article:

"Forsdahl's best known paper is entitled: Are poor living conditions in childhood and adolescence an important risk factor for ateriosclerotic disease? The short answer is that they are not."

(p309, Barker 2002)

However, the ecological studies by Barker and Osmond have been heavily criticized (e.g. Elo and Preston 1992) because the authors failed to control for current socioeconomic conditions, statistical details presented were insufficient to judge the significance of the reported results, the units and dates of the analyses changed haphazardly from study to study, and statistical controls were inadequate. 
In 1991 Ben Shlomo and Davey Smith (1991) addressed the idea that the relation between past infant mortality rates and present adult mortality simply reflects an unchanging distribution of impoverished socio-economic circumstances over time. They used $1895-1903$ infant mortality rates in 43 administrative county units in England and Wales and calculated the correlation with current mortality rates with and without correction for current socioeconomic circumstances. They found that the correlations between infant mortality and adult death rates only remained significant for bronchitis, emphysema and asthma as soon as current socioeconomic conditions were corrected for.

Ecological studies of similar research designs have been continued for different countries until today (e.g. Elford et al. 1992, Pringle 1998, Maheshwaran et al. 2002, Leon and Davey Smith 2000) other studies have looked at migrants within a country and whether region of birth contributes to adult mortality independent of the region of residence (Strachan et al. 1995, Schneider et al. 1997a,b, Regidor 2002). Most recently, the survey of Charles Booth, which was undertaken at the end of the $19^{\text {th }}$ century in London was digitized using GIS (geographical information systems). The survey portrays the social and economic conditions and displayed social class of inner London on a street-by-street basis. These maps have been digitized, georeferenced and linked to contemporary ward boundaries. This linkage allowed matching Booth's measurements of social class with measurements of social class in the 1991 census population and with standardized mortality rates for cause-specific death (Dorling et al. 2000, Orford et al. 2002). An index of relative poverty was calculated for the end of the $19^{\text {th }}$ century and the end of the $20^{\text {th }}$ century. Using partial correlation coefficients they found that the index of poverty derived from Booth's $19^{\text {th }}$ century observations contributed more to predicting deaths from stroke and stomach cancer in the late $20^{\text {th }}$ century than that derived from the 1991 census. For other causes of death the modern index contributed more. The authors of the study point out that almost everyone surveyed by Booth's enquiry will have died or has moved by 1991 . The $19^{\text {th }}$ century index therefore is a truly ecological index and describes area type rather than aggregate characteristics of the resident population. They conclude that the 
"ecological associations with past and present deprivation levels of areas do reflect individual level associations of deprivation at different stages of the life course and health outcomes. In short, the longer people spend both in poverty and in poor places, the earlier they tend to die."

(p1547, Dorling et al 2000)

Above statements is the antipode to the theory proposed by Barker. To answer the question which of the two hypotheses is true other study designs than ecological ones were needed. Thus, in the 1990s the emphasis shifted to longitudinal studies on individual level that included both information about early-life circumstances and lifecourse information for adult ages.

\section{The fetal-origins hypothesis of adult diseases}

Since waiting for a cohort to age is time-consuming, Barker and colleagues decided to follow a retrospective approach. They traced subjects on whom data are available from their first year of life. It involved the follow-up of an historical cohort of 5654 men born between 1911 and 1930 in Hertfordshire, England (Barker et al. 1989). Information about early-life circumstances was obtained from records kept by attending midwives and local health visitors who made periodic visits during the first year of life. The authors' analysis showed that men with the lowest birthweights and weights at age one had the highest death rates from coronary heart disease and chronic obstructive lung disease. For causes other than the two no such trend was seen. Joseph and Kramer (1996) cite thirty studies the followed the same retrospective study-design and investigated the link between measurements of placental weight, birthweight, abdominal and head circumfences, ponderal index at birth, weight at age 1, infant feeding practices, maternal skinfold thickness and maternal weight gain in pregnancy. The outcomes that were associated with these measurements were clinical phenomena like blood pressure, serum cholesterol, plasma glucose, plasma fibrinogen, serum concentrations of factor VII and immunoglobulin E, abdominal obesity, and lung function. Direct associations have also 
been observed between fetal/and or infant growth indices and the prevalence of coronary heart disease, renal complications, and autoimmune thyroiditis. Birthweight, weight at age one and type of infant feeding were correlated with mortality from coronary heart disease, cardiovascular disease, chronic obstructive lung disease, ovarian cancer, and suicide.

Based on these findings it has been hypothesized that physiologic or metabolic "programming" occurs at critical periods of early development and substantially determines the occurrence of pathologic phenomena later in life. Barker and his colleagues originally proposed this theory in their 1989 paper and have since then further developed it. Most recent studies (Eriksson et al. 1999, Forsen et al. 1999, Eriksson et al. 2001, Forsen et al. 2000, Eriksson et al. 2000) suggest that low birthweight, shortness or thinness at birth, followed by poor infant growth and thereafter rapid growth are associated with coronary heart disease, hypertension and Type 2 diabetes. Barker writes:

People who are small at birth remain biologically different through life because of the persisting constraints and adaptations that accompany slow early growth. Their different morphology and physiology leads them to respond differently to the biological and social environments in later life. Thus the discontinuity in nutritional experience that leads to later disease does not seem to be primarily poor nutrition in childhood and adolescence followed by excess nutrition in adult life (...). Rather it is poor nutrition in-utero and during infancy, the so-called 'fetal' phase of endocrine control of growth, followed by improved nutrition in the second phase of growth, which begins in early childhood" (p. 310, Barker 2002)

One of the strongest and most consistent line of support for the fetal-origins hypothesis of adult disease has been a large series of studies about the relationship between low birthweight, indicating fetal restricted growth, and increased blood pressure later in life. It has been estimated that $1 \mathrm{~kg}$ higher birthweight is typically associated with a 2-4 $\mathrm{mm}$ Hg lower systolic blood pressure (for a review see Huxley et al. 2002). A recent paper by Leon et al. (2000) demonstrates that among 165,136 Swedish men aged 18 years a $1 \mathrm{~kg}$ increase in gestational age-adjusted birthweight was associated with a fall of $1.6 \mathrm{~mm} \mathrm{HG}$ 
in systolic blood pressure. However, it has been pointed out (Kramer 2000) that a 1-kg difference in birthweight is enormous (about five or six times the difference in mean birthweight between infants of smoking and non-smoking mothers) and reasonable differences in birthweight are more in the range of a 100g. This makes the effect of birthweight on adult systolic blood pressure levels rather small. In addition, frequent concerns are voiced about confounding by socioeconomic status (e.g. Joseph and Kramer 1996, Kramer 2000).

A recent study by Huxley et al (2002) casts further doubt on the causal pathway between low birthweight and increased blood pressure. The authors review 55 studies that had reported regression coefficients of systolic blood pressure on birthweight. When they weighted each study with the inverse of the variance of the regression coefficient to correct for "statistical size" they found a clear trend: the association between birthweight and blood pressure was weaker in larger studies. It ranged from $-1.9 \mathrm{~mm} \mathrm{HG} / \mathrm{kg}$ in those with less than 1000 participants to $-0.6 \mathrm{~mm} \mathrm{Hg} / \mathrm{kg}$ with more than 3000 participants. Furthermore, among 49 studies, which only reported the direction of the association but not the correlation coefficient, only 25 studies found an inverse association. The authors come to the conclusion that the

"strong association between birthweight and subsequent blood pressure may chiefly reflect the impact of random error, selective emphasis of particular results, and inappropriate adjustment (....) for confounding factors. These findings suggest that birthweight is of little relevance to blood pressure levels later in life." (p. 659, Huxley et al. 2002)

\section{Life course factors}

The main idea underlying the fetal origins hypothesis of adult diseases is that a critical time period exists early in life. Exposure to deleterious factors during this critical period affects adult health independent of intervening experience later in life. In an extension of this theory effect modifiers later in life, e.g. catch-up growth of low 
birthweight babies, is recognized. The pathway is predominantly biological. A life-course approach takes into account that there are mediating factors between the exposure early in life and the manifestation of the disease later in life. A second pathway may be that negative social factors in the early-life environment set individuals onto life trajectories that negatively affect their later health. This pathway is predominantly social. A third pathway is that the cumulative effects of repeated exposure to negative factors adversely affect health status either through a biological process (e.g. repeated infections per se) or through a social process (e.g. repeated infections result in lower educational attainment).

The life course approach to chronic disease epidemiology challenges the idea of a critical period and rather tries to disentangle the effect of a critical period from mediating factors of biological or social origin. Ben-Shlomo and Kuh (2002) define the life course approach as

"the study of long-term effects on chronic disease risk of physical and social exposures during gestation, childhood, adolescence, young adulthood and later adult life. It includes studies of the biological, behavioral and psychosocial pathways that operate across an individual's life course, as well as across generations, to influence the development of chronic diseases".

(page 285, Ben-Shlomo and Kuh 2002)

This definition encompasses the whole lives of generations and, as the authors mention, is "empirically complex". A large series of studies have been published that fall under this life-course definition (for a review and definition see e.g. Ben Shlomo and Kuh 2002) many of them dealing with socioeconomic differences early and later in life.

\section{Month of Birth}

How does the indicator month of birth fit into above research? Month of birth is used as an indicator for a critical period early in life. Negative factors during this period affect the metabolism of the body and influence later susceptibility to disease. There is no 
modification of this effect by later life circumstances and the pathway is purely biological.

Month of birth is not simply another indicator of birthweight. First, birthweight studies usually are based on small samples, obtained from hospital populations. Month of birth is widely available for complete populations; thus, studies based on the month of birth are free from selection biases. Second, birthweight restricts the critical period to the pregnancy of the mother. Month of birth measures seasonal influences during pregnancy and during the first year(s) of life. Third, birthweight is influenced by socio-economic factors. Thus, the relationship between birthweight and mortality and clinical outcome measures later in life may be confounded by unobserved socioeconomic differences. Birthweight studies certainly need a life-course approach to adjust for possible confounding factors. Also the month of birth is not free of socioeconomic confounding. However, Chapter 2 demonstrates that the social differences that affect the month of birth tend to reduce the month-of-birth effect in life span rather than to enlarge it.

Month of birth has been extensively used in epidemiological research (see Chapter 3), particularly in the field of schizophrenia and other diseases of the mental and nervous system. However, since these epidemiological studies are mainly interested in finding the biological trigger of a particular disease they have failed to demonstrate the general importance of the month of birth, and thus the early-life environment, on human life span. If life expectancy of the contemporary elderly is significantly influenced by the month of birth then the month of birth must be related with heart disease and cancer since they are the major causes of death among the elderly. So far, no studies exist that investigate this relationship for heart disease and only few for cancer.

Differences in life span by month of birth, thus, demonstrate the importance of the first period of life and the health of the mother during pregnancy independent of other life course factors. This monograph shows that the variance in adult life span by month of birth is small compared to the total variance and to the differences among social groups or between men and women. The finding, however, that these differences by month of birth are most probably linked to prenatal or early postnatal conditions related to nutrition or disease is of broad significance with profound implications for clinical practice and public health policy. 


\section{TWO}

\section{DIFFERENCES IN LIFE SPAN BY MONTH OF BIRTH IN Austria, Denmark, Australia, AND HaWAiI}

One of the first who was interested in the effect of month of birth on longevity was Ellsworth Huntington. In his book "Seasonality" (1938) he described the relationship between the seasons of the year and social, psychological and demographic phenomena.

On the basis of 10,890 persons in the Dictionary of American Biography who died at the average age of 68.9 years he found that those born in February died at age 69.7 years, those born in June at average age 67.8 years. He observed a secondary maximum in September and October. He obtained similar results for 13,891 New Englanders from genealogical memoirs of 80 families; 3019 New Englanders and New Yorkers; 12,173 people from New York, New Jersey and Pennsylvania and 9921 people from Maryland, Virginia, North and South Carolina, a few from states farther south or west; and 7517 people in the British "Who Was Who".

Huntington comes to the conclusion that in all populations (with the exception of the British population) people born in February or March live longer than those born in July or August. Huntington's finding stimulated extensive research in the area of psychology. Since the 1930s more than 200 studies have been conducted about the prevalence of schizophrenia and month of birth (for a review see Torrey 1997). More recently researchers tried to explain the differences in the prevalence of schizophrenia by month of birth with virus infections like measles or flu of the mother during pregnancy. Results, however, are not conclusive. Eysenck took up the topic of the impact of month of birth on life span in his book “Astrology. Science or Superstition?” in 1982 (Eysenck \& Nias 1982) and Miura edited a series of epidemiological studies in his book entitled "Seasonality" (Miura 1987). In the 1980s and 1990s quite a few epidemiological studies were conducted that found a relationship between month of birth and specific diseases e.g. allergies, insulin dependent diabetes, congenital malformations, Parkinson's and Alzheimer's disease, breast cancer, 
etc. (see Chapter 3). In all these studies month of birth is used as an indicator for the environment early in life.

This chapter takes up the topic and provides evidence from population data that month of birth and life span are indeed related. Contrary to earlier research this study is not based on sample data but on complete population data for countries of the Northern and Southern Hemisphere.

Huntington had conjectured that the month of birth is an indicator for environmental factors that are linked to the seasons of the year. If this is true, then the patterns of two geographically close populations should resemble each other, and the pattern in the Northern Hemisphere should be mirrored in the Southern Hemisphere. Furthermore, life spans of people who were born in the Northern Hemisphere but who died in the Southern Hemisphere should resemble the pattern of the Northern Hemisphere.

The first step, therefore, was to obtain data on the populations of Denmark, Austria, and Australia to test this conjecture. Statistics Denmark provided longitudinal data based on the Danish population register that follows every person living in Denmark from 1968 to the present. Statistics Austria and Statistics Australia provided death certificates for all deaths that occurred between 1988 and 1996 in Austria, and between 1993 and 1997 in Australia. In addition to the three countries data for Hawaii were obtained. Hawaii is of particular interest for the study of differences in life span by month of birth because it is located close to the equator. The data for Hawaii are based on the US death records for the years 1989 to 1997; these records include place of birth.

The first part of the chapter explores whether differences in life span after age 50 by month of birth exist in the four populations. The age range is restricted to ages 50 and above in order to exclude the possibility that the differences in life span simply reflect differences in survival during the first part of life by month of birth rather than at old age. The second part of the chapter is devoted to the testing of five hypotheses. The first hypothesis assumes that the interaction between age and the seasons of mortality causes the differences in life span by month of birth. For example, people born in April are older than people born in November when the high mortality of winter strikes them. The second hypothesis tests whether the differences are due to unobserved social factors that influence 
or result from the seasonal timing of births. The third hypothesis considers whether deadlines for school attendance may have an impact. The fourth hypothesis explains the differences in adult life span by differential survival in the first year of life, while the fifth hypothesis assumes that debilitation in-utero or in the first year of life increases the infant's susceptibility to diseases at adult ages.

\section{Data and Methods}

The Danish data consist of a mortality follow-up of all Danes who were at least 50 years old on 1 April 1968; 1,371,003 people were followed up to week 32 of 1998. The study excludes 1,994 people who were lost to the registry during the observation period. Among those who are included in the study, 86\% (1,176,383 individuals) died before week 32 of 1998; 14\% (192,626 individuals) were still alive at the end of the follow-up. Exact dates of birth and death are known for a total of 681,677 Austrians who died between 1988 and 1996 and for 219,820 native-born Australians who died between 1993 and 1997 at ages 50+. 42,969 decedents were born in Hawaii and died between 1989 and 1997.

For Denmark remaining mean life expectancy at age 50 was calculated on the basis of life tables that were corrected for left truncation. This was achieved by calculating occurrence and exposure matrices that take into account an individual's age on 1 April 1968. For example, a person who was 70 at the beginning of the study and who died at age 80 enters the exposures for ages 70 to 80 but is not included in the exposures for ages 50 to 69. The central age-specific death rate is based on the occurrence-exposure matrix. The corresponding life-table death rate is derived by the Greville Method (Greville 1943). For Austria, Australia and Hawaii remaining life span at age 50 was estimated by calculating the average of the exact ages at death.

To test whether the seasonal difference in the risk of death accounts for the differences in adult life span by month of birth the monthly deviations from the annual death rates were calculated. Since longitudinal data are needed for this analysis, it could only be performed for Denmark. Let $x$ denote age in integer years and let $y$ denote current year. Let $i$ denote age in months since last birthday and let $j$ denote current month; let $D_{i j}^{x y}$ be the number of deaths that occur for people of age $x+i / 12$ years at time $y+j / 12$, 
and let $T_{i j}^{x y}$ be the corresponding size of the exposed population at risk of death. Let $n j$ denote the number of days in current month $j$. When calculating the exposed population all deaths were assumed to occur in the middle of each month. The relative deviation of the monthly death rate from the annual death rate, $R_{i j}^{x y}$, was calculated as

$$
R_{i j}^{x y}=\frac{D_{i j}^{x y}}{T_{i j}^{x y} n_{j}} / M_{x y}
$$

where

$$
M_{x y}=\frac{\sum_{i=1}^{12} \sum_{j=1}^{12} D_{i j}^{x y}}{\frac{365.25}{12} \sum_{i=1}^{12} \sum_{j=1}^{12} T_{i j}^{x y}}
$$

The surface of the logarithm of the monthly deviations from the annual death rates is modeled by the equation

$$
\ln \left(R_{i j}^{x y}\right)=a_{0}+\sum_{k=1}^{12} a_{k} I_{1 k}+\sum_{k=1}^{12} b_{k} I_{2 k}+\sum_{k=1}^{12} c_{k} I_{3 k}+\sum_{k=0}^{1} \alpha_{k} I_{4}+\sum_{j=0}^{1} \beta_{j} I_{5} \sum_{k=1}^{12} a_{k} I_{1 k}
$$

The variables $I_{1}$ to $I_{5}$ are indicator variables. They take the value one for a particular characteristic and zero otherwise. $I_{l k}$ indicates month of birth (reference month: January), $I 2 k$ current month (reference month: January), $I_{3 k}$ age since last birthday in months rounded up to the nearest integer (reference age: one month), $I_{4}$ sex (reference sex: males), $I_{5}$ cohort (reference birth cohort: born between 1889 and 1918; other cohort born before 1889). The parameter values $a_{0}, a_{k}, b_{k}, c_{k}, \alpha_{\rho}$ and $\beta_{k}$ are estimated by applying weighted least squares; the weights are the exposed population $T_{i j}$. The term $\sum_{j=0}^{1} \beta_{j} I_{5} \sum_{k=1}^{12} a_{k} I_{1 k}$ estimates whether the differences by month of birth differ between those born before and after 1889 . The parameter values $a_{1}, b_{l}, c_{l}, \alpha_{0}$ and $\beta_{0}$ are set equal to zero. 
To test whether selective survival or debilitation during the first year of life explains the differences in remaining life expectancy at age 50 data on infant mortality for Denmark aggregated over the five-year period 1911-1915 were used. The tabulations in the "Statistik tabelvaerk " provide number of deaths by age of the infant in months and month of death. Thus, the actual date of birth of the deceased infants can fall within a period of two months and on average falls on the first day of each month. On the basis of the monthly number of births aggregated over the period 1911-1915 death rates for each month of the first year of life were then calculated. In order to center the number of births at the first day of each month the average number of births of two adjacent months are used in the calculations.

To estimate the impact of month of birth on the monthly death rates in the first year of life a similar model as for adult ages was used. The logarithm of the monthly deviations from the annual death rate was modeled by applying equation [2.4]:

$$
\ln \left(R_{i j}\right)=a_{0}+\sum_{k=1}^{12} a_{k} I_{1 k}+\sum_{k=1}^{12} b_{k} I_{2 k}+c_{1} \ln x+\sum_{k=1}^{12} \alpha_{k} \ln x I_{2 k}
$$

The variables $I_{1}$ and $I_{2}$ are indicator variables. They take the value one for a particular characteristic and zero otherwise. $I_{l k}$ indicates month of birth (reference month: January), $I_{2 k}$ current month (reference month: January). Age $x$ is in months rounded up to the nearest integer. To reduce the number of parameters in the model and because the decline in mortality during the first year of life can be modeled by a power function, $x$ is included as a numerical variable. The term $\sum_{k=1}^{12} \alpha_{k} \ln x I_{2 k}$ corrects for the interaction in the death rates between age and current month. The infant mortality surface consists of only 144 data points (12 birth months x 12 ages). Monthly births are only available for both sexes combined and infant deaths by age in months and month of death are aggregated over the five year period 1911-1915. Hence the model does not include sex and cohort effects. The parameter values $a_{0}, a_{k}, b_{k}, c_{k}$ and $\alpha_{k}$ were estimated by least squares regression. 


\section{Results}

A similar relationship between month of birth and life span exists in both of the Northern Hemisphere countries. Adults born in autumn (October - December) live longer than those born in spring (April - June). The difference in life span between the spring and autumn born is twice as large in Austria (0.6 years) as in Denmark (0.3 years).

In Denmark remaining life expectancy at age 50 is 27.52 years. The average age at death is lowest among those born around week 18, and it peaks at week 51. The life span of Danes born in specific months varies periodically around the mean (Fig.2.1A). For those born in the second quarter, life spans are $0.19 \pm 0.05$ years shorter than average; for those born in

the fourth quarter they are $0.12 \pm 0.04$ years longer than average. This difference is statistically significant (Cox-Mantel statistic: $\mathrm{p}<0.001)$.

In Austria deaths occurred at an average age of 77.70. The mean life span of people born in specific months of the year deviates from this average (Fig.2.1A). The average age at death is lowest for those born around week 20 and highest for those born around week 46. The deviation in mean age at death is highly significant (Bonferroni test: $\mathrm{p}<0.001$ ) for those born in the second and the fourth quarters. The life spans of people born between weeks 14 and 26 are $0.28 \pm 0.03$ years below average; life spans of those born between weeks 40 and 52 are $0.32 \pm 0.03$ years above average.

The pattern in the Northern Hemisphere is mirrored in the Southern Hemisphere. The mean age at death of people born in Australia in the second quarter of the year is 78.00; those born in the fourth quarter die at a mean age of 77.65 years. The difference of 0.35 years is statistically significant (Bonferroni test: $\mathrm{p}<0.001$ ) (Fig. 2.1B).

Significant differences in the life span by month of birth exist for Hawaii (Fig. 2.1B). The mean age at death of people born in Hawaii is 74.50 years. Mean age at death of the March-born is 0.53 years above the average, those of the October-born is 0.29 years below the average. The difference between the two months is statistically significant at $\mathrm{p}=0.004$ (Bonferroni test).

Based on above results one can conclude that the pattern in the Southern Hemisphere is a reversed mirror image of the Northern Hemisphere pattern. This can be 
Figure 2.1 A: Austria: Mean ages at death by week of birth . The fitted line is estimated by a cosine term with a period of 52 weeks.
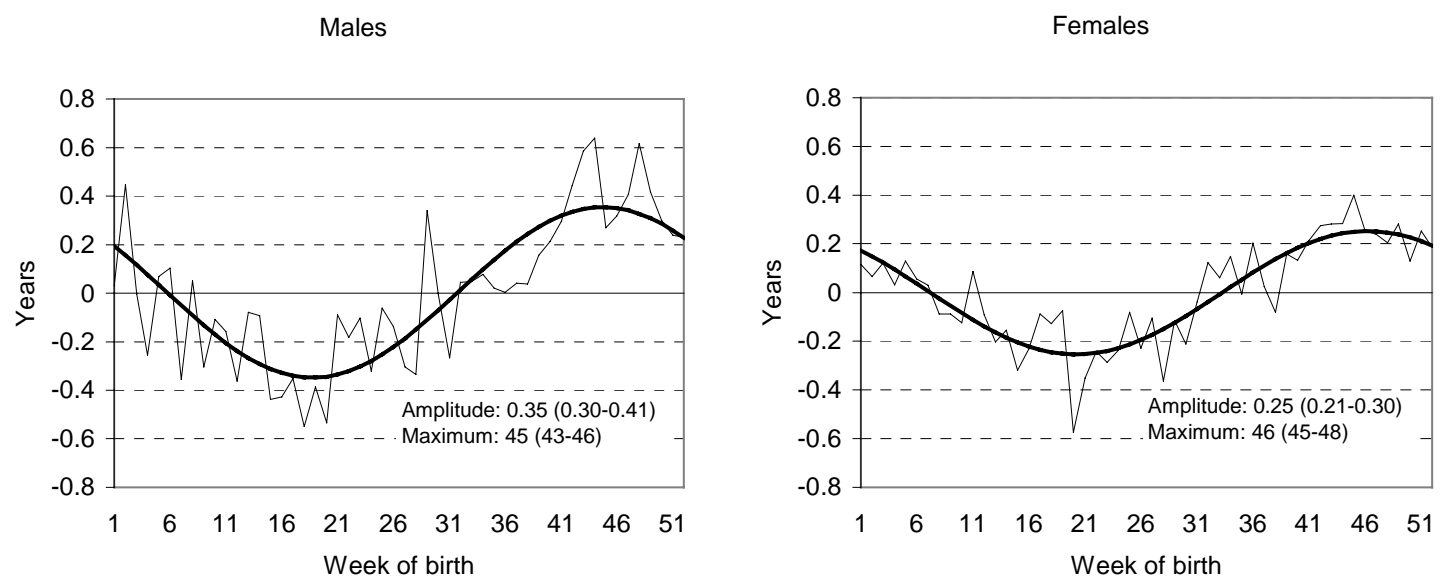

Figure 2.1 B: Australia: Mean ages at death by week of birth. The fitted line is estimated by a cosine term with a period of 52 weeks.

Males

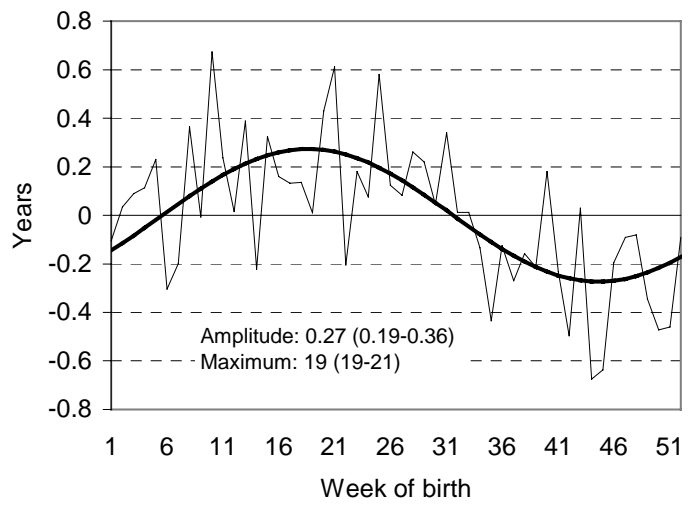

Females

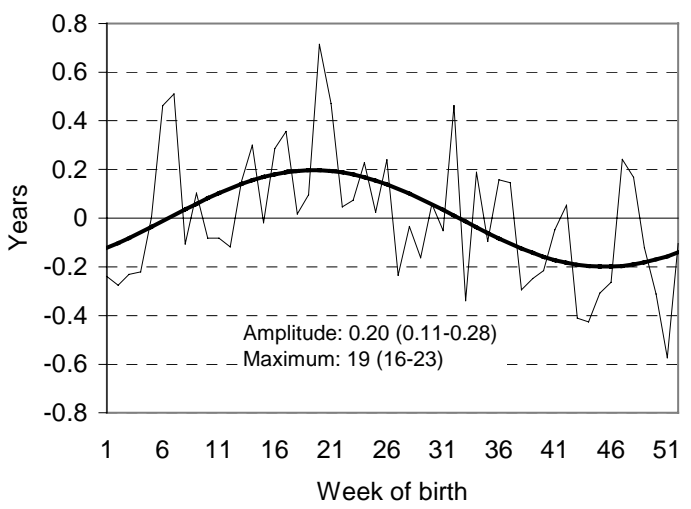


Figure 2.1 C: Denmark: Remaining life expectancy at age 50 by week of birth. The fitted line is estimated by a cosine term with a period of 52 weeks.
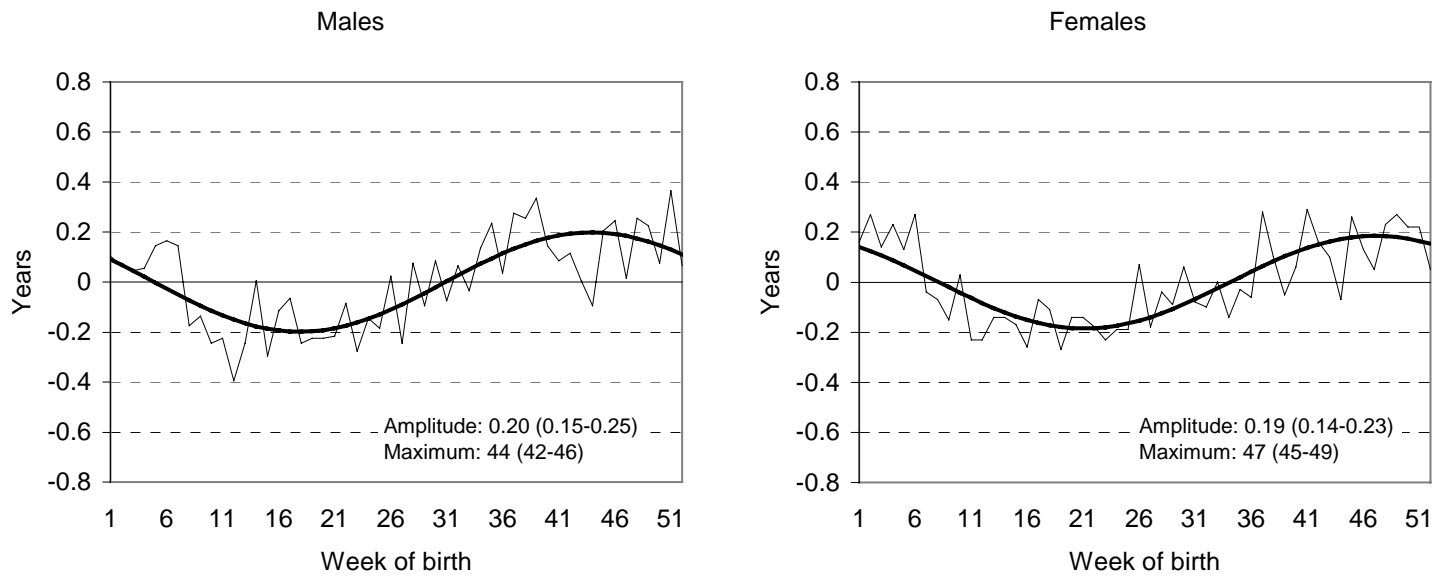

Figure 2.1 D: Hawaii: Mean ages at death by month of birth. The fitted line is estimated by a cosine term with a period of 12 months.
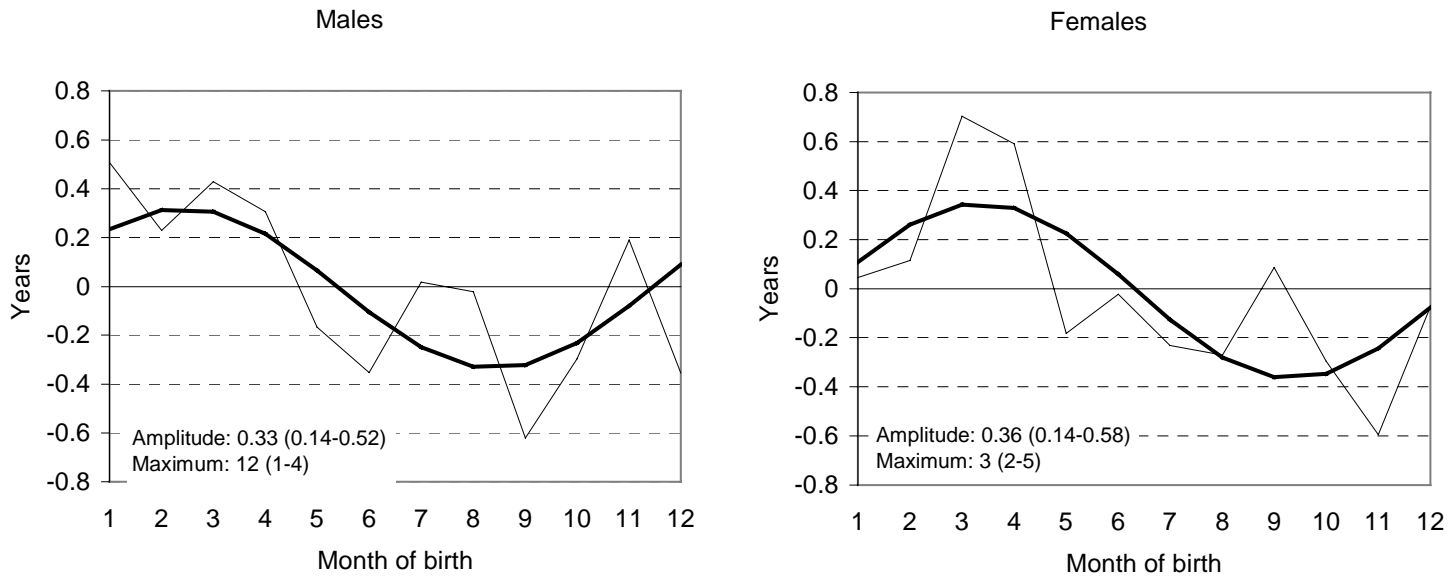
clearly seen from the correlations of the month-birth-patterns. The correlation of the deviations in life span by month of birth between Austria and Denmark is 0.83 (Pearson correlation, one sided test: $\mathrm{p}<0.0001)$. Between Austria and Australia it is $-0.79(\mathrm{p}<0.001)$ and between Denmark and Australia -0.80 ( $\mathrm{p}<0.001)$.

Single cosinor analysis with a period of 52 weeks (or 12 months) for the four population shows that that the differences by week of birth or by month of birth follows a seasonal pattern. For each of the four populations ages at death (Austria, Australia and Hawaii) and remaining life expectancy at age 50 (Denmark) are fitted by a cosine term age $=\mathrm{a}_{0} * \cos \left(\mathrm{t}-\mathrm{a}_{1}\right)$ where $\mathrm{a}_{0}$ is the amplitude, $\mathrm{a}_{1}$ the acrophase (maximum) and $t=$ week of birth $/ 52 * 2 \pi$ (Hawaii: $t=$ month of birth $/ 12 * 2 \pi$ ). The parameters are estimated using least squares estimation procedure. Figures $2.1 \mathrm{~A}-\mathrm{D}$ show the weekly means together with the fitted cosine terms. The fit of the sinusoidal functions is highly significant with $\mathrm{p}<0.001$.

Since Australia is a whole continent the analysis of the month-of-pattern for different birth regions may provide evidence concerning the underlying causal mechanisms. It appears that the reversal of the pattern, compared to the Northern Hemisphere, exists in almost all Australian states and territories: mean age at death in the first half-year is generally higher than in the second half-year (Table 2.1, Fig. 2.2).

Table 2.1: Mean age at death by state of birth and quarter of birth, amplitude and peak estimated by cosinor analysis based on Australian death records for the years 1993 to 1997.

\begin{tabular}{|c|c|c|c|c|c|c|c|c|}
\hline & \multicolumn{4}{|c|}{ Quarter of birth } & \multirow{2}{*}{$\begin{array}{l}\text { Max. } \\
\text { Dif. }^{+}\end{array}$} & \multicolumn{2}{|c|}{ Cosinor Analysis } & \multirow[t]{2}{*}{ Deaths } \\
\hline & 1 & 2 & 3 & 4 & & Amplitude & $\begin{array}{c}\text { Maximum } \\
\text { Week }\end{array}$ & \\
\hline $\begin{array}{l}\text { New South } \\
\text { Wales }\end{array}$ & 77.1 & 77.2 & 77.0 & 76.9 & $\begin{array}{c}0.39 \\
* *\end{array}$ & $\begin{array}{c}0.23 \\
0.14-0.31\end{array}$ & $\begin{array}{c}19 \\
16-22\end{array}$ & 126,308 \\
\hline Victoria & 77.1 & 78.2 & 78.1 & 77.3 & $\begin{array}{c}0.89 \\
* *\end{array}$ & $\begin{array}{c}0.38 \\
0.13-0.63\end{array}$ & $\begin{array}{c}22 \\
16-27\end{array}$ & 14,130 \\
\hline Queensland & 77.4 & 77.7 & 77.5 & 77.6 & 0.31 & n.s. & n.s. & 20,686 \\
\hline $\begin{array}{l}\text { South } \\
\text { Australia }\end{array}$ & 78.3 & 78.5 & 78.2 & 77.9 & $\begin{array}{c}0.61 \\
* *\end{array}$ & $\begin{array}{c}0.33 \\
0.17-0.49\end{array}$ & $\begin{array}{c}20 \\
16-24\end{array}$ & 32,260 \\
\hline $\begin{array}{l}\text { Western } \\
\text { Australia }\end{array}$ & 77.5 & 77.4 & 77.2 & 77.0 & $\begin{array}{c}0.49 \\
*\end{array}$ & $\begin{array}{c}0.24 \\
0.05-0.43\end{array}$ & $\begin{array}{l}16 \\
9-22\end{array}$ & 23,395 \\
\hline Tasmania & 78.6 & 79.5 & 78.3 & 77.9 & 1.60 & n.s. & n.s. & 1,843 \\
\hline
\end{tabular}

** Bonferroni test: $\mathrm{p}<0.01$, * Bonferroni test: $\mathrm{p}<0.1$, bold figures indicate the minimum and the maximum mean age at death

+ :Maximum difference in mean age at death between quarters

n.s.: cosinor term not significant 
Figure 2.2: Australia: Mean age at death by week of birth and region of birth. The fitted line is estimated by a cosine term with a period of 52 weeks. The cosine term is significant for all regions with the exception of Queensland and Tasmania.

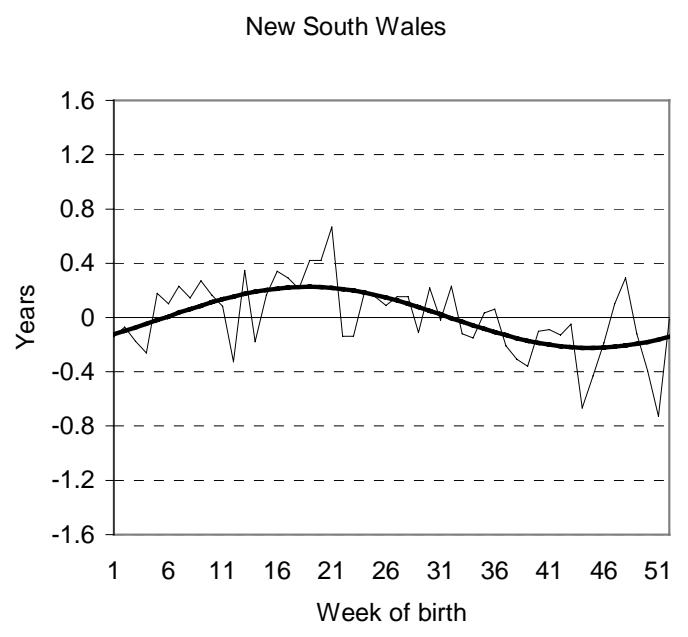

Queensland

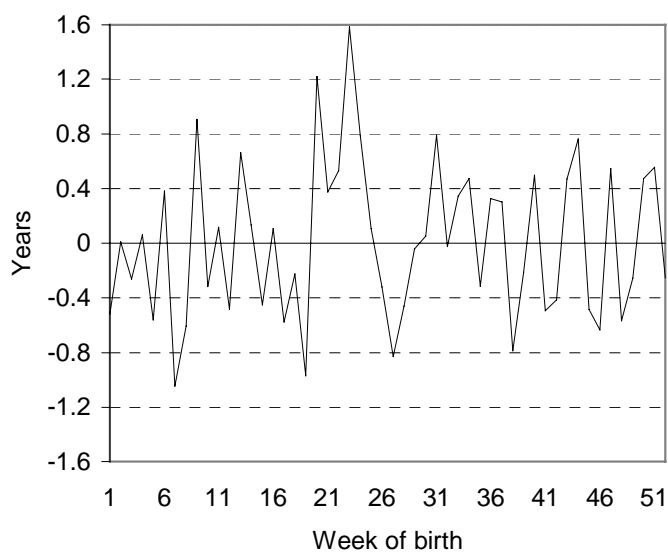

Western Australia

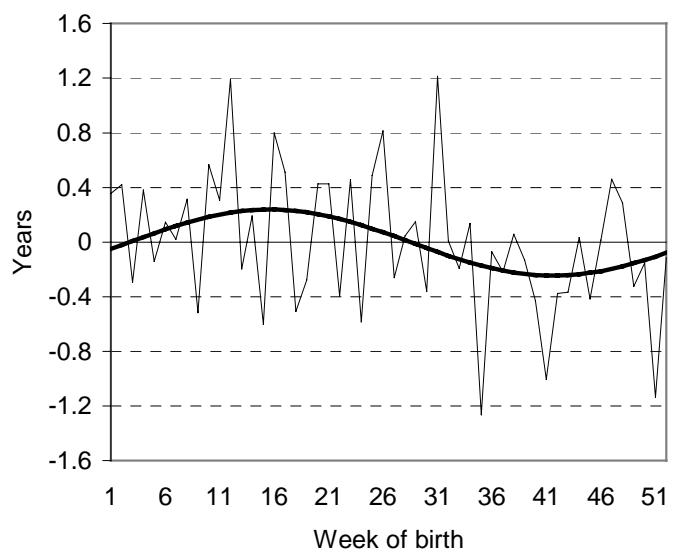

Victoria

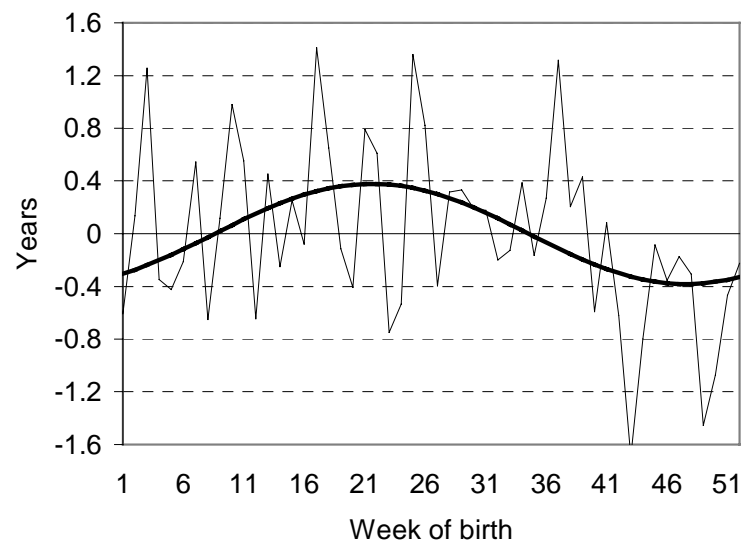

South Australia

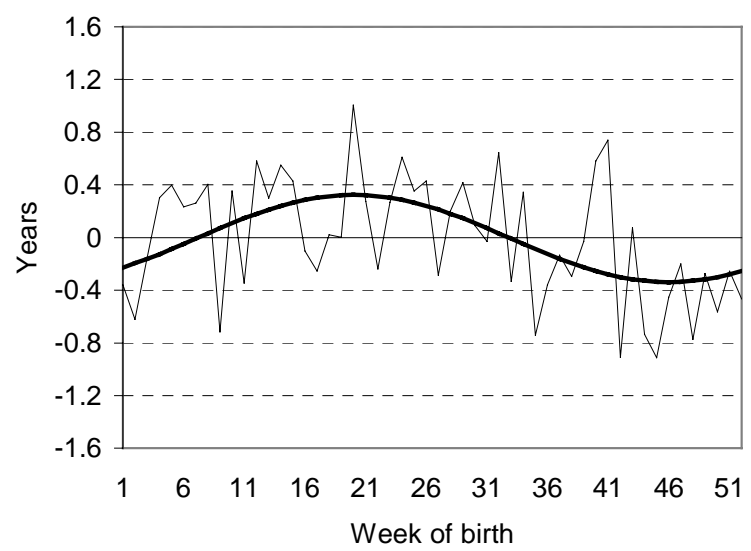

Tasmania

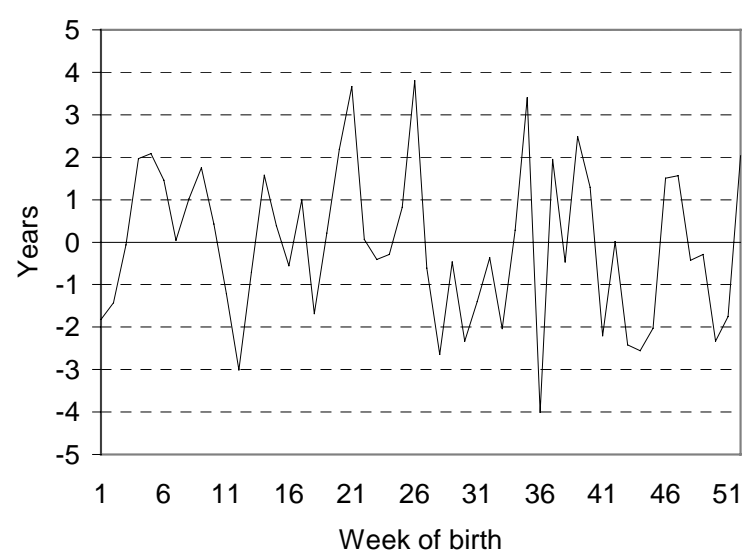


The peak-to-trough difference between those born in the second and the fourth quarter is significant for New South Wales (0.39 years), Victoria (0.89 years) and South Australia (0.61 years). It is of borderline significance $(\mathrm{p}<0.1)$ for Western Australia $(0.49$ years $)$. The largest, however, statistically not significant difference $(p=0.157)$ exists with 1.6 years for Tasmania. The cosine analysis supports the results. The cosine functions are generally highly significant with the exception of Tasmania and Queensland. The regional differences in the pattern of life span by month of birth are not significant (ANOVA F-test for the interaction effect between month of birth and region: $\mathrm{p}=0.585$ ).

The most interesting result of the regional analysis is that the peak-to-trough difference for Queensland is not significant. The non-significant result is not due to small numbers of observations. There are more observations for Queensland than, for example, Victoria, where the difference is highly significant. Figure 2.3 reveals that in Queensland, like in the other Australian states, mean age at death is highest for those born in May or June. It is lowest, however, for those born in January and February. The two major cities of Queensland are Brisbane (27.39 South Latitude, 153.12 East Longitude) and Townsville (19.25 South Latitude, 146.77 East Longitude). Therefore, geographically Queensland is almost a mirror image of Hawaii where Honolulu, the capital of the state Hawaii is situated

Figure 2.3: Queensland and Hawaii:

Deviation in life span for people born in a specific month from the average remaining life span at age 50 .

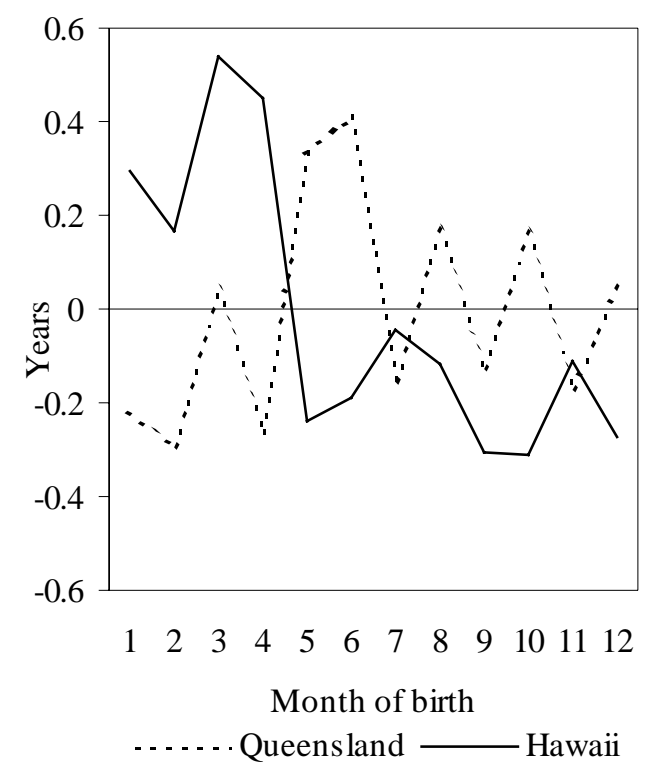
at 21:18 North Latitude and 157:51 West Longitude. Comparing the month-of-birth patterns for these to countries one finds that they are reversed: in Hawaii mean age at death is highest for those born during the first four months, in Queensland it is lowest; from May on mean age at death is generally lower in Hawaii and generally higher in Queensland. The Spearman correlation between Hawaii and Queensland is -.594 and significant at $\mathrm{p}=0.021$. 
Comparing the seasons of the year, both in Hawaii and Queensland mean age at death of those born at the beginning of the winter season, which is characterized by lower temperatures, live longer. In tropical northern Australia the wet season corresponds with summer and lasts from November through April. The dry season corresponds with winter and lasts from May through October. In Hawaii the wet season coincides with moderate temperatures and lasts from October to May, while the hot and dry summer lasts from June to September.

The Australian data distinguish between native-born Australians and Aborigines. The Australian dataset contains death records of 2,254 Aborigines and 218,279 native-born non-indigenous Australians. These figures exclude records with birth dates 1 January and 1 July because of a heaping of birth dates during these two days. Most probably unknown birth dates were assigned randomly to one of the two dates. The mean age at death of aborigines is almost 10 years lower (67.9 years) than that of the non-indigenous Australian population (77.8 years). The week-of-birth pattern is similar (Fig. 2.4), however, the amplitude is much larger among aborigines (1.17 years, 95\% CF: 0.40-1.94). The cosine function peaks in week 20 (95\% CF: 15-25). The amplitude among the native-born nonindigenous Australian population is 0.24 years (95\% CF: 0.18-0.30), mean age at death peaks for decedents born in week 19 (95\% CF:17-22). The fit of the cosine functions is higly significant at $\mathrm{p}<=0.001$.

Figure 2.4: Aborigines and Native-born Australians excluding Aborigines: Deviation in mean age at death for people born in specific weeks from the average age at death (ages 50+) estimated by a cosine function with a period of 52 weeks.
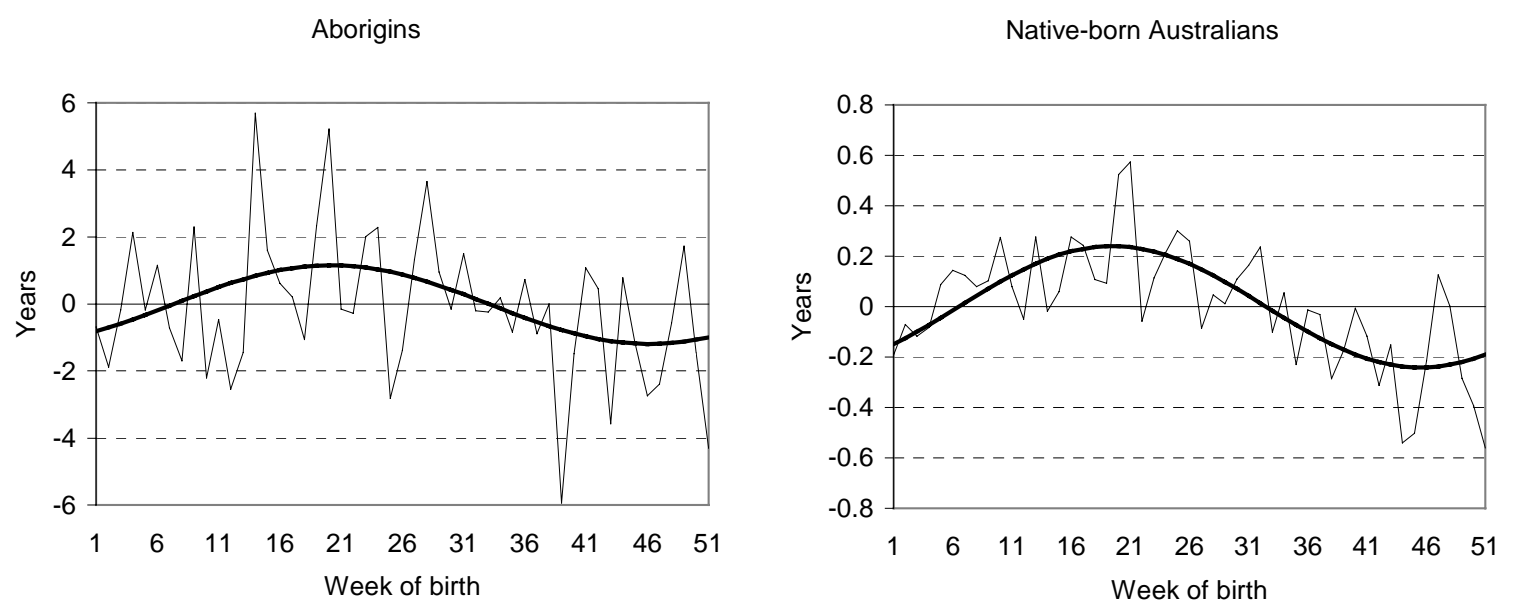
Table 2.2: Difference in mean age at death for people born in a specific season from average age at death by major causes of death; Austria 1990-1997.

\begin{tabular}{|c|c|c|c|c|c|c|}
\hline \multirow{2}{*}{$\begin{array}{l}\text { Causes of death } \\
\text { (ICD Number) }\end{array}$} & \multicolumn{5}{|c|}{ Season of birth } & $\begin{array}{c}\text { Number of } \\
\text { deaths }\end{array}$ \\
\hline & $\begin{array}{c}\text { Winter } \\
\text { (Jan-Mar) }\end{array}$ & $\begin{array}{c}\text { Spring } \\
\text { (Apr-Jun) }\end{array}$ & $\begin{array}{l}\text { Summer } \\
\text { (Jul-Sep) }\end{array}$ & $\begin{array}{l}\text { Autumn } \\
\text { (Oct-Dec) }\end{array}$ & $\mathrm{p}^{*}$ & \\
\hline $\begin{array}{l}\text { Heart disease } \\
(390-429,440-458)\end{array}$ & -0.08 & -0.30 & 0.06 & 0.33 & .00 & 257167 \\
\hline CVD (430-438) & -0.01 & -0.23 & -0.03 & 0.27 & .00 & 80367 \\
\hline Malignant neoplasms & & & & & & \\
\hline Breast (174) & 0.12 & -0.25 & 0.00 & 0.14 & .53 & 12201 \\
\hline $\begin{array}{l}\text { Uterus \& female genito } \\
\text { organs }(179-184)\end{array}$ & 0.05 & -0.08 & 0.10 & -0.07 & .92 & 9530 \\
\hline $\begin{array}{l}\text { Prostate \& male genito } \\
\text { organs }(185-187)\end{array}$ & -0.18 & -0.05 & 0.01 & 0.24 & .40 & 9401 \\
\hline $\begin{array}{l}\text { Urinary system } \\
(188-189)\end{array}$ & -0.09 & 0.07 & -0.39 & 0.42 & .06 & 8508 \\
\hline $\begin{array}{l}\text { Haemoblastoses } \\
(201-208)\end{array}$ & -0.19 & -0.07 & -0.02 & 0.28 & .44 & 9147 \\
\hline Lung (162) & -0.14 & -0.18 & 0.06 & 0.26 & .06 & 24178 \\
\hline Stomach $(151)$ & -0.10 & -0.44 & 0.03 & 0.50 & .00 & 12689 \\
\hline Intestines (152-154) & -0.02 & -0.12 & 0.12 & 0.02 & .70 & 21233 \\
\hline Other & -0.07 & -0.24 & -0.01 & 0.33 & .00 & 39359 \\
\hline $\begin{array}{l}\text { Respiratory system } \\
(460-479,488-519)\end{array}$ & 0.04 & -0.18 & -0.16 & 0.33 & .05 & 18018 \\
\hline $\begin{array}{l}\text { Pneumonia and influenza } \\
(480-487)\end{array}$ & -0.01 & -0.10 & -0.35 & 0.45 & .02 & 10807 \\
\hline $\begin{array}{l}\text { Digestive system } \\
(520-579)\end{array}$ & 0.23 & -0.20 & -0.28 & 0.24 & .01 & 27384 \\
\hline Diabetes mellitus (250) & -0.06 & -0.33 & 0.19 & 0.20 & .06 & 13537 \\
\hline Other natural & -0.26 & -0.22 & -0.08 & 0.58 & .00 & 27197 \\
\hline Violent (E800-E999) & -0.04 & -0.41 & -0.01 & 0.49 & .00 & 21998 \\
\hline
\end{tabular}

Bold figures: maximum and minimum difference from average age at death * p value: Anova F-Test for all seasons 
For Austria the data permit an analysis of causes of death for the years 1990-1997 (Table 2.2). There is a general tendency for people born in the first half of the year, especially in the second quarter, to die at younger ages than those born in the second half of the year, especially in the fourth quarter. The differences between people born in the second and fourth quarters are significant for both heart disease and cerebrovascular disease. In the group of malignant neoplasms significant differences exist for stomach cancer and the residual group 'other neoplasms'. Differences for lung cancer, cancer of the urinary system and diabetes mellitus are of borderline significance $(\mathrm{p}=0.06)$. Significant differences exist for chronic respiratory diseases, pneumonia and influenza, digestive diseases, the residual group 'other natural causes of death', and for violent causes of death. Although the Austrian death data consist of more than 600,000 decedents, the number of deaths from a particular cause of death can become quite small, especially when the data are further distinguished by month of birth. Some of the non-significant results may thus be caused by insufficient numbers of observations. Chapter 3 reports the cause-specific results from the analysis of about 16 million death certificates from the United States.

After establishing the month-of-birth pattern in lifespan the reminder of the chapter is devoted to the testing of five hypotheses.

\section{Seasonal distribution of deaths.}

The first hypothesis assumes that the observed relationship is caused by the interaction of the seasonal distribution of deaths and the monthly increase in adult mortality. For example, since the April-born during their whole life are always older than the fall-born when the high mortality risk of winter strikes them they may experience higher mortality overall. In other words, month of birth is not so much related to the beginning or life but is rather a life-cycle indicator. This hypothesis has already been widely discussed and tested in the research about schizophrenia. In this research it is referred to as the "age prevalence and age incidence effect". Torrey et al (1997) review a large number of studies that deal with this "statistical artifact" and its description here is largely based on Torrey's article. The studies about age-prevalence and age-incidence deal with the problem of the interaction between age and seasonality in the incidence of schizophrenia, although the term 
seasonality is not mentioned explicitly. Lewis and Griffin $(1981$, p590) explain the effect as follows:

"For example, people who are 30 years old have a higher incidence of schizophrenia than people who are 29 years old. Therefore, people born in 1937, may have a higher incidence in 1967 than in 1966. When first admissions from 1967 are pooled with first admissions from 1966, people born in 1937 and admitted in 1967 will have more influence on the final result than people born in 1937 and admitted in 1966. The difference in the influence between any 2 years is not great, but over the course of an entire data set it becomes noticeable and should be corrected."

Lewis and Griffin try to explain -in a slightly complicated way- that the incidence of schizophrenia is seasonal and that people born in different seasons of the year are hit by the higher risk of developing schizophrenia at slightly different ages. This is similar to the problem one faces with mortality.

Torrey et al. write that although

"the age incidence and the age prevalence effects have elicited extensive and spirited discussion among statisticians and psychiatric researchers (...), the effects have been shown to be negligible."

Hare (1975) and Lewis and Griffin (1981) had proposed a formula to correct for the effect. Torrey et al. mention thirteen studies that used the correction but still found significant winter-spring birth excess among schizophrenic patients.

In Denmark, Austria and Australia the risk of death is lowest in summer and highest in winter. The differences between the summer trough and the winter peak are considerable, and depend on the time period, age, climate and social conditions. In all three countries death rates after age fifty increase by about $0.8 \%$ per month of age. The question is whether the increasing mortality with age together with the seasonal differences in mortality may cause the differences in life span by month of birth. 
This question can be answered using the register data from Denmark. The longitudinal nature of the Danish data permits simultaneous modeling of cohort effects (i.e. month of birth), period effects (i.e. current month), and age effects (i.e. age in months). Thus, one can explicitly estimate the effect of increasing mortality with age and the seasonality in mortality on the effect of month of birth. Birth cohorts by year and month of birth were constructed and the deviation of their monthly death rates from their annual death rates between April 1968 and August 1998 was calculated. This procedure standardizes for the yearly increase with age in mortality and results in a surface of relative

Figure 2.5 A: Danish register data: Deviations in standardized death rates by month of birth, current month and age in month

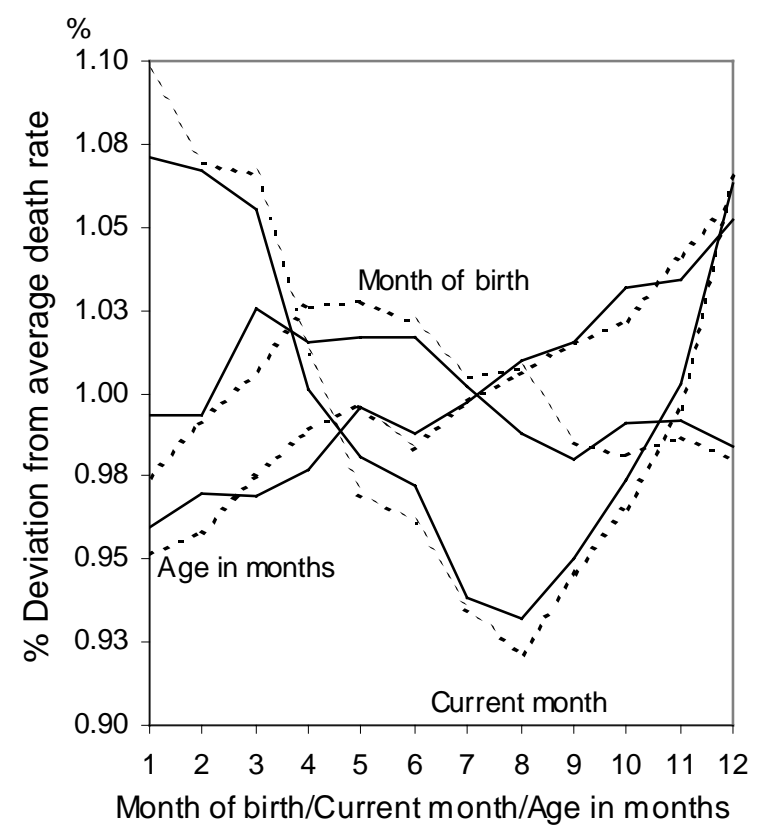

deviations over age and time. The deviations depend on the current month (i.e. month of death), the age in months, and sex. As expected, mortality increases by about $10 \%$ for males and females combined within twelve months (Fig. 2.5A, solid lines females, dashed lines males). Mortality is lowest in August and highest in January; the difference is about $17.6 \%$ for males and $13.9 \%$ for females. The maximum difference in the death rates by month of birth is approximately $5.3 \%$ for males and $4.5 \%$ for females. The monthly pattern is similar for females and males. Although all three factors examined influence adult mortality simultaneously (Fig. 2.5B) they are independent of each other. Figure 2.5C reveals that considerable differences do indeed exist in age-specific mortality trajectories over a year of life depending on the month of. 
Figure 2.5 B: Danish register data: death rates by age for June and December-born

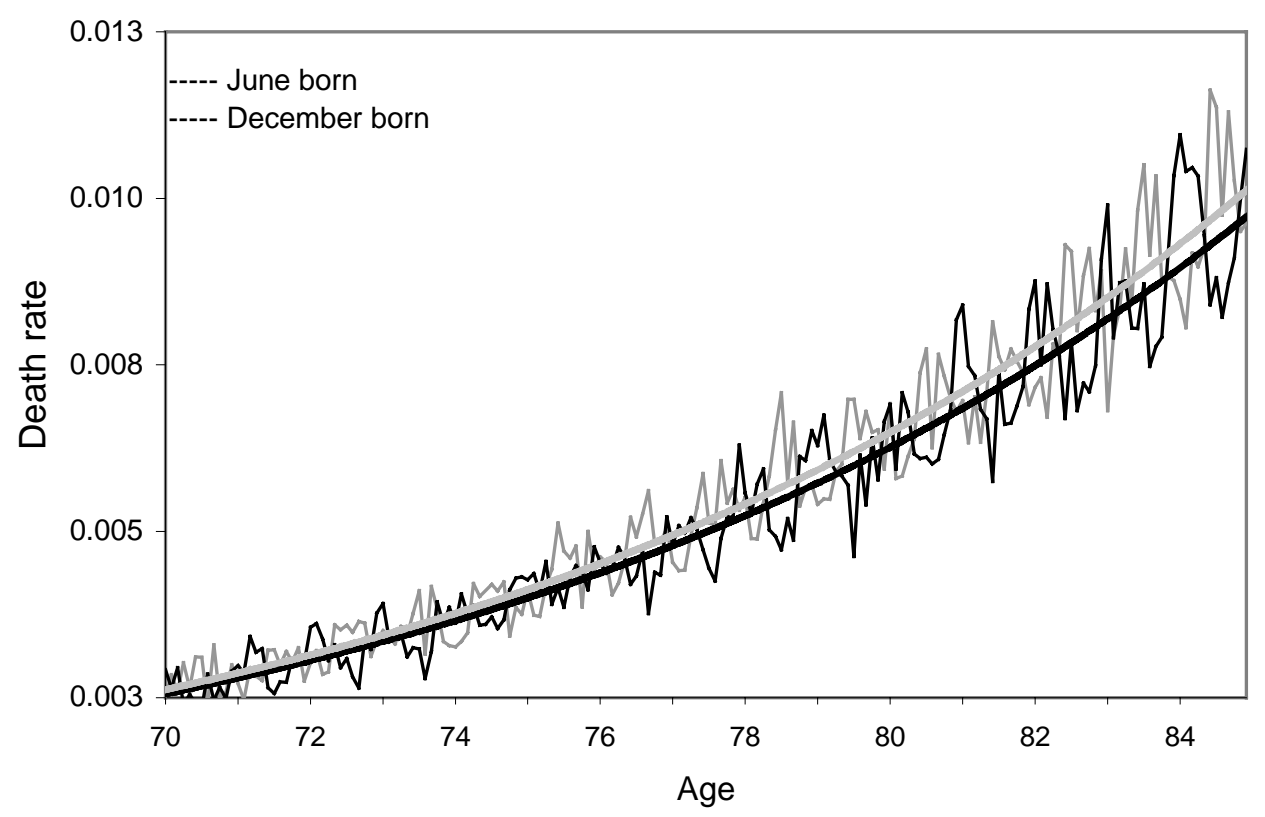

Figure 2.5 C: Danish register data: death rates over the course of one year depending on the month of birth

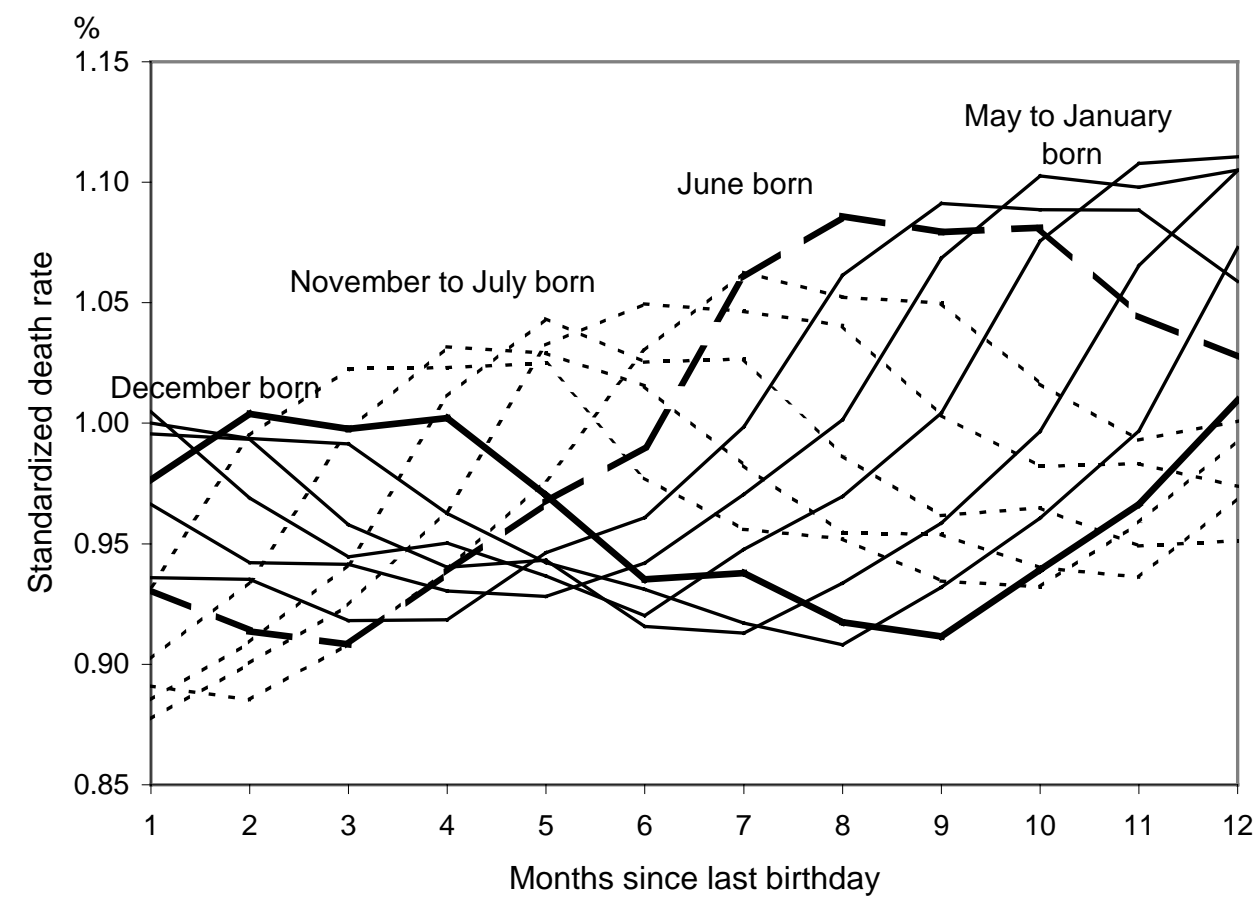


Table 3: The logarithm of the relative deviations from yearly Danish death rates by month of birth, age in months, current month, sex, and cohort.

\begin{tabular}{|c|c|c|c|c|c|}
\hline Covariates & Par. Estimates & & Covariates & Par. Estin & nates \\
\hline Month of birth & & & Current month & & \\
\hline January (RG) & 0 & & January (RG) & 0 & \\
\hline February & 0.0174 & $* *$ & February & -0.0150 & \\
\hline March & 0.0356 & $* *$ & March & -0.0610 & $* *$ \\
\hline April & 0.0417 & $* *$ & April & -0.0948 & $* *$ \\
\hline May & 0.0414 & $* *$ & May & -0.1030 & $* *$ \\
\hline June & 0.0435 & $* *$ & June & -0.1302 & $* *$ \\
\hline July & 0.0237 & $* *$ & July & -0.1442 & $* *$ \\
\hline August & 0.0215 & $* *$ & August & -0.1241 & $* *$ \\
\hline September & 0.0115 & $* *$ & September & -0.1031 & $* *$ \\
\hline October & 0.0111 & $* *$ & October & -0.0737 & $* *$ \\
\hline November & 0.0168 & $* *$ & November & -0.0123 & \\
\hline December & 0.0045 & & December & 0.0084 & \\
\hline Age & & & Sex & & \\
\hline 1 month (RG) & 0 & & Male (RG) & 0 & \\
\hline 2 months & 0.0023 & & Female & -0.0238 & $* *$ \\
\hline 3 months & 0.0098 & $*$ & Cohort & & \\
\hline 4 months & 0.0239 & $* *$ & $1863-1888$ & 0.7170 & $*$ \\
\hline 5 months & 0.0355 & $* *$ & $1889-1918(\mathrm{RG})$ & 0 & \\
\hline 6 months & 0.0306 & $* *$ & Constant & -0.0540 & $* *$ \\
\hline 7 months & 0.0412 & $* *$ & & & \\
\hline 8 months & 0.0452 & $* *$ & & & \\
\hline 9 months & 0.0525 & $* *$ & & & \\
\hline 10 months & 0.0638 & $* *$ & & & \\
\hline 11 months & 0.0732 & $* *$ & & & \\
\hline 12 months & 0.0900 & $* *$ & & & \\
\hline
\end{tabular}


As compared to the univariate analysis of month of birth, age, and month of death (current month) results do not change when the impact of the different factors is estimated simultaneously (Table 2.3) using the multivariate regression model described in Equation 2.3. To test whether the interaction between age and month of death (current month) affects the month-of-birth pattern an interaction-term between the two factors was included in the multivariate model. Table 2.4 shows that the inclusion of the interaction term does not affect the parameter values for the month-of-birth. This result implies that the differences in life span by month of birth are not caused by the seasonal fluctuations in mortality.

Social differences in the seasonal distribution of births - the procreational habits hypothesis.

Table 2.4: Effect of the seasonality of death on differences in life-span by month of birth: The logarithm of the relative deviations from yearly Danish death rates by month with (Model 2) and without (Model 1) correction for the interaction between current month and age.

\begin{tabular}{lcccc}
\hline & \multicolumn{2}{c}{ Model 1 } & \multicolumn{2}{c}{ Model 2 } \\
\cline { 2 - 5 } & Par. Estimates & p-value & Par. Estimates & p-value \\
\hline Dec & 0.0000 & & 0.0000 & \\
Feb & 0.0088 & 0.0373 & 0.0092 & 0.0338 \\
Mar & 0.0272 & 0.0000 & 0.0273 & 0.0000 \\
Apr & 0.0316 & 0.0000 & 0.0333 & 0.0000 \\
May & 0.0320 & 0.0000 & 0.0334 & 0.0000 \\
Jun & 0.0343 & 0.0000 & 0.0357 & 0.0000 \\
Jul & 0.0160 & 0.0002 & 0.0176 & 0.0002 \\
Aug & 0.0139 & 0.0010 & 0.0148 & 0.0013 \\
Sep & 0.0040 & 0.3465 & 0.0050 & 0.2681 \\
Oct & 0.0035 & 0.4149 & 0.0061 & 0.1749 \\
Nov & 0.0084 & 0.0521 & 0.0113 & 0.0121 \\
Dec & -0.0031 & 0.4687 & -0.0007 & 0.8753 \\
\hline
\end{tabular}

Model 1: corrects for sex, age since last birthday, current month and cohort. Age since last birthday is parameterized as a linear function

Model 2: same as model 1 but includes an interaction term between current month and age 
The second hypothesis assumes that the causal mechanism is linked to socioeconomic differences in the seasonal distribution of births. With only a few exceptions births are distributed seasonally over the year. It has been shown that both social and biological factors influence this seasonality (Lam and Miron 1996, Doblhammer et al. 2001). The hypothesis is that if the seasonality in birth is partly driven by the preference of couples for certain seasons then the intensity of the preference may differ between social groups.

In schizophrenia research this hypothesis is known as the procreational habits hypothesis. In their review Torrey at al. (1997) mention Huntington (1938) as the first to explain the seasonal birth pattern in individuals with schizophrenia by the idiosyncratic seasonal conception pattern of their parents. And they cite James (1978) who describes the exceptional conception pattern as

" in the summer, people wear fewer clothes in bed, and... a schizoid spouse is more likely then to notice his (or her) co-spouse there and accordingly to initiate sexual behaviour".

Other contemporary proponents of this theory are Hafner et al. (1987) and Bleuler (1991) who proposes that conceptions among depressed individuals are more likely to take place in spring, when depression is less severe. In their review Torrey et al. come to the conclusion that the procreational habits theory can be ruled out as an explanation for the winter-spring excess births among schizophrenic. First, the theory predicts that individuals with schizophrenia who have a family history of the disease should have a greater winter-spring birth excess which is clearly not the case. Second, the procreational habits theory also predicts that siblings of individuals with schizophrenia should also have a winter-spring birth excess. Torrey et al. (1997) cite six studies that did not find a winter-spring birth excess among siblings of schizophrenia.

To test this hypothesis in the context of mortality education was used as an indicator of social group. Parental education is not contained on birth certificates in the beginning of the $20^{\text {th }}$ century. It was thus assumed that in 1991 a person's educational level was closely linked to the educational level of his or her parents. The Austrian microcensus 
of the year 1991 reveals that the educational status of the 15- to 19-year old Austrians depends to a large part on the social and educational status of the parents (xxx), despite tuition-free access to all levels of education since the 1970s. Thus, for earlier birth cohorts that did not benefit from the expansion of the Austrian education system, the intergenerational correlation in education must have been even stronger than it is today.

The seasonal distribution of the birth dates of Austrians aged 50+ by educational group on the basis of the 1981 census was then calculated. It appears that the spring peak in births is stronger among adults with high or medium education while those with basic education are over-represented among the autumn born (Fig.2.6).

Fig. 2.6. Per cent deviations in the seasonal distribution of births of Austrians (ages 50+) by education from the average seasonal distribution of births. medium (small dashed line), high (long dashed line), basic education (solid line) and differences in mean age at death (bold solid line).

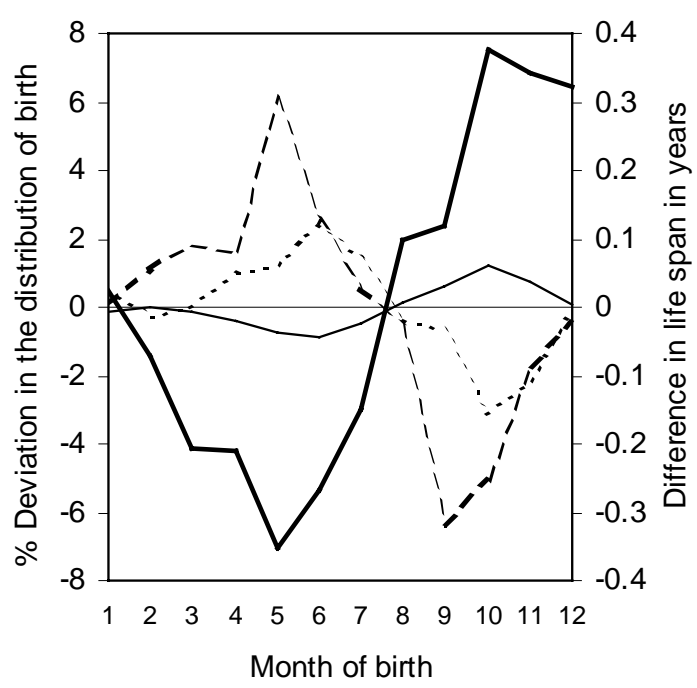

The correlation between mean age at death by month of birth and the deviations in the monthly birth distribution from the average monthly pattern is -0.78 (Pearson correlation, one-sided test: $\mathrm{p}<0.001)$ for adults with high education, $-0.84 \quad(\mathrm{p}<=0.001)$ for adults with medium education and 0.88 $(p<0.001)$ for adults with basic education. A recent study about the seasonality of births in former Czechoslovakia comes to the same result (Bobak \& Gjonca 2001). A similar result was found on the basis of a $10 \%$ sample of the 1971 census of economically active, British-born males. Non-manual workers tended to be born in spring and manual workers in autumn and winter (Smithers et al. 1984).

One can therefore conclude that the month-of-birth pattern in longevity is not due to differences in the conception pattern by socio-economic group. On the contrary, it appears 
that the differences in life span would be even larger if socioeconomic differences were taken into account.

\section{The deadline hypothesis}

Another prominent hypothesis in sociological and psychological research is that children who are born after a certain deadline have to wait another year before they can enroll at school, which makes them about a year older than the youngest children in their class. For example, at the beginning of the 20th century school started on 1 October in Austria. Those children who had not turned six before this date had to wait another year. Thus, children born in autumn experienced an age advantage over their classmates.

Research suggests that this age advantage affects scholastic aptitude, which might translate into a lifelong advantage in various regards. Alton and Massey (1998) studied the General Certificate of Secondary Education (GCSE) examinations. Almost all pupils in England, Wales and Northern Ireland take this examination at age 16. The authors find that there is a steady decline in grades from pupils born in September to August, i.e. from the oldest to the youngest pupils. At age 18 these differences have vanished. The authors attribute this to a selection effect because only the students who did well at the GCSE examinations would continue to the advanced level. A significant interaction between reading failure and age category (overage at school entrance vs. correct age) by season of birth was observed among $2^{\text {nd }}$ graders (Flynn et al. 1996). Although the authors mention entrance cutoff birth dates to kindergarten as a probably explanation they do not rule out that the reported associations may be attributed to selective sampling.

The affect of relative age has been widely tested in the area of sports. Dudink (1994) finds a significant relationship between date of birth and success in tennis and soccer. In both disciplines half of the tennis players in the top rankings of the Dutch youth league and a third of the English soccer players in league clubs were born during the first three months of the competition year. The consistent asymmetry on the birth-distribution of senior professional soccer players has led Helsen et al. (1998) to investigate whether this asymmetries already exist in youth categories in soccer. Their results indicate that youth players born from August to October at ages 6 to 8 are more likely to be identified as 
talented and are exposed to higher levels of coaching. These players are born early in the selection year and are relatively older. Those born relatively later in the selection year tend to dropout as early as 12 years of age. A study of the effect of a horse's month of birth in its future sport performance (Langlois \& Bloin 1998) showed that under the age of 4 horses that were born in the second part of the year were particularly disadvantaged at flat races. The disadvantage was not so strong in jumping races and for trotters. After age 4 the effect was of much smaller magnitude. They suggest that two effects may be responsible for the results: a relative age-effect, which is more prominent in races were older horses are favored. This relative-age effect decreases with age (probably due to selection). The second effect is mainly seen among older horses in equestrian competitions and is not further specified by the authors.

Angrist and Krueger (1991) performed the most widely known study that explores the deadline effect with regard to outcomes in schooling and earnings. The authors, however, argue the opposite way than the studies cited above. Since compulsory schooling laws require students to stay in school until their $16^{\text {th }}$ or $17^{\text {th }}$ birthday the oldest students may drop out slightly earlier which should be reflected in their later earnings. In their study they exploit an "unusual natural experiment" to estimate the effect of compulsory schooling laws on educational attainment and earnings. The explain the experiment as follows:

"The experiment stems from the fact that children born in different months of the year start school at different ages, while compulsory schooling laws generally require to remain in school until their sixteenth or seventeenth birthday. In effect, the interaction of school-entry requirements and compulsory schooling laws compel students born in certain months to attend school longer than students born in other months. Because one's birthday is unlikely to be correlated with personal attributes other than age at school entry, season of birth generates exogenous variation in education that can be used to estimate the impact of compulsory schooling on education and earnings" (page 980).

In their study they find that children born in the first quarter of the year have a slightly lower average level of education than children born later in the year. According to 
the authors school districts typically require a student to have turned six by January 1 of the year in which he or she enters school. Therefore, the students born at the beginning of the year enter school at and older age and attain the legal drop-out age earlier in their educational careers than students born later in the year. In support of their study they report that the seasonal pattern of education is not evident in college graduation rates, nor in graduate school completion rates. Since compulsory schooling laws do not affect these two types of schools, the authors conclude that the relationship between years of schooling and month of birth is entirely due to compulsory schooling laws. In their second part of their paper they showed that not only educational attainment but also earnings later in life are related to the month of birth.

In a recent paper by Pflug (2001) the author repeats the study by Angrist and Krueger for the Netherlands and presents evidence that season of birth influences school performance not in terms of compulsory schooling effects but by means of learning abilities. They refer to the arguments presented above that it is the relative age among class mates that influences learning ability and, as a result of education, earnings later in life.

Further criticism of Angrist's and Kruegers study was raised by Bound and Jaeger (1996). They showed that the association between quarter of birth and earnings or other labor market outcomes existed for cohorts that were not bound by compulsory school attendance laws. Furthermore, Angrist and Krueger did not take into account that differences in the birth distribution of social groups exist and that other factors, like health, may be related to the season of birth.

Based on above studies there seems to exist firm evidence that the relative age among pupils influences their scholastic aptitude and their sporting success. In Austria at the beginning of the $20^{\text {th }}$ century school started on 1 October and children who had not turned six before this date had to wait another year. Thus, the fall born were the oldest among-their class mates. Nevertheless one finds that the fall-born achieve lower educational levels than the spring-born, which is contrary to the evidence presented above. In addition, at the turn of the $20^{\text {th }}$ century in Austria many schools, particularly in rural areas, combined several grades into one class and one teacher taught the different grades 
Selective survival in the first year of life or debilitation in-utero or in infancy.

The fourth hypothesis assumes that selective survival during infancy is the causal mechanism that explains the relationship between month of birth and life expectancy. Specifically, the hypothesis is that autumn-born infants suffer higher mortality in their first year of life than spring-born infants. This would leave the relatively more robust individuals alive, who would experience lower mortality at adult ages.

Infant mortality decreases dramatically over the first year of life. Based on births and infant deaths in Denmark between 1911 and 1915 the probability of death decreases from 0.023 in the first 24 hours of life to 0.00275 in the twelfth month of life. At the same time infant mortality is highly seasonal. However, the pattern of seasonality depends on age. Although at almost all ages death rates are highest in the winter months in the first five months of life a prominent secondary peak exists for the summer months of July, August, and September. This secondary peak tends to become smaller and even tends to disappear from the $6^{\text {th }}$ month of life onwards (Fig. 2.7). In a model of the effect of month of birth on survival during the first year of life one, therefore, has to account for the changes in the seasonality of deaths with age and for the strong decrease in the death rate over the first twelve months.

Using Danish data from the years 1911 to 1915 on seasonal infant mortality in the first year of life it appears that according to the model in Equation 2.4 infants born in June are the most vulnerable. Table 2.5 contains the parameter estimates of the model described in Equation 2.4 and of a model without correction for the interaction between month of death and age. Both models fit the data well with an adjusted $R^{2}$ of 0.93 for the model without correction of age at death and current month and an adjusted $R^{2}$ of 0.96 for the model with correction. The latter model predicts that the standardized death rate during the first year of life is about $31 \%$ higher for the June-born than for the February-born. The correction for the interaction between the seasonality of death and age has two effects: First, it decreases the mortality disadvantage of the June-born and, second, it shifts the whole pattern to the left. 
Figure 2.7: Deviation from the average death rate at a particular age (in months) by month of the year (current month) in Denmark 1911 - 1915
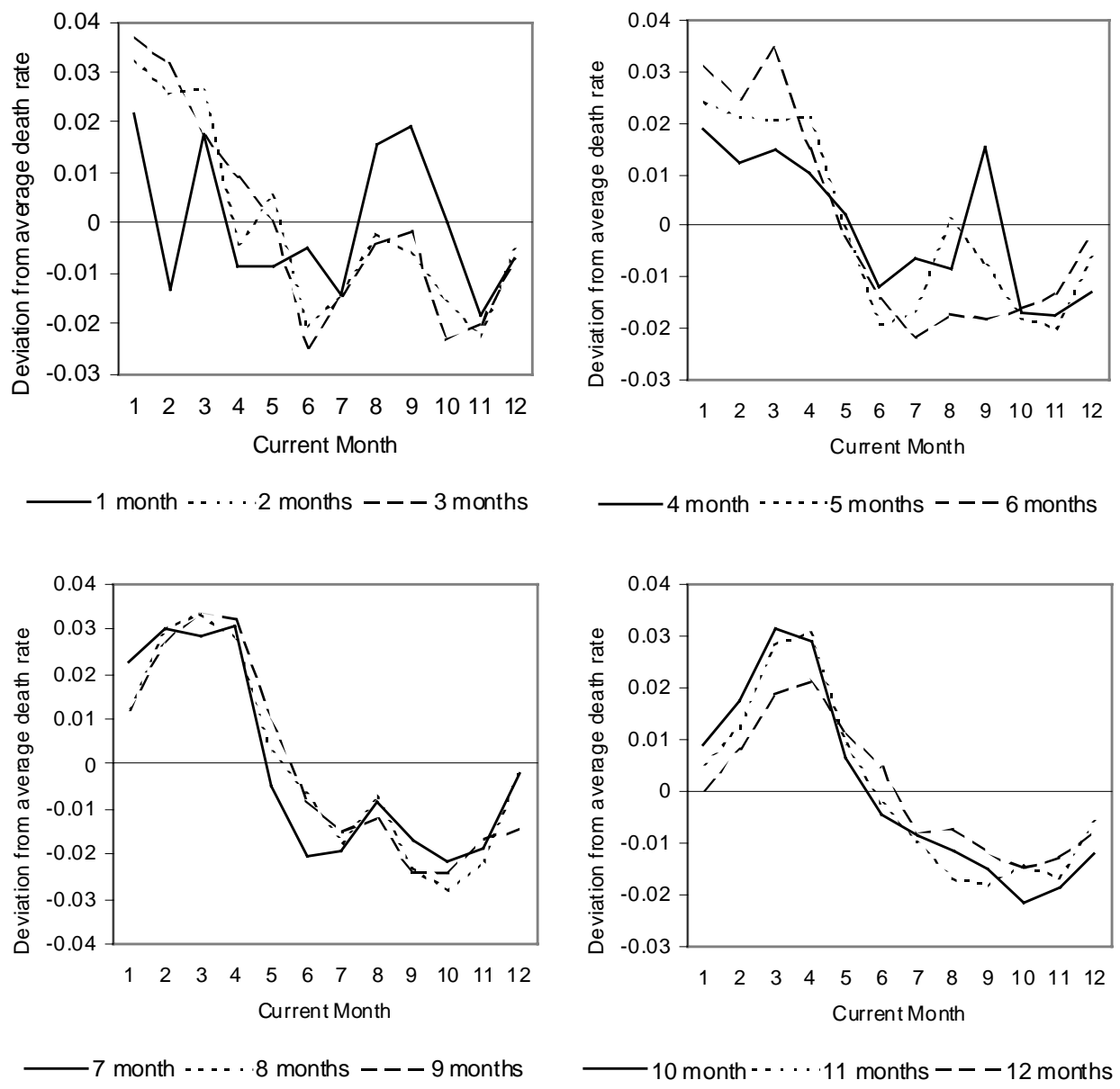
Table 2.5: Effect of the seasonality of death on infant mortality by month of birth

\begin{tabular}{|c|c|c|c|c|}
\hline & \multicolumn{2}{|c|}{ Model 1} & \multicolumn{2}{|c|}{ Model 2} \\
\hline & $\begin{array}{c}\text { Parameter } \\
\text { estimate }\end{array}$ & p-value & $\begin{array}{c}\text { Parameter } \\
\text { estimate }\end{array}$ & p-value \\
\hline Intercept & -1.529 & 0.0000 & -1.352 & 0.0000 \\
\hline \multicolumn{5}{|l|}{ Current month } \\
\hline January & 0.358 & 0.0000 & 0.241 & 0.1462 \\
\hline February & 0.421 & 0.0000 & 0.084 & 0.6175 \\
\hline March & 0.506 & 0.0000 & 0.050 & 0.7673 \\
\hline April & 0.451 & 0.0000 & -0.165 & 0.3345 \\
\hline May & 0.217 & 0.0052 & -0.147 & 0.3916 \\
\hline June & -0.017 & 0.8188 & -0.339 & 0.0498 \\
\hline July & -0.122 & 0.1122 & -0.241 & 0.1616 \\
\hline August & -0.052 & 0.4955 & -0.068 & 0.6898 \\
\hline September & -0.174 & 0.0241 & 0.072 & 0.6715 \\
\hline October & -0.291 & 0.0002 & -0.033 & 0.8433 \\
\hline November & -0.232 & 0.0028 & -0.060 & 0.7164 \\
\hline December & 0.000 & & 0.000 & \\
\hline \multicolumn{5}{|l|}{ Month of birth } \\
\hline January & -0.072 & 0.3488 & -0.044 & 0.5058 \\
\hline February & -0.070 & 0.3572 & -0.023 & 0.7308 \\
\hline March & -0.023 & 0.7672 & 0.018 & 0.7964 \\
\hline April & 0.080 & 0.2983 & 0.095 & 0.1662 \\
\hline May & 0.206 & 0.0078 & 0.165 & 0.0179 \\
\hline June & 0.304 & 0.0001 & 0.233 & 0.0010 \\
\hline July & 0.301 & 0.0001 & 0.195 & 0.0054 \\
\hline August & 0.254 & 0.0011 & 0.136 & 0.0486 \\
\hline September & 0.203 & 0.0088 & 0.081 & 0.2334 \\
\hline October & 0.112 & 0.1436 & 0.025 & 0.7099 \\
\hline November & 0.020 & 0.7904 & -0.023 & 0.7328 \\
\hline December & 0.000 & & 0.000 & \\
\hline Ln (age) & -0.854 & 0.0000 & -0.938 & 0.0000 \\
\hline \multicolumn{5}{|c|}{ Interaction $\ln ($ age $) *$ current month } \\
\hline January* $\ln ($ age $)$ & & & 0.071 & 0.4390 \\
\hline February*ln(age) & & & 0.203 & 0.0305 \\
\hline March* $\ln ($ age $)$ & & & 0.274 & 0.0042 \\
\hline April*ln(age) & & & 0.369 & 0.0002 \\
\hline May* $\ln ($ age $)$ & & & 0.218 & 0.0234 \\
\hline June $* \ln ($ age $)$ & & & 0.193 & 0.0448 \\
\hline July $* \ln ($ age $)$ & & & 0.071 & 0.4549 \\
\hline August $* \ln ($ age $)$ & & & 0.010 & 0.9197 \\
\hline September $* \ln ($ age $)$ & & & -0.148 & 0.1179 \\
\hline October $* \ln ($ age $)$ & & & -0.155 & 0.0970 \\
\hline November $* \ln ($ age $)$ & & & -0.103 & 0.2574 \\
\hline December $* \ln ($ age $)$ & & & 0.000 & \\
\hline
\end{tabular}


This is not the first study to recognize that historically infant mortality depended strongly on the season of birth and that the seasonal pattern of infant deaths depends on age. Already in 1938 Huntington presented similar results for Belgium and New York (Huntington 1938), Breschi. \& Bacci (1996) came to similar conclusion for Switzerland and Belgium, and Lumaa et al (1998) for Finland.

Figure 2.8: Standardized death rates of Danish infants born in a specific month and difference in remaining life expectancy at age 50 by month of birth

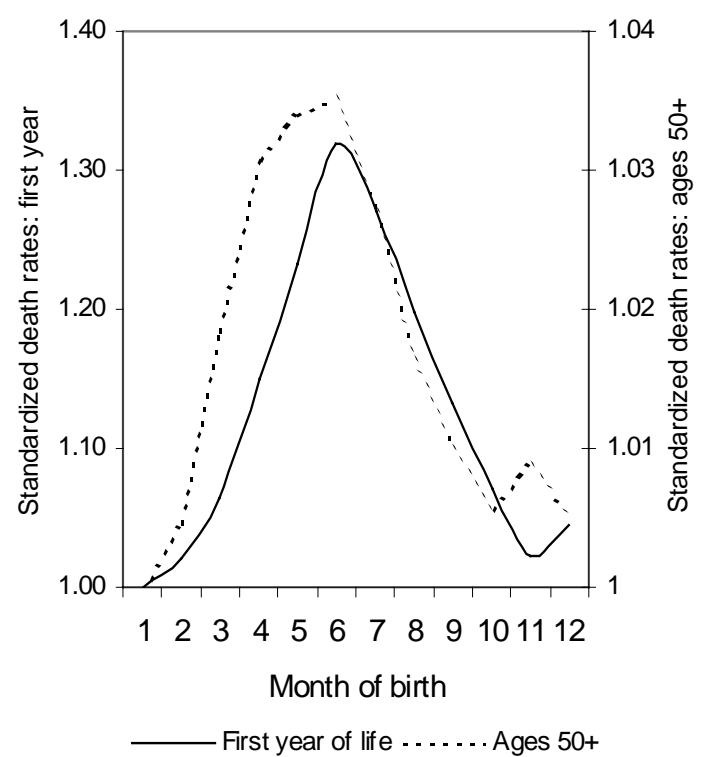

If selective survival during infancy explains the differences in adult life span, then one would expect a significant negative correlation between the probability of death in the first year of life and after age 50. If debilitation in-utero or during the first year of life (our fifth hypothesis) is the causal mechanism, then one would expect a significant positive correlation because rates of debilitation are highly correlated with mortality.

For Denmark the correlation between infant mortality in the first year of life and adult mortality after at age 50 (Figure 2.8) is 0.87 and statistically significant $(\mathrm{p}<0.0001)$. This result clearly rules out the selection-hypothesis and indicates that the causal mechanism of the month-of-birth pattern in life span is related to debilitating factors that affect either the mother during pregnancy or the infant in the first year of life.

\section{Conclusion}

From the analysis of the four countries Austria, Denmark, Australia and Hawaii four main conclusions can be drawn:

First, the differences in life span by month of birth are tied to the seasons of the year. This is clearly shown by the reversal of the pattern in the Northern and the Southern Hemisphere. 
Second, the pattern does also exist in regions close to the equator: Hawaii is one example, Queensland in Australia another. This finding rules out the explanation that differences in the length of daylight are the underlying causal mechanism. This hypothesis will be further explore on the basis of the US death data (Chapter 3).

Third, although Queensland and Australia are close to the equator these two countries experience two distinct seasons of the year, namely a wet and a dry season. In both countries those who experience a mortality advantage later in life are born at the beginning of the season when temperatures are more moderate. In non-tropical regions with four distinct seasons those born in fall and winter have longer lives.

Fourth, within a country the pattern may vary greatly among different groups. This is shown by the analysis of the month-of-birth pattern among Aborigines in Australia. Among the Aborigines not only is the peak-to-trough difference more than nine times as large as among other native-born Australians but also the pattern is different. The next chapter will explore whether this is also true for different social and racial groups in the United States.

The test of the five hypotheses clearly reveals that the month-of-birth pattern is not the result of an age-artifact caused by the seasonality of death, nor is it the result of social factors such as social differences in the seasonal distribution of births or age at entry into school. There is no support for the hypothesis that differential infant survival is the causal factor behind the observed phenomenon. On the contrary for Denmark a strong and highly significant positive correlation between the differences in infant mortality and the differences in mortality after age 50 by month of birth exist, which is consistent with the hypothesis that debilitation early in life is the causal mechanism.

The results support the theory of a critical period early in life that affects adult health and survival without other mediating life-course factors. The model of infant mortality does not permit any conclusions about whether debilitation occurred in-utero or during early infancy. The results are consistent with both the effect of seasonal differences in nutrition and of seasonal differences in the disease environment early in life. In past decades the food supplies in general, and the availability of fresh fruit and vegetables in particular, differed from season to season. Mothers who gave birth in autumn and early 
winter had access to plentiful food and fresh fruit and vegetables throughout the third trimester of pregnancy, the period of peak growth of the fetus; those who gave birth in spring and early summer experienced longer periods of inadequate nutrition during their last trimester. On the other hand, historically infant mortality was primarily the result of infectious disease, which occurred seasonally. The close correlation between infant mortality by month of birth and the month-of-birth pattern in adult life span therefore suggests that infectious disease plays an important role.

In the Danish data differences in adult life span by month of birth are significantly smaller in the more recent cohorts than in the oldest cohorts. For those born before 1888 the differences are amplified by a factor of $\mathrm{e}^{0.72}=1.72$. That is, the difference in adult mortality by month of birth is almost twice as large for the cohorts born from 1863 to 1888 compared with those born between 1889 and 1918. Chapter 4 provides a more detailed analysis of the cohort changes in the month-of-birth pattern. This shift lends further support to the explanation that the relationship between month of birth and adult life expectancy is caused by prenatal and early postnatal conditions related to nutrition and infectious disease because considerable improvements in maternal and infant health took place between the first and second period (Preston \& Haines 1991). 


\section{THREE}

\section{DIFFERENCES IN LIFE SPAN BY MONTH OF BIRTH IN THE UNITED STATES}

The most important criticism about research on early life environment and later life health and mortality is concerned with how this research is interpreted (for an overview see Kuh \& Davey Smith 1993). It has been argued that the strong correlation between early environment and adult mortality may simply be an effect of continued deprivation over the whole life course rather than of factors that act early in life (Ben-Shlomo \& Davey Smith 1991).

This study uses month of birth as an indicator for early life circumstances. The previous chapter provided evidence that month of birth does not have any further life course interpretations that affect mortality. The comparison of the pattern for people born in the Northern Hemisphere to those born in the Southern Hemisphere suggests that the effect of the month of birth on life span is related to the seasons of the year. In both hemispheres, the remaining life expectancy after age 50 is lower for people born in spring than for those born in fall. Thus, in the Northern Hemisphere the pattern is a mirror image of the Southern Hemisphere's pattern.

Furthermore, the previous chapter showed that a significant positive correlation exists between infant mortality in the first year of life by month of birth and mean age at death by month of birth. This led to the conclusion that it is debilitation rather than selection that leads to the differences in life span by month of birth.

The aim of this chapter is [N1]to gain deeper insights into the mechanisms that cause the differences in life span by month of birth by using information about the social, demographic and geographic characteristics of the decedents. It explores whether the differences vary with educational background, marriage status, region of birth, race and sex on the basis of 15.6 million US death certificates for the years 1989 to 1997 . One would expect that the differences depend on social factors: they should increase with lower education and they should be larger for African-Americans than for whites. 
Evidence exists that marital status is partly determined by health selection into marriage (Goldman, Lord \& Hu 1993) and that the never married are frailer than the ever-married population (Goldman \& Hu 1993). Differences in life span by month of birth should therefore be larger among the never married than among the ever married.

The information about state of birth permits testing four hypotheses that have been put forward to explain the month-of-birth effect. The state of birth provides information about the approximate latitude of birth and thus the seasonal differences in the hours of daylight. It has been shown that the seasonal changes in the hours of daylight influence the human neuroendocrine functions (Wehr 1998). Several researchers have postulated that the winter-spring birth excess observed in schizophrenia and bi-polar disorders might be caused by variations in internal chemistry or neural development brought about by seasonal variations in light (Turnquist 1993, Quested 1991, Morgan 1978, Jongbloet 1975 and Pallast et al. 1994). If the effect of month of birth on mortality later in life is due to seasonal differences in daylight, then the effect should be correlated with latitude and should be smaller in the southern part of the US than in the northern part.

The state of birth provides information about the prevailing macro climate. According to the widely used Köppen classification (Köppen 1936), the United States consists of six major climatic zones. Regions between 30 and 60 degrees North latitude belong to the humid continental climate zone characterized by changeable weather, hot summers and cold winters. On the eastern side of the continent between 20 and 35 degrees North latitude, the humid subtropical climate prevails. This climate is characterized by uniform precipitation throughout the year with moist and hot summers and mild winters. The mild-latitude steppe and desert climate are found in the continental interior and include the tropical and subtropical steppe climates in the south. Temperature conditions are extremely variable, with the annual means decreasing and the annual range increasing to the North. In the higher latitudes, winters are severely cold with meager precipitation. In the South the tropical and subtropical steppe climate is located primarily on the periphery of true deserts. The Mediterranean Climate of Southern California features hot dry summers and cool wet winters. The Marine west coast climate, which extends between 35 and 60 degrees North latitude, is characterized 
by ample precipitation in all months, small annual temperature ranges, mild winters and moderate summers with rarely more than 20 degrees Celsius. This area is confined to a narrow coastal strip of the West Coast.

Seasonal differences in temperature depend on the climate. Huntington (1938) was one of the first to formulate the hypothesis that temperature, in particular high temperature at the time of conception, causes the differences in life span by weakening the "germ plasma".

“.....season of birth is related to length of life primarily, although perhaps not wholly, through the condition of the parents and hence of the germ plasma at the time of conception. This by no means excludes the hypothesis of a permanent depressive effect when a very young infant experiences undue heat or disease regardless of any selection through death (page 186)".

More recent research has shown that the sperm quality of male outside workers decreases during periods of high temperature (Centola \& Eberly 1999). Pasamanick (1986) proposed that hot summers were the cause of protein deficiency at the time of conception. As temperatures are generally highest in July/August, infants born in March and April should experience the lowest life expectancy. The peak-to-trough difference should be largest in regions with high summer temperatures.

The third hypothesis is that infectious disease causes the differences in life span by month of birth. The information about state of birth is linked to the burden of infectious diseases through climate. Climate influences the incidence of infectious diseases through temperature, humidity, and precipitation in the form of normal and severe rainfall, wind and ocean currents. Thus, the incidence of infectious disease is generally highly seasonal. Among the vectorborn diseases e.g. malaria and dengue fever were once common in the southern United States. The incidence of waterborne diseases, which account for as much as 80 percent of the annual mortality due to infectious diseases (Clark, 1993), is correlated with warmer temperatures and flooding (Colwell 1996, Gueri, Gonzalea \& Morin 1986). Transmission of infections via food through viruses, bacteris or protozoa causes significant illness. Campylobacteriosis is a common 
diarrheal disease of bacterial origin, which is generally acquired by drinking contaminated milk or water or by eating improperly cooked meat or fowl. There is a pronounced seasonality in its incidence since it normally occurs during the spring (Korlath et al. 1985). The incidence of other foodborne diseases, like salmonella enteritidis (Shears \& Wright 1985) or cyclospora cayetanenis (Madico et al. 1997), coincide with peak climatological temperatures. The seasonal variability of many respiratory diseases suggests the existence of a weather-related factor in the transmission of airborne diseases. The respiratory syncytial virus, which peaks in the fall (Shears \& Wright 1995), commonly causes bronchitis and mild upper respiratory tract infections that can result in severe, and even fatal lower tract problems, especially among infants.

The southern part of the US should have been an unhealthier environment for infants (when controlled for urban/rural residence, race and socioeconomic status) because of a higher incidence of infectious and parasitic disease and gastroenteritis. An increase in the peak-to-trough difference from north to south would thus suggest that infectious disease plays a major role.

On the other hand, the respiratory diseases, which early in life are mainly caused by seasonal virus infections, were spread more in the poorly ventilated conditions accompanying winters in the $\operatorname{North}^{1}$ (Preston \& Haines 1991).

The fourth hypothesis is that nutrition of the mother during pregnancy and of the baby in the first year of life is the causal mechanism that underlies the month-of-birth pattern. Diet is the result of a complex interaction of social, economic and environmental factors. At the beginning of the $20^{\text {th }}$ century, large regional differences in diet existed in the US. What the different diets had in common was that they do not resemble contemporary US dietary patterns (Levenstein 1988, 1993). People ate meat -- either fresh meat in the middle or upper classes, or salted meat among the poor -- with potatoes or another starchy, staple food. Other vegetables and fruits took up a niche on their table. The first vitamin was only discovered in 1911; in the early 1900s nutritionists were even opposed to greens, which were thought to require more bodily energy for digestion than

${ }^{1}$. The text refers to New England, Middle Atlantic, East North Central, West North Central as the North; to South Atlantic, East South Central and West South Central as the South; Mountain and Pacific as the West. 
they provided (Dyson 2000). With the notable exception of the South, there is no indication that even the poorest workers suffered from insufficient quantities of food. The problem was rather the quality and the variety, especially during winter and spring, when affordable supplies dried up. As mentioned above, there were large regional differences in diet. Diet was particularly poor in the rural South, where farmers -- many of whom were tenant farmers -- survived on the "three M's", that is, meat (salted pork), meal (mainly corn meal) and molasses. Sharecroppers moved too frequently to develop their own vegetable gardens or to raise their own livestock. As a result, milk and fresh meat, even fresh pork, were usually rarities on croppers' tables. The tenancy system discouraged the production of non-cash crops and tenants depended on the sale of flour, molasses, sugar and salt pork, which mainly came from the large meat factories in Chicago. In the summer time, greens and berries could be gathered, but the hard work required during planting time in the spring and harvest time from August to December, normally inhibited those endeavors, particularly in the cotton belt (Levenstein 1993). Contemporary dietary studies have shown that, particularly in winter and early spring, diets in the rural South lacked variety whereas better nutrition and a wider variety of foods was shown to exist in the urban South (Dirks \& Duran 2001).

In summary, in the North and in urban areas people suffered from seasonal deficiencies in nutrients while in the rural South they experienced deficient nutrition during the whole year with downright malnutrition in winter and early spring.

The effects of region of birth, race, and education are inherently confounded. There are two other confounding factors, namely age and cohort. The next chapter will show that the differences in life span by month-of-birth are smaller in the more recent cohorts and that they become smaller with age (see Chapter 4). Due to the cross sectional nature of the US death records one cannot distinguish between age and cohort effects. However, the calculations are age-standardized when the data are analyzed by univariate methods and controls for the main effects of sex, education, race and region on age at death used when multivariate methods are applied. 
Table 3.1: Number, proportion and mean age at death of the US decedents by region, sex, education, marital status and race.

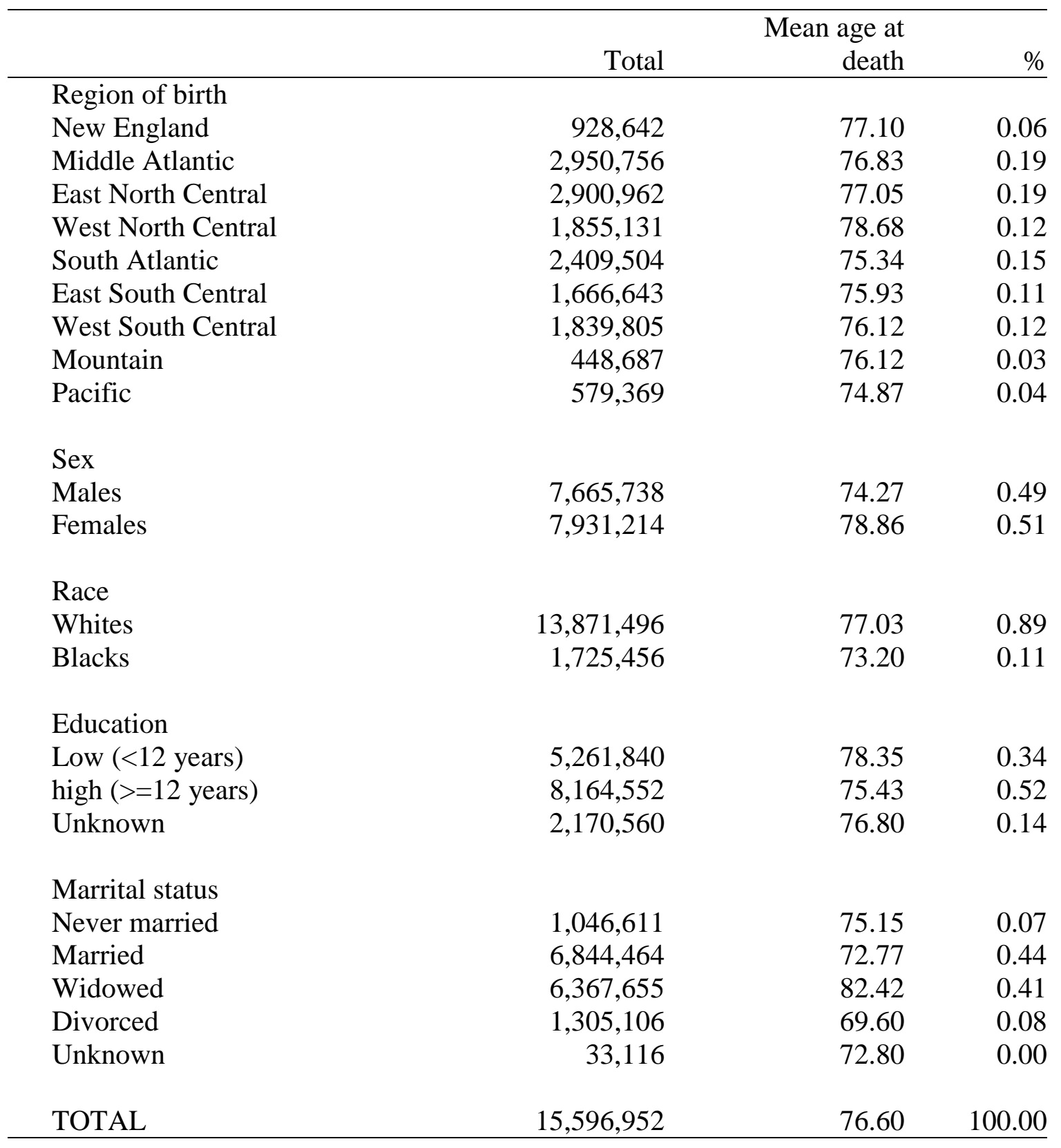

\section{Data}

This chapter is based on the publicly available Multiple Cause of Death Data for the years 1989 to 1997 from the National Center for Health Statistics (NCHS) to which the information about month of birth was added. This study consists of 15,596,952 death records for all black and white US-born decedents who died in the United States between 
1989 and 1997. Table 3.1 gives an overview of the data regarding mean age at death and the proportion of the decedents that fall into the different categories of education, marriage status, race and region of birth. Two educational groups are distinguished: the 5.3 million decedents with a basic education have less than a high school education or did not finish high school (up to eleven years of education); the 8.2 million decedents with a high education have at least finished high school. There is also a residual group of 2.2 million death records with an unknown educational level. The analysis is restricted to blacks and whites to guarantee that a sufficient number of deaths were given for each month of birth. The states of birth are grouped according to the grouping in the death records into the nine regions of New England, Middle Atlantic, East North Central, West North Central, South Atlantic, East South Central, West South Central, Mountain and Pacific; Hawaii and Alaska are excluded.

Data on mean temperature by state for the years 1895 to 2001 come from the NOAA-CIRES Climate Diagnostic Center. The file is provided online and updated monthly. The statewide values are available for the 48 contiguous states and are computed from the divisional values weighted by area (Karl \& Koss 1984).

Latitude and longitude for the centers of population of the 48 contiguous states in the year 2000 are provided online by the American Congress on Surveying and Mapping under http://www.acsm.net/statecenters.html.

\section{Methods}

All univariate results are age standardized. Let $p_{j}(x)$ be the proportion of deaths at age $x$ in group $j$ and $p(x)$ be the respective proportion in the standard population which is the total black and white US population between ages 50 and 100. Each age $\mathrm{x}$ in group $\mathrm{j}$

is re-weighted such by $W_{i}(x)=\frac{p(x)}{p_{j}(x)}$, that for each group $\mathrm{j}$ the same mean age at death is derived.

Equation 3.1 estimates the simultaneous effects of the characteristics of the decedents on their age at death

$$
x_{j}=\alpha_{0}+\beta^{\prime} Y_{j}+\gamma^{\prime} I_{j}+u_{j} .
$$


Let $x_{j}$ be age at death, $Y_{j}$ the matrix of the indicator variables sex, education, race, region and marital status, and $I_{j}$ the matrix of the two-way interactions between the variables; $\alpha_{0}$, $\beta$, and $\gamma$ are the parameter estimates. The error term $u_{j}$ follows a normal distribution with mean zero and variance $\sigma^{2}$. The above model assumes that the observed data stem from normal distributions with equal variances but with different means. The descriptive analyses show that the distribution of age at death deviates significantly from a normal distribution and that the variances of the different categories are not homogenous. The differences in the variances are small, however, and mainly significant because of the large numbers of observations. The sensitivity of the model to the violation of the model assumptions was tested by using different starting ages, and by using log and rank transformations of age. It appears that the results were largely insensitive to these changes and one can thus conclude that the model is robust and that the results are not influenced by the violations of the model assumptions.

\section{Results}

A highly significant difference in mean age at death by month of birth exists for US decedents who died between 1989 and 1997. Those born in June and July die about 0.44 of a year earlier than the October-born. The difference is slightly larger for males $(0.434$ of a year) than for females ( 0.402 of a year).

\section{Latitude and Temperature}

There is no positive correlation between the peak-to-trough difference in the mean age at death and the latitude, on the contrary, a small but significant negative correlation (Spearman correlation $=-0.308, \mathrm{p}=.033$ ) is found. The correlation of the month-of-birth effect with the maximum difference in temperature, another indicator for latitude, is also negative and significant (Spearman correlation=-0.293, $\mathrm{p}=.048$ ). There is a small positive correlation between the peak-to-trough difference in mean age at death and both, maximum (Spearman correlation $=0.281, \mathrm{p}=.059$ ) and minimum temperature (Spearman correlation $=0.326, \mathrm{p}=.027$ ). When the causes of death are divided into cancer mortality, mortality from cardiovascular disease, mortality from other natural and non-natural 
Figure 3.1: Scatterplots of the maximum difference in mean age at death and temperature for the 48 contiguous states of the US.

Minimum Temperature

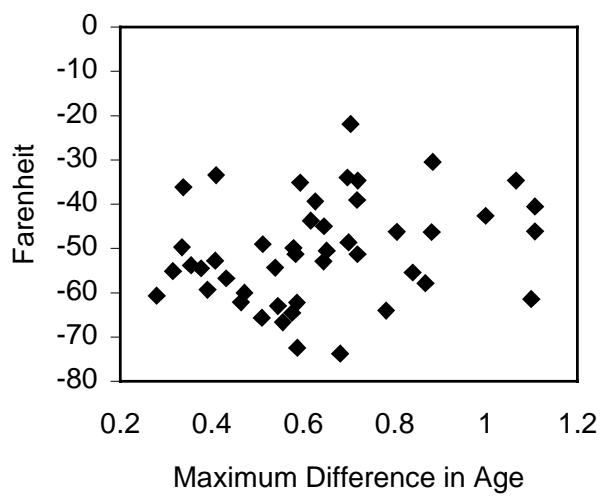

Maximum Difference in Temperature

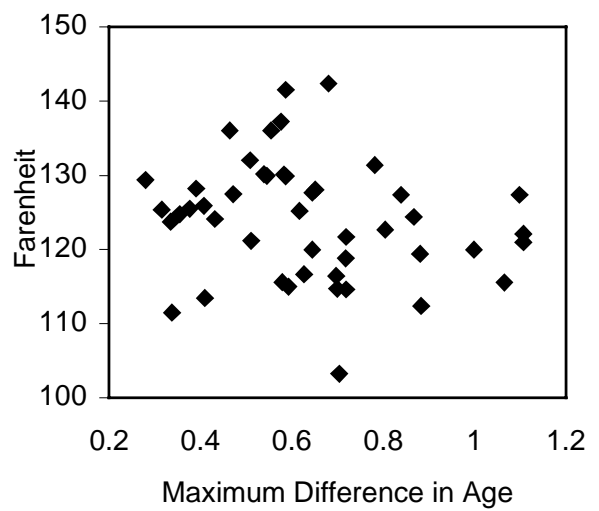

Maximum Temperature

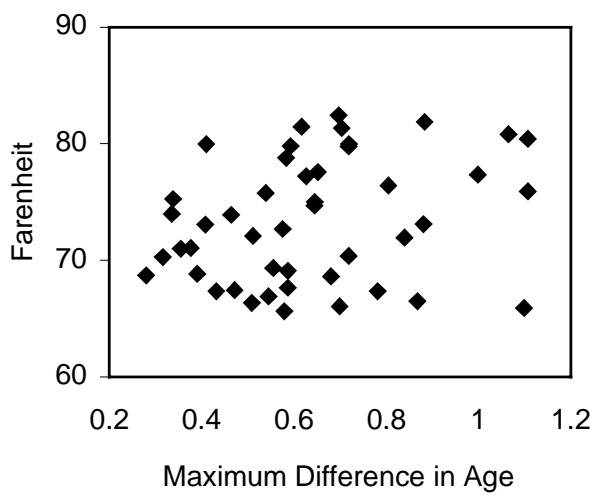

Latitude

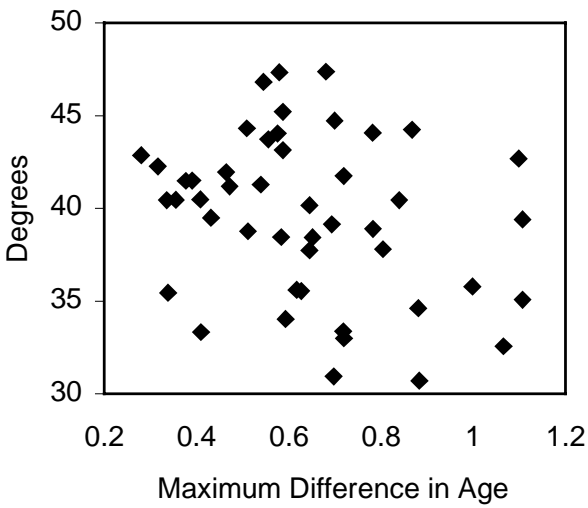

diseases, one finds that the already low correlation results mostly from mortality related to cardiovascular disease. Figure 3.1 shows the scatterplots of the peak-to-trough differences in mean age at death by month of birth and the four variables.

\section{Education}

Comparing the two educational groups one finds that the mean age at death of those with a basic education is 78.35 years, while it is 75.43 years for people with a high education. This is contrary to the evidence from a large body of literature stemming from 
research over the last three decades, which proves that the lower educated have shorter life spans than the higher educated (Kitagawa \& Hauser 1973, Valkonen 1989, Elo \& Preston 1996). In the cross sectional death

Figure 3.2: Education and the differences in mean age at death by month of birth, US death records 1989 to 1997.

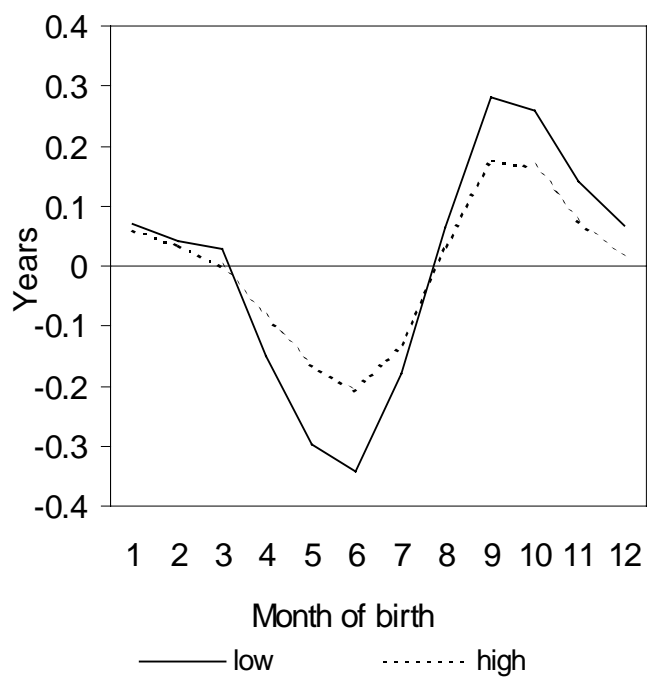

Figure 3.3: Race and the differences in mean age at death by month of birth, US death records 1989 to 1997.

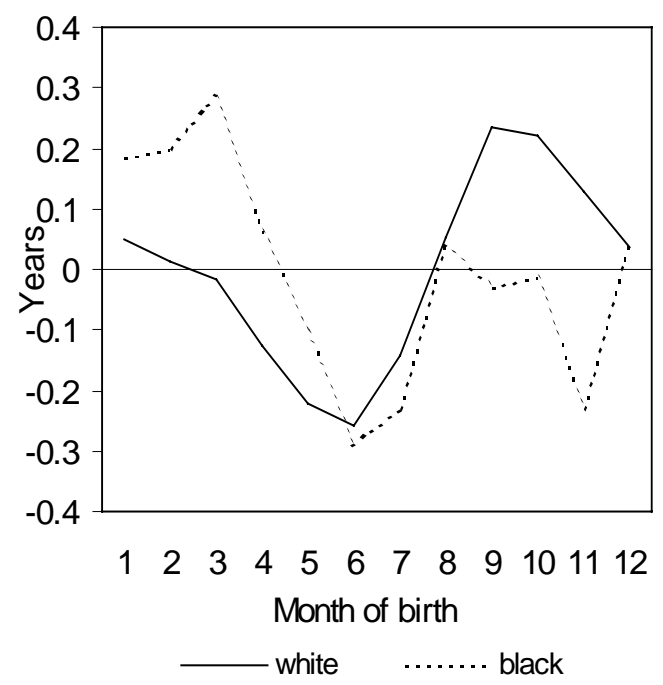

data the higher mean age at death of the lower educated is caused by a change in the educational distribution over time. The oldest decedents are more likely to have received basic education than those who died in their 60 s or 70 s.

Figure 3.2 shows that the age standardized differences in lifespan by month of birth vary significantly ( $\mathrm{p}<.0001)$ according to education levels. The difference between the spring trough and the winter peak is 0.62 of a year ( $p$-value $<.0001)$ for those with a low education and 0.38 of a year for the highly educated ( $\mathrm{p}$-value <.0001).

\section{Race}

The month-of-birth pattern of the 1.7 million blacks with a mean age at death of 73.2 years differs significantly $(\mathrm{p}<.0001)$ from that of the 13.9 million whites who died at an average age of 77.03 years (Fig. 3.3). The pattern for whites reveals the familiar features: a sinusoidal curve with a June trough and a September peak. The agestandardized difference between the two months is 0.49 of a year and is highly significant $(p<.0001)$. The pattern for the black decedents, however, differs not only 
Figure 3.4: Deviation of mean age at death of decedents born in specific month from average mean age at death by marital status: US death records 1989 to 1997, ages 50100.
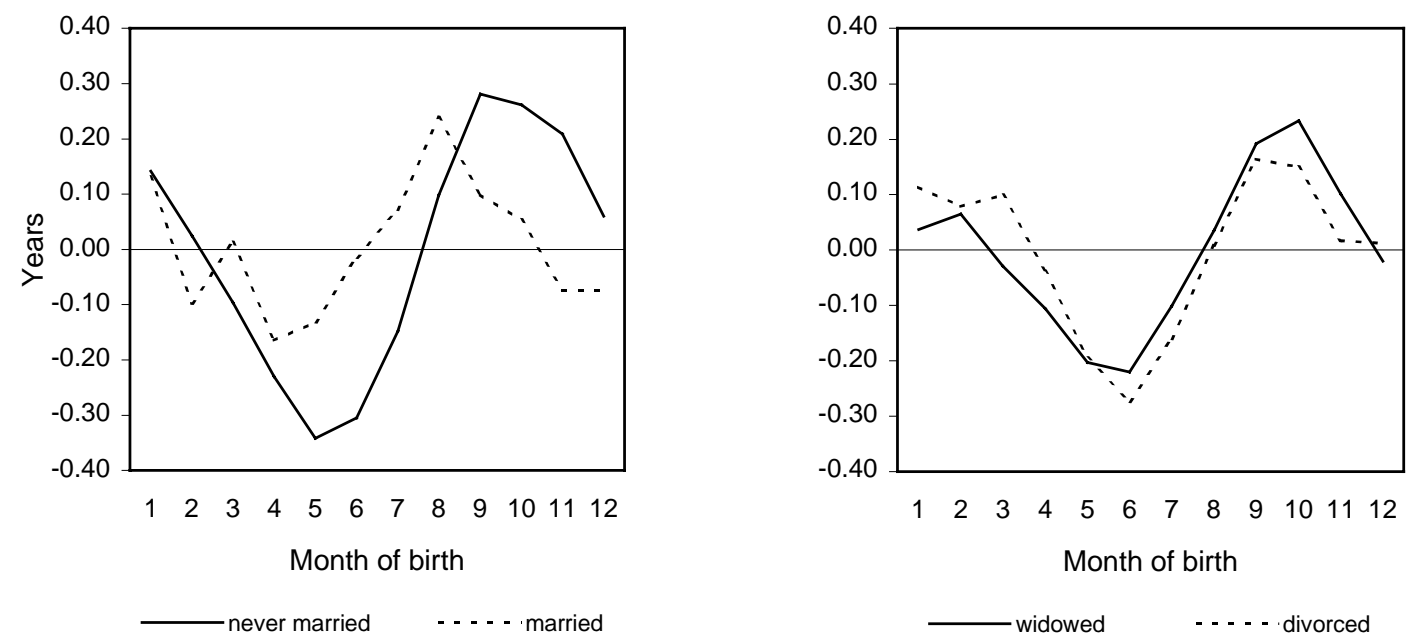

with respect to the number of years between the trough and the peak $(0.57$ of a year, $\mathrm{p}<0.001)$ but also with respect to the shape of the curve. The mean age at death is highest for those born between January and March. As in the case of whites, the mean age at death is lowest for decedents born in July.

\section{Marital Status}

There exists a highly significant difference $(\mathrm{p}<0.0001)$ in the month-of-birth pattern by marital status. As expected, the age standardized difference between the peak and the trough is largest for the never-married $(0.62$ of a year, $p<.0001)$, and smallest for the married $(0.40$ of a year, $\mathrm{p}<.0001)$; the widowed $(0.45, \mathrm{p}<0.0001)$ and the divorced $(0.44, \mathrm{p}<0.0001)$ are intermediate (Fig. 3.4). 


\section{Region of birth}

The age standardized peak-to-trough difference in the month-of-birth pattern increases from the North to the South. The difference is smallest in New England with

Table 3.2: Peak-to-trough difference in mean age at death of decedents born in a specific month by race, education and birth region.

\begin{tabular}{lllllll}
\hline & \multicolumn{5}{c}{ Age standardized difference in years } \\
\cline { 2 - 7 } & \multicolumn{2}{c}{ US total } & \multicolumn{2}{c}{ Race } & Education \\
\cline { 2 - 7 } & $\begin{array}{c}\text { Month of } \\
\text { Peak/Trough difference }\end{array}$ & black & white & low & high \\
\hline & & & & & \\
Region of birth & & & & & \\
New England & Sep/Jun & 0.31 & 1.47 & 0.31 & 0.45 & 0.35 \\
Middle Atlantic & Sep/Jun & 0.36 & 0.53 & 0.37 & 0.47 & 0.36 \\
East North Central & Sep/Jun & 0.46 & 0.81 & 0.45 & $0.65^{* *}$ & $0.34^{* *}$ \\
West North Central & Oct/Jul & 0.44 & 0.84 & 0.44 & $0.67^{* *}$ & $0.37^{* *}$ \\
South Atlantic & Oct/Jun & 0.46 & $0.65++$ & $0.63++$ & $0.53^{*}$ & $0.57^{*}$ \\
East South Central & Oct/Jun & 0.86 & $0.68++$ & $1.02++$ & $0.89^{*}$ & $0.81^{*}$ \\
West South Central & Oct/Jun & 0.69 & $0.97++$ & $0.77++$ & $0.89^{* *}$ & $0.58^{* *}$ \\
Mountain & Oct/May & 0.46 & 2.60 & 0.55 & 0.61 & 0.53 \\
Pacific & Sep/Jun & 0.42 & 1.68 & 0.42 & 0.69 & 0.33 \\
\hline
\end{tabular}

All peak-to-trough differences are significant at $\mathrm{p}<.0001$.

++ indicates significant racial differentials at $\mathrm{p}<.0001$.

** indicates significant educational differentials at $\mathrm{p}<.0001$.

* indicates significant educational differentials at $\mathrm{p}=.05$.

0.31 of a year and largest in the East South Central Region with 0.86 of a year (Table 3.2). The differences in the West are intermediate. The pattern is similar in all regions with a trough in June/July and a peak in September/October. Most regions reveal a secondary peak in the first three months of the year.

Region of birth, education and race are highly confounded, therefore the differences in the month-of-birth pattern are explored by education and by race. The regional differences are neither due to differences in education (Fig. 3.5) nor to differences in race (Fig. 3.6). 
Figure 3.5: Deviation of mean age at death of decedents born in a specific month from average mean age at death by region of birth and education: US death records 1989 to 1997, ages 50-100.

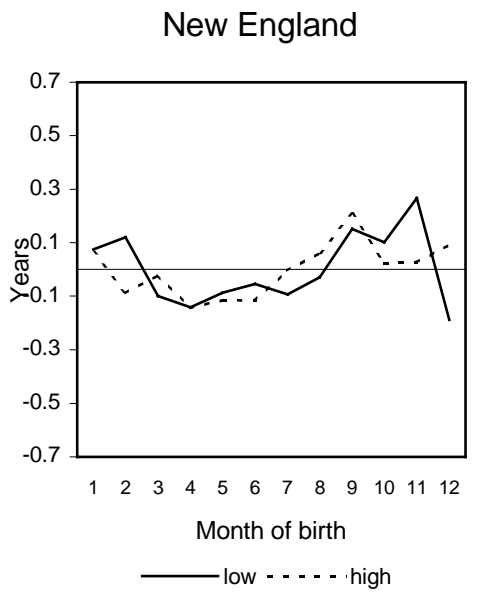

West North Central

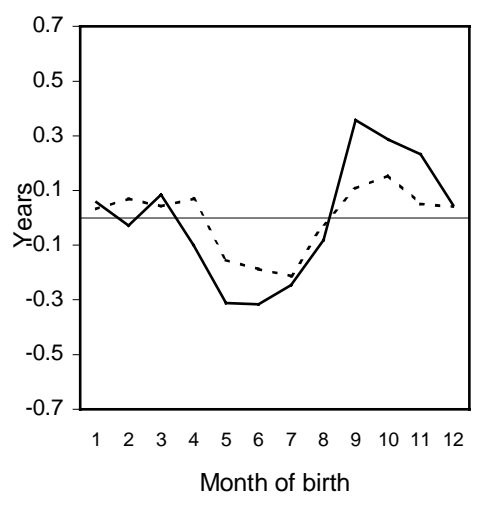

- low - . . . . high

West South Central

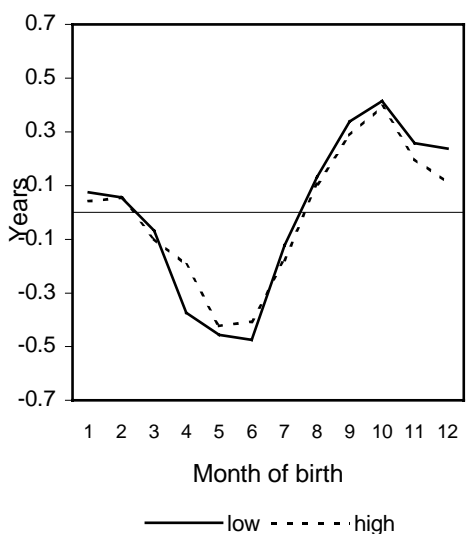

Middle Atlantic

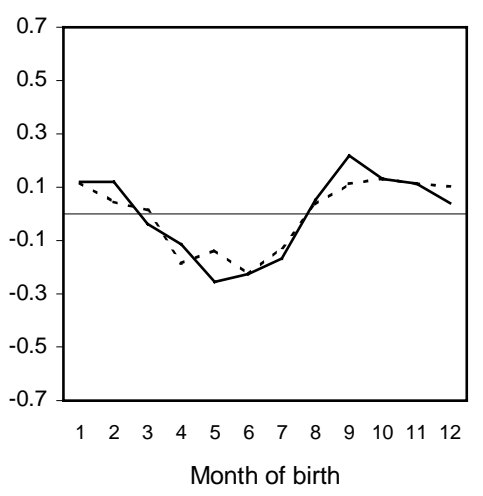

- low ..... high

South Atlantic

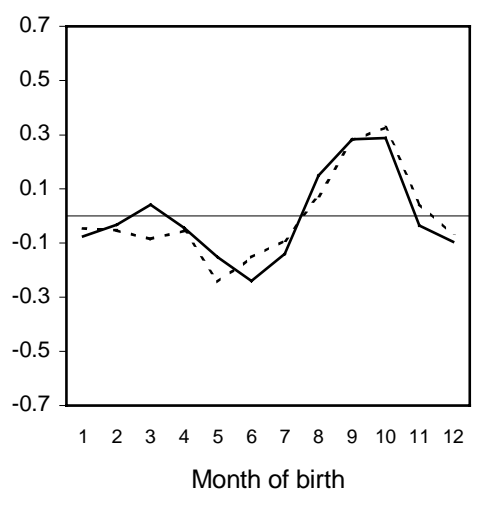

Mountain

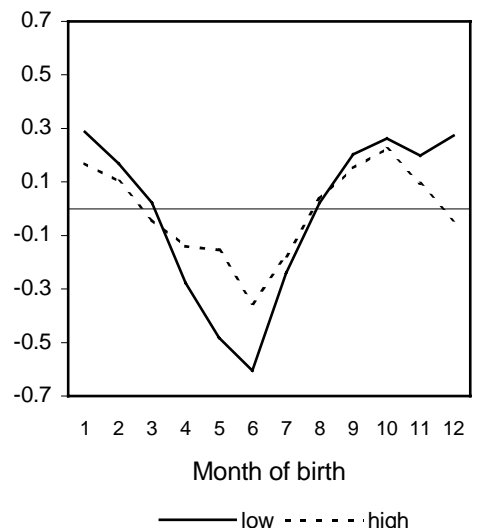

East North Central

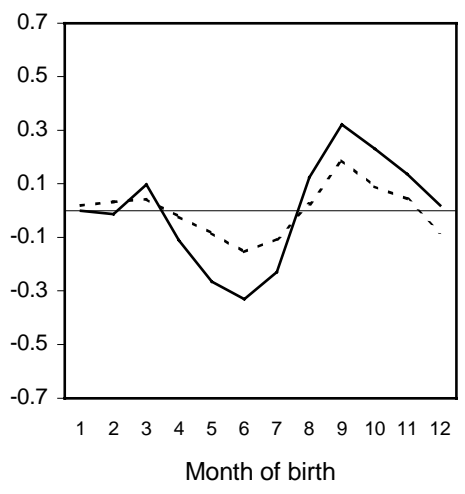

low ..... high

East South Central

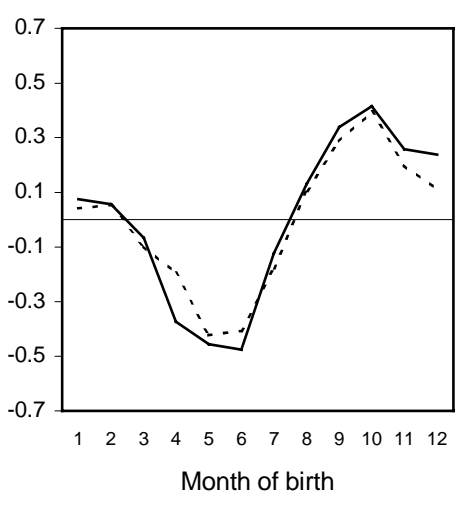

Pacific

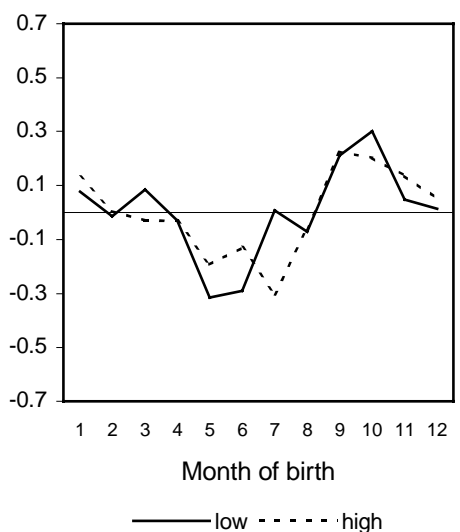


Figure 3.6: Deviation of mean age at death of decedents born in a specific month from average mean age at death by region of birth and race: US death records 1989 to 1997, ages 50-100.

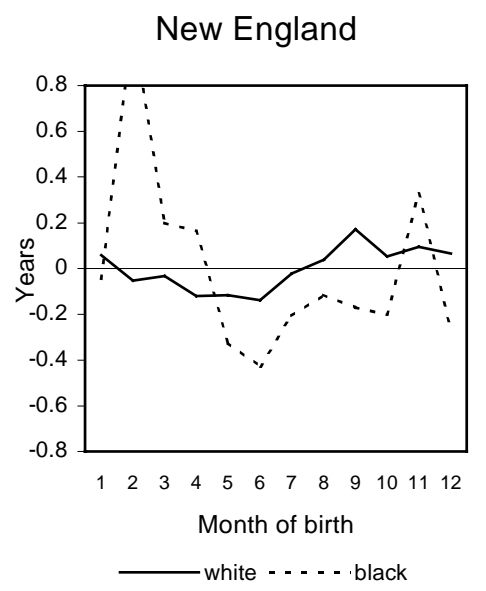

West North Central

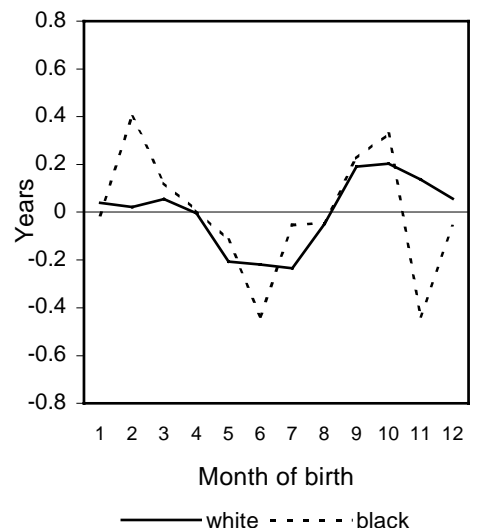

West South Central

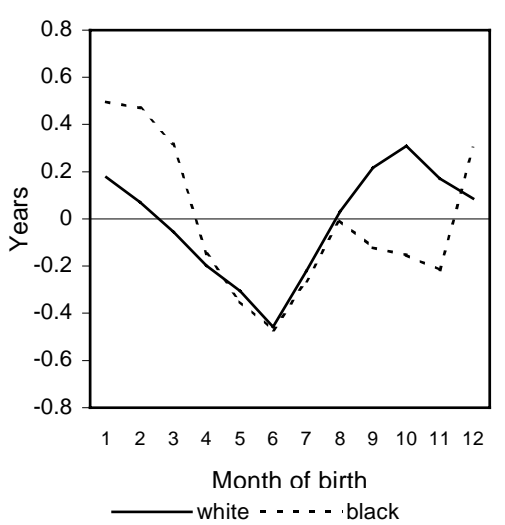

Middle Atlantic

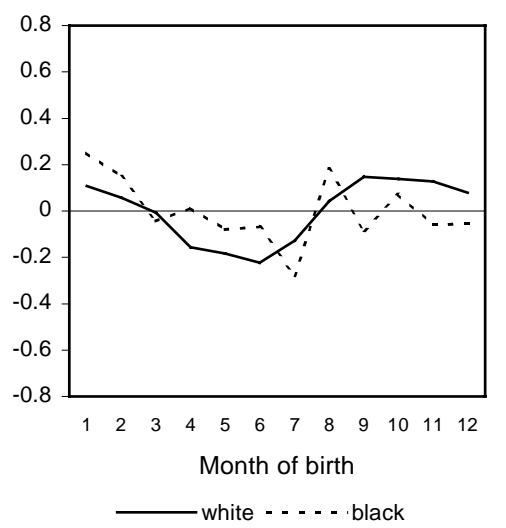

South Atlantic

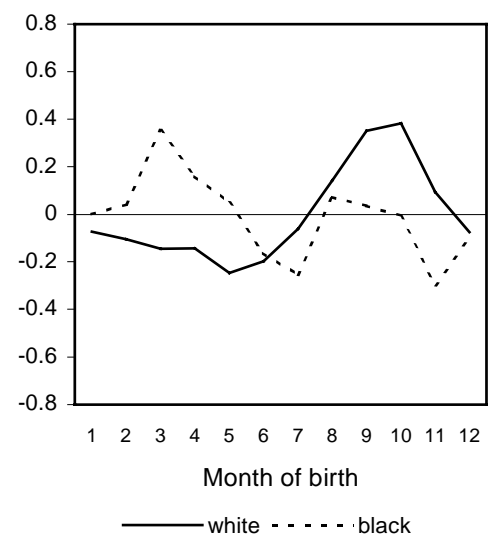

Mountain

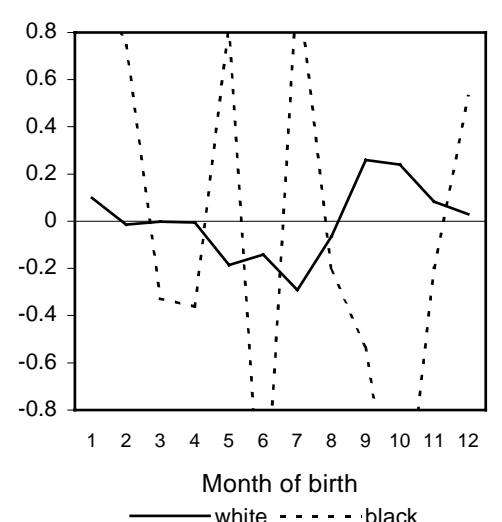

East North Central

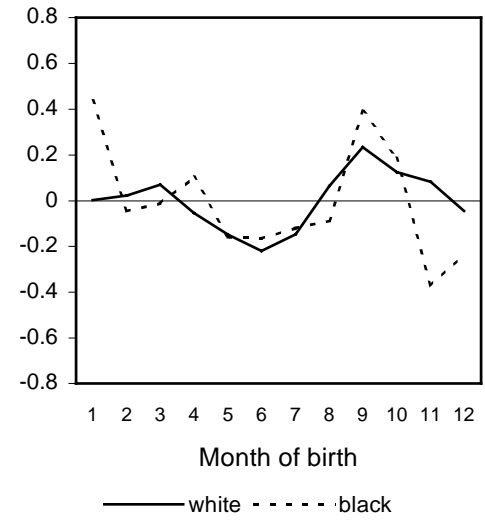

East South Central

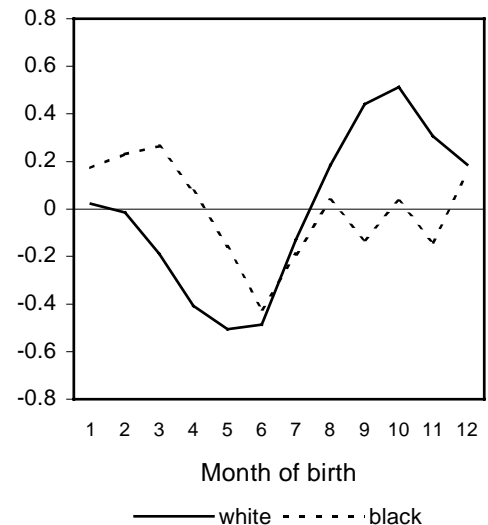

Pacific

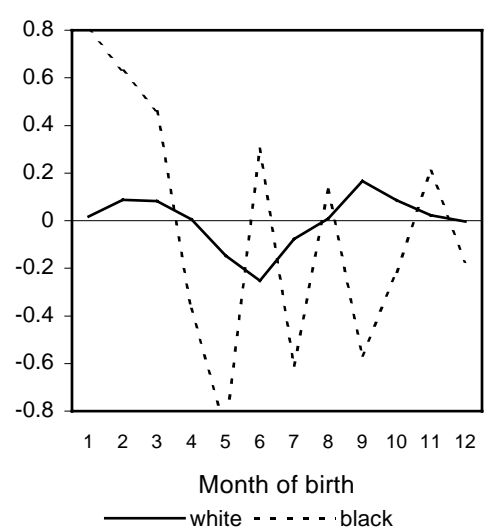


The highly significant racial differences $(\mathrm{p}<.0001)$ in the month-of-birth pattern stem solely from the South. In the North the pattern does not differ by race. In the South the pattern for whites follows a sinusoidal curve with a peak in October and a trough in June/July. The curve for blacks has its major peak in the first three months of the year and its trough in June/July. Contrary to whites, those born in fall do not experience a major mortality advantage later in life. The erratic month-of-birth pattern for blacks born in the mountain and pacific region is caused by small numbers, since at the first part of the $20^{\text {th }}$ century hardly any blacks are born in these two regions.

The two educational groups follow the same sinusoidal pattern in all regions and the difference between the trough and the peak is generally larger among the poorly educated than among the highly educated. Particularly striking and highly significant is the difference between the educational groups in the East and West North Central regions and in the East and West South Central regions. For both educational groups the regional differences in the month-of-birth pattern increase significantly from the North to the South.

\section{Multivariate results}

The differences in the month-of-birth pattern depend on education, race, marital status, and region of birth. In our multivariate analysis of the ages at death, the main effects of sex, month of birth, education, race, region of birth, marital status and all the two-way interactions of the variables are highly significant at $p<.0001$. Overall the model explains 25 percent of the variation in ages at death. About 86 percent of the model explanation is due to the effect of marital status and only 0.4 percent, to the effect of month of birth. The large majority (70\%) of the 0.4 percent result from the interactions of month of birth with region of birth and race (Table 3.3). 
Table 3.3: Contribution of the interactions between month of birth and sex, education, race, marital status and region of birth to the overall model explanation of the month-ofbirth effect of 0.4 per cent.

\begin{tabular}{lcc}
\hline Month of birth (Mob) effect & Per cent & p-value \\
\hline & & \\
Mob & 3.3 & $<.0001$ \\
Mob*sex & 1.0 & $<.0001$ \\
Mob*education & 8.6 & $<.0001$ \\
Mob*race & 33.2 & $<.0001$ \\
Mob*marital status & 17.4 & $<.0001$ \\
Mob*region of birth & 36.5 & $<.0001$ \\
Total contribution of the month of birth & 100.0 & $<.0001$ \\
effect $(0.4 \%)$ to the overall model & & \\
explanation of $25 \%$ & & \\
\hline
\end{tabular}

\section{Conclusion}

A significant maximum difference of 0.44 of a year in mean age at death by month of birth is found for the United States on the basis of 15 million death certificates. This difference is comparable to the differences found for Austria (0.6 of a year), Denmark ( 0.3 of a year) and Australia (0.6 of a year) but it is much smaller than the 2.6 years that was recently published for Kiev (Vaiserman 2002). The pattern of the differences resembles those of Austria and Denmark.

The differences depend on race, region of birth, marital status, and education. They are larger for the less educated, for the never married, for blacks, and they increase from the North to the South. This increase is not caused by differences in the educational or racial composition of the decedents but is independent of these characteristics. The peak-to-trough difference in lifespan is slightly larger for African-Americans than for whites and their pattern follows a different curve. This difference in the pattern, however, is only visible in the South.

The month-of-birth effect is largest among the never married, which supports the view that the month of birth is related to the frailty of the population. There has been 
ample research to show that there is a health selection into marriage (Lillard \& Panis 1996) and that the never married experience higher mortality (Goldman \& Hu 1993).

There is no negative correlation between the maximum differences in the monthof-birth pattern and the latitude of state of birth. This allows to rule out the hypothesis that the differences are related to the seasonality in the duration of sunshine through its effect on neuroendocrine functions. To accept this hypothesis a positive correlation would have been necessary.

The trough in life expectancy for those born in June and July rather than in April and May permits the rejection of the hypothesis that high temperature at the time of conception is the responsible factor. Those born in June and July were conceived in September and October, which is between one and three months after the period of maximum temperatures (July and August).

The rejection of the two hypotheses is consistent with the outcome of a review of more than 250 studies about schizophrenia and bipolar disorder (Torrey et al. 1997). The studies that tested the existence of a correlation between latitude and the month-of-birth effect came to mixed conclusions: some suggested the existence of a latitude gradient (Dalen 1975, Torrey 1977) while others did not (Torrey et al. 1991). McNeil et al. (1975) was unable to find a correlation between summer temperatures at the time of conception and winter births of individuals with schizophrenia. Hare and Moran (1981) and Watson et al. (1984) did not find a correlation between summer temperatures and winter births. This finding does not exclude the possibility that temperature or duration of sunshine in the first period of life has an effect on the susceptibility to very specific diseases later in life. However, in terms of life expectancy these diseases are of minor importance. In order to affect life expectancy major groups of causes of death such as malignant neoplasms and heart disease would need to be correlated with latitude or duration of sunshine which in the US is clearly not the case.

The regional differences in the month-of-birth pattern are consistent with the hypothesis that nutrition and infectious disease in-utero or in the first year of life are the causal mechanisms. The amplitude of the month-of-birth pattern is largest in the South, which is the part of the US where in the first half of the $20^{\text {th }}$ century diet, particularly in rural areas, was deficient throughout the year and where malnutrition was common in 
winter and early spring. It is also the part of the US with the highest incidence of infectious diseases, particularly of the gastro-intestinal tract, due to the hot and humid climate.

The multivariate model of age at death shows that educational differentials in the month-of-birth pattern are small compared to racial or regional differences. This finding is further support for the hypothesis that the factors that are mainly responsible for infant mortality in general are also the factors that cause the differences in lifespan by month of birth. The second chapter of this Monograph shows the high positive correlation between the month-of-birth pattern in infant mortality and in life expectancy. From Preston and Preston we know that the three single most important factors that explain most of the variance in US child mortality at the beginning of he $20^{\text {th }}$ century were race, size of the birthplace and region (Preston \& Haines 1991). The contemporary view at the beginning of the $20^{\text {th }}$ century was that the mother's health status and whether the mothers breastfed their babies were two factors - in addition to housing, sanitation and general poverty that were closely linked with the survival of infants. In other words, infant mortality was largely determined by the nutrition and health of the mother and by breastfeeding, which helped prevent infectious disease in the first months of life.

In the present analysis, the size of the birthplace is missing, which may explain the puzzling finding that the month-of-birth pattern among African-Americans is not much larger than among the white population. African Americans, particularly in the South, were mainly living in rural areas where life circumstances were healthier than in urban areas. Among the childhood conditions that predicted survival to advanced ages among African Americans, the factors that were found to be most predictive were having a farm background, literate parents, and living in a two-parent household (Preston, Hill \& Drevenstedt 1998). In other words, correcting for the size of the place of birth may significantly increase the month-of birth effect for African-Americans.

The difference between urban and rural environment may also account for the finding that the pattern differs between blacks and whites in the South of the US. One explanation is that the hard farm-work in the second part of the year prevents AfricanAmerican infants born in fall from experiencing mortality advantages similar to that of the white population. Peak growth in-utero is during the third trimester. For infants born 
in fall, the peak growth coincides with a period of heavy work and therefore of high energy expenditures from their pregnant mothers. Evidence from The Gambias shows that the high energy expenditure and low energy intake of pregnant mothers during the last trimester result in a peak-to-trough difference in birthweight of approximately 200300g (Moore 1998) and in a significant difference in survival to age 45 by month of birth (Moore et. al 1997). A heavy workload on the fields would also prevent mothers from breastfeeding their infants and would expose the infants to a higher risk of infectious disease. The explanation that the poverty of African-Americans in the South at the beginning of the $20^{\text {th }}$ century together with their specific seasonal agricultural workload prevents the fall-born from experiencing a mortality advantage similar to the white population is further explored in chapter six. 
Page: 49

[N1]SB: „Tries“ introduces a degree of uncertainty, as if you would not really believe in what you can do. In order to avoid this verb, I suggest you write: „The aim of this presentation is to ...". That sounds more confident. The more confident you appear, the more confidence the listener/reader has in you. :) 


\section{FOUR}

\section{MONTH OF BIRTH AND CAUSES OF DEATH IN THE UNITED STATES}

Since US death records contain more then 15 million decedents it is possible to verify the month-of-birth pattern for the same causes of death that were analyzed in the second chapter on the basis of the Austrian data. In general, the month-of-birth patterns for Austria are confirmed. However, those causes of death that were of borderline significance or insignificant in the Austrian study are now significant in the US data set (e.g. lung cancer, diabetes mellitus).

The following part of this chapter presents the results for different causes of death and relates the findings to existing research. Some literature exists about the relationship between month of birth and the incidence of malignant neoplasms. Extensive research has been done on nervous and mental disorders. Hardly any studies exist about the relationship of month of birth and circulatory disease.

Although the dataset consists of more than 15 million decedents the month-ofbirth patterns for some of the causes of death tend to be erratic, particularly for African Americans. Periodic cubic splines based on the method developed by Reinisch (1967) have therefore been applied to the mean ages at death by month of birth. In the following figures both the smoothed and unsmoothed values are presented.

\section{Malignant neoplasms}

There exist highly significant differences $(\mathrm{p}<=0.001)$ in mean age at death by month of birth for breast cancer, prostate cancer, lung cancer, colorectal cancer and the residual group of other cancers. Differences are significant at $\mathrm{p}=0.05$ for stomach cancer, pancreatic cancer and liver cancer, and not significant $(p>0.05)$ for uterus cancer. None of the cancers reveal differences by sex or educational status (Table 4.1, Figs. 4.1 and 4.2). Lung cancer is the only malignant neoplasm with significant differences by race. Similar to total mortality, mean age at death for blacks peaks among the March-born and does not 
reveal a fall peak as in the case of whites. Contrary to total mortality there is no NorthSouth trend in the magnitude of the difference. Differences are smallest in the Middle Atlantic region, and seem to be largest in the Mountain region. However, not only the magnitude changes between the regions but also the shape of the curve, with the East South Central region revealing a particularly distinct pattern. Next to breast and lung cancer also the month-of-birth pattern of stomach, colorectal and the residual group of other cancers differs significantly by region of birth.

These results are consistent with the results of Jansson and Malahy (1981), which are based on the Third National Cancer Survey of the United States that consisted of about 180,000 patients. They find that patients born between January and April are diagnosed with cancer 1-1.5 years later and live one year longer than do patients born in June to August. They do not find differences in the season-of-birth distributions of cancer patients for males and females. They find differences in the month-of-birth distribution for different sites of the lesions: colon, rectum and breast cancer patients have an almost identical distribution, while stomach and lung cancer patients have significantly different season-of-birth distributions. The authors attribute this to differences in the geographic distributions and to social differences.

When the authors compared the maximum difference between the monthly temperature at a place and the maximum difference between monthly frequencies of birth among cancer patients they find a positive correlation of $r=0.89$. This is different to the present finding that only a small correlation exists between the maximum mean age at death by month of birth and temperature variables. Jansons and Malahy's approach, however, confines monthly differences in the seasonal distribution of the number of births with the month-of-birth effect on life span. The high correlation, thus, is most probably the result of the correlation between the seasonal distribution of births and temperature, which, among others, has been demonstrated by Lam and Miron (1996). The authors conclude that the relationship between month of birth and cancer probably reflects general differences in the health status of persons born at different times of the year rather than being related to the etiology of cancer.

A Swedish study compares the birth distribution of 115,670 women with breast cancer to the total number of live births by month of birth from 1858 to 1968 (Yuen et al. 
Table 4.1: Natural Causes of Death: Significance levels of the effect of month of birth $(\mathrm{MoB})$ and its interactions with sex, education, race, marital status and region.

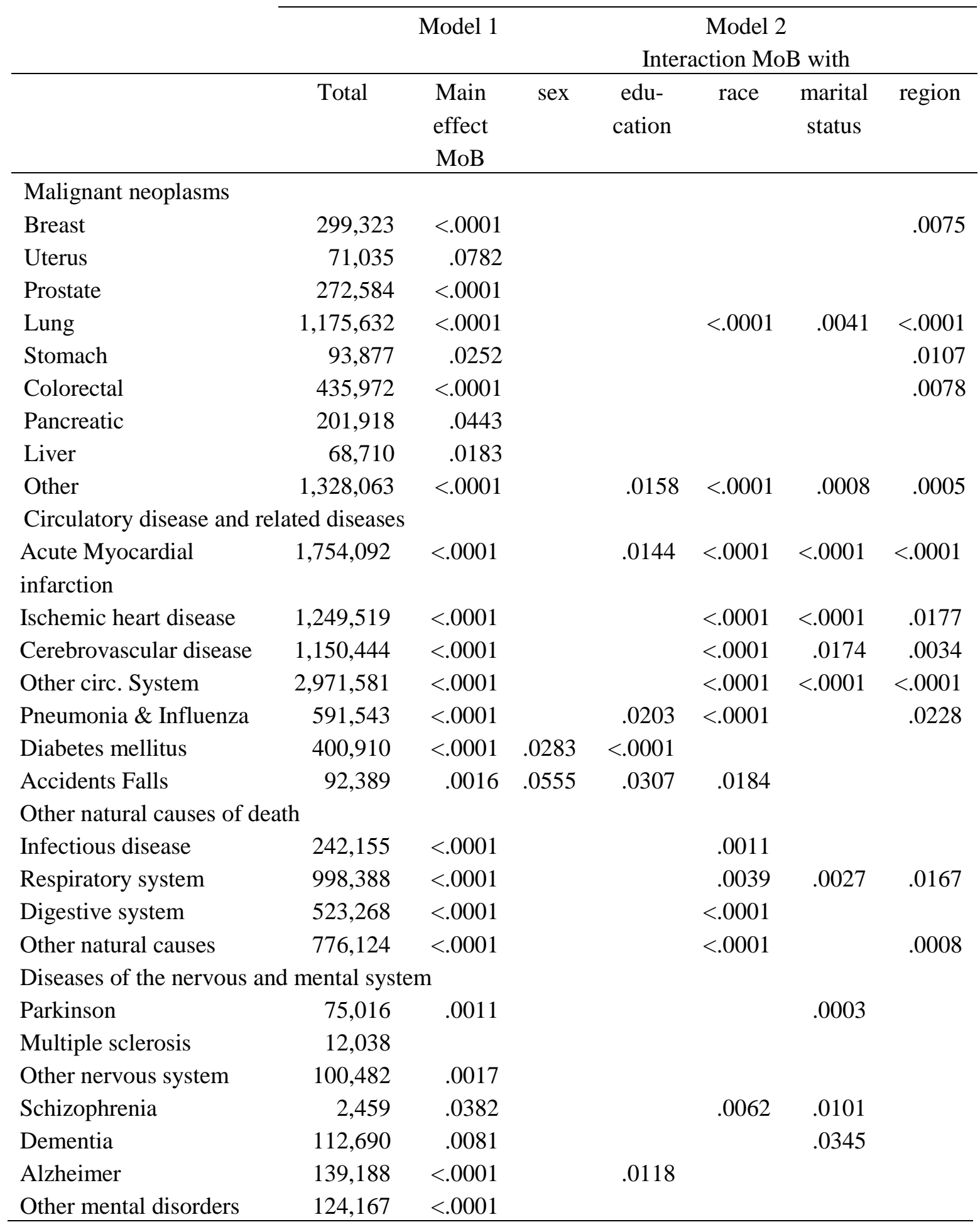

Model 1 includes main effects of month of birth (MoB), education, race, region, marital status and sex. All main effects are highly significant.

Model 2 includes all main effects and all interaction effects significant at a level of 0.05 . The main effect of month of birth is significant for all causes of death. 
Figure 4.1 Malignant Neoplasms whites: Deviation of mean age at death of decedents born in a specific month from average mean age at death, United States, death records 1989 to 1997. Original data (dashed line), smoothing cubic splines (solid line).
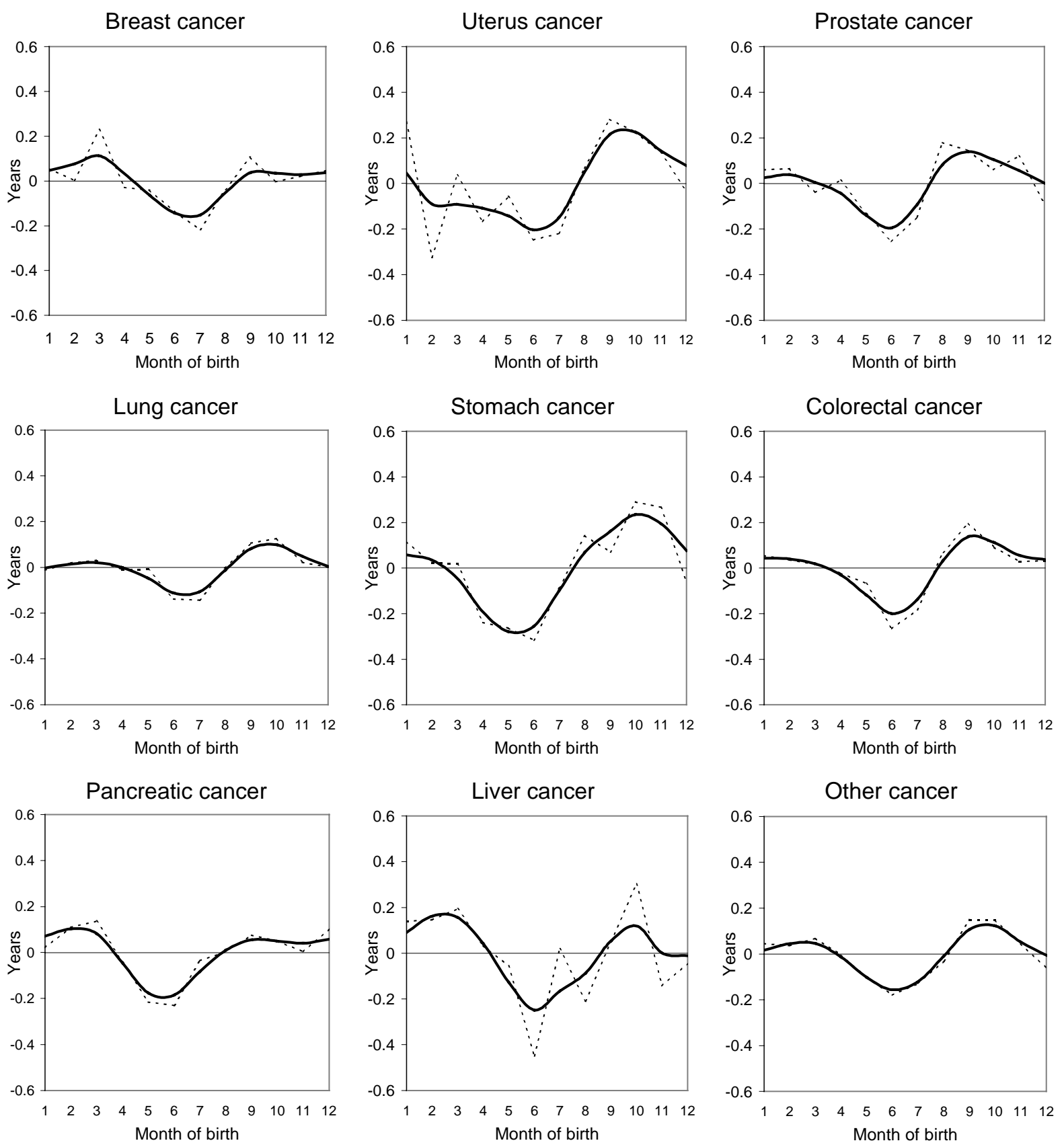
Figure 4.2: Malignant Neoplasms blacks: deviation of mean age at death for decedents born in a specific month from average mean age at death, United States, death records 1989 to 1997. Original data (dashed line), smoothing cubic splines (solid line).
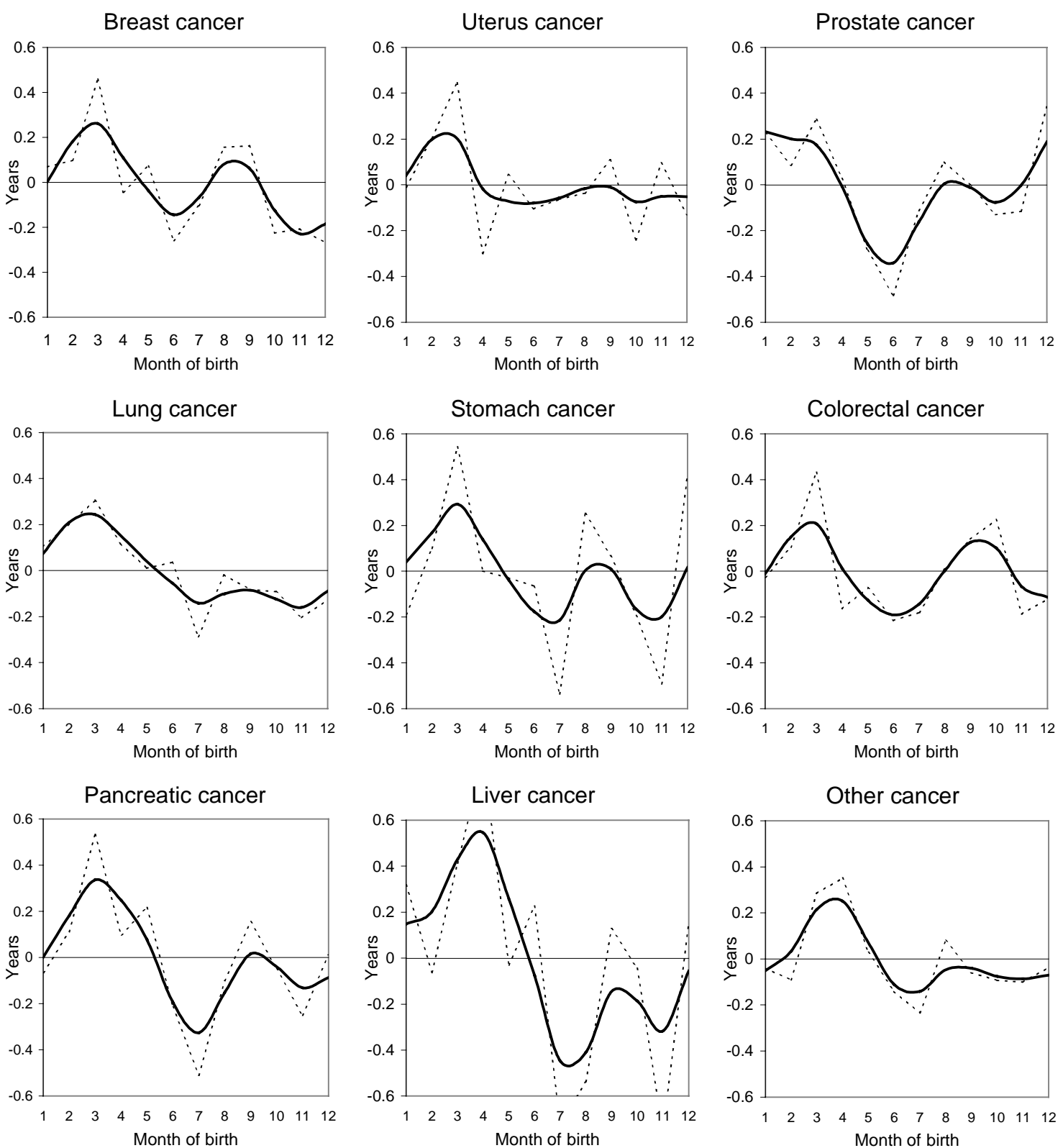
1994). Month of birth was a significant risk factor for breast cancer, but not for cancers of the other sites (440,948 women). For the older birth cohorts (1880-1920) they find an increased risk for women born in May and June. The pattern for women born after 1950, however, was completely different with a maximum in autumn. As age and cohort is confounded in their analysis these women were a maximum of 39 years old and thus, represent pre-menopausal breast cancer, whose etiology may differ from breast cancer of post-menopausal women. They discuss theories of seasonal fluctuations in pregnancy estrogen, other pregnancy hormones or post-natal exposures like diet. They also mention seasonal differences in birthweight as a risk for breast cancer. Differences in the result for pre- and postmenopausal breast cancer incidence are also reported in an earlier study by Nakao(1988). A Japanese study (Hu et al. 1996) did not find differences in the breast cancer risk according to the month of birth of 81,162 women who died of breast cancer.

A series of studies about testicular cancer was conducted in the late 80s. Results, however, are not conclusive. Two studies found significant bi-monthly cycles (Prener \& Carstensen 1990, Kinlen and Willos 1987), one, a significant 4-months cycle (Knox \& Cummins 1985) and Bernstein et al. (1986) observed a significant annual cycle with a distinct peak in August confined to teratomas.

Three recent studies describe month-of-birth patterns in childhood leukemia (Sorensen et al. 2001, Higgins et al. 2001, Feltbower et al. 2001) with an increased risk for children born in winter/early spring. Infectious disease is discussed as the causal factor.

\section{Diseases of the circulatory system}

The differences in lifespan by month of birth largely result from circulatory diseases (Table 4.1). Acute myocardial infarctions, ischemic heart disease, cerebrovascular disease, the residual group of other heart diseases, as well as the causes of death related to circulatory diseases like accidental falls, diabetes mellitus (ICD9 250), and pneumonia and influenza show a distinct month-of-birth pattern (Fig. 4.3 and Fig. 4.4). Those born in spring die earlier than those born in fall. There are no differences by sex, but highly significant differences by race. Among blacks the peak in mean age at death is shifted to the first three months of the year. In addition to the differences by race, 
highly significant differences by marital status exist, with the never married who were born in May and June being particularly disadvantaged. In addition, highly significant regional differences do exist and the month-of-birth effect is strongest in the East South Central and the West South Central region.

Most research that explores the effect of early life circumstances on late life health and mortality focuses on circulatory diseases (for reviews see Elo and Preston 1992, Kuh \& Davey Smith 1993; Barker 1994, Barker 1995, Davey Smith et al. 1997, Davey Smith et al. 2000). Surprisingly, only two studies exist on how these diseases are related to month of birth. They both explore the relationship between month of birth and cerebral hemorrhage. Caroll \& Haddon (1964) included deaths under age 34 and did not find arelationship. Nonaka \& Imaizumi (2000) studied subarachnaoid hemorrhage (ICD9 code 430) in Japan by comparing the month-of-birth distribution on death records from the years 1986-1994 with the monthly distribution of births for the years 1900-1959. They found an excess risk of $8-23$ percent for the June- to September-born. More attention has been paid to diseases that are considered as a risk factor for circulatory diseases, in particular insulin dependent diabetes. There are sixteen recent studies (Block et al. 1994, Chen et al. 1998, Dahlquist \& Kaellen 1996, Fichera et al. 2001, Helgasson \& Jonasson 1981, Hummel et al. 2001, Jongbloet et al. 1998, Kida et al. 2000, Kordonouri et al. 2002, Laron et al. 1999, Neu et al. 2000, Rothwell et all 1999, Samuelsson et al. 1999, Songini et al. 2001, Ursic-Bratina et al. 2001, Willis et al. 2001) that are concerned with the influence of month of birth on insulin dependent diabetes in children. With the exception of Chen et al., all these studies find a significant relationship between month of birth and the incidence of Diabetes I. The authors of the studies primarily attribute the relationship to intrauterine infections, perhaps during the yearly influenza epidemics in autumn and winter, although the exact mechanism is still unknown. 
Figure 4.3 Heart Disease: deviations of mean age at death for decedents born in a specific month from average mean age at death, United States whites, death records 1989 to 1997. Original data (dashed line), smoothing cubic splines (solid line).
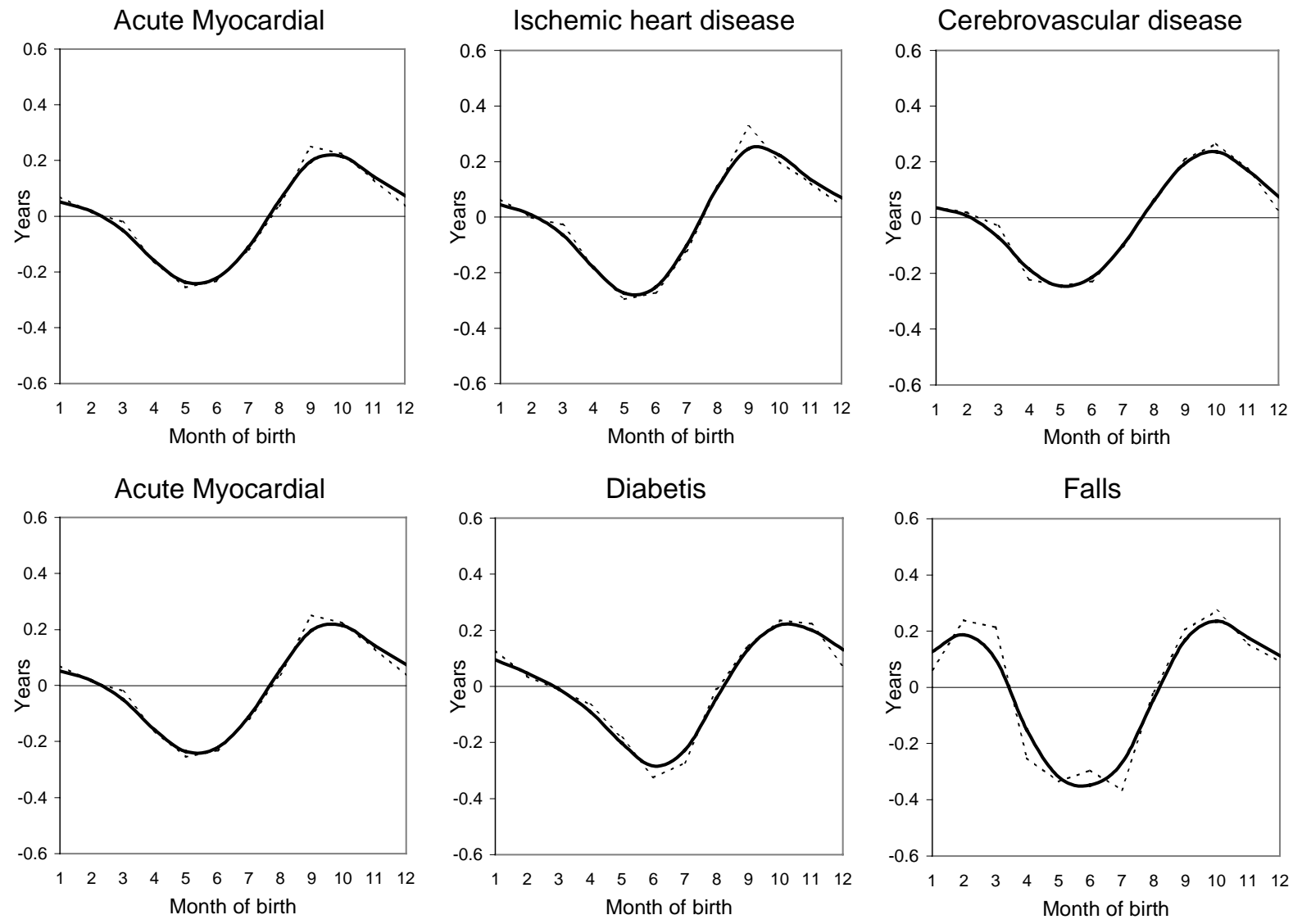
Figure 4.4 Heart Disease: deviations of mean age at death for people born in a specific month from average mean age at death, United States blacks, death records 1989 to 1997. Original data (dashed line), smoothing cubic splines (solid line).
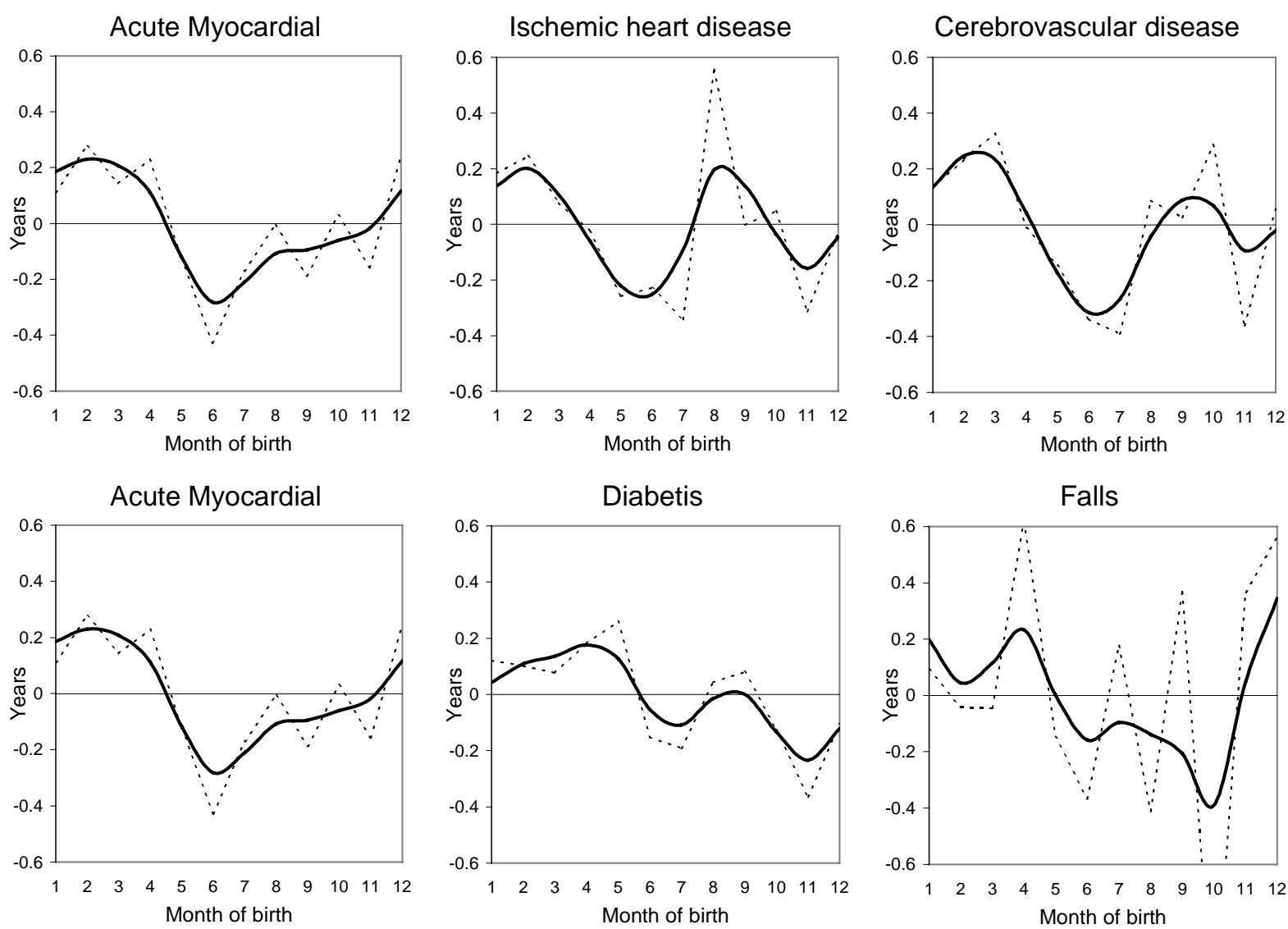
Diseases of the respiratory and digestive system, and infectious disease

There exists a highly significant month-of-birth effect for chronic diseases of the respiratory system and for pneumonia and influenza (Table 4.1, Fig. 4.5 and Fig. 4.6). The effect differs by region and race and in the case of chronic respiratory diseases also by marital status. Considerable evidence exists that lower respiratory tract infections early in life lead to chronic obstructive lung disease late in life (for a review see Elo and Preston 1992). In young children, viruses are the principal etiological agents that cause lower respiratory tract infections. Elo and Preston point out that since the lungs of children undergo developmental changes it is plausible that clinically severe infections could have lasting effects. A large series of literature exists, which shows a significant relationship between month-of-birth and atopic disease in childhood. One frequently explored disease is wheezing and asthma. A study of Queensland, Australia, shows that school children who experience frequent wheezing (one or more episodes per month) are $60 \%$ more likely to be born in spring or summer (Duffy 1991). In Hong Kong the prevalence of wheezing is highest for girls born in January/February and lowest for those born in July/August (Lau and Karlberg 1998). In Singapore adolescents born in two main seasons, namely March-May and September-November, show a higher prevalence of asthma and asthma-like diseases (Chew et al. 1998).

A series of studies explores IgE antibodies. A Swedish study (Nielsson et al. 1997) found that children (ages 0-15) born during the tree pollen season (spring) were less likely to develop allergic rhinoconjunctivits, $\operatorname{IgE}$ antibodies to pollen, or a positive screening test for $\operatorname{IgE}$ antibodies than children born during the rest of the year. The prevalence of IgE antibodies to food and animal dander was higher in children born in autumn and winter (September to February). An earlier Swedish study (Eriksson \& Holmen 1996) on adults (ages 14+) came, however, to slightly different results. Those born between February and May had a higher prevalence of isolated pollen allergy. A Dutch study (Aalberse et al. 1992) suggests that for the three seasonal allergens birch pollen, grass pollen and house dust mite an increased elevated risk exists for those born up to three months before the main season of the allergen. For cat and dog allergy those born between November and January had an increased risk as compared to the May-born. The authors conclude that a sensitive period exists in the first months during which 
allergy exposure is more likely to prime for an allergy later in life. A French study (de Montis 1998) confirms the results concerning house dust mite allergy and finds a peak for people born in October and a trough for those born in April. Further evidence for a significant relationship between allergies to house dust mites and pollen, and month of birth comes from a Turkish study (Erel et al. 1998). A German study, however, does not find a corrlation between allergic sensitization and manifest atopic disease and month of birth (Schaefer et al. 1993).

While the studies about the prevalence of wheezing and asthma in childhood by month of birth suggest that the spring- born have a higher risk of atopic manifestation a study of lower respiratory tract infections in childhood comes to the opposite conclusion. The study is based on British school children and middle aged adults and finds that admission for bronchiolitis in the first year of life was three times more common among children born from September to November than those born from March to May. Admissions for asthma were significantly more common among children and young adults born in autumn. Among adults however, those born in autumn had a higher forced ventilatory capacity and there was little variation in hospital admissions for chronic bronchitis/emphysema and pneumonia although there was a tendency that those born in spring had higher admission rates (Strachan et al. 1994). The authors conclude that there is no evidence in their study for a causal link between chest illness in infancy and later development of chronic bronchitis and emphysema.

Significant differences in the month-of-birth effect do also exist for mortality from infectious diseases in less developed countries. A recent study of the relationship between month of birth and mortality in The Gambia found that those born shortly after the hunger season had a higher risk of dying before their $45^{\text {th }}$ birthday (Moore 1997). All the deaths were caused by either pregnancy related deaths or by infectious disease. The authors conclude that malnutrition together with a high energy expenditure of mothers in their last trimester of pregnancy affected the immune systems of their babies.

Two studies explore the relationship between month of birth and Crohn's disease. They are routed in a recent finding that infections early in life or in utero - in particular measles - seem to be important risk factors for the development of Crohn's disease later in life (Ekbom et al. 1996). However, other studies failed to find a relationship (Nielsen 
et al. 1998). Since the incidence of measles and other possible infectious agents is seasonal the seasonal variation might be reflected in the pattern by month of birth in people with Crohn's disease. Results from the two studies exploring the month-of-birth effect are not consistent. In Britain people born in the first half of the year seem to have a slightly increased risk of Crohn's disease (Haslam et al. 2000), in Denmark, the peak in prevalence is observed for people born in August (Toft-Sorensen et al. 2001).

A recent study (Ivarsson et al. 2003) explores the month-of-birth pattern of coelic disease in Swedish children below age 15. The authors find an excess of children born during the summer, as compared to winter for children under age two. For children aged two to 15 no pattern existed. They suggest that infections might be the exposure of importance.

\section{Non-natural causes of death}

There exist significant differences in mean age at death by month of birth for suicides, car accidents (MTV), and for the residual group of all other non-natural causes of death (Table 4.2, Fig. 4.5 and Fig. 4.6). Those born in spring experience a higher risk than those born in fall. Considering the large number of deaths that fall into each of these groups the month-of birth-effect is only of borderline significance.

The evidence about a month-of-birth effect for suicide is mixed. A recent study on Alaska natives showed more suicides among summer births (Kettl et al. 1997). Likewise, Pokorny (1960) found an overrepresentation of suicide cases among July-born. Salib (2002) of those born in May. Three other studies could not find a relationship (Lester 1987, Lester et al. 1970, Sanborn \& Sanborn 1974). Although, at a first glance, the relationship between month of birth and the risk of suicide may be surprising, plausible explanations exist. Suicide at old age is often related to chronic disease which, according to our results, is significantly influenced by the month of birth. Chotai et al. (1999) report differences in suicide methods according to month of birth. Those who preferred hanging rather than poisoning or petrol gases were significantly more likely to be born in February to April than October to January, particularly among males aged 45 or younger. Similar findings are reported by Salib (2002). The suicide attempts may thus be independent of the month of birth. Those born in late winter/early spring, however, may 
use suicide methods that lead to death more often than those born in fall. This leads to research about the effect of month of birth on personality, which, due to its extensive nature, is beyond the scope of this chapter.

Differences in mean age at death by month of birth for car accidents may be explained by the month-of-birth pattern for alcoholism that has been demonstrated repeatedly (Goldberg \& Newlin 2000, Modestin et al. 1995, Levine \& Wojcik 1999,

Figure 4.5: Natural and Non-Natural Causes of death: deviation of mean age at death for decedents born in a specific month from average mean age at death, United States whites, death records 1989 to 1997. Original data (dashed line), smoothing cubic splines (solid line).
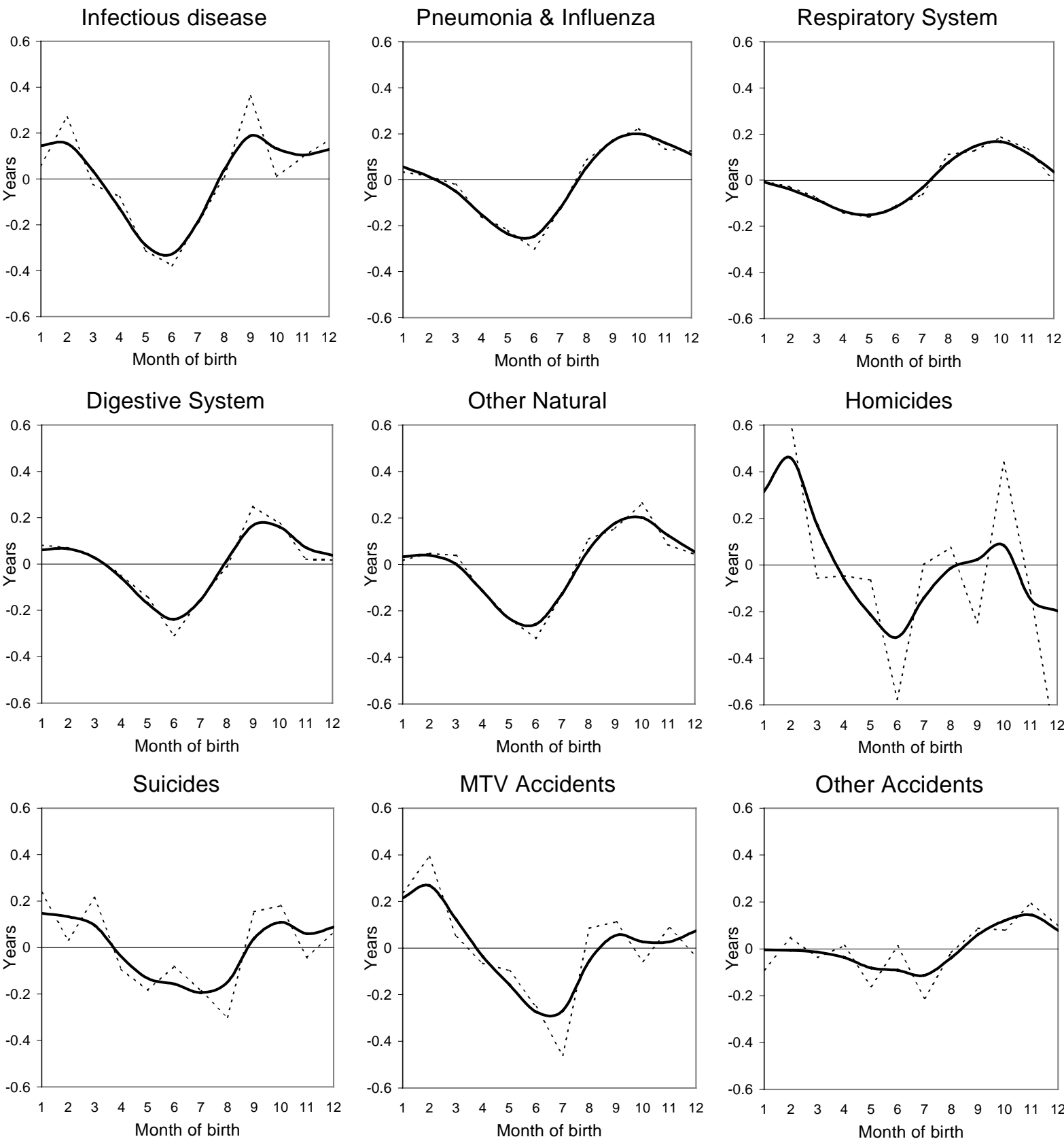
Figure 4.6: Natural and Non-Natural Causes of death: Deviation of mean age at death of decedents born in a specific month from average mean age at death, United States blacks, death records 1989 to 1997. Original data (dashed line), smoothing cubic splines (solid line).
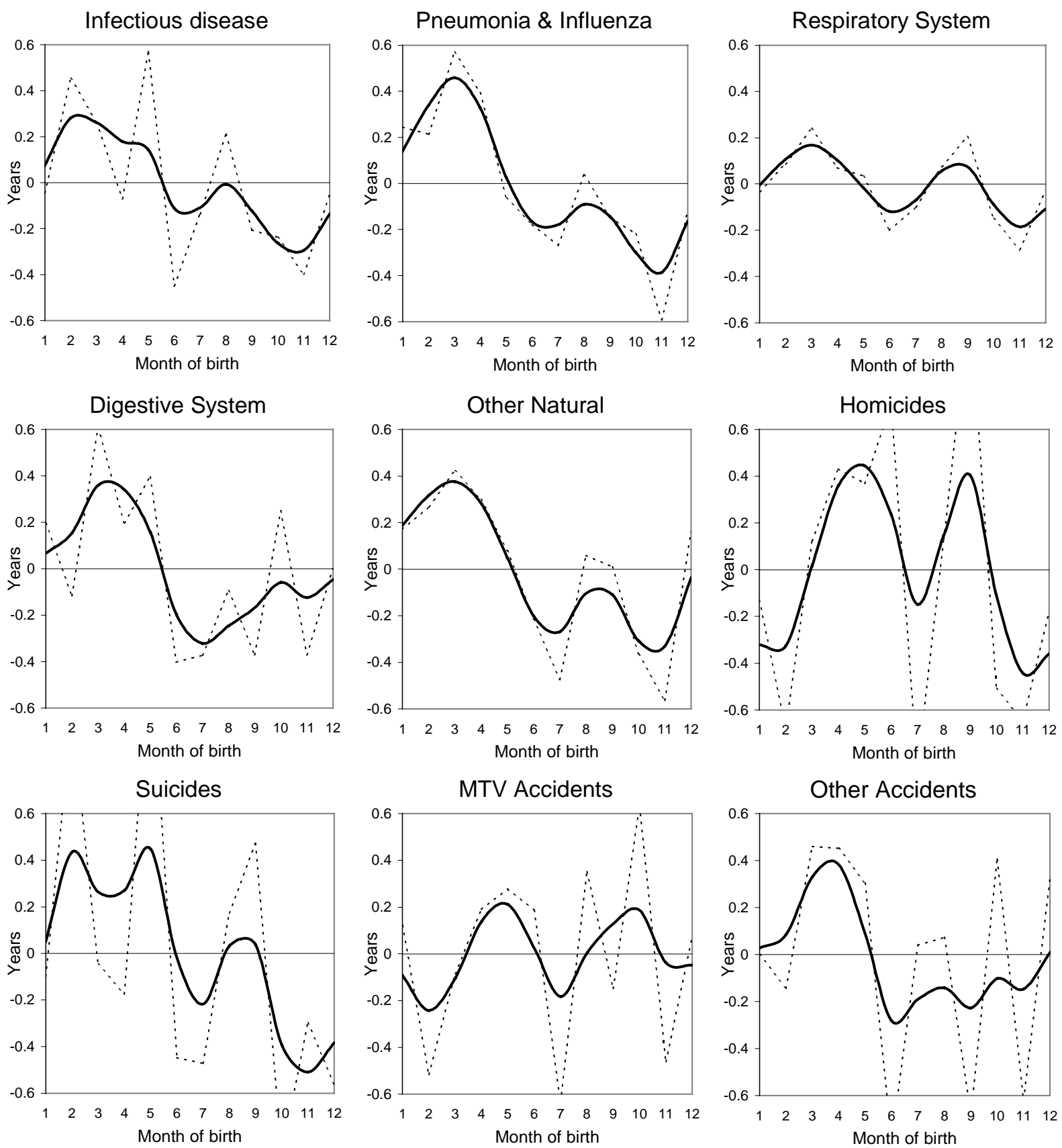
Table 4.2: Non-natural Causes of Death: significance levels of the effect of month of birth (MOB) and its interactions with sex, education, race, marital status and region.

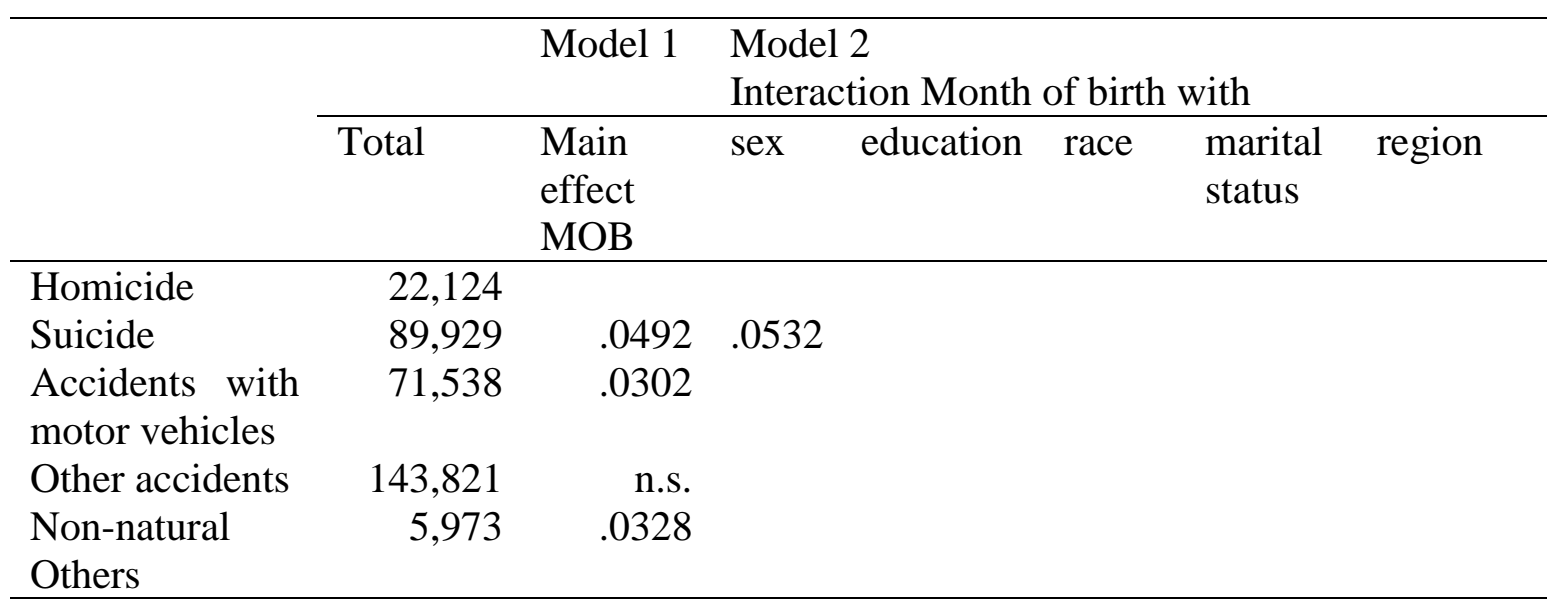

Model 1 includes main effects of month of birth (MOB), education, race, region, marital status and sex. All main effects are highly significant.

Model 2 includes all main effects and all interaction effects significant at a level of 0.05 . The main effect of month of birth is significant for all causes of death.

London 1998, Kunugi et al. 1998, Lang 1931) although two other studies did not find a pattern (Dalen 1975, Watson et al. 1984).

\section{Diseases of the nervous and mental system}

Most of the research about the relationship between month of birth and the incidence of diseases has been conducted for mental disorders, in particular schizophrenia and other bipolar disorders (for reviews see Torrey et al. 1997, Fossey \& Shapiro 1992, Bradbury \& Miller 1985). Torrey et al. review more than 250 studies, covering 29 Northern and five Southern Hemisphere countries, and find a remarkable consistency in the results. There is a 5-8 percent winter/spring excess of births for both schizophrenia and mania/bipolar disorders. The season-of-birth effect has also been studied for autistic disorder (Barak et al. 1995, Bolton et al. 1992, Ticher et al. 1996), Alzheimer patients (Philpot et al. 1989, Dysken et al. 1991, Henderon et al. 1991, Vitiello et al 1991, Vezina et al. 1996), and for anorexia nervosa patients (Nielsen 1992, Rezaul et al. 1996, Eagles et al. 2001). With the exception of a few studies, they all find significant differences in 
the birth distribution of the patients as compared to the general population or the control group. For diseases of the nervous system significant differences by month of birth have been shown for Parkinson's disease (Miura et al. 1987, Mattock et al. 1988), multiple sclerosis (Miura et al. 1987, Rothwell et al. 1999, Sadovnick et al. 1994, Salemi et al. 2000, Wiberg et al. 1994) and epilepsy (Procopio \& Marriott 1998).

The present results confirm the findings of all these studies (Table 4.14, Fig. 4.7 and Fig. 4.8) with the exception of multiple sclerosis, which in this study may be attributable to the small number of observations.

\section{Conclusion}

Heart disease, certain types of cancers, and other natural causes of death like chronic obstructive lung disease reveal a strong month-of-birth pattern. This result is consistent with the large literature about the effect of early life circumstances on late life disease and mortality. Davey Smith and Kuh (2001) mention stroke, stomach cancer and bronchitis as important contributors to adult mortality that declined on a cohort basis between the mid $19^{\text {th }}$ century and today. High positive correlations between infant mortality in 1921-1925 and mortality from chronic bronchitis, ischemic heart disease, stomach cancer, and rheumatic heart disease have been demonstrated (Osmond and Barker 1986a), as well as for stroke (Barker \& Osmond 1989).

In the US death data a strong month-of-birth pattern exists also for lung cancer. It is still hotly debated whether early life factors affect lung cancer (Forsdahl 1973, Barker and Osmond 1986a) or whether indirect effects of the childhood environment mediated through current life-course conditions influence lung cancer (Ben Shlomo \& Davey Smith 1991, Elo \& Preston 1992). The significant month-of-birth pattern suggests that early life factors play a role in the development of lung cancer independent from lifecourse factors.

The month-of-birth pattern exists for many different causes of death with very different disease etiologies. This suggests that there is more than one single causal mechanism, and that both nutrition and infectious disease are important factors. In above studies by Barker and colleagues heart disease has been primarily linked to fetal 
Figure 4.7: Diseases of the Nervous and Mental System: deviations of mean age at death for decedents born in a specific month from average mean age at death, United States whites, death records 1989 to 1997. Original data (dashed line), smoothing cubic splines (solid line).
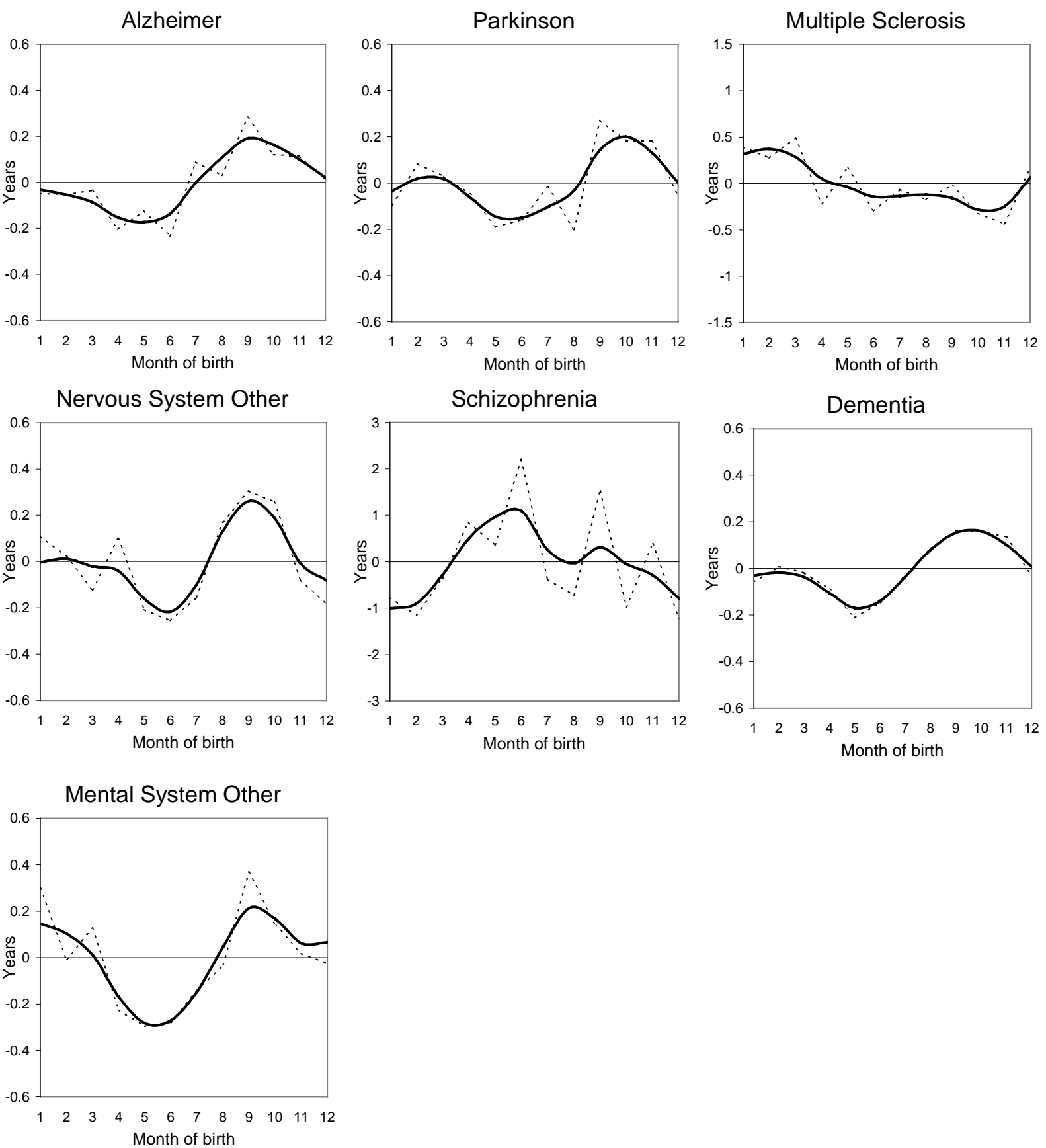
Figure 4.8: Diseases of the Nervous and Mental System: deviations of mean age at death for decedents born in a specific month from average mean age at death, United States blacks, death records 1989 to 1997 . Original data (dashed line), smoothing cubic splines (solid line).
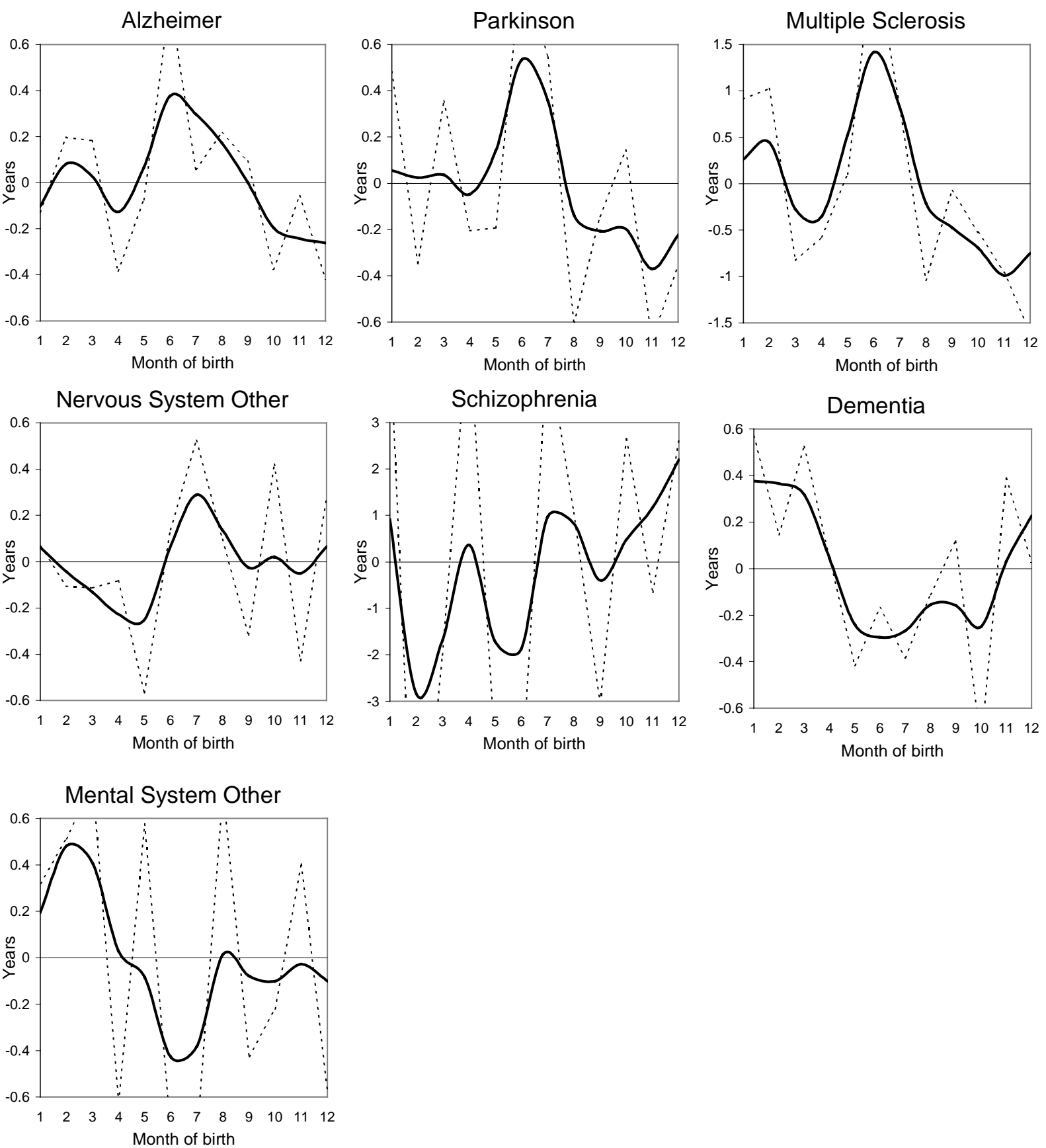
development and nutrition during pregnancy. Chronic obstructive lung disease was linked to lower respiratory tract infections during infancy and childhood, which in children are mainly caused by viruses (Elo \& Preston 1992). Other diseases in which a major role for persistent viruses has been suggested include multiple sclerosis, Parkinson's disease, juvenile diabetes, and presenile dementia (Elo and Preston 1992). Resent research suggests a relationship between Helicobacter pylori infections in childhood and stomach cancer (Elo and Preston 1992).

A surprising result is the similarity of the month-of-birth pattern of very different causes of death. One generally finds a trough in mean age at death for those born in spring and early summer and a mortality advantage for the fall (whites) and winter-born (blacks). One possible explanation is that the spring and early summer-born are twofold disadvantaged. On the one hand, their last trimester in-utero falls into the season of the year where the lack of certain micronutrients such as vitamins is most severe. On the other hand their mortality risk during their first year of life is higher than of those born during other seasons. This is an indication for the effect of infectious disease, which largely determined infant mortality at the beginning of the $20^{\text {th }}$ century.

For most causes of death the month-of-birth pattern differs significantly between whites and blacks. In general the trough in mean age at death is similar for both groups, namely in spring/early summer, however among African Americans the peak is shifted from fall to winter. Therefore the difference in the month-of-birth patterns for the two groups in total mortality is not caused by one or two major groups of causes of death but it is a general feature of most causes.

The month-of-birth patterns of most cancers, circulatory diseases, pneumonia and influenza, and of diseases of the respiratory system differ significantly by region of birth (not shown). For circulatory diseases the locations of the peaks and troughs remain generally the same for all regions of birth and primarily the amplitude changes; for the other causes of death also the peaks and troughs vary by region of birth. This is a further indication that the causal mechanisms that underlie the month-of-birth patterns are different for different diseases. 


\section{FIVE}

\section{DOES THE MORTALITY ADVANTAGE OF THE FALL-BORN EXIST AT ALL AGES}

\section{AND DOES IT CHANGE OVER COHORTS?}

The last chapters provide ample evidence that life span and month of birth are related. Two questions arise: First, does this influence also exist for ages 1 to 49? Second, is the magnitude of the excess mortality of the spring-born similar in all age groups? There are at least two different hypotheses concerning these questions. A first hypothesis is that the excess mortality of the spring-born is age-specific because of the changing distribution of causes of death with age. The analysis of the US death certificates in Chapter 4 shows that the monthof-birth effect exists in all major groups of causes of death, however, its magnitude differs. The excess mortality of the spring-born is largest for heart disease and considerably smaller for the group of malignant neoplasms. Thus, the month-of-birth pattern might be comparatively small at younger ages and may increase its magnitude at middle and old ages when heart disease becomes an important cause of death. A second hypothesis is that the differences decrease with age due to mortality selection. Among both the spring- and the fallborn the frailer will die first resulting into an ever more homogeneous and "robust" population at higher ages. In practice both forces most probably will work simultaneously.

In trying to test these two hypotheses one has to overcome two problems. The first problem is that longitudinal data are needed to identify age-specific effects; the second, that data-sets have to be large to allow the estimation of age-specific mortality at ages where death rates are low.

Longitudinal data based on population registers exist in Scandinavian countries, and usually were started during the 1960's. In the case of Denmark the register was established in April 1968 and it contains everybody who was alive in March 1968. This study uses the Danish register data together with a mortality follow-up until 1998. Because of the small numbers of death at younger ages in Denmark today it is not possible to use the register for studying age-specific changes in the month-of-birth pattern for contemporary young cohorts. This is also true for other Scandinavian countries with population registers. Numbers of death are only sufficient after age 50 to study age-specific patterns in mortality by season of birth. 
Thus, the Danish register data provide only partly an answer to the question of how the month-of-birth pattern changes with age.

The second longitudinal data set used in this chapter is the Danish twin register, which contains twins born in Denmark between the years 1870 to 1930 . The twins were followed from age six onwards until August 1995. Twins have two advantages when studying agespecific month-of-birth patterns. First, the mortality of twins does not differ from the mortality of singletons once they survive their $6^{\text {th }}$ birthday (Christensen et al. 2001). Second, the differences in life span by season of birth should be larger among twins than among singletons. The reason is twofold: in-utero twins belong to the most vulnerable group because they have to share scarce resources and seasonal differences in nutrition should therefore affect them more severely. In addition they have lower birthweights than singletons which should make them more susceptible to infectious disease during their first years of life.

In theory both the Danish register data and the Danish twin data would permit the calculation of age-specific death rates by quarter of birth using simple life table techniques. In practice, however, it appears that these death rates are highly volatile and do not lead to conclusive results. In order to arrive at consistent estimates of age-specific death rates a functional form is imposed on the age-specific intensities of death.

Finally, a demographic method is applied that has been widely used in the study of genetic traits of longevity. The method permits the use of repeated cross-sections of populations to estimate the effect of the "fixed attribute" month of birth on survival. Seeking for repeated large cross-sectional data the US censuses for the years 1960, 1970 and 1980 were obtained. These are the only three censuses that contain information about the quarter of birth. The census data were extracted from http://www.ipums.umn.edu/usa/index.html. The seasonal distribution of birth dates for e.g. ages 10-19 in 1960 was then compared with the distribution for ages 20-29 in 1970, and for ages 30-39 in 1980. The changes in the distributions between the three census rounds indicate whether a significant excess mortality of the spring-born exists.

All three datasets lead to the same conclusion, namely that the excess mortality of the spring-born exists at all ages. The Danish register data show that the excess mortality after age 50 is lower in more recent cohorts and that it decreases with age. The excess mortality of the spring-born is larger among the Danish twins than among the general Danish population. It exists at all ages and also tends to decrease with age. The US census data reveal that the mortality advantage of the fall born exists at all ages and that the difference in survival between the spring- and the fall-born starts to accelerate at middle ages. However, the census 
data do not permit a distinction between cohort and age effects. It is therefore not obvious whether the increase in the excess mortality of the spring-born around age fifty is due to the age-specific onset of diseases with a strong month-of-birth pattern or due to cohorts that experienced worse conditions early in life.

\section{Method and Data}

The Danish register data and the Danish twin data are analyzed by imposing a functional form on the age specific force of mortality. In the Danish register data mortality increases from age 50 on following a Gompertz function [5.1]

$\mu(x)=a e^{b x}$

where $\mu(x)$ is the force of mortality at age $x, a$ is the age-independent level of mortality and $b$ the increase in mortality over age. The parameter estimates a and $\mathrm{b}$ are estimated by solving the likelihood function. All individuals are distinguished according to their quarter of birth and for each quarter a separate model is estimated. The age-specific death rates of the four models are presented in the form of ratios of the first three quarters to the last quarter. These ratios are compared with the ratios of the age-specific probabilities of death for one-year age groups on the basis of simple life table methods.

The Danish register data consist of sufficiently large numbers of exposures and deaths to distinguish between age and cohort effects. Two ten-year birth cohorts are followed over an age-span of 20 years. The birth cohort April 1908 to March 1918 enters the study period between ages 50, and 59 and 11 months. They are followed from age 60 to age 79 in order to theoretically allow each member of the cohort to reach each age. The second cohort is aged 60 to 69,11 months at the 1968-baseline and is followed from age 70 to age 89. This specification allows to study age-specific death rates at ages 70 to 79 for both cohorts.

The Danish twin data include all twins from age six onwards. Contrary to older ages the force of mortality does not follow a simple parametric form between ages 6 and 100. In the twin data mortality decreases between ages 6 and 15, sharply increases until age 20, stagnates until age 40 and increases exponentially thereafter. A possible solution is to estimate four mortality functions, which are joined together at ages 15, 20 and 40.

The following model [5.2] is specified

$$
\ln \mu_{i j}\left(x, U_{j}\right)=\alpha_{0}+\alpha^{\prime} y(x)+\beta^{\prime} C_{i j}+\delta I_{i j}+U_{j}
$$


in which $\ln \mu_{i j}\left(x, U_{j}\right)$ denotes the logarithm of the force of mortality at age $x$ for individual $i$ of twin pair $j$, and $\alpha_{0}+\alpha^{\prime} y(x)$ the age-dependent baseline hazard. Let $C_{i j}$ stand for the tenyear birth cohorts and their parameters $\beta, I_{i j}$ for an indicator variable that indicates the halfyear people are born in $\left(I_{i j}=0\right.$ if they are born in the first half-year, 1 otherwise), and $\delta$ for the parameter.

Since the large variability in mortality under age 20 leads to unstable estimates of the age independent mortality level $\alpha_{0}$ the analysis is restricted to ages 20 and above. The baseline hazards $y(x)$ is $a$ vector of piecewise-linear spline transformations of age $x$

$$
y(x)=\left(\begin{array}{l}
\left(\min \left[x, v_{1}\right]\right) \\
\left(\max \left[0, \min \left[x-v_{1}, v_{2}-v_{1}\right]\right]\right) \\
\left(\max \left[0, x-v_{2}\right]\right)
\end{array}\right)
$$

with the nodes $v_{1}$ and $v_{2}$ of the splines set at ages 40 and 60 . Thus, three slopes of mortality are estimated: the first slope estimates the yearly percentage increase in mortality between ages 20 and 40, the second, between ages and 40 and 60, and the third, after age 60 .

Since the lifespans of twins are not independent, a random variable $U_{j}$ is included that accounts for unobserved shared heterogeneity among twins. The random variable $U_{j}$ is assumed to follow a normal distribution with mean zero and variance $\sigma$. Separate models are estimated for the two sexes.

In order to release the model from the proportionality assumption concerning the baseline hazard for people born in a specific half-year, model 5.4 is specified.

$$
\ln \mu_{i j}\left(x, U_{j}\right)=z_{i}\left(\alpha_{01}+\alpha_{1}^{\prime} y_{1}(x)\right)+\left(1-z_{i}\right)\left(\alpha_{02}+\alpha_{2}^{\prime} y_{2}(x)\right)+\beta^{\prime} C_{i j}+U_{j}
$$

In Equ. $5.4 \ln \mu_{i j}\left(x, U_{j}\right)$ denotes the logarithm of the force of mortality at age $x$ for individual $i$ of twin pair $j, \alpha_{01}+\alpha_{1}{ }^{\prime} y_{1}(x)$ and $\alpha_{02}+\alpha_{2}{ }^{\prime} y_{2}(x)$ the age-dependent baseline hazards for people born in the first and second half of the year, and $z_{i}$ an indicator variable for the first or second half-year of birth $\left(\mathrm{z}_{i}=1\right.$ if born in the second half-year, $\mathrm{z}_{i}=0$ if born in the first half-year).

Specifying two baseline functions overcomes the proportionality assumption and permits the estimation of two separate age independent levels of mortality $\left(\alpha_{01}\right.$ and $\left.\alpha_{02}\right)$ and of separate age-dependent slopes of mortality ( $\alpha_{1}{ }^{\prime}$ and $\left.\alpha_{2}{ }^{\prime}\right)$. The baseline hazards $y_{1}(x)$ and 
$y_{2}(x)$ as well as the terms $C_{i j}, \beta$, and $U_{j}$ are defined similar to Equ. 5.2. Separate models are estimated for the two sexes. All estimations are performed in aML vers. 2.

In order to compare the pattern in life expectancy by season of birth between twins and the general Danish population life tables are calculated by week of birth. For each week of birth the median age of survival is estimated. The 52 age values are smoothed by

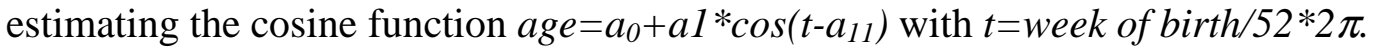

To estimate differences in survival according to the quarter of birth on the basis of the US censuses for the year 1960, 1970, and 1980 a method called Survival-Attributes Assay (Vaupel 1991, Christensen et al. 2001) is applied. This method uses cross-sectional data on "fixed-attributes" in order to estimate the effect of a fixed trait on survival.

The Survival-Attributes Assay can be demonstrated on a simple example. Let $\mathrm{N}_{50}$ be the number of people at age 50. Let $\mathrm{p}_{50}$ be the proportion of 50-year-olds who have some fixed attribute such as the season of birth. Let $p_{70}$ be the proportion at age 70 . Let $s$ be the conditional survival probability from age 50 to age 70 for the individuals who have the fixed attribute. Let $\mathrm{S}$ be the conditional survival probability from age 50 to 70 for the entire cohort. Then because

$$
\mathrm{p}_{50} \mathrm{~N}_{50} \mathrm{~s}=\mathrm{N}_{50} \mathrm{~S} \mathrm{p}_{70}
$$

It follows that

$$
\mathrm{S}=\mathrm{S} \mathrm{p} \mathrm{p}_{70} / \mathrm{p}_{50}
$$

Thus, the relative risk of surviving from age 50 to age 70 of people born in a specific quarter is the ratio of their observed proportions in the two cross-sections. In this study the proportion of the population within ten-year age groups is calculated that is born in a certain quarter of the year. These age groups are then followed over the three census rounds.

This is a very simple and useful method but it relies on some crucial assumptions. The most important of these assumptions is that the 70-year-olds in the third cross-section were similar to the 50-year-olds in the first cross-section. The three US census rounds used in this study, however, permit following a ten-year cohort on an aggregate level over a period of 20 years. The 70-year-olds in 1980 are the survivors of the 60-year-olds in 1970 and the 50year-olds in 1960. In other words, the change in the proportion of the fixed attribute over an age range of twenty years is solely due to age effects and cohort effects do not confound it. Cohort effects, however, confound comparisons of ages further apart than 20 years. 
The three US census rounds 1960, 1970 and 1980 are used because these are the only census rounds that include information about the quarter of birth. Data are extracted from the "Public Use Microdata Samples", which are accessible under http://www.ipums.umn.edu/usa/index.html. The extract is restricted to the native-born white and black US population aged 0 to 100. For whites this gives a sample size of 1,490,444 in 1960, $1,672,107$ in 1970 , and $1,812,839$ in 1980 . For blacks 187,849 observations for the year 1960, 220,670 observations for 1970, and 256,447 observations for 1980.

The Danish population register is described in the second chapter. The Danish twin registry was established in 1954 as the first nationwide twin registry in the world. The registry includes all twin pairs born in Denmark between 1870 and 1910 and all same-sex pairs born between 1911 and 1930. The birth registers from all 2,200 parishes of the relevant calendar years were manually scrutinized to identify all twin births. Through regional population registers (in operation since 1924) and other public sources, a search was made for the twins, or whenever needed, their closest relatives. For twins dying or emigrating at an early age it was impossible to obtain reliable data to be used in zygosity classification.

Consequently, pairs were not followed up if one or both partners died or emigrated before the age of six. In this study 12,530 female and 11,237 male twins are followed until August 1995 and for each twin the exact date at death or at censoring is known.

\section{Results}

Comparison of the month-of-birth pattern in the Danish register data and the Danish twin data

In both populations life expectancy decreases sharply for those born in the first quarter, it reaches a trough for people born in the second quarter, increases sharply for the summer-born and peaks for the fall-born. 
Figure 5.1: Differences in life expectancy by week of birth in the Danish register population $\left(\mathrm{e}^{50}\right)$ and the Danish twin register $\left(\mathrm{e}^{6}\right)$. The fitted lines are estimated by a cosine term with a period of 52 weeks.
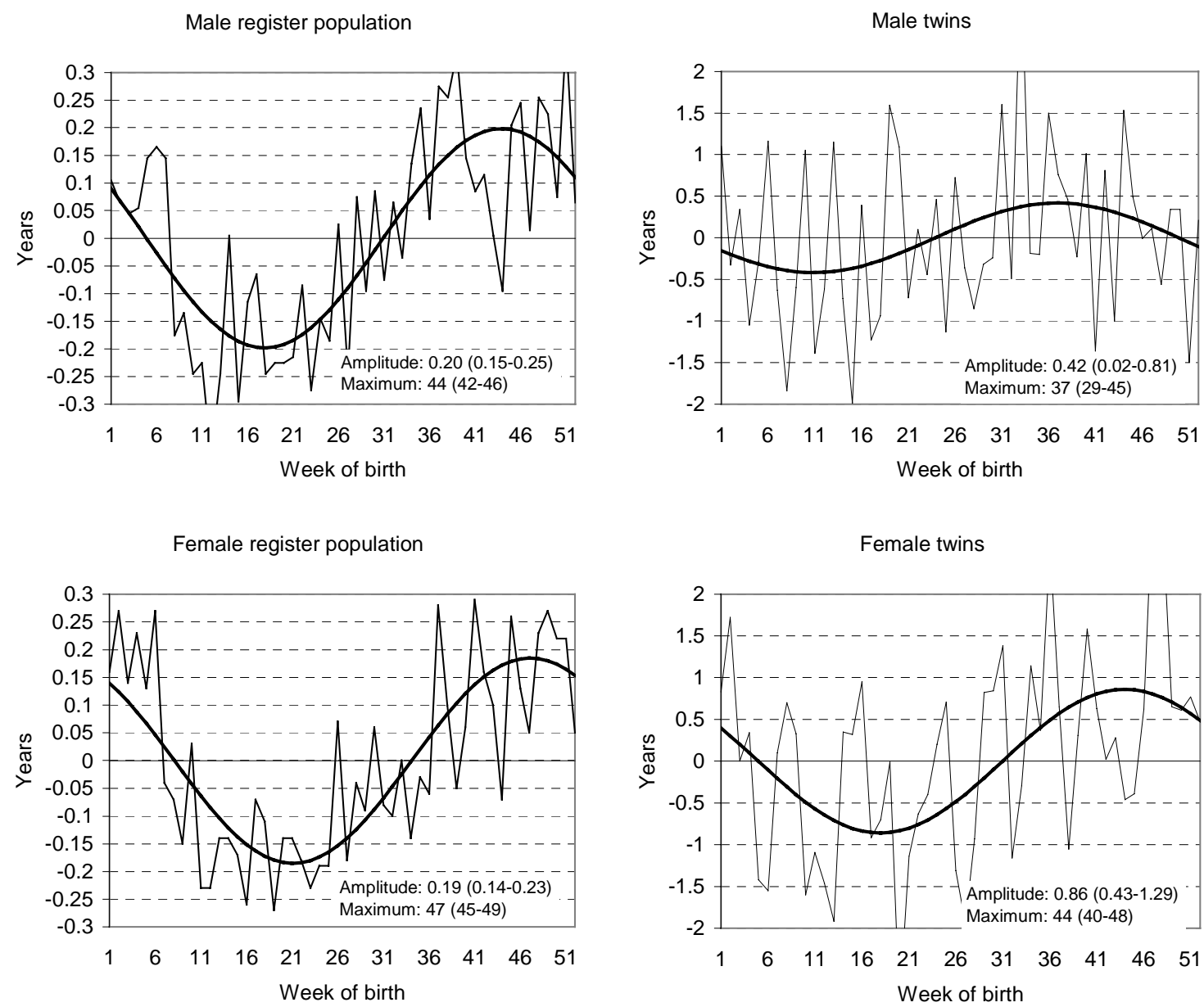

The fit of the sinusoidal functions is significant for both sexes $(p=0.001)$ and both registers.

The striking difference between the pattern of the twins and of the general population lies in the amplitude. In the female register population the amplitude is 0.19 years, among the twins, 0.85 years; among males the difference is 0.20 years and 0.42 years, respectively. Thus, the peak-to-trough difference among the female twins is about four times as large as among the register population. In interpreting this difference one has to keep in mind that among twins it reflects difference in life expectancy from age 6 onwards, while among the general Danish population it refers to differences in remaining life expectancy at age 50. 
Figure 5.2 contains the parameter estimates $a$ and $b$ of the Gompertz models for the two cohorts 1889 to 1908 , and 1909 to 1918 which are the basis for the mortality ratios displayed in Fig. 5.3. As discussed, in the Gompertz-model the parameter $a$ depicts the ageindependent mortality level, and $b$ the increase in mortality over age. Excess mortality of the spring-born as compared to the fall-born implies a significantly higher level parameter $a$ for the spring-born. If the excess mortality is age-dependent then also parameter $b$ should differ significantly.

Significant differences in both the level and the increase of mortality between the spring- and the fall-born exist in the older female cohort, although the increase of mortality is only of borderline significance. The level of mortality is lower among the fall-born while the increase in mortality with age is higher. This implies that with advancing age mortality increases more rapidly among the fall-born and the excess mortality of the spring-born becomes lower. A similar tendency but not significant exists among males and the younger female cohort. Figure 5.3 shows the ratio of the age specific death rates for people born in the first three quarters of the year to the death rates of those born in the fourth quarter. The solid lines are based on the mortality estimates from the Gompertz models, the dashed lines on the life table estimates. The dark black line pertains to the birth cohort 1909 to 1918, the light dark line, to birth cohort 1898 to 1909. For men there is little evidence of age-specific mortality patterns after age 60 with the exception that the excess mortality of those born in the first half of the year decreases between ages 70 and 89. Among females this differs insofar as the excess mortality tends to increase between ages 60 and 70 and starts to decrease at later ages. There is still a decrease in excess mortality for the higher ages. There is a strong cohort effect among women, a weak effect among men. In the overlapping age groups 69 to 79 the excess mortality of the spring-born is much larger in the older female cohort than in the younger cohort. Although there is a similar tendency for all cohorts and both sexes one has to keep in mind that on the basis of the Gompertz model the differences are only significant for the older female cohort. 
Figur 5.2: Danish population register: Parameter estimates $a$ (level of mortality) and $b$ (increase in mortality with age ) of the Gompertz model specified in Equ. 5.1 and 95\% confidence intervals by quarter of birth for the two birth cohorts April 1909-March 1918 and April 1898 - March 1908.

\section{Fe m ales}

cohort $1909-1919$
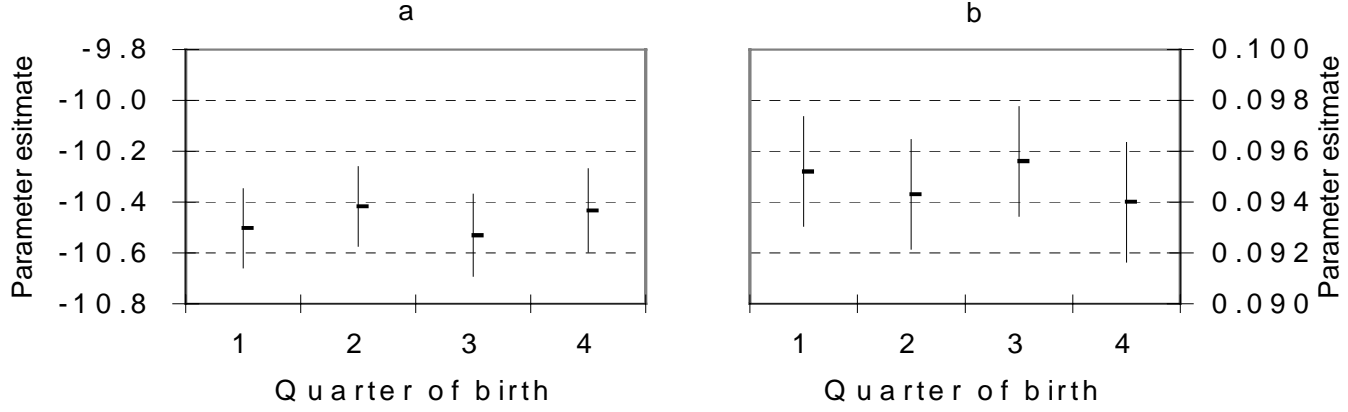

cohort $1898-1909$

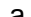
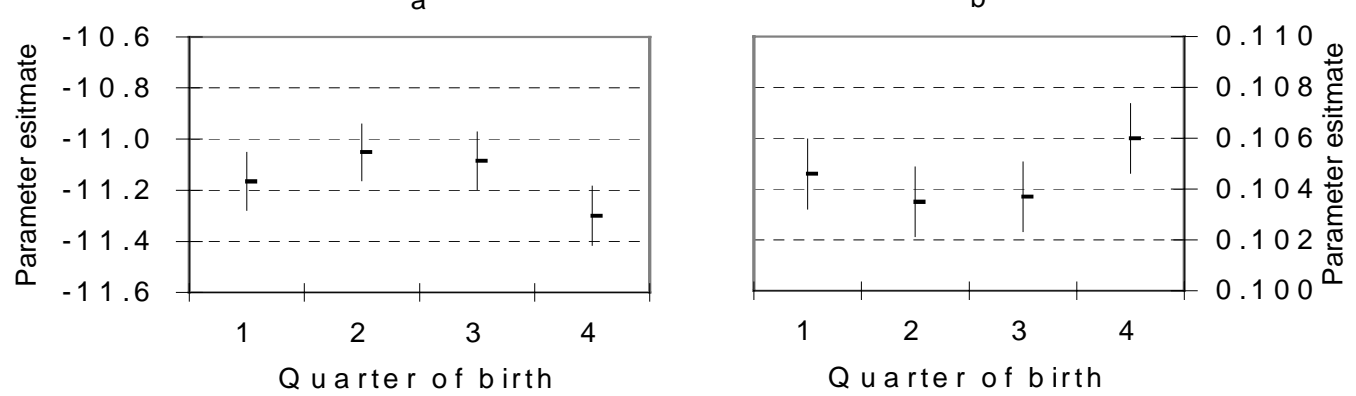

$\mathrm{M}$ a les

cohort $1909-1919$

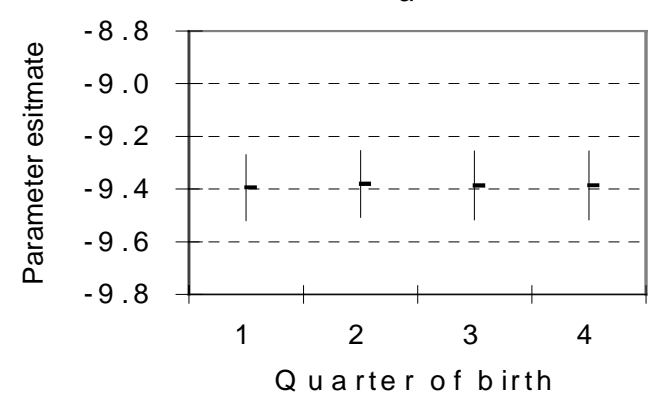

b

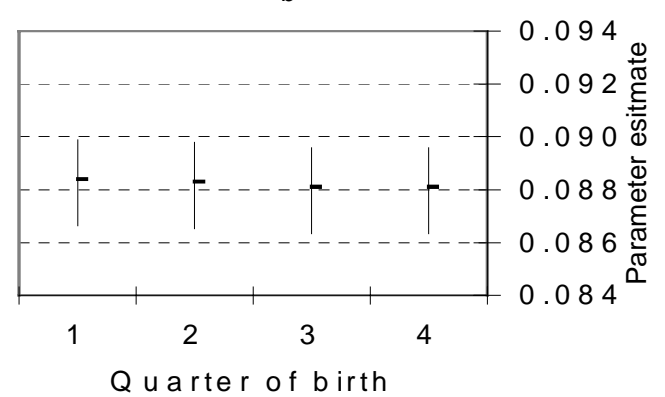

cohort $1898-1909$

a

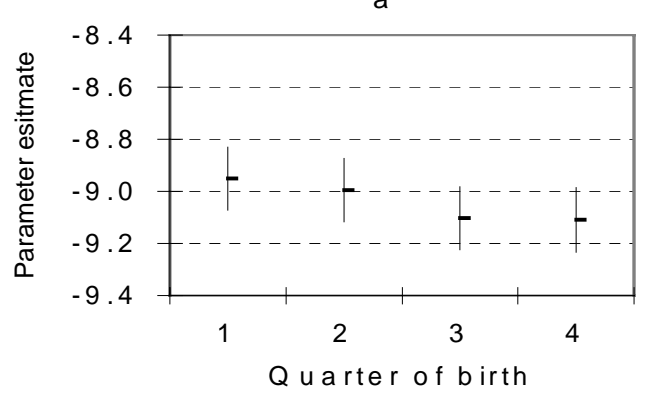

b

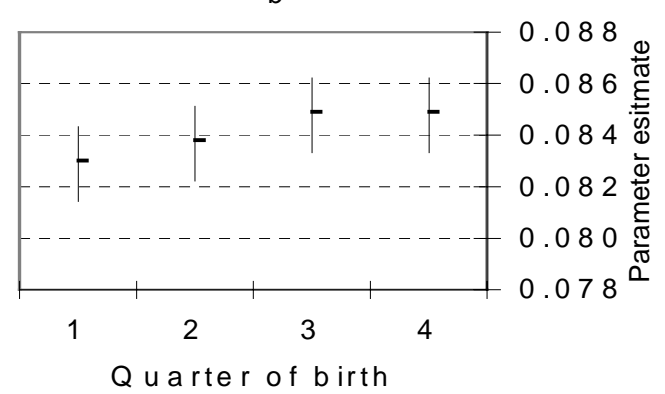


Figure 5.3: Danish population register: Ratios of death rates by quarter of birth for the two birth cohorts April 1909-March 1918 and April 1898 - March 1908.

Females
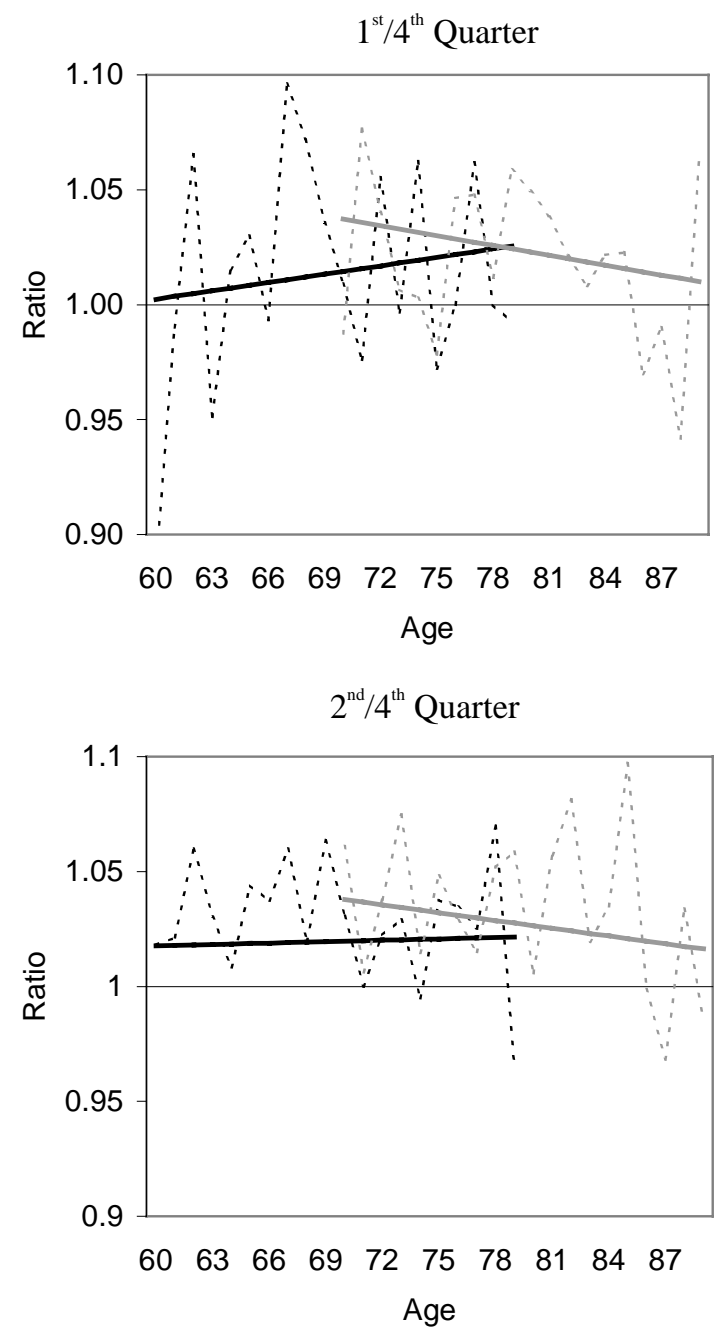

$3^{\text {rd }} / 4^{\text {th }}$ Quarter

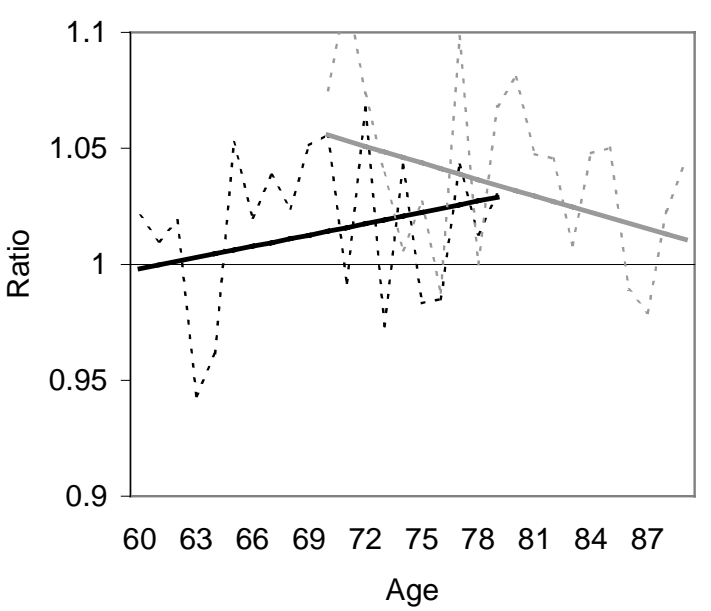

Cohort 1898-1909: Gompertz function Cohort 1898-1909:Life table
Males
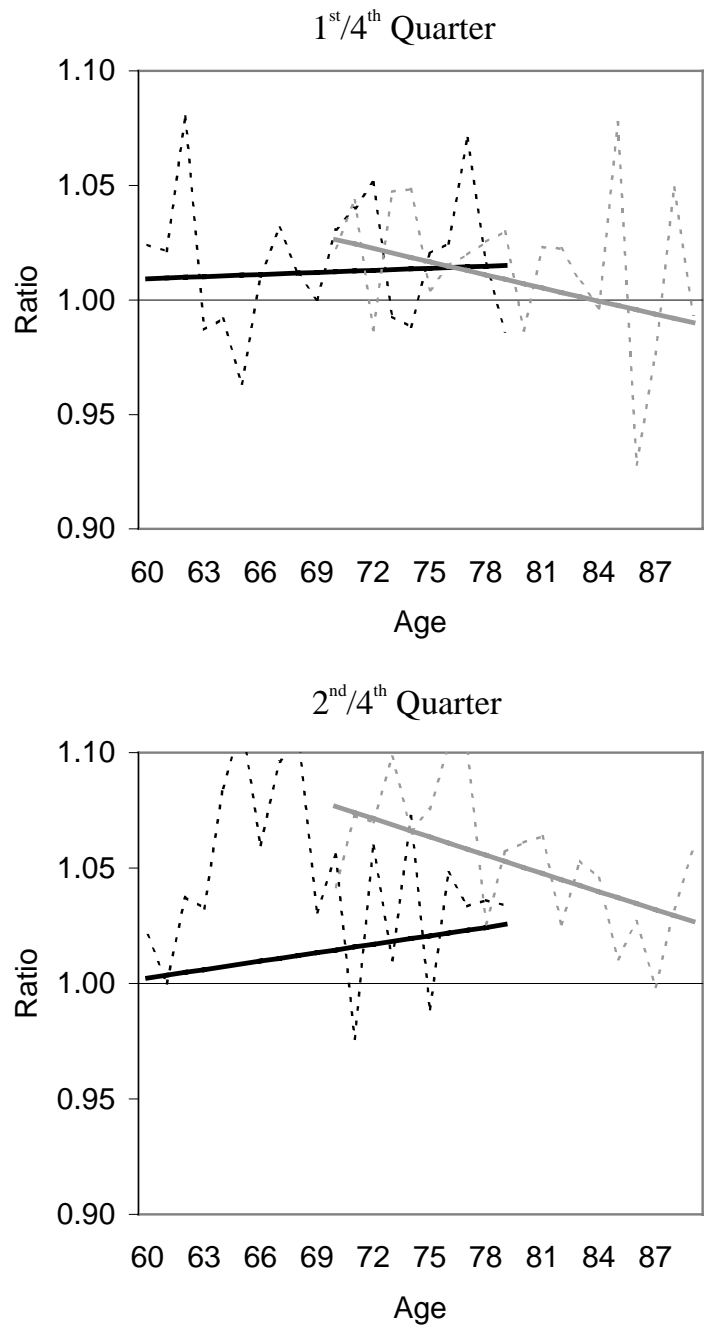

$3^{\text {rd }} / 4^{\text {th }}$ Quarter

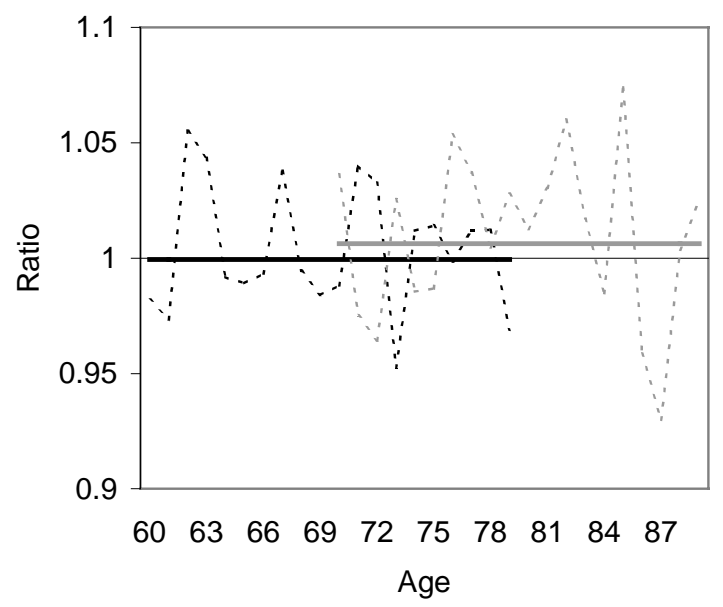

Cohort 1909-1918:Gompertz function

Cohort 1909-1918:Life table 
Age specific mortality at ages $20+$ in the Danish Twin Data

Significant differences in the force of mortality after age 20 by half-year of birth exist among female twins (Table 5.1). The proportional hazard model specified in Equ. 5.2 reveals that those born in the first half-year experience excess mortality of 8 per cent $(p<0.000)$. The increased mortality risk of 4 per cent among male twins is not statistically significant. Although the mortality of twins is followed from age six onwards the analysis has to be restricted to ages 20+. Only few death counts are observed under age 20, which causes problems when estimating $\alpha$, the age independent level of mortality. Restricting the analysis to age $20+$ stabilizes the estimates of $\alpha$. This is particularly true for the second model in which the proportionality assumption has been overcome by estimating separate baseline functions for those born in the first and second half-year.

Although the differences between the two baseline functions in Equ. 5.4 are statistically not significant a general trend emerges. Table 5.2 shows that the age independent mortality levels $\exp \left(\alpha_{01}\right)$ and $\exp \left(\alpha_{02}\right)$ are lower for those born in the second-half year (males $1^{\text {st }}$ half-year: $\exp (-6.17)=0.0021,2^{\text {nd }}$ half-year $\exp (-6.25)=0.0019$; females $1^{\text {st }}$ half-year: $\exp (-6.26)=0.0019,2^{\text {nd }}$ half-year $\left.\exp (-6.41)=0.0017\right)$. Among males the difference between the $1^{\text {st }}$ and $2^{\text {nd }}$ half-year born reaches its maximum around age 40, among females around age 60. After these ages the differences start to decline. For females the difference between those born in the $1^{\text {st }}$ and $2^{\text {nd }}$ half-year disappears around age 40 and accelerates between ages 40 and 60 (Fig. 5.3). 
Table 5.2: Danish twin data: Parameter estimates of the proportinal hazard model specified in Equ. 5.2.

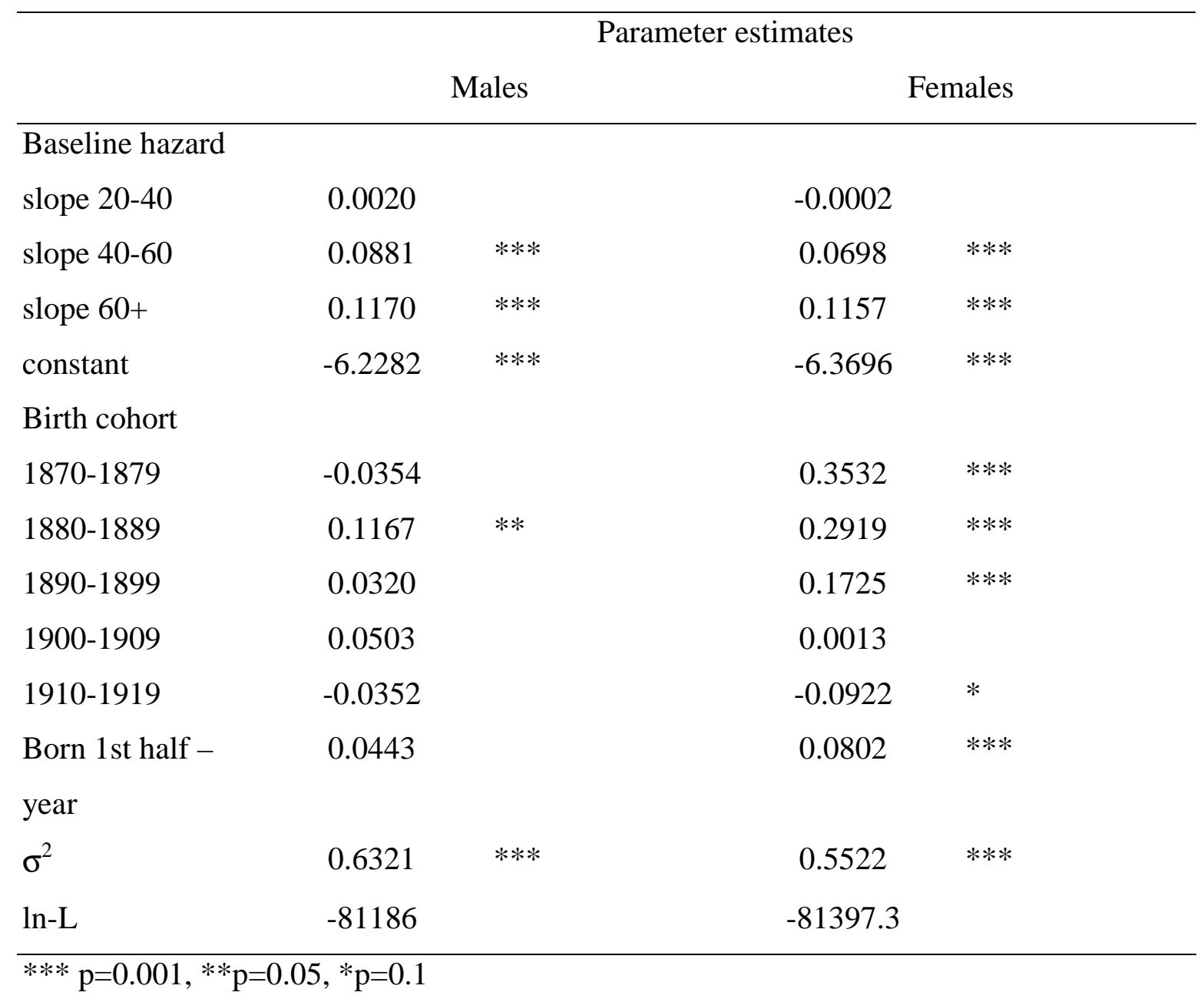


Table 5.3: Danish twin data: Parameter estimates of the hazard model with two baseline functions specified in Equ. 5.3.

\section{Males}

Parameter estimates

\section{Females}

Parameter estimates

Baseline hazard born in $1^{\text {st }}$ half-year

Constant $\alpha_{01}$

Slope $20-40$

Slope 40-60

Slope 60+

Baseline hazard born in $2^{\text {nd }}$ half-year

Constant $\alpha_{02}$

Slope 20-40

Slope 40-60

Slope 60+

Birth cohort

1870-1879

1880-1889

1890-1899

1900-1909

1910-1919

$\sigma^{2}$

$\ln -\mathrm{L}$

$* * * \mathrm{p}=0.001, * * \mathrm{p}=0.05, * \mathrm{p}=0.1$

$\begin{array}{llll}-6.1696 & * * * & -6.2545 & * * * \\ 0.0035 & & -0.0039 & \\ 0.0858 & * * * & 0.0734 & * * * \\ 0.1166 & * * * & 0.1135 & * * *\end{array}$

$-6.2447 \quad * * *$

$-6.4126 \quad * * *$

$0.0001 \quad 0.0041$

$0.091 \quad * * * \quad 0.0658 \quad * * *$

$0.1174 \quad * * * \quad 0.1179 \quad * * *$

$-0.0379 \quad 0.3545 \quad * * *$

$0.1164 \quad * * \quad 0.2924 \quad * * *$

$0.0317 \quad 0.1745 \quad * * *$

$\begin{array}{ll}0.0507 & 0.0027\end{array}$

$-0.0354 \quad-0.0902 *$

$0.6323 \quad * * * \quad 0.5524 \quad * * *$

$\begin{array}{ll}-81185.3 & -81395.9\end{array}$ 
Figure 5.3a: Danish twin data: (a) hazards for the $1^{\text {st }}$ and $2^{\text {nd }}$ half-year born of the hazard model specified in Equ. 5.4 and (b) ratios $1^{\text {st }} / 2^{\text {nd }}$ half-year born of the hazards .
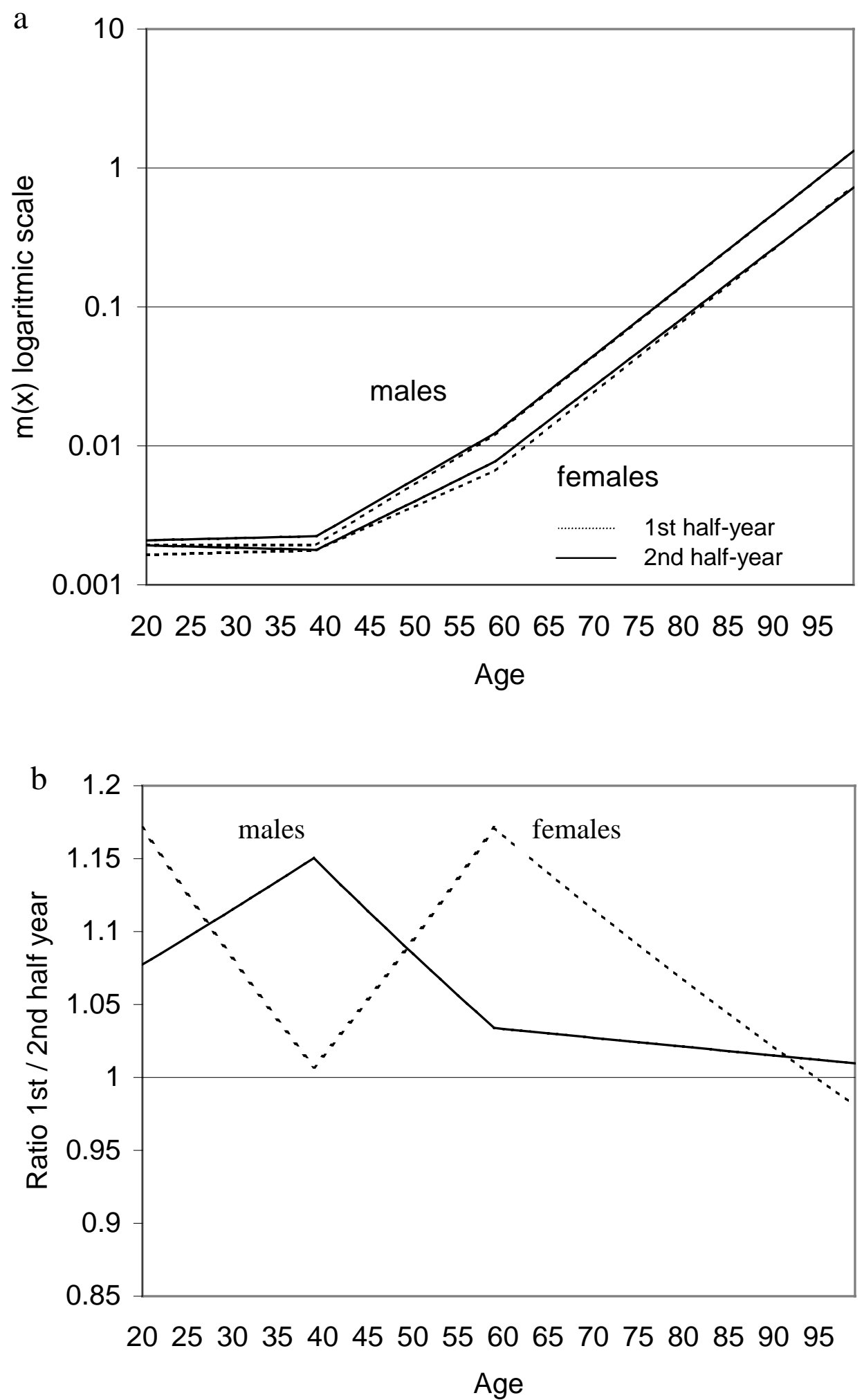


\section{US census data}

The eight trajectories in each square of Figure 5.4 depict the change in the distribution of people born in a specific month as they age. For example, the first trajectory shows the percentage of people aged 0-9 in 1960, 10-19 in 1970, and 20-29 in 1980; the second trajectory, the percentage of people aged 10-19 in 1960, 20-29 in 1970, and 30-39 in 1980. The differences in the starting values of the trajectories for a particular age group most probably are random effects due to census sampling.

Among whites the proportion of people who are born in the first and the fourth quarter continuously increases with age; the proportion of those born in the second and third quarter continuously decreases. Based on the Chi-square test statistic the changes in the proportion are significant starting from age group 30 to 39 , however, the mortality disadvantage of the spring-born seems to be particularly large from age $60 \mathrm{on}$. The decrease between ages 0 and 39 in the proportion of people born in the fourth quarter is highly significant $(\mathrm{p}=0.001)$.

An almost similar age pattern exists for blacks (results not shown): a continuous increase in the proportion of those born in the first quarter of the year; a decrease in the proportions of those born in the second and the third quarter. The pattern of those born in the fourth quarter is less consistent suggesting both an increase in the proportion during middle ages and a decrease at older ages. For blacks the changes in the distribution tend to be not significant, mainly due to the smaller numbers of observations, especially for the oldest age groups.

The US results from the comparison of the three census rounds are consistent with the results from the US death data. An increasing proportion with age of those born in the first and the fourth quarter is consistent with a higher mean age at death

The bars in Figure 5.4 show the relative risks of the 20-year survival probabilities conditional on age for people born in a specific quarter compared to the average population. At younger ages the mortality advantage of the fall-born and the disadvantage of the spring-born is minor. For males it is a maximum of one percent over an age range of 20 years. In other words, up to age 40 the conditional survival probability of surviving the next 20 years is about one percent higher for the fall-born than for the average population; it is one percent lower for the spring-born. Differences in the 20-year survival

start to accelerate from age group 40-49 on, when those born in the fourth quarter have a higher chance of $2.4 \%$ to survive the next 20 years; this advantage increases to $7.8 \%$ for ages 60-69. The disadvantage in the 20-year survival of the second-quarter born starts at ages 50- 
Figure 5.4: US census data: Changes in the proportion of people born in a specific month (lines) and relative risks of 20-year survival (bars) for US whites based on the census data for the years 1960, 1970, and 1980; (a) females, (b) males.
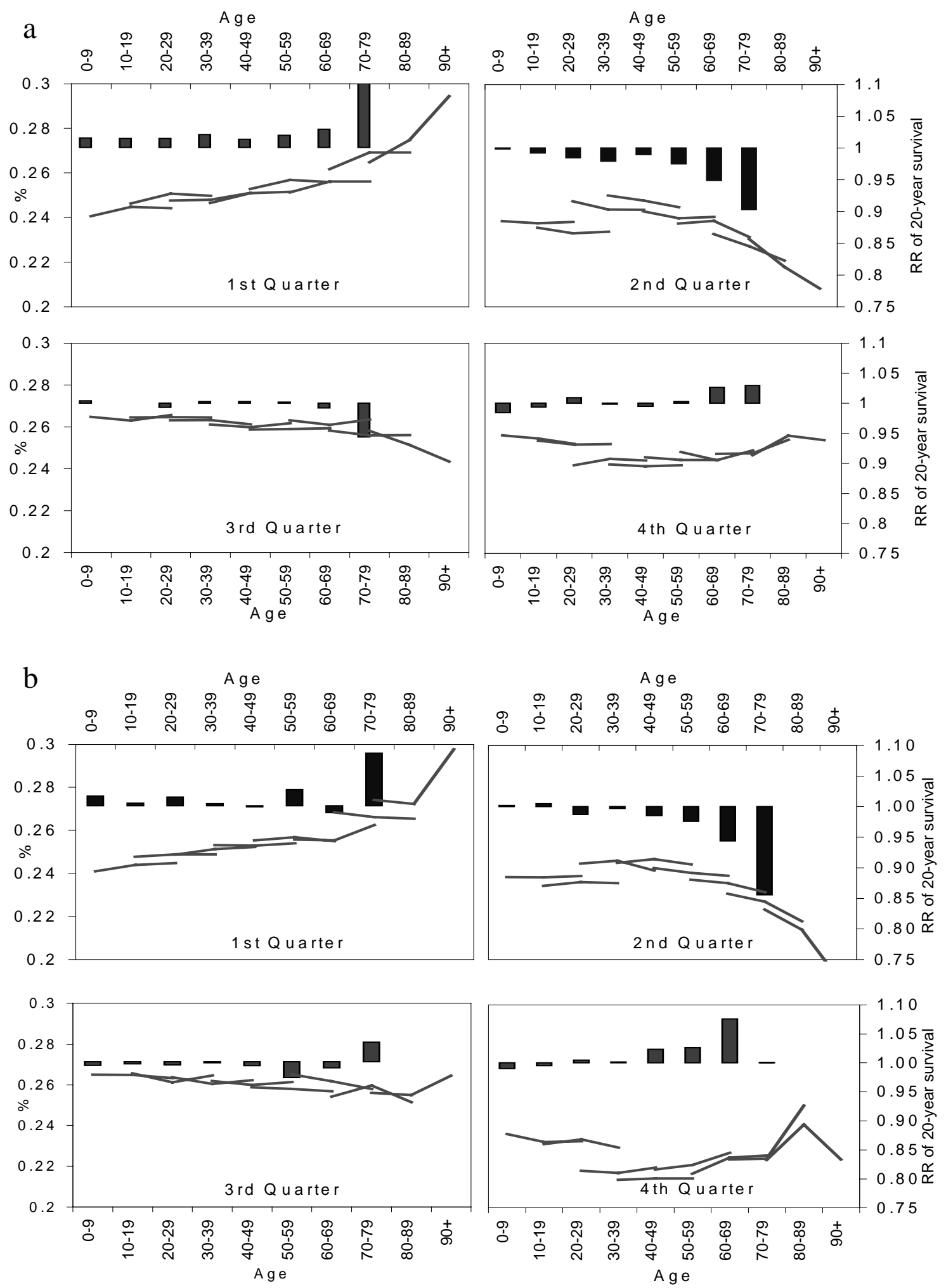
59 and is about minus 2.8 per cent. It increases to minus 5.6 per cent for the age group 60-69. Similar trends, however, more consistent emerge for women.

\section{Discussion and Conclusion}

All three populations lead to the same conclusion: the mortality advantage of the fallborn and the disadvantage of the spring-born exist in all age groups, but its magnitude is age dependent. Both among the Danish twins and the general Danish population the excess mortality of those born in the first half-year decreases in the highest age groups. In both populations this decrease is stronger among females than among males. The decreasing excess mortality at the highest ages is consistent with the effect of mortality selection. Among both the spring- and the fall-born only the strongest survive up to the highest ages and differences according to the month of birth start to fade out.

The magnitude of the excess mortality differs also at younger ages. The results from the twin data suggest that among men the excess mortality reaches its maximum around age 40 and slowly declines thereafter. The slow decline in the excess mortality above 40 is supported by the results from the general Danish population. Among female twins the peak in excess mortality appears to be around 60 followed by a fast decline. Again, the Danish general population supports this finding where the peak of excess mortality appears to be in the mid-60s, followed by a rapid decline.

Most interestingly, among female twins the excess mortality of the first-half year born disappears at middle ages (age 40). Pre-menopausal breast cancer may be one explanation. A Swedish study that compared the birth distribution of 115,670 women with breast cancer to the total number of live births in their birth cohorts found different month-of-birth patterns for women with pre-menopausal and post-menopausal breast cancer. Pre-menopausal breast cancer risk was increased for women born in autumn, postmenopausal breast cancer risk for those born in late spring (Yuen et al. 1994).

The comparison of the week of birth pattern in life expectancy among the general Danish population and the Danish twins shows high correlation, particularly among females. The male twin pattern, however, diverges to a larger extent from the pattern of the male general population although the fitted sinusoidal function is significant. Particularly, male twins born in the fourth quarter do not experience a mortality advantage similar to males in the Danish population.

An second example of two populations that do not experience identical season-ofbirth patterns are African Americans and whites in the United States (see Chapter 3). Similar 
to Danish twins African Americans born in fall do not experience a mortality advantage. One possible explanation for the disadvantage of the black fall-born as compared to the white population is the seasonal distribution of agricultural work-load in the cotton growing South of the US together with general year-all malnutrition. In other words, social factors most probably are responsible for the different patterns. This is not likely in the case of the Danish twins. However, male twins certainly belong to the most vulnerable groups in-utero and in the first year of life, even more vulnerable than female twins. In general male fetuses have higher spontaneous abortion rates than female fetuses, and they have higher mortality rates throughout infancy, childhood and adulthood. Their particular frailty may therefore make them more susceptible to seasonal factors that are not harmful otherwise.

On the basis of the Danish register data the difference in remaining life expectancy at age 50 between the fall- and the spring-born is 0.3 years; among the Danish twins it ranges from 0.58 years in the youngest cohort (1910-1930) to 0.88 years in the cohort 1890-1909. In other words, for both sexes together the difference is at least two to three times as high among twins than among the general population. For females the diffference is about four times as larger in the twins than in the register population. Larger differences among twins than among the general population are in accordance with the hypothesis that seasonal changes in nutrition and infectious disease affect the fetus in-utero and the infant the first year of life. Twins have to share scarce resources in-utero, they usually have lower birthweights than singletons and have a higher risk of mortality during their first years of life.

In Denmark the extent of the peak-to-trough difference in lifespan changes over cohorts: at similar ages they are larger in the older cohort (1898-1908) than in the younger cohort (1909-1918). This decrease was first described in Doblhammer \& Vaupel (2001). The age-specific analysis now provides further evidence that the extent of the season-of-birth pattern in life span decreases over time period 1898 - 1918, when considerable improvements in nutrition have taken place and public health measures have reduced the risk of infectious disease. The decrease over birth cohorts appears to be stronger among females than among males.

The age specific analysis on the basis of the three US censuses further supports the finding that the mortality advantage of those born in the second half of the year exists at all ages. Contrary to the Danish data, however, the mortality disadvantage of the spring-born starts to accelerate from age 40-50 onwards. The most probable explanation is that this increase reflects a cohort effect rather than an age effect since the US data do not permit to distinguish between age and cohort effects for ages more than twenty years apart. Particularly 
the oldest age groups were born at a time before dietary patterns started to change and to resemble contemporary dietary patterns (Levenstein 1988, 1993). They were also born before improvements in infrastructure and public health measures that significantly reduced infant mortality mainly caused by infectious disease (Preston \& Haines 1991).

In all three datasets, namely the Danish twins, the Danish register population and the US censuses, the extent of the age-specific month-of-birth patterns seems to be sex-specific. First, the decrease of the excess mortality at advanced ages is more pronounced among females than males; this appears also to be true for the decrease over cohorts. Second, the twenty-year survival risk in the US censuses appears to be more consistent among females than males. Third, among females the excess mortality of those born in the first-half year reaches its maximum at a later age (60s) than among males (40s). Finally, sex-specific causes of death may be responsible for the finding that at middle ages the mortality advantage of the fall-born disappears among female twins. This result is consistent with a study by Gavrilov et al. (2002) who report sex-specific differences in the month-of-birth pattern among the European nobility. In particular, they find a more consistent pattern among females with higher excess mortality than among males.

The month of birth pattern in adult mortality exists at all ages. Over the whole lifecourse those born in the first part of the year experience higher mortality than those born in the second part. The month of birth pattern in age-specific because of two reasons: first, different causes of death are important at different ages and the magnitude of the excess mortality depends on the cause of death. Second, mortality selection results in a more homogenous group at higher ages because both among the $1^{\text {st }}$ and $2^{\text {nd }}$ half-year-born only the most robust individuals survive and differences become therefore smaller.

All three datasets provide evidence that the month of birth pattern decreases in younger cohorts. This finding raises the question whether the differences still exist in individuals born today or whether the differences in life span by month of birth are merely of historical interest. An answer to this question will be provided in Chapter 7. 


\section{SIX}

\section{THE MONTH-OF-BIRTH PATTERNS OF MIGRANTS AND FARMERS}

The second chapter provides evidence that the month-of-birth pattern is tied to the seasons of the years by comparing differences in the life span of people born in the Northern and the Southern Hemisphere. This idea is taken one step further in the analysis of the month-of-birth pattern of migrants. Two groups of migrants are explored. The first group moved from the Northern to the Southern hemisphere - more precisely, people born in Britain who died in Australia. The second group consists of internal US migrants who moved between different regions of the US and, thus, died in a different region than they were born. The underlying idea is that migrants should be subject to the month-of-birth pattern of their birth region rather than of their residence region. This chapter provides evidence that this conjecture is indeed true. However, the month-of-birth pattern of the US migrants from the South to the North does not always lead to consistent results.

The second part of the chapter explores whether unobserved social differences exist in the month-of-birth pattern, and whether these unobserved social differences may explain the inconsistencies in the South to North migration patterns. The only socioeconomic information on US death certificates is education and usual occupation (for some states only). Education probably does not capture the main socioeconomic differences that affect early life circumstances in the South at the beginning of the $20^{\text {th }}$ century. At that time the South still was an agricultural society with the majority of the population born in rural areas. The educational system was much less developed than in the industrialized North with a large majority of the population having basic education only. On the other hand, the rural population was by far not a homogenous group since the social class relations in the South were structured along the ownership of land. In this social structure those who did not own land were particularly poor off.

The second socioeconomic information in the death certificates is usual occupation, which is generally difficult to relate to early life circumstances. There is one exception, namely, the two occupations farmer and farm worker. Farmers and farm workers generally are born in rural areas and Preston et al. (1998) showed that a rural place of birth and particularly a farming background increases positively old-age survival of African Americans. Thus, the 
conjecture is that the month-of-birth pattern of farmers and farm workers should differ from the remaining population since their early life circumstances in terms of nutrition and infectious disease environment were different. However, in the South farm workers who did not own land were particularly poor off and one may therefore expect that the fluctuations in the month-of-birth pattern of farm workers are larger than among farmers.

If differences in the month-of-birth patterns of the urban and rural-born populations exist and if there are differences in the pattern among the rural population associated with the ownership of land then this might explain the inconsistencies in the month-of-birth pattern of migrants from the South to the North of the US. Depending on whether the migrants of a particular region of the US primarily came from urban or rural areas, whether they were land owner or landless may significantly alter the month-of-birth pattern in mean age at death.

\section{Data and Method}

\section{Migrants}

The Australian death data provide information about the age at immigration and the country of origin. 43.074 British-born immigrants to Australia who died at ages 50+ with known age at immigration.

The United States consists of nine geographical regions according to the classification given in the death records. All decedents whose residence states differed from their birth states are treated as migrants (see Tables 6.1 and 6.2). Figure 6.1 shows the fifteen largest migration flows in terms of absolute numbers based on the migration matrix. The largest migration flow among US born decedents is from the North to the South: 438,061 decedents were born in Middle Atlantic and lived in South Atlantic at the time of their death; the second largest, from North to West: 330,396 migrants were born in West North Central and moved to the Pacific region; the third largest flow is from the South to the North: 283,129 decedents born in East South Central moved to East North Central. 
Table 6.1: Migration matrix for white and black decedents

\begin{tabular}{|c|c|c|c|c|c|c|c|c|c|c|}
\hline \multirow{2}{*}{$\begin{array}{l}\text { White } \\
\text { decedents } \\
\text { Region of } \\
\text { birth }\end{array}$} & \multicolumn{10}{|c|}{ Region of Residence } \\
\hline & $\mathrm{NE}$ & MA & ENC & WNC & SA & ESC & WSC & M & $\mathrm{P}$ & TOTAL \\
\hline $\mathrm{NE}$ & 667698 & 49434 & 16469 & 4345 & 101438 & 4602 & 9355 & 15619 & 48911 & 917871 \\
\hline MA & 81430 & 1942430 & 124060 & 16551 & 429699 & 17058 & 36256 & 62723 & 150729 & 2860936 \\
\hline ENC & 13796 & 47736 & 1981961 & 87133 & 242174 & 41024 & 66930 & 114219 & 233541 & 2828514 \\
\hline WNC & 5684 & 14938 & 118286 & 1035654 & 62914 & 15037 & 90713 & 150613 & 326102 & 1819941 \\
\hline SA & 8012 & 50195 & 75902 & 8193 & 1398012 & 52868 & 29238 & 18633 & 41299 & 1682352 \\
\hline ESC & 2387 & 8827 & 143998 & 15736 & 136889 & 793420 & 68853 & 17933 & 40192 & 1228235 \\
\hline WSC & 2247 & 6682 & 31140 & 46927 & 35410 & 28353 & 1082852 & 70190 & 179791 & 1483592 \\
\hline M & 1596 & 3603 & 9885 & 13357 & 9607 & 2240 & 17087 & 245472 & 141450 & 444297 \\
\hline $\mathrm{P}$ & 2058 & 4120 & 6908 & 6225 & 10382 & 2171 & 10036 & 34969 & 492391 & 569260 \\
\hline \multirow{2}{*}{$\begin{array}{l}\text { Black } \\
\text { decedents } \\
\text { Region of } \\
\text { birth }\end{array}$} & \multicolumn{10}{|c|}{ Region of Residence } \\
\hline & $\mathrm{NE}$ & MA & ENC & WNC & SA & ESC & WSC & $\mathrm{M}$ & $\mathrm{P}$ & TOTAL \\
\hline $\mathrm{NE}$ & 6422 & 1415 & 298 & 50 & 792 & 58 & 60 & 77 & 420 & 9592 \\
\hline MA & 1250 & 69531 & 3473 & 235 & 8362 & 351 & 477 & 516 & 2550 & 86745 \\
\hline ENC & 334 & 2869 & 54100 & 1524 & 2484 & 1185 & 879 & 811 & 4537 & 68723 \\
\hline WNC & 104 & 779 & 6054 & 17499 & 735 & 358 & 816 & 1043 & 4294 & 31682 \\
\hline SA & 11461 & 149515 & 49969 & 1461 & 491893 & 7057 & 2916 & 1586 & 10160 & 726018 \\
\hline ESC & 2264 & 20739 & 139131 & 16138 & 23708 & 196459 & 15665 & 2565 & 21036 & 437705 \\
\hline WSC & 587 & 4405 & 35735 & 14921 & 3963 & 4373 & 215952 & 7975 & 66374 & 354285 \\
\hline M & 15 & 131 & 230 & 124 & 137 & 52 & 185 & 776 & 917 & 2567 \\
\hline $\mathrm{P}$ & 26 & 227 & 210 & 58 & 175 & 47 & 158 & 157 & 5331 & 6389 \\
\hline
\end{tabular}




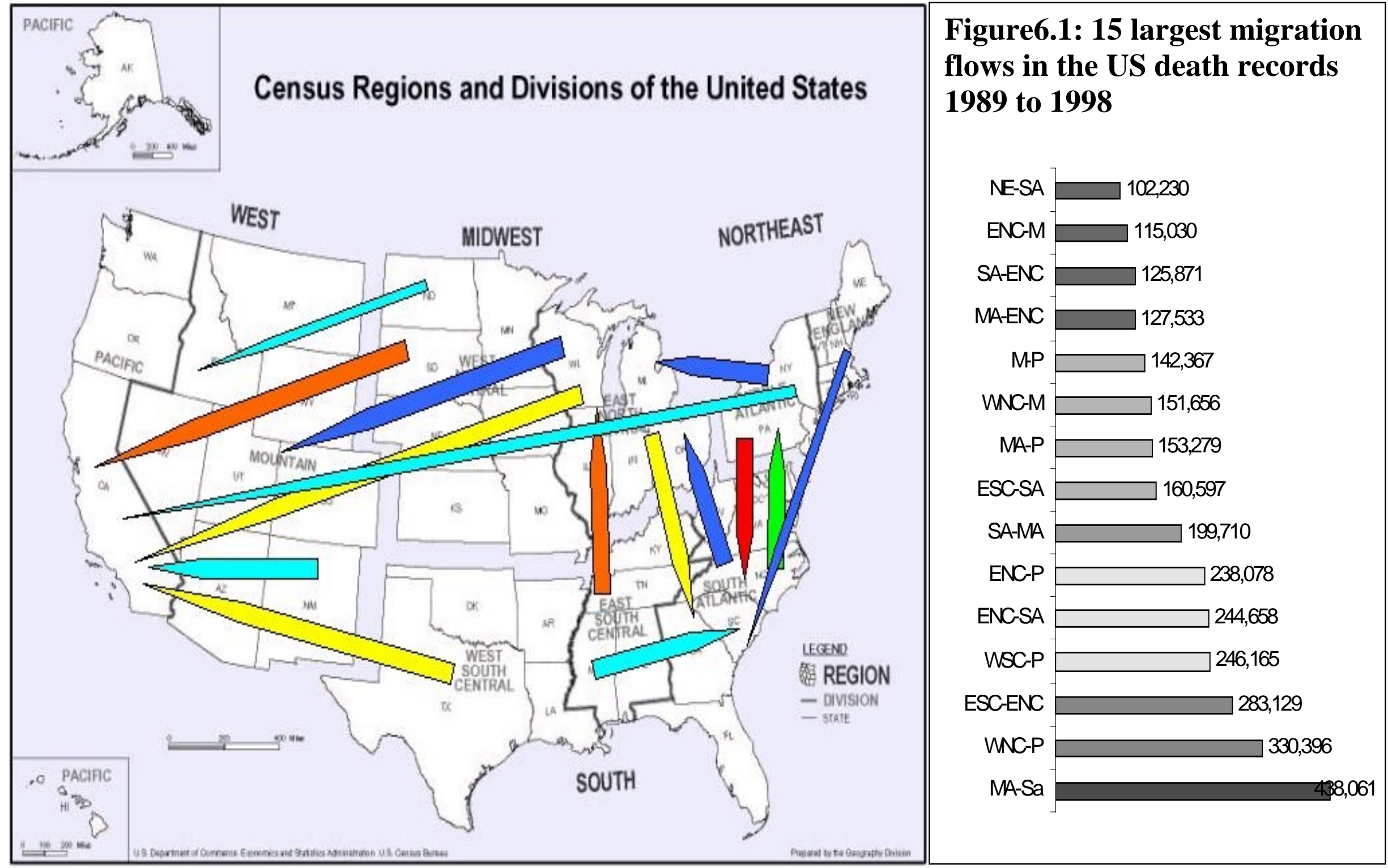


In order to test the hypothesis that the age at death of migrants follows the month-of birth pattern of their birth region rather than of their residence region, regions with substantially different month-of-birth patterns are needed. This is true for the South and the North of the US.

Equ. 6.1 is used to estimate the simultaneous effects of the characteristics of the decedents on their age at death

$$
x_{j}=\alpha_{0}+\beta^{\prime} Y_{j}+\gamma^{\prime}{ }_{j}+u_{j}
$$

Let $x_{j}$ be age at death, $Y_{j}$ the matrix of the indicator variables month of birth, sex, education, migrant and marital status, and $I_{j}$ the matrix of the two-way interactions between the variables; $\alpha_{0}, \beta$, and $\gamma$ are the parameter estimates. The error term $u_{j}$ follows a normal distribution with mean zero and variance $\sigma^{2}$. The variable migrant indicates whether a person died in the birth region or has moved to another region. Of particularly interest is the two-way interaction between the variables month-of-birth and migrant because the value of the Fstatistics indicates whether the month-of-pattern of the migrants differs significantly from their birth or residence region.

For each migration flow two models are estimated. The first model compares the nonmigrants of the birth region with those who migrated, e.g. decedents born in Middle Atlantic who remained in their birth state with those who moved to South Atlantic. The second model compares the migrants with the non-migrants of the residence region, e.g. the migrants from Middle Atlantic to South Atlantic with those who were born and who died in South Atlantic.

\section{Farmers, non-farmers and farm workers}

Only a subset of the US states reports the usual occupation in their death records - in the North these are the states Indiana, Kansas, Maine, New Hampshire, New Jersey, Ohio, Rhode Island, Vermont and Wisconsin. In the South, Georgia, Kentucky, North Carolina, Oklahoma, South Carolina and West Virginia provide the information and in the Mountain region, Colorado, Idaho, Nevada, New Mexico and Utah.

All people who died in their birth regions were extracted. In the North and the Mountain region the analysis is restricted to white males only because of the different monthof-birth pattern between blacks and whites. For the South the large number of black farmers 
permits estimation of a separate model for blacks. Females were excluded from the analysis because female farmers may be classified as housewives.

Occupations in the death records are classified according to the "Instruction Manual of the Alphabetical Index of Industries and Occupations, 1998". The 1990 census code for farmer is 473 , the code for form worker, 479. These two groups are compared to the residual group "non-farmers"; death records with unknown occupation are excluded.

In the North death records report farmer or farm worker as usual occupation for 53,143 white males. These are about 9 per cent of the death records that contain information about the usual occupation. In the South there are 54,328 white male farmers (12 per cent) and in the mountain region 10,516 (14 per cent). Among blacks in the South 15,052 (13 per cent) are farmers.

A Generalized Linear Model similar to Equation [6.1] is estimated. The model includes the indicator variables region, marital status, education, month of birth and farmer, and the two-way interactions between the variables month of birth and farmer, and education and farmer. The variable farmer distinguishes farmers from all others who are called nonfarmers.

A second model with a similar specification is estimated that distinguishes between farmers and farm workers. Since farmers and farm workers have similar educational levels education is not included in the latter model. Among whites 51,160 farmers and 1,983 farm workers are found in the North; 52,572 farmers and 1,576 farm workers, in the South and 9,555 farmers and 961 farm workers, in the Mountain region. Among blacks in the South there are 11,736 black farmers and 3,316 farm workers.

\section{Results}

\section{British Migration to Australia}

The comparison of the month-of-birth pattern of British immigrants with the pattern of people born in Australia reveals a striking difference (Figure 6.2 A). For those born between November and January the peak in mean age at death of British immigrants to Australia is 0.36 years higher than the trough of their Australian-born counterparts (one sided t-test, $\mathrm{p}<0.001)$. For those born between March and May the life span of British immigrants is 0.26 years lower than that of native Australians (one sided t-test: $\mathrm{p}<0.007$ ).

However, the month-of-birth pattern of the migrants is bimodal while the pattern for Austria, Denmark or the total US is unimodal (see Fig. 2.1). One explanation may be that the 
month-of-birth pattern for the total population in Britain is bimodal, another, that migrants are not representative of the total population. They may be socially selected and there is ample evidence that they are selected for better health status (Young 1987, Ringbäck et al. 1999,

Razum et al. 1998, Swerdlow 1991,

Figure 6.2: Deviation of mean age at death by month of birth from average age at death of British migrants and native-born Australians.

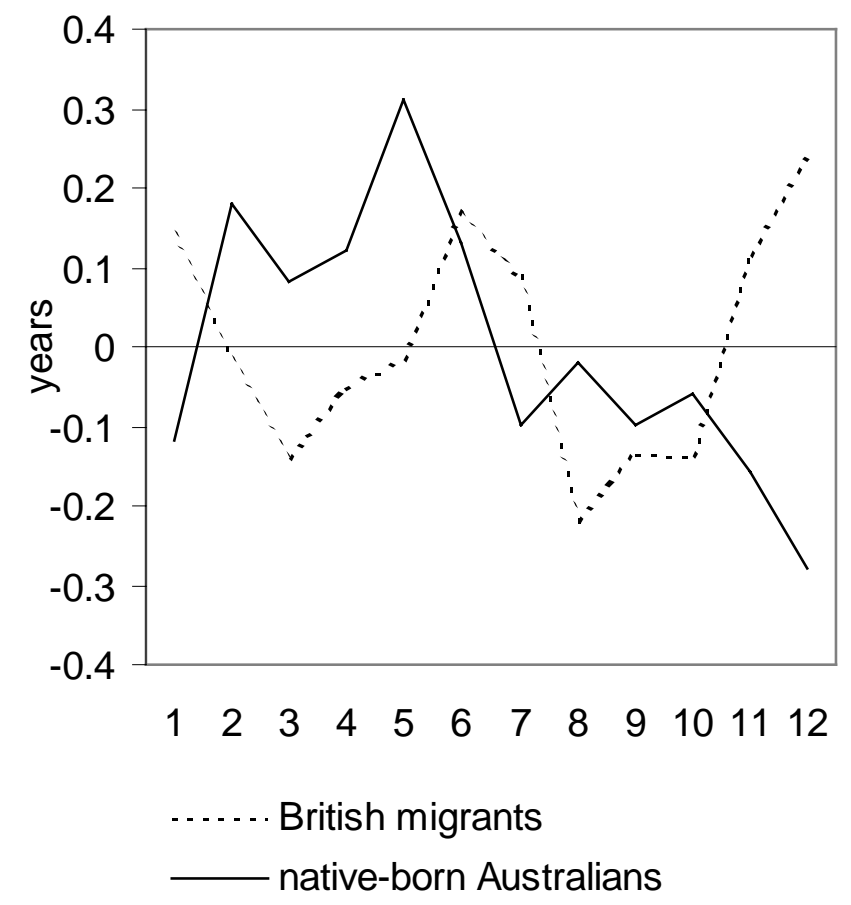

Kliewer 1992, Lechner \& Mielck 1998).

Australian death data contain the duration foreign born have lived in Australia before their death. In theory this information would permit to test whether the critical period early in life is in-utero or later. If the critical period is in-utero then the month-of-birth pattern of migrants that came during their first year of life should resemble the pattern of their birth countries overseas. Thus, the correlation with the month-of-birth pattern of native-born Australians should be negative. A positive correlation would be an indication that the critical period is in the first year of life. In practice, one cannot distinguish between the period inutero and the first year of life because age at immigration can only be calculated in full years. In other words, migrants who came during their first year of live may have spent a few weeks or almost a whole year in their birth country. A second problem is that only 358 British immigrants came during their first year of life. Among these migrants no significant month-of-birth pattern exists, with the exception of a particularly low mean age at death in June. The correlation between the month-of-birth pattern of the migrants who came during their first year of life and the native-born Australians is negative $(\rho=-.209, p=0.519)$ but not significant. The same is true for those who came during their second $(\rho=-.265$, $\mathrm{p}=0.405, \mathrm{n}=569)$ and third year of life $(\rho=-.024, \mathrm{p}=0.940, \mathrm{n}=778)$. If one combines those who came during the first two years of life a negative correlation of $\rho=-.344$ at $p=0.27$ exists. The 
month-of-birth patterns of the migrants who came after their third year of life and the nativeborns are unsystematic and statistically not significant.

Internal US Migration

White North-South migration

Part A of Figure 6.3 compares the month-of-birth pattern of the migrants from Middle Atlantic to South Atlantic with the pattern of the non-migrants of their birth region (Middle Atlantic), part B, with the pattern of the non-migrants of their residence region (South Atlantic). The month-of-birth pattern of the migrants does not differ significantly from the pattern of the non-migrants of the birth region; it differs significantly from the pattern of the non-migrants of the residence region. Results are similar for the two other North-South migration flows from New England to South Atlantic and from East North Central to South Atlantic.

\section{White South-North migration}

The results are more complex for the South-North migration flows (Fig. 6.4). The month-of-birth pattern of migrants from East South Central to East North Central differs significantly from the pattern of their birth regions and their residence regions. Among the migrants the difference between spring and fall-born is smaller than among the non-migrants of their southern birth region; it is larger, than among the non-migrants of their northern residence region. The correlation between the month-of-birth pattern of migrants and of nonmigrants of the birth region is larger $(\rho=0.811, p=0.001)$ than between migrants and nonmigrants of the residence region $(\rho=0.734, p=0.007)$.

The pattern of migrants from South Atlantic to East North Central does neither differ from their birth nor from their residence region, and the same is true for migrants from South Atlantic to Middle Atlantic. For both migration flows the correlation between the month-ofbirth patterns is contrary to the expectation. The pattern of the migrants from South Atlantic to East North Central is significantly correlated with the pattern of the non-migrants of the residence region $(\rho=0.748, p=0.005)$; it is not correlated with the pattern of the birth region $(\rho=0.413, p=0.183)$. There is no difference in the correlation of the migrants from South Atlantic to Middle Atlantic with their birth region $(\rho=0.678, p=0.015)$ and their residence region $(\rho=0.655, p=0.021)$. 
Figure 6.3: The month-of-birth pattern among white migrants from the North to the South: differences in mean age at death by month of birth from the average mean age at death at ages 50+. A) non-migrants birth region (dashed line), migrants (solid line), B) non-migrants residence region (dashed line), migrants (solid line).

Birth region

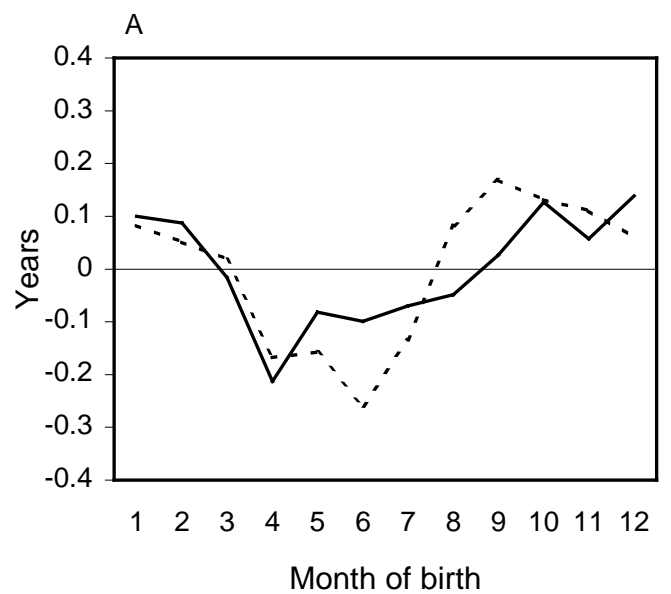

$p=0.186$
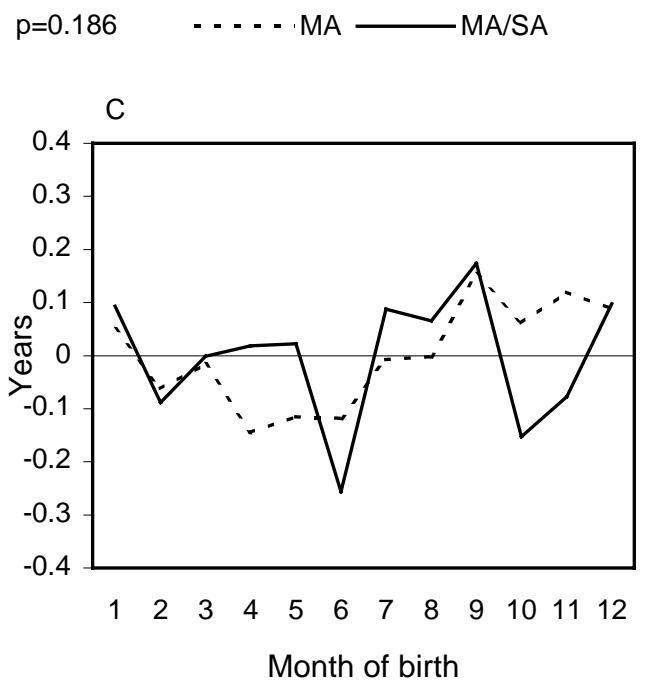

$p=0.19$
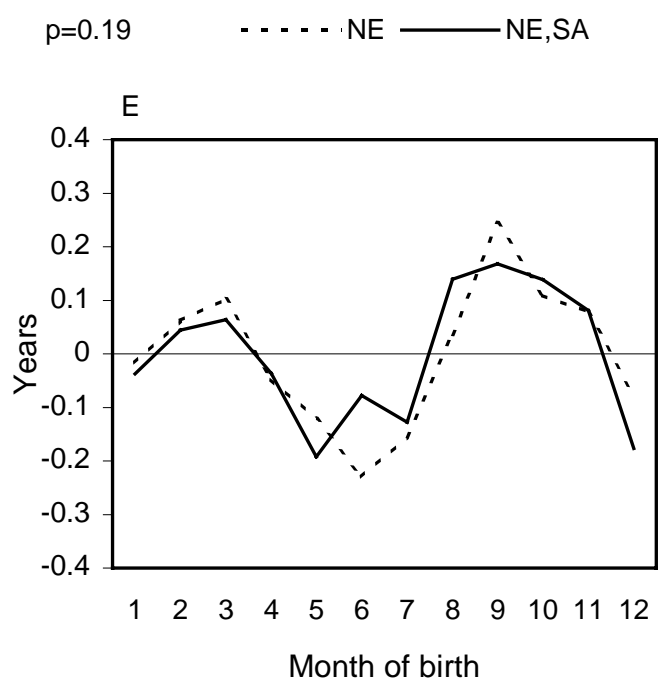

$\mathrm{p}=0.46$
Residence region
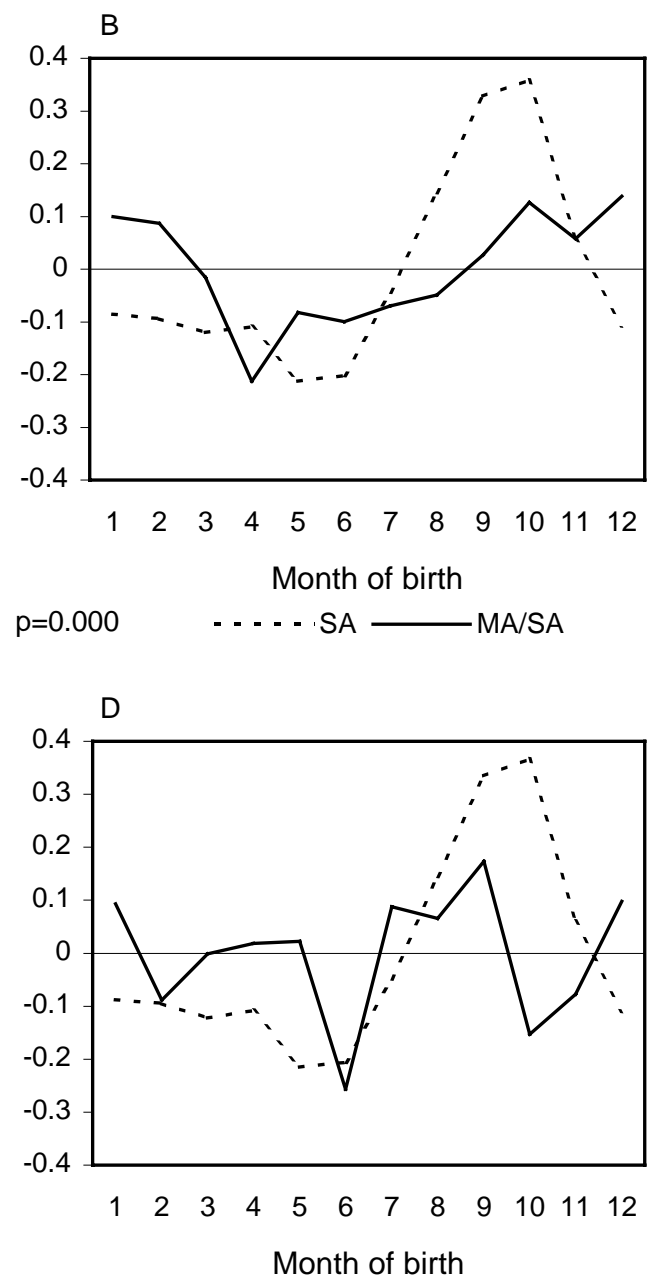

$\mathrm{p}=0.002 \quad \cdots \cdot \mathrm{SA} \longrightarrow \mathrm{NE}, \mathrm{SA}$

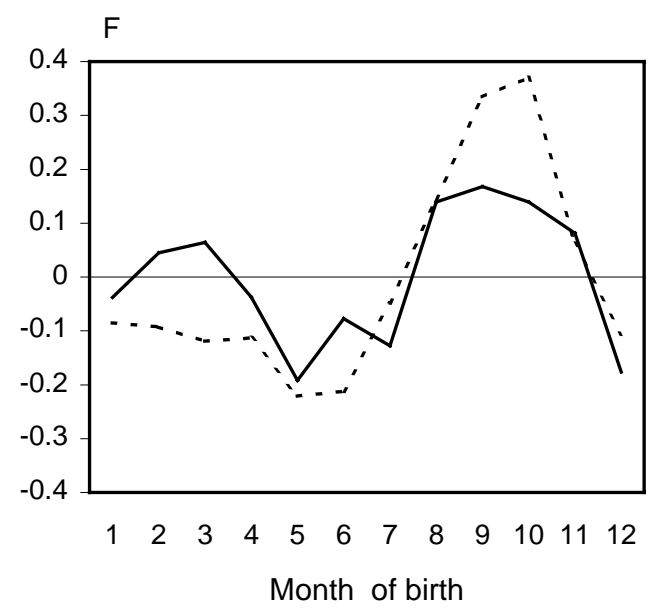

$p=0.002$

- ENC/SA 
Figure 6.4: The month-of-birth pattern among white migrants from the South to the North: differences in mean age at death by month of birth from the average mean age at death at ages 50+. A) non-migrants birth region (dashed line), migrants (solid line), B) nonmigrants residence region (dashed line), migrants (solid line).
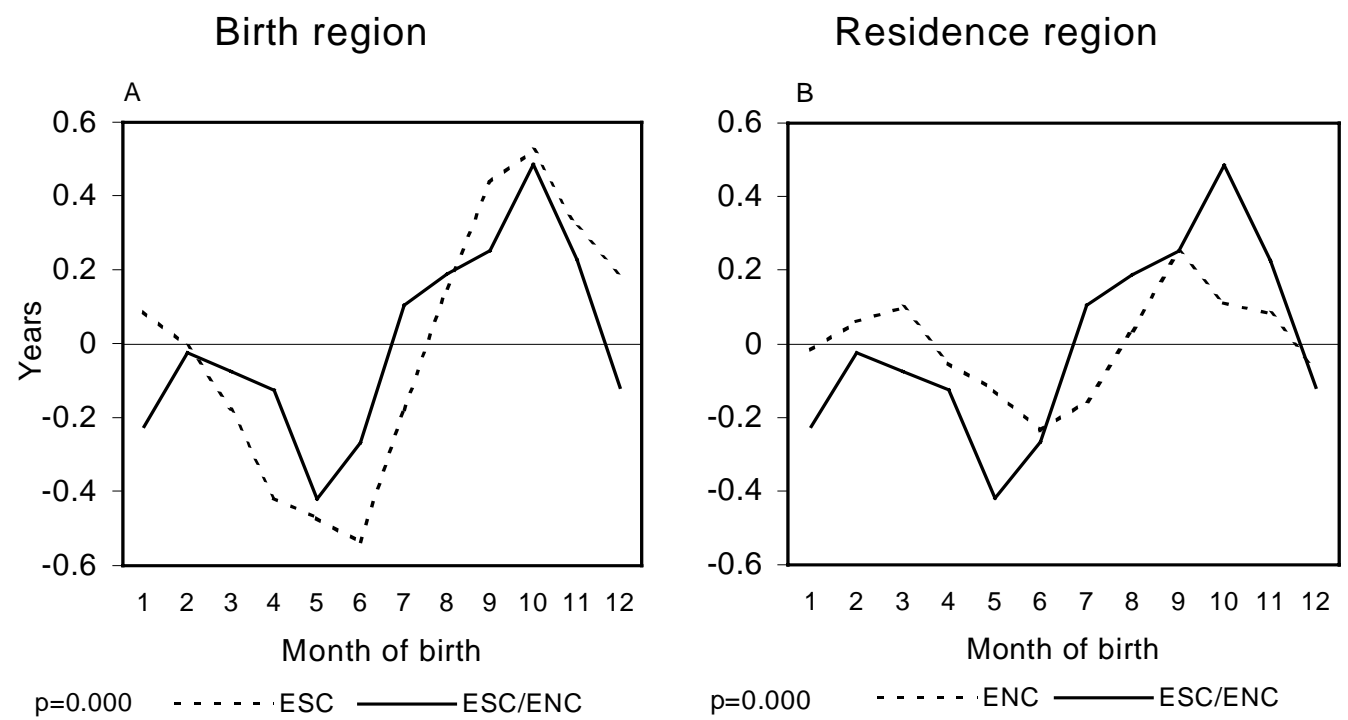

$\mathrm{p}=0.000 \quad \ldots$. ENC — ESC/ENC
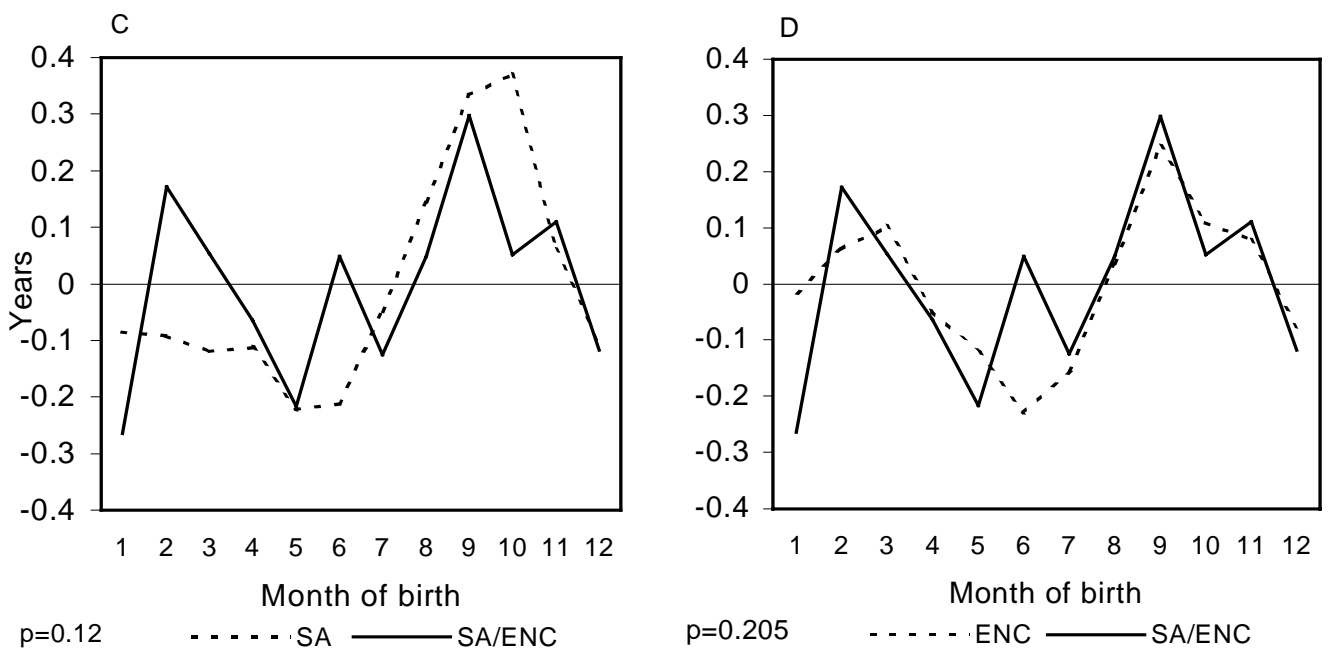

$p=0.205$

- ENC $\longrightarrow$ SA/ENC
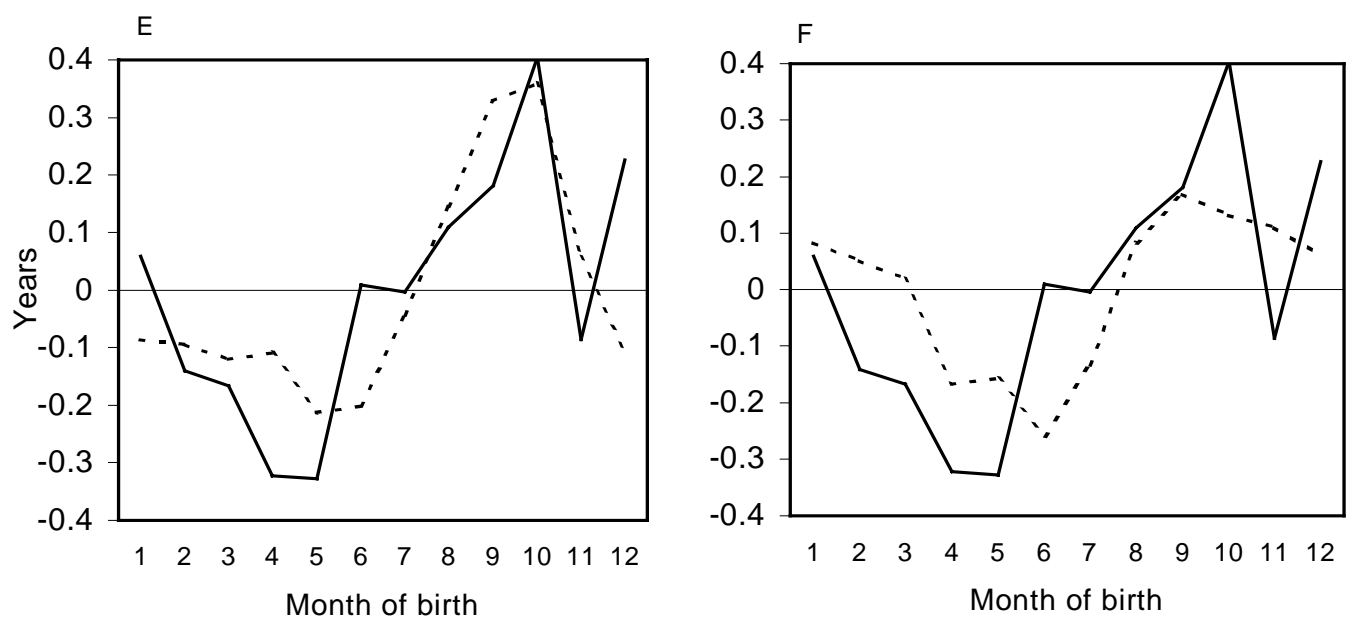

$p=0.747$

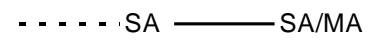

$\mathrm{p}=0.415$ SA/MA 


\section{Black South-North Migration}

A sizeable proportion of the South-North migration is due to African Americans who moved north. Combining the three southern regions into the South and the four northern regions into the North no significant differences between the month-of-birth patterns of the migrants, those who remained in the South and those who are born in the North are found. The non-significant result is mainly caused by the large standard errors of the mean age at death of those born in the North. The correlation coefficients between the three groups show that the pattern of the migrants is stronger correlated with that of the southern non-migrants ( $\rho=0.804, p=0.002)$ than with the pattern of those who were born in the North $(\rho=0.650$, $\mathrm{p}=0.022$ ).

Above evidence suggests that both the month-of-birth patterns of migrants from Britain to Australia and of migrants within the US depends on their region of birth rather than on their region of residence. However, results are not always consistent and in the reminder of the chapter the explanation is explored that unobserved social characteristics are responsible for these inconsistencies.

In the US North to South migration is retirement migration which has intensified over the years. This can be clearly seen in the proportion of migrants among the decedents of a given birth year (Fig. 6.5, solid line): $11 \%$ of those who were born in 1880 were North-South migrants as compared to almost $16 \%$ of those who were born in 1946 . On average these migrants are more likely to be married, have higher income and education and are healthier than the non-migrant population (Biggar 1980, Speare \& Mayer 1988). The above analysis accounts for the effects of family status and education and, thus, is able to compare the migrants with the average population of their birth region and their residence region. 
Figure 6.5: Proportion of migrants by year of birth and region of birth in the US death records 1989 to 1997 for whites (A) and South to North migrants for blacks (B).

A

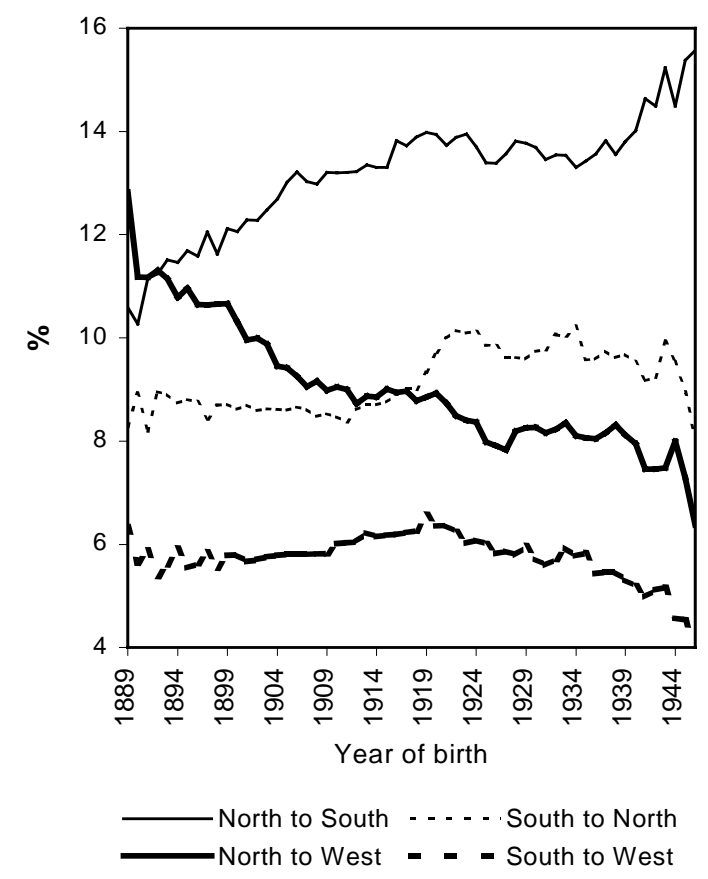

B

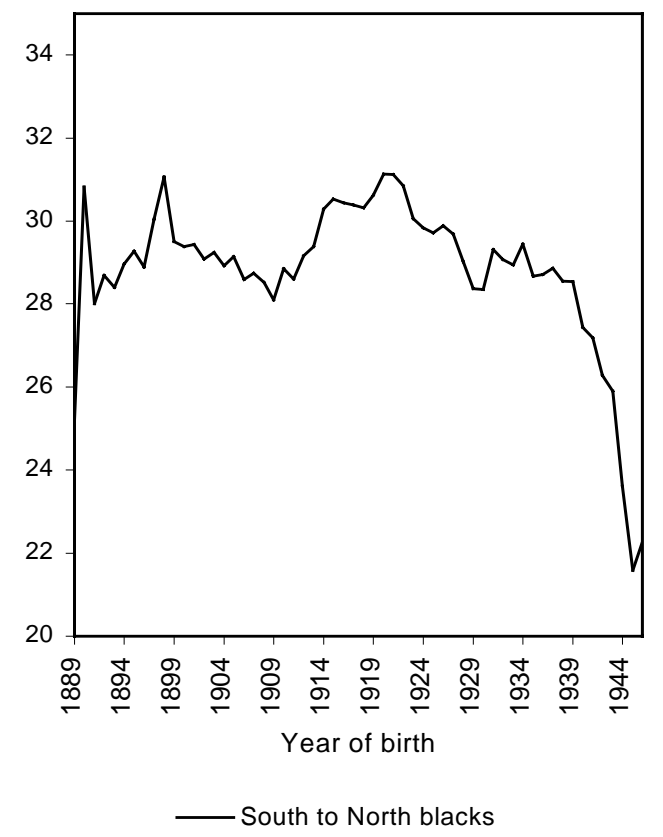

South to North migration is labor migration. The death data clearly depict the different migration waves. Figure 6.5 shows the proportion of migrants among the decedents by year of birth. When one adds the average migration age (20-25 years) to the year of birth then Figure 6.5 reflects the continuous South-North migration flow during the 1920s - a period of loss of agricultural jobs in the South - and during the Great Depression in the 1930s, which was a time of general impoverishment of the rural southern population. A migration upsurge occurred after World War II, the South-North migration peaked in the 1950's and a third wave occurred at the end of the 60's.

Those who left were mainly farm owners who had lost their land, share tenants and sharecroppers who were displaced by the boll weevil infestation of cotton in the earlier years. In the latter years the mechanization of the agriculture and the reduction of cotton acreage had created a large rural surplus population that had no other options than to migrate (Fligstein 1981). Although the large majority of the South to North migrants were born in rural areas they were by no means a homogenous group. On the contrary, large social differences existed among them. The social class relations in the South, particularly in the cotton growing part of 
the South, were structured along the ownership of land (Fligstein 1981). The class system of the South distinguished between plantation owners and merchants on the one hand, and farm laborers, tenants and small farm owners on the other hand. Farm laborers occupied the lowest rank in this class system. These people were wage laborers and worked under the direct supervision of a farm owner. Tenants were divided into sharecroppers, share tenants and cash tenants. They are distinguished by the amount of control imposed by the plantation owner or merchant. Sharecroppers were often almost in the position of the wage hand as the landlord told the sharecropper what to plant and when to plant. Share tenants were closer to being true renters thus the landlord did not have the right to supervise their daily activity. Cash tenants had the most independence.

For the analysis of the month-of-birth pattern it is important to recognize that farm laborers, sharecroppers and to some extent also share tenants often did not have the means for subsistence farming and only planted cash crops. This implies that for their food supply they fully depended on their landlord or the merchant, which resulted in a extremely deficient nutrition well into the 1930s known as the three M's: Meat, mealy (corn) and molasses (Levenstein 1993, 1998).

One may argue that the unobserved social differences in the rural South are the main reason for the inconsistencies in the South-North migration and this hypothesis is explored in the reminder of this chapter.

\section{The month-of-birth pattern of farmers, non-farmers and farm-workers}

Preston et al.(1998) showed rural place of birth, and in particular a farming background, positively influences old-age survival of African Americans. Since urban or rural place of birth is not provided on the US death certificates indirect information is used. An alternative information concerns the usual occupation of the decedent. The occupation farmer usually implies a rural place of birth and in addition, the death records provide a distinction between farmer and farm worker.

Two competing hypothesis may be formulated concerning the month-of-birth pattern in urban and rural environments. The first hypothesis is based on the fact that at the beginning of the $20^{\text {th }}$ century infant mortality in rural areas was lower than in urban areas (Preston and Hayens (1991). Infant mortality was mainly the result of infectious disease which spread more easily in urban areas due to crowded conditions in combination with the lack of sanitary infrastructure. Thus, if the month-of-birth pattern is primarily caused by infectious disease 
then the swings in the pattern should be smaller in rural areas. On the other hand, at that time nutrition was better in urban areas (see Chapter 3) because of better means of preservation and transportation and because of the desperate situation of the sharecroppers and share tenants, particularly in the South. If nutrition plays a major role, then the differences should be larger among the rural population. The Generalized Linear Model that was fitted to the mean ages at death of farmers and non-farmers did not find any significant differences (results not shown). There is a tendency, however, that both in the North and the South farmers tend to have larger differences in the month-of-birth pattern than non-farmers. No difference exists for blacks in the South.

The difference between farmer and farm worker may reflect the social stratification of the South better than education does. Since farm workers most probably stem from landless rural families their early-life environment must have been worse than that of farmers. The expectation therefore is that the peak-to-trough difference in the month-of-birth pattern of farm workers is larger than among farmers. In the North and the Mountain region the monthof-birth pattern does not differ significantly between the two occupational groups. In the South, however, a significant difference exists for white males at $\mathrm{p}=0.037$, while there is no significant difference for black males from the South (Fig. 6.6).

Figure 6.7: Age-adjusted differences in mean age at death of Southern farmer and farm worker by month of birth
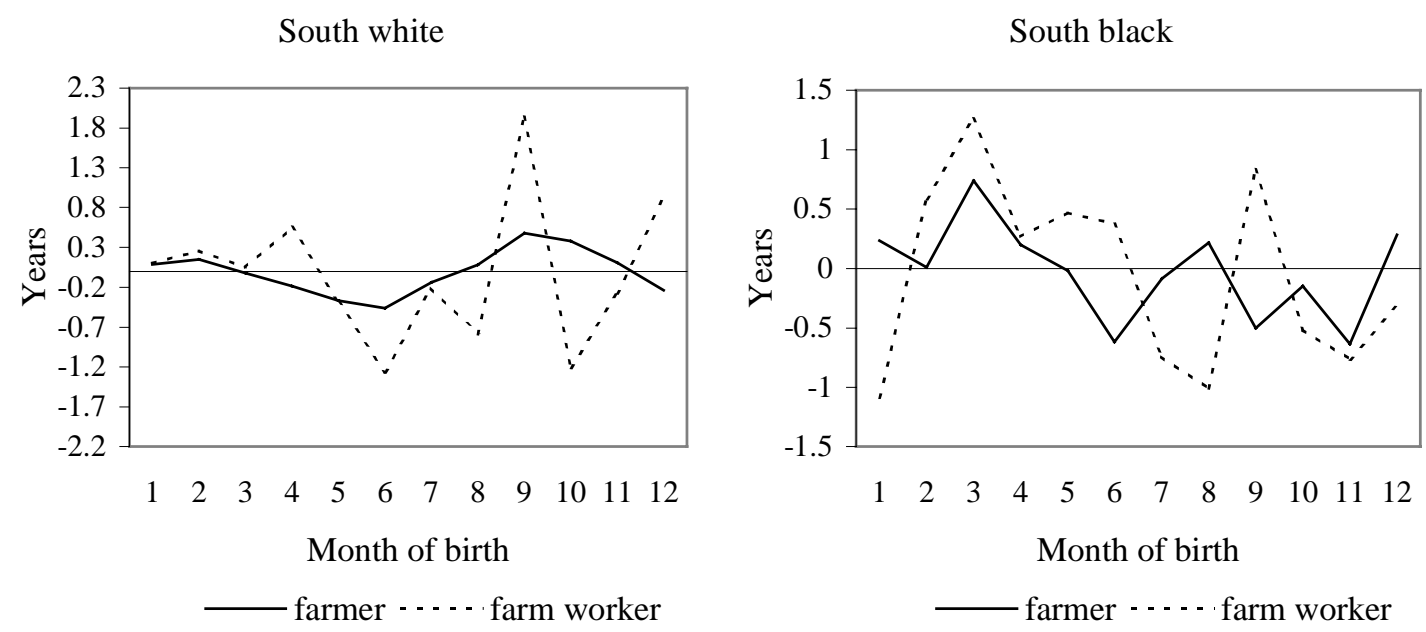


\section{Conclusion}

The age standardized mean ages at death show a tendency that the peak-to-trough difference among farmers it larger than among non-farmers. The multivariate analysis shows that this difference is not significant. In the North, the difference in the month-of-birth pattern between farmers and the rest of the decedents is mainly due to social differences reflected in education. As soon the model corrects for educational differences no further differences remain. In the South and the mountain region no significant differences in the month-of-birth pattern between farmers and non-farmers exist and education has no impact on this difference.

The most probable explanation for above finding is that a considerable proportion of the residual group "non-farmer" may have actually been born on farms or, more generally, in rural areas. Thus, existing differences cannot be identified based on the specification used in this study. This explanation might be particularly true for the South where the boll weevil infestation, the Great Depression and the transformation of Southern agriculture during the first part of the $20^{\text {th }}$ century forced many small farm owners and tenants off their land.

In the agricultural South significant differences in the month-of-birth pattern of white farmer and farm worker exist. This is according to the expectation because in the South white farm worker were particularly disadvantaged in terms of their social position since the large majority of whites used to own their farm.

No significant differences in the month-of-birth pattern between farmer and farm worker exist among blacks. This can be explained by the fact that the large majority of the black farmers were sharecroppers or share tenant with no freedom to decide what and when to plant. Like farm workers, they depended on their landlord for food and had no means for subsistence farming. In other words, among blacks there was not a lot of difference in the social status of farm worker and farmer.

Returning to the question of the inconsistent results of the white South - North migration flows it now appears that the explanation given above is correct. In the South the social composition is not properly reflected in educational attainment. The agricultural South was not stratified by education but by land ownership. The overall month-of-birth pattern of Southern migrants, thus, may largely depend on whether the migration flow was dominated by farmers (or sons and daughters of farmers) or by the landless that worked as farm workers.

However, there still exists another explanation. A large body of literature suggests that migrants are selected for better health. Since month of birth may not only affect mortality but also health the tendency to migrate may depend on the month of birth, which would confound the results. 


\section{SEVEN}

\section{Do THE DIFFERENCES IN LIFE SPAN BY MONTH OF BIRTH PERSIST AMONG COHORTS BORN TODAY AND ARE THEY RELATED TO BIRTHWEIGHT AND SYSTOLIC BLOOD PRESSURE?}

\section{Introduction}

The fetal-origins hypothesis (Barker 1995) suggests that low birthweight and fast catchup growth in the first months of life is associated with higher susceptibility to cardiovascular disease later in life. Central to this hypothesis is the reported inverse relationship between birtweight and systolic blood pressure later in life (for a review see Joseph \& Kramer 1996). However, a recent study has cast doubt on whether there is an association at all (Huxley et al. 2002).

The fetal-origins hypothesis uses birtweight as a surrogate measure of fetal nutrition, and malnutrition in-utero and/or exposure to infectious disease have been proposed as the causal mechanisms that link birthweight to later blood pressure (Barker 1989, Eriksson et al. 2000, Forsen et al. 2000, Eriksson et al. 2001). Other studies show that genetic factors, may contribute to the relationship between blood pressure and birthweight (Christensen et al. 2001).

The previous chapters provide evidence that life span after age 50 depends on the month of birth and that seasonal differences in nutrition and the incidence of infectious disease during pregnancy of the mother or in the first months of life are the most likely causal factors. Nutrition and the incidence of infectious disease vary seasonally. Thus, in the context of the fetal-origins hypothesis one would expect that seasonal fluctuations in nutrition and infectious disease incidence should reflect themselves in seasonal fluctuations in birth weight. Taking this idea one step further one would also expect to find a month-of-birth pattern in measures related to later-life health like current weight, current height and current systolic blood pressure. 
The fetal-origins hypothesis claims that nutrition and infectious disease during pregnancy of the mother is responsible for an increased susceptibility of the child to heart disease once it reaches adult ages. This claim, however, has been repeatedly challenged (Kuh and Davey-Smith 1993). Deprivation in-utero and during childhood may simply be the starting point of deprivation throughout life. The increased susceptibility later in life may, thus, be the result of the life-long accumulation of detrimental effects.

The season of birth does not have any life course interpretation. Differences in mortality and health-related measures later in life by season of birth thus indicate that the fetal environment and the first months of life influence the susceptibility to chronic disease later in life independently from other life course factors.

The first hypothesis is that seasonal fluctuations in nutrition and in the incidence of infectious disease reflect themselves in a seasonal pattern in birthweight and that this pattern is correlated with the season-of-birth pattern in systolic blood pressure, current weight and current height of the same twins in their young adult years. It is tested on the basis of the Minnesota twin family study. The second hypothesis is, that the month-ofbirth pattern in the twin's birthweight is positively correlated with the differences in mean age at death by month of birth for decedents aged 50+ who were born in Minnesota. If this is the case, then it could suggest that the differences in life span by month of birth also exist in contemporary cohorts.

Twins are exposed to harsher conditions in-utero than singletons because they have to share resources. It has been argued (Phillips 1993) that even small differences in the birth weight of twins could reflect important differences in intrauterine conditions because twins have already considerably lower birth weights than singletons. Since the interest is primarily in the effect of month of birth in contemporary populations, these seasonal effects may be more readily detected among twins than among singletons because they should be larger among twins.

Evidence concerning the relationship between month of birth and birth weight, length at birth, current adult and adolescent height and weight exist for different regions of the worlds and for different time periods (Table 7.1) and is briefly reviewed below. However, only few of these studies have information for all these measures and many are 
based on historical populations or populations from developing countries. No previous studies concerning the effect of month of birth on blood pressure seem to exist.

\section{Birthweight}

Plenty of evidence exists concerning seasonality in birthweight. The studies range from contemporary populations in tropical and sub-tropical regions among whom malnutrition is endemic over contemporary populations in Australia, Japan, Ontario and Denmark, to historic births between the end of the $19^{\text {th }}$ century and the middle of the twentieth century in Germany and Austria. Evenly important, studies on weight gain in developing countries demonstrate that the seasons of the year significantly influence both birth weight and weight velocity during infancy and childhood.

In tropical and sub-tropical regions hot and rainy summers are usually associated with low birth weight (Pollit and Arthur 1989, Roberts et al. 1982, Bantje and Niemeyer 1984, Kinabo 1993, Wendl-Richter 1997), and slow weight gain in infants and children (Brown et al. 1982, Chen et al. 1979) and weight loss in women (Chen et al. 1979, Cole 1993).

In Bangladesh (Brown et al. 1982) the percentage of expected monthly gain in infant weight or length varied three- or fourfold during different months of the year. The most acute growth faltering was observed during the hot and rainy period in August and September. On the other hand, both velocity of infant growth and the weight of women increase in cold dry winters, from about February to June.

A longitudinal study of infants born in rural Taiwan showed that birth weights were lowest during the hot and wet months of June, July and August (Adair and Pollit 1985, 1983). The authors did not find a statistically significant effect in weight gain during the first trimester by month of birth. However, the summer cohorts, despite their lower birth weights, tended to surpass the weight of infants born in other months for a greater part of the reminder of the first year. This is mainly due to the higher weight gains in fall and winter. By 12 months, there were no significant differences in weight between any of the four cohorts.

Similar results are obtained in a study of infants born in Shanghai (Xu et al. 2001). In particular, weight velocity was higher in fall and winter than in summer in all 
age groups. The study, however, fails to report whether differences in birth weight do exist.

Seasonality in birth weights has also been observed in contemporary populations of developed countries. A study of indigenous Australians demonstrates that significantly very low birth weight babies $(<1500 \mathrm{~g})$ were born during the wet season (Rousham \& Gracey 1998) than during the dry season, while there was no significant seasonal difference among births of 1500-2499g. The authors conclude "since very low birth weight babies have a strong likelihood of being pre-term the findings suggest that seasonality of birth weight may be due to the increase in pre-term births rather than an increase in rates of intra-uterine growth retardation."

A Japanese study of all births occurring between 1974 and 1983 found similar significant differences in mean birth weight and mean birth weight at 40 weeks of gestation (Matsuda et al. 1995). The pattern is bimodal with peaks in spring and fall and troughs in winter and summer. These results indicate that both pre-term births and the intrauterine growth rate contribute to the seasonality in birth weight.

A Danish study of gestational age, length, and weight at birth of all infants born between 1973 and 1994 found seasonal variation in mean length and weight at birth, however, fails to report the exact patter of the differences in birth weight (Wohlfahrt et al. 1998).

A comparison of seasonal variations in birth weights between rural Zaire and Ontario (Fallis \& Hilditch 1989) did not find a statistically significant seasonal variation in birthweight in Ontario. This is also true for 1750 men and women born in Hertforshire between 1920 and 1930, were the authors failed to find any significant seasonality in birth weight. However, the number of subjects included in the study might be too small to find significant results.

Seasonality in birthweight has been widely studied in Germany on the basis of historical data. In a study of 101444 births in Berlin and Leipzig (Otto \& Noack 1957) for the years 1936-1953 (Berlin) and 1937-1953 (Leipzig) the authors find that infants born in fall and early winter had higher birthweights that those born in the first half of the year. The difference is about $35 \mathrm{~g}$. In the same study they report differences in birth weight on the basis of data from Marburg, Wien and Odessa over the years 1920-1922. In 
this data-set the difference between the peak in mean birth weight in fall and the trough in February is more than $60 \mathrm{~g}$.

Based on 26.515 births in Hamburg in the time period 1912 to 1922 Hellmuth \& Wnorowski (1923) concluded that the fall-born have higher birthweights, however, differences are not significant. A study of weight at birth in Vienna between 1865-1930 (Ward 1987) shows a difference of $58 \mathrm{~g}$ between infants born in winter and spring (trough) and summer and fall (peak).

\section{Current weight}

Fewer studies have been performed on the relationship between current weight and month of birth. An early study was performed by Hillman and Conway (1972) among 9,103 patients who attended a public health nutrition clinic in the United States during the 5-year period 1966 to 1970. They found a significant deficit of the birth months October and November $(\mathrm{p}<=0.01)$ among the 5,627 overweight patients and a single peak in March. This pattern was most pronounced in patients aged 20 to 30 years. Although the overall patterns for under and normal weight patients did not vary significantly, they found a relative deficit of birth dates during June and July $(p<0.05)$. The authors suggest that the relationship between month of birth and overweight changes with age, "an impression consonant with the concept that the pathogenesis of later acquired (adult) obesity commonly differs from the type that is manifested in childhood". They found that under age 20 the spring- and early summer born seem to be less overweight, above age 20, those born in the second part of the year. They mention, however, that their results are only partly consistent with other studies about season of birth and body form.(Chenoworth and Canning 1941, Mills 1941, Fitt 1955). The study by Fitt (1955) is based on data from New Zealand. He reports mean height and weight of adult men in the New Zealand army by month of birth. Taking their weight for height ratio then one finds a bi-modal pattern. Those born between February and July and in October-November are slimmer than those born in August, September and January.

In a study of 2500 young women those born in September and October show the highest weights (Hillman et al 1970). A recent study about birth weight, climate at birth and the risk of obesity later in life (Phillips \& Young 2000) studied 1750 men and women born 
in Hertfordshire between 1920 and 1930. Average age at the time of the interview was 64.9 years. Among men the prevalence of obesity varied with month of birth and was greater among those born in January to June than those born in July to December. Among women there was no specific trend.

Several studies on the relationship between current weight and birth weight, which do not consider the month of birth, have been performed. A study of 14-year old Polish adolescents (Koziel and Jankowska 2002) shows that boys who were small for their gestational age at birth (SGA) had lower body mass index at age 14, while SGA girls had accumulated more centralized fat. In a study of 3447 women born in Helsinki who developed coronary heart disease (Forsen et al. 1999) the mean heights and weights at ages 7 to 15 of women who developed coronary heart disease were below those of all other women. However they had experienced catch-up growth in childhood since at birth the difference in height and weight was larger than at adolescence. A similar study for males (Forsen et al. 1997, Erikson et al. 1999) finds the highest death rates from coronary heart disease later in life among boys who were thin at birth and who had caught up in weight by the age of seven.

In conclusion, the studies on current weight and weight gain indicate that a relationship with the month of birth does exist. However, this relationship is complicated by the fact that it seems to differ with age and for the two sexes. The latter might be explained by differences in the tempo of growth during adolescence between boys and girls.

\section{Length at birth and height gain during the first year of life}

Many studies about seasonal differences in height by month of birth look at height gain during the first years of life or at lengths at birth. For example, Xu et al (2001) found that that in Shanghai birth month has some association with attained size but this is reduced during the first two years of life. Similar results rare obtained in a study of infants born in Gambia (Cole 1993). All the studies confirm the general knowledge reflected in the German saying that "Mairegen laesst die Kinder wachsen ("Rain in May lets children grow)" that height gain differs by the seasons of the year. This implies that 
at the same age infants and children grow with different velocity depending on their month of birth.

There is one contemporary study about differences in lengths at birth (Wohlfahrt et al. 1998). It is a population-based study of $1.166,206$ children born in Denmark between 1973 and 1994. Children born in April were $2.2 \mathrm{~mm}$ longer than those born in December. In their study of births in Leipzig and Berlin Otto and Noack (1957) do report both the seasonal distribution in birth weight and length at birth. They find that length at birth peaks in March, April and October and reaches a trough in May and June. In a second article Otto and Glaas (196x) use the same data from Leipzig and calculate mean gestational age, mean birth weight, and mean length at birth by month of birth. On the basis of these three measures it appears that corrected for their gestational age the fallborn infants are tall and heavy while the spring-born infants are tall and thin.

\section{Current height}

Already by 1941 Fitt had analysed the relationship between month of birth and current height among children and adolescents (Fitt 1941) and came to not always consistent results with other contemporary studies (Mills 1941, Chenoweth and Canning 1941). The latter found trends that were similar but not always identical to Fitt's analysis. Fitt attributes this to the different ages of the adolescents and that they were still growing at different rates. In his 1955 article he presents results for 21,342 height measures of adult men of a large sample of the men of the New Zealand army draft of World War II. Arranging the height measures by month of birth he finds a cyclical pattern. Those born in June are the shortest and the tallest are born between September and February. The peak-to-trough difference in height is 0.31 inch $=0.8 \mathrm{~cm}$. Turning to the Northern Hemisphere Weber et al. (1998) report a sinusoidal cycle for the heights of the entire male population aged 18 for ten 1-year birth cohorts. The Austrian Federal Army throughout the whole year in five conscription centers measured these cohorts. They find that the tallest are born in March and the shortest in September. The peak-to-trough difference is $0.6 \mathrm{~cm}$. These results are consistent with a study by Breitinger (1966) who found a similar pattern for those born in January to June and July to December. 
Table 7.1: Previous studies about season-of-birth patterns in birthweight, current weight, current height, and weight/height gain

\begin{tabular}{|c|c|c|c|c|c|c|c|c|}
\hline Topic & Authors & Country & $\begin{array}{l}\text { Time } \\
\text { period }\end{array}$ & $\begin{array}{l}\text { Size of } \\
\text { the } \\
\text { sample }\end{array}$ & Minimum & Maximum & $\begin{array}{l}\text { Peak-trough } \\
\text { difference }\end{array}$ & $\begin{array}{c}\text { Correction } \\
\text { for } \\
\text { gestational } \\
\text { age }\end{array}$ \\
\hline \multirow{7}{*}{$\begin{array}{l}\text { Birth } \\
\text { weight by } \\
\text { month of } \\
\text { birth }\end{array}$} & $\begin{array}{l}\text { Adair and Pollit } \\
\text { 1983, } 1985\end{array}$ & Taiwan & $\begin{array}{l}\text { 6-year } \\
\text { time } \\
\text { period }\end{array}$ & 450 & $\begin{array}{l}\text { June-August } \\
\text { (rainy season) }\end{array}$ & $\begin{array}{l}\text { November-April } \\
\text { (mild winter) }\end{array}$ & $152 g$ & no \\
\hline & $\begin{array}{l}\text { Bantje and } \\
\text { Niemeyer } 1984\end{array}$ & Tanzania & $1972-1981$ & 7134 & $\begin{array}{l}\text { February, March (rainy } \\
\text { season), June }\end{array}$ & $\begin{array}{l}\text { September- } \\
\text { November }\end{array}$ & $37 g$ & $\begin{array}{l}\text { yes, for } \\
\text { subset }\end{array}$ \\
\hline & $\begin{array}{l}\text { Fallis and Hilditch } \\
1989\end{array}$ & $\begin{array}{c}\text { rural Zaire }(Z) \\
\text { Ontario, Canada ( } \\
\text { C) }\end{array}$ & $\begin{array}{c}1 \text { January } \\
1972-31 \\
\text { December } \\
1981(Z), \\
1979- \\
1983 \text { (C) }\end{array}$ & $\begin{array}{l}8,815(Z) \\
15,954 \\
(\mathrm{C})\end{array}$ & $\begin{array}{l}\text { November }(Z) \text { (rainy } \\
\text { season); } \\
\text { no seasonality in ( C) }\end{array}$ & $\begin{array}{c}\text { June }(Z) \\
\text { (dry season); } \\
\text { no seasonality in } \\
\text { (C) }\end{array}$ & $196 \mathrm{~g}(\mathrm{Z})$ & \\
\hline & $\begin{array}{l}\text { Hellmuth and } \\
\text { Wnorowski } 1923\end{array}$ & $\begin{array}{l}\text { Hamburg, } \\
\text { Germany }\end{array}$ & $\begin{array}{l}1 \text { January } \\
1912-30 \\
\text { September } \\
1922\end{array}$ & 26,515 & $\begin{array}{l}\text { December - March } \\
\text { (winter) }\end{array}$ & June - October & & yes \\
\hline & Kinabo 1993 & $\begin{array}{l}\text { Morogoro, } \\
\text { Tanzania }\end{array}$ & $\begin{array}{c}1985- \\
1989\end{array}$ & 19,783 & $\begin{array}{l}\text { February, March (rainy } \\
\text { season) }\end{array}$ & $\begin{array}{c}\text { August } \\
\text { (dry season) }\end{array}$ & & no \\
\hline & $\begin{array}{l}\text { Matsuda et al. } \\
1995\end{array}$ & Japan & $\begin{array}{c}\text { January } \\
1974- \\
\text { December } \\
1983\end{array}$ & $7,622,012$ & summer and winter & $\begin{array}{l}\text { spring and } \\
\text { autumn }\end{array}$ & & yes \\
\hline & Moore 1998 & The Gambia & $\begin{array}{l}1949- \\
\text { cont. }\end{array}$ & 3,102 & $\begin{array}{l}\text { hungry season (July - } \\
\text { December) }\end{array}$ & $\begin{array}{l}\text { harvest season } \\
\text { (January - June) }\end{array}$ & $200-300 \mathrm{~g}$ & yes \\
\hline
\end{tabular}




\begin{tabular}{|c|c|c|c|c|c|c|c|c|}
\hline Topic & Authors & Country & $\begin{array}{l}\text { Time } \\
\text { period }\end{array}$ & $\begin{array}{l}\text { Size of the } \\
\text { sample }\end{array}$ & Minimum & Maximum & $\begin{array}{l}\text { Peak-trough } \\
\text { difference }\end{array}$ & $\begin{array}{l}\text { Correction } \\
\text { for } \\
\text { gestational } \\
\text { age }\end{array}$ \\
\hline & $\begin{array}{l}\text { Otto and Glass } \\
196 x\end{array}$ & Leipzig, Germany & $\begin{array}{c}1936- \\
1956\end{array}$ & 53,638 & Spring & autumn & $43 \mathrm{~g}$ & yes \\
\hline \multirow[t]{5}{*}{$\begin{array}{l}\text { Birth } \\
\text { weight } \\
\text { by month } \\
\text { of birth }\end{array}$} & $\begin{array}{l}\text { Otto and Noack } \\
1957\end{array}$ & $\begin{array}{l}\text { Berlin; Leipzig; } \\
\text { Marburg, Wien, } \\
\text { Odessa; Germany }\end{array}$ & $\begin{array}{c}1936- \\
1953, \\
1937- \\
1953, \\
1920- \\
1922\end{array}$ & $\begin{array}{c}48,497(\mathrm{~B}) \\
52,947(\mathrm{~L}) \\
39,000 \\
(\mathrm{M}, \mathrm{W}, \mathrm{O})\end{array}$ & $\begin{array}{l}\text { December - June } \\
\quad(B, L) ; \\
\text { November - June } \\
(M, W, O)\end{array}$ & $\begin{array}{c}\text { July - November } \\
(\mathrm{B}, \mathrm{L}) ; \\
\text { July - October } \\
(\mathrm{M}, \mathrm{W}, \mathrm{O})\end{array}$ & $\begin{array}{c}35 \mathrm{~g} \\
(\mathrm{~B}, \mathrm{~L}) \\
60 \mathrm{~g} \\
(\mathrm{M}, \mathrm{W}, \mathrm{O})\end{array}$ & \\
\hline & $\begin{array}{l}\text { Pollitt and Arthur } \\
1989\end{array}$ & Sui Lin, Taiwan & $?$ & 225 & $\begin{array}{l}\text { hot, rainy season, } \\
\text { summer } \\
\text { (May } 15-\text { Aug 14) }\end{array}$ & $\begin{array}{l}\text { dry season, } \\
\text { spring } \\
\text { (Feb. 15- } \\
\text { May 14) }\end{array}$ & $218.7 \mathrm{~g}$ & no \\
\hline & $\begin{array}{l}\text { Rousham and } \\
\text { Gracey } 1998\end{array}$ & $\begin{array}{l}\text { Kimberley region, } \\
\text { Western Australia }\end{array}$ & $\begin{array}{c}1981- \\
1993\end{array}$ & 4,508 & $\begin{array}{l}\text { January - March, } \\
\text { (wet season Jan - } \\
\text { June) }\end{array}$ & $\begin{array}{l}\text { July - October, } \\
\text { (dry season } \\
\text { July - Dec) }\end{array}$ & & \\
\hline & Ward 1987 & Vienna, Austria & $\begin{array}{c}1865- \\
1930\end{array}$ & 12,700 & winter and spring & $\begin{array}{l}\text { autumn } \\
\text { (September - } \\
\text { December) }\end{array}$ & $58 \mathrm{~g}$ & yes \\
\hline & $\begin{array}{l}\text { Wendl-Richter } \\
1997\end{array}$ & $\begin{array}{l}\text { North Western } \\
\text { Burkina Faso }\end{array}$ & $\begin{array}{c}1987- \\
1989\end{array}$ & 2,026 & $\begin{array}{c}\text { August } \\
\text { (hunger, field work) }\end{array}$ & $\begin{array}{c}\text { April, May } \\
\text { (dry season) }\end{array}$ & & no \\
\hline \multirow{2}{*}{$\begin{array}{l}\text { Length at } \\
\text { birth by } \\
\text { month of } \\
\text { birth }\end{array}$} & $\begin{array}{l}\text { Otto and Glass } \\
196 x\end{array}$ & Leipzig, Germany & $\begin{array}{c}1936- \\
1956\end{array}$ & 53,638 & Winter & $\begin{array}{l}\text { September, } \\
\text { October }\end{array}$ & $1,92 \mathrm{~mm}$ & yes \\
\hline & $\begin{array}{l}\text { Otto and Noack } \\
1957\end{array}$ & $\begin{array}{l}\text { Berlin and Leipzig, } \\
\text { Germany }\end{array}$ & $\begin{array}{c}1936 / 37- \\
1953\end{array}$ & $\begin{array}{c}101444 \\
(48,497+ \\
52,947)\end{array}$ & $\begin{array}{c}\text { December, January; } \\
\text { May-July }\end{array}$ & $\begin{array}{l}\text { March - April, } \\
\text { October }\end{array}$ & $1.5 \mathrm{~mm}$ & \\
\hline
\end{tabular}




\begin{tabular}{|c|c|c|c|c|c|c|c|c|}
\hline Topic & Authors & Country & $\begin{array}{l}\text { Time } \\
\text { period }\end{array}$ & $\begin{array}{l}\text { Size of the } \\
\text { sample }\end{array}$ & Minimum & Maximum & $\begin{array}{l}\text { Peak-trough } \\
\text { difference }\end{array}$ & $\begin{array}{c}\text { Correction } \\
\text { for } \\
\text { gestational } \\
\text { age }\end{array}$ \\
\hline & $\begin{array}{l}\text { Wohlfahrt et al. } \\
1998\end{array}$ & Denmark & $\begin{array}{c}1973- \\
1994\end{array}$ & $1,166,206$ & December & April & $2.2 \mathrm{~mm}$ & yes \\
\hline \multirow{2}{*}{$\begin{array}{l}\text { Weight gain } \\
\text { in infants by } \\
\text { current } \\
\text { month }\end{array}$} & Brown et al. 1982 & $\begin{array}{l}\text { (two rural villages } \\
\text { in) Bangladesh }\end{array}$ & $\begin{array}{l}\text { April } 1978 \\
\text { - June } \\
1979\end{array}$ & 174 & March - June & $\begin{array}{l}\text { August - } \\
\text { December }\end{array}$ & & \\
\hline & Xu et al. 2001 & Shanghai, China & $\begin{array}{c}1 \text { January } \\
1980-31 \\
\text { December } \\
1990\end{array}$ & 4,128 & $\begin{array}{l}\text { wet season, summer } \\
\text { (May - July) }\end{array}$ & $\begin{array}{c}\text { autumn and } \\
\text { winter (August - } \\
\text { January) }\end{array}$ & & \\
\hline \multirow[t]{2}{*}{$\begin{array}{l}\text { Height gain } \\
\text { in infants by } \\
\text { current } \\
\text { month }\end{array}$} & Cole 1993 & $\begin{array}{c}\text { West Kiang, The } \\
\text { Gambia; } \\
\text { Cambridge, } \\
\text { England }\end{array}$ & $\begin{array}{c}\text { May } 1974 \\
\text { - April } \\
1980(\mathrm{G}) \\
1984- \\
1988(\mathrm{E})\end{array}$ & $\begin{array}{l}686(\mathrm{G}) \\
191(\mathrm{E})\end{array}$ & $\begin{array}{c}\text { June - October (hungry } \\
\text { season) }(G)\end{array}$ & $\begin{array}{l}\text { August }(\mathrm{E}) \\
\quad(\mathrm{G} ?)\end{array}$ & & \\
\hline & Xu et al. 2001 & Shanghai, China & $\begin{array}{c}1 \text { January } \\
1980-31 \\
\text { December } \\
1990\end{array}$ & 4,128 & autumn and winter & $\begin{array}{l}\text { spring and } \\
\text { summer }\end{array}$ & & \\
\hline \multirow{2}{*}{$\begin{array}{l}\text { Weight loss } \\
\text { in women } \\
\text { by current } \\
\text { month }\end{array}$} & Cole 1993 & The Gambia & $\begin{array}{c}1978- \\
1988\end{array}$ & 529 & $\begin{array}{l}\text { hungry season } \\
\text { (June - October) }\end{array}$ & $\begin{array}{c}\text { harvest season } \\
\text { (November - } \\
\text { May) }\end{array}$ & $\begin{array}{l}4 \mathrm{~kg} \text { in } 1978 \\
2 \mathrm{~kg} \text { in } 1988\end{array}$ & \\
\hline & Chen et al. 1979 & Bangladesh & $\begin{array}{l}\text { March } \\
1976- \\
\text { Septembe } \\
\text { r } 1977\end{array}$ & 200 & May-July & $\begin{array}{l}\text { September- } \\
\text { October }\end{array}$ & $2 \mathrm{~kg}$ & \\
\hline
\end{tabular}




\begin{tabular}{|c|c|c|c|c|c|c|c|c|}
\hline Topic & Authors & Country & $\begin{array}{l}\text { Time } \\
\text { period }\end{array}$ & $\begin{array}{l}\text { Size of the } \\
\text { sample }\end{array}$ & Minimum & Maximum & $\begin{array}{l}\text { Peak-trough } \\
\text { difference }\end{array}$ & $\begin{array}{c}\text { Correction } \\
\text { for } \\
\text { gestationa } \\
\text { I age }\end{array}$ \\
\hline \multirow[t]{5}{*}{$\begin{array}{l}\text { Current } \\
\text { weight by } \\
\text { month of } \\
\text { birth }\end{array}$} & $\begin{array}{l}\text { Chenoweth and } \\
\text { Canning } 1941\end{array}$ & $\begin{array}{l}\text { Cincinnati, United } \\
\text { States }\end{array}$ & $\begin{array}{c}\text { birth } \\
\text { cohorts } \\
1904- \\
1921\end{array}$ & $\begin{array}{c}10,005 \\
\text { freshmen }\end{array}$ & $\begin{array}{c}\text { August - November } \\
\text { (September - December) }\end{array}$ & $\begin{array}{l}\text { March - June } \\
\text { (spring from } \\
\text { March - June) }\end{array}$ & $0.8 p p$ & \\
\hline & Fitt 1955 & New Zealand & $\begin{array}{l}\text { data from } \\
\text { army draft } \\
\text { for World } \\
\text { War II. }\end{array}$ & $\begin{array}{l}21,177 \\
\text { men }\end{array}$ & $\begin{array}{l}\text { May and June } \\
\text { (late autumn) }\end{array}$ & $\begin{array}{c}\text { December } \\
\text { (early summer) }\end{array}$ & 1.32 pounds & \\
\hline & $\begin{array}{l}\text { Hillman and } \\
\text { Conway } 1972\end{array}$ & United States & $\begin{array}{c}1966- \\
1970\end{array}$ & $\begin{array}{c}9,103 \\
(5,627 \\
\text { overweight } \\
2,597 \\
\text { underw., } \\
879 \\
\text { normal w.) }\end{array}$ & $\begin{array}{l}\text { deficit of normal und } \\
\text { underweight people, born } \\
\text { in June and July }\end{array}$ & $\begin{array}{c}\text { deficit of } \\
\text { overweight } \\
\text { people, born in } \\
\text { October, } \\
\text { November; and a } \\
\text { peak in march }\end{array}$ & & \\
\hline & Mills 1955 & $\begin{array}{l}\text { rural population } \\
\text { from Kentucky, } \\
\text { Kansas, Wis- } \\
\text { consin, North } \\
\text { Carolina; United } \\
\text { States }\end{array}$ & $\begin{array}{c}1912- \\
1939\end{array}$ & $\begin{array}{l}45000 \\
\text { freshmen } \\
\text { and - } \\
\text { women } \\
\text { (ages } 16 \text { - } \\
\text { 19) }\end{array}$ & October - December & April - June & $\begin{array}{l}\text { boys: } 0,71 \\
\text { pounds; } \\
\text { girls: } 0,41 \\
\text { pounds }\end{array}$ & \\
\hline & $\begin{array}{l}\text { Phillips and } \\
\text { Young } 2000\end{array}$ & Hertfordshire, UK & $\begin{array}{l}1920- \\
1930\end{array}$ & 1,750 & July - December & January - June & & \\
\hline
\end{tabular}




\begin{tabular}{|c|c|c|c|c|c|c|c|c|}
\hline Topic & Authors & Country & $\begin{array}{l}\text { Time } \\
\text { period }\end{array}$ & $\begin{array}{l}\text { Size of the } \\
\text { sample }\end{array}$ & Minimum & Maximum & $\begin{array}{c}\text { Peak- } \\
\text { trough } \\
\text { difference }\end{array}$ & $\begin{array}{c}\text { Correction } \\
\text { for } \\
\text { gestational } \\
\text { age }\end{array}$ \\
\hline \multirow{3}{*}{$\begin{array}{l}\text { Current } \\
\text { height by } \\
\text { month of } \\
\text { birth }\end{array}$} & $\begin{array}{l}\text { Chenoweth and } \\
\text { Canning } 1941\end{array}$ & $\begin{array}{c}\text { Cincinnati, United } \\
\text { States }\end{array}$ & $\begin{array}{l}1904- \\
1921\end{array}$ & $\begin{array}{c}10,005 \\
\text { freshmen }\end{array}$ & August - October & $\begin{array}{c}\text { spring } \\
\text { (March - June) }\end{array}$ & $0.3 \mathrm{pp}$ & \\
\hline & Mills 1955 & $\begin{array}{c}\text { rural population } \\
\text { from Kentucky, } \\
\text { Kansas, } \\
\text { Wisconsin, North } \\
\text { Carolina; United } \\
\text { States }\end{array}$ & $\begin{array}{l}1912- \\
1939\end{array}$ & 45,000 & October - December & April - June & $\begin{array}{l}\text { boys: } 0,16 \\
\text { inches; } \\
\text { girls: } 0,04 \\
\text { inches }\end{array}$ & \\
\hline & Weber et al. 1998 & Austria & $\begin{array}{c}1984- \\
1993 \\
\text { (birth } \\
\text { cohorts } \\
1966- \\
1975 \text { ) } \\
\end{array}$ & $\begin{array}{l}507,125 \\
\text { men }\end{array}$ & Autumn & spring & $0.6 \mathrm{~cm}$ & \\
\hline
\end{tabular}


The past studies about month of birth and height lead to three conclusions: First, at birth the spring-born seem to be the tallest infants. There is evidence, however, that they are tall and thin while the fall-born are tall and heavy. Second, due to the seasonality in the velocity of growth infants and children at the same age have very different weights according to their month of birth, which complicates the analysis. Third, at adult ages the spring-born are the tallest in the Northern Hemisphere while in the Southern Hemisphere the pattern is shifted by a quarter of a year.

\section{Data and Method}

This study is based on adolescent twin participants of the same sex from the Minnesota Twin Family Study. Two cohorts are assessed: the first consists of twins that were approximately 11 years old (age range 11 to 12 years), the second of twin aged approximately 17 years (age range 17 to 18 years). A description of the Minnesota Twin Family Study and how the measurements were obtained can be found in Christensen, Støvring and McGue (2001).

The sample used in this study consists of 1353 twin-pairs (660 male, 693 female). Twin-pairs with missing measurements and outliers are excluded. Outliers of height, current weight, current systolic blood pressure and birth weight are identified by standardizing the variables using their means and their standard deviations. The standardized z-scores are calculated separately for each sex and age group by expressing the distance between any case of a variable and its mean in terms of standard deviations. Those twins with standardized scores that exceed the value 2.5 or are below the value 2.5 are defined as outliers and the twin-pair is excluded from the calculations. Table 2 contains the number of twin pairs that are used in the different calculations.

US death records for the years 1989 to 1998 were used to calculate mean age at death by month of birth for people born in Minnesota.

The mean of each outcome measure is calculated by week of birth and applying periodic cubic splines based on the method developed by Reinisch (1967) derives smoothed patterns. Periodic spline refers to the property of the spline that the first three derivatives of week 1 and week 52 are continuos. The algorithm is implemented through the IML module of SAS. 
Table 7.2: Number of twin pairs used in the GLM models

Current Weight Current Height $\begin{gathered}\text { Current } \\ \text { Systolic BP }\end{gathered}$ Birth weight

Systolic BP

Ages 11-13

Males

Females

347

340

359

346

363

Ages 17-19

Males

268

350

348

347

Females

299

273

274

273

308

305

305

Both Ages

Males

615

632

620

636

Females

639

658

653

652

To test whether the seasonal pattern is significant a Generalized Linear Model of the form

$y=\alpha_{0}+\beta_{1} M O B+\beta_{2} m s m n t s n+\beta_{3} b t h y r+u$

is specified for each of the four outcome measures current height, current weight, birth weight and systolic blood pressure. $Y$ denotes one of the four outcome measures, MOB the month of birth, msmntsn the quarter of the year when the measurement was taken (not included in the birthweight equation), and bthyr the year of birth. The error term $u$ follows a normal distribution with mean zero and variance $\sigma^{2} ; \beta_{1}, \beta_{2}, \beta_{3}$ are the unknown parameter sets. Since twin data are correlated Generalized Estimating Equations (GEEs) based on Liang and Zeger (1986) are used to estimate the models. The GEE method is implemented through the "REPEATED" statement of the "GENMOD" procedure in SAS.

To test whether nutrition and infectious disease during pregnancy affect both birthweight and systolic blood pressure levels later in life a linear regression model on the basis of the smoothed weekly averages of the four outcome measures is estimated. The model 
explains the week-of-birth pattern in systolic blood pressure by the week-of-birth pattern in current weight, current height and birthweigth.

\section{Results}

Table 7.3: P-values of the GLM models for the effect of month of birth on birthweight, current weight, current height and systolic blood pressure

\section{P-values (type 3 test statistic of the GEE estimation procedure) \\ Current Weight Current Height Current Birth weight \\ Systolic BP}

Ages 11-13

Males

0.0657

Females

0.1349

$<.0001$

$\mathbf{0 . 0 3 2 0}$

0.464

0.0007

0.1726

0.911

Ages 17-19

Males

0.501

0.0342

0.5528

0.1282

Females

0.366

0.1135

0.1715

0.222

Both Ages

Males

Females

0.2603

.0365

Significant month-of-birth patterns exist for all four outcome-measures (Table 7.3), however, the significance depends on age and sex. Among males all four outcomemeasures are highly significant for both age groups combined, although the significance results primarily from the younger age group. Particularly for current weight and systolic blood pressure no significant month-of-birth pattern exists among the older male twins. Among females differences in height and systolic blood pressure are significant for both age groups combined. The significance results from both age groups.

In general the week-of-birth patterns of the four outcome-measures differ considerably, the patterns for current weight and systolic blood pressure differ even by 
Figure 7.1: Mean birthweight by week of birth.

Boys

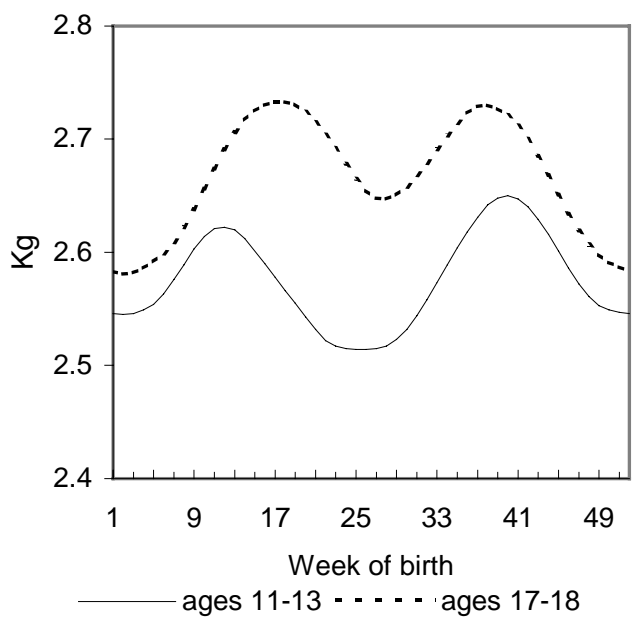

Girls

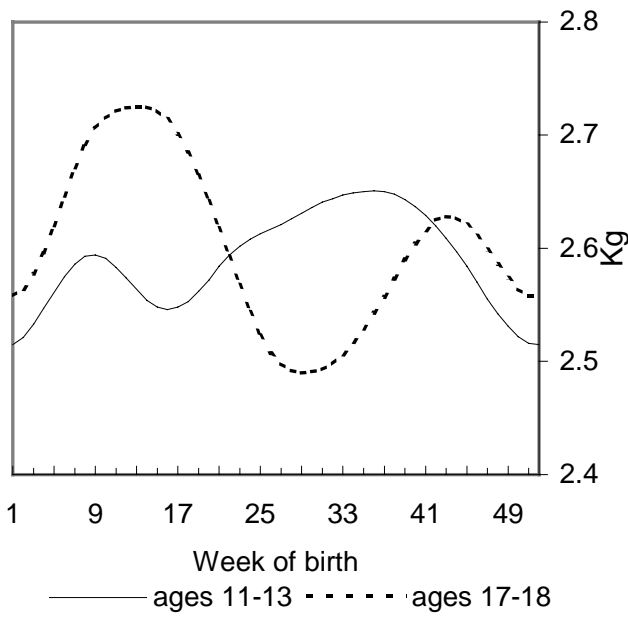

Figure 2: Mean current height by week of birth.

Boys

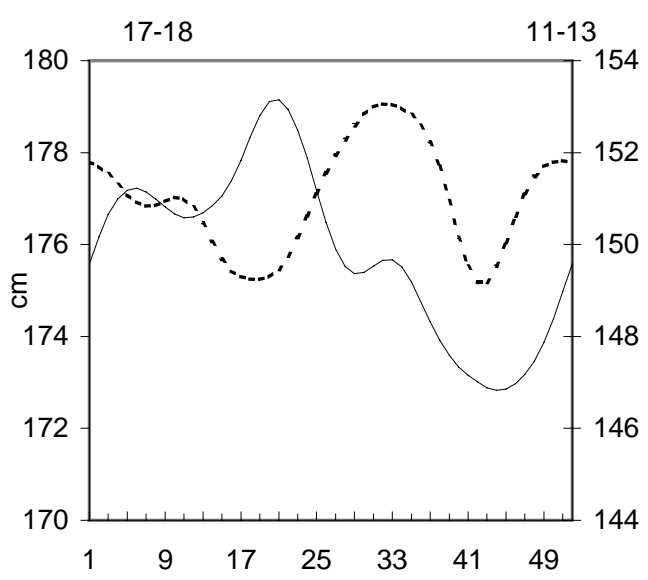

ages 17-18
Girls

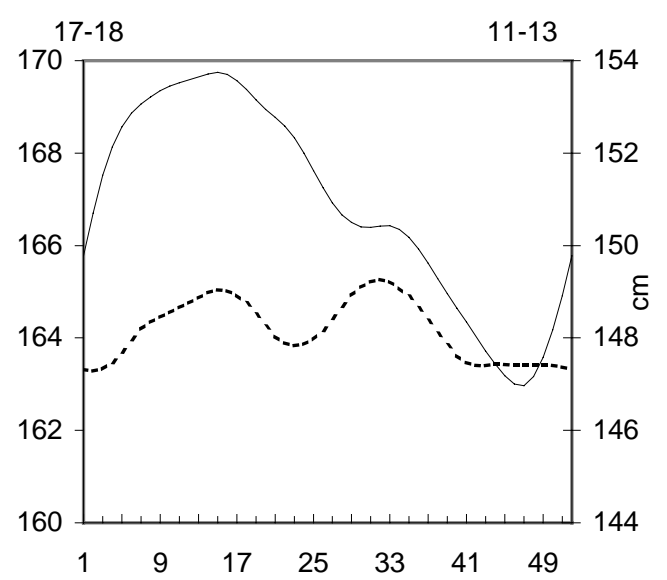

- . - ages 17-18 ages 11-13 
Figure 7.3: Mean current systolic blood pressure by week of birth.
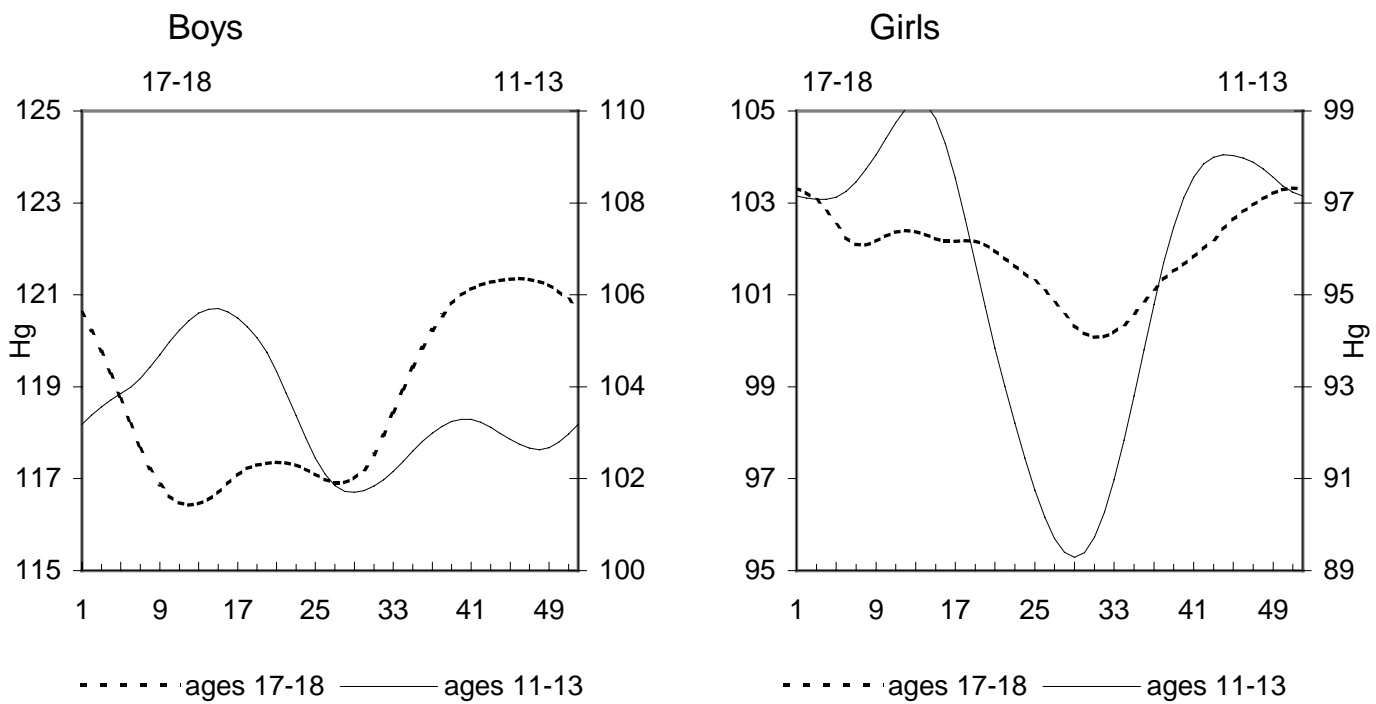

Figure 7.4: Mean current weight by week of birth.
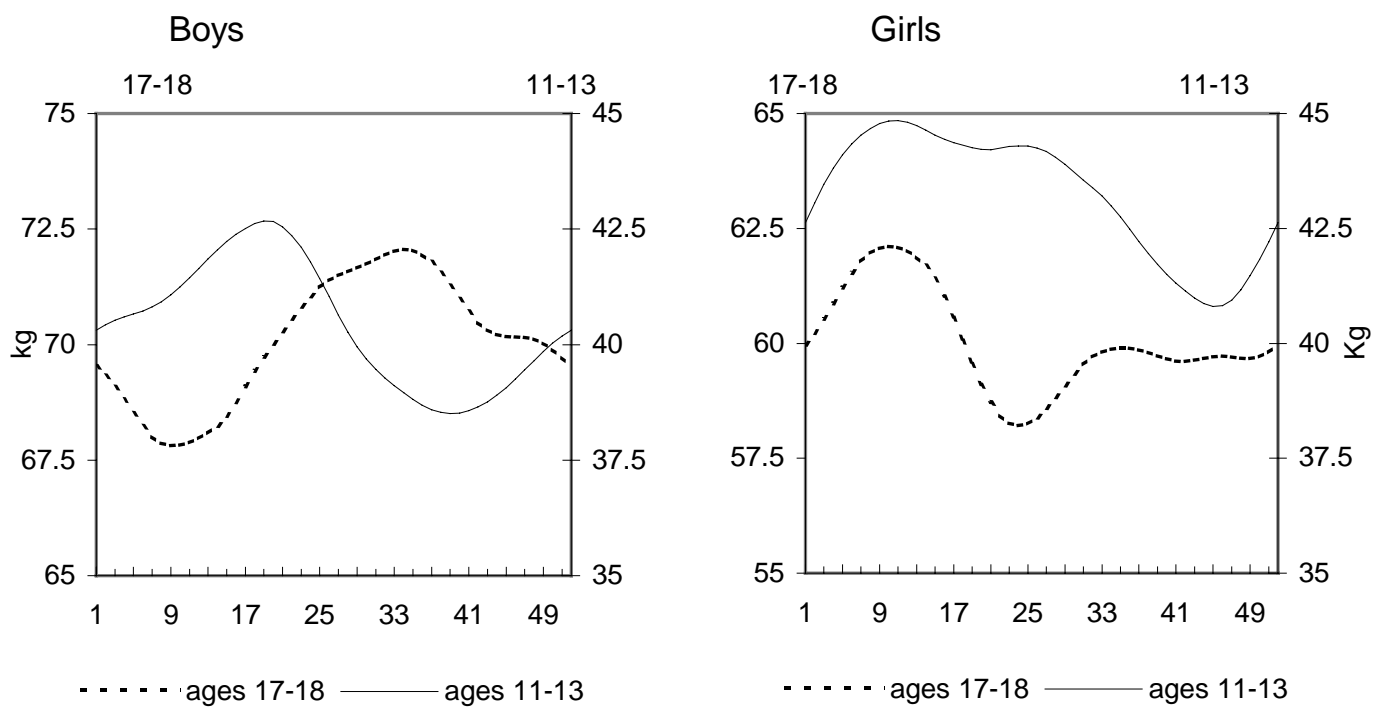
sex and age. One exception is birthweight where a clear bimodal pattern exists for both sexes. It peaks in late winter to early spring (weeks 12-18) and fall (weeks 38-43) and is lowest in summer (weeks 25-28) and winter (weeks 1-2). There is one exception among the younger female cohort: similar to the others, they reveal a winter trough (week 1) and a fall peak (week 36), however, the summer trough is shifted to week 16 in spring.

The week-of birth pattern in height is generally unimodal. At age 11-12 twins born in the first half of the year are taller $(6.3 \mathrm{~cm}$ males, $6.8 \mathrm{~cm}$ females $)$. Height peaks for twins born in weeks 20 (males) and 14 (females) and is lowest for twins born in week 43 (males) and 46 (females). Among the older twins the summer-born (week 31 males and females) seem to be the tallest.

Also current weight follows an unimodal pattern: Among the younger twins the spring-born achieve the highest weights (males: week 19, females: week 11), the fallborn the lowest (males: week 39, females: week 45). The pattern does not change when weight is corrected for height (not shown). The pattern reverses in the older male cohort where weight peaks for the late summer-born (week 34) and reaches a minimum for the winter-born (week 9). Among the older female twins the peak in weight remains unchanged (week 10) the trough, however, is shifted towards the late spring-born.

Among males the week-of-birth pattern in systolic blood pressure tends to reflect the pattern in current weight, without exactly mirroring it. However, one has to keep in mind that neither the pattern in systolic blood pressure nor in weight is statistically significant. For both female cohorts systolic blood pressure reaches a trough among the summer-born (younger cohort: week 29, older cohort: week 31) and peaks in fall/winter (younger cohort: weeks 44 and 13, older cohort: week 51).

The week-of-birth pattern in systolic blood pressure is a function of the week-ofbirth patterns in current weight, height and birthweight. The linear regression models on basis of the smoothed outcome-measures by week of birth show that among the younger male cohort 47 per cent of the variation in the systolic blood pressure is explained by the variation in current height and current weight. The introduction of birthweight increases the model explanation to 94 per cent (Table 7.4, Figure 7.5). Among females of the same age current height and weight explain 56 per cent of the variation in systolic blood pressure, the information about birthweight increases the model explanation to 75 per 
cent. Among the older male twins current weight and height do not explain the seasonal pattern in systolic blood pressure (adj. $\mathrm{R}^{2}=0.03$ ), the model fit improves to $\mathrm{R}^{2}=0.29$ with the introduction of birth weight. Among the older female twins the systolic-bloodpressure pattern is largely a function of the patterns in current weight and height $\left(\mathrm{R}^{2}=0.724\right)$ and birthweight only adds a minor improvement to the fit of the model $\left(\mathrm{R}^{2}=0.796\right)$.

In conclusion, among twins aged 11-12 the week-of-birth pattern in birthweight is an important predictor of the week-of-birth pattern in systolic blood pressure. The influence of birthweight is stronger among males than females. With age the seasonal pattern in birthweight looses importance. It explains a negligible component of the week-of-birth pattern in systolic blood pressure among females. Figure 7.6 shows the differences in mean age at death and in birthweight by month of birth. Mean age at death is based on US death records for decedents aged 50+ who were born in Minnesota. The correlation coefficients between the life span pattern and the birthweight pattern are of borderline significance for males ( $\rho$ age 11-12 $=0.53, \mathrm{p}=0.074, \rho$ age $17-18=\rho 0.52, \mathrm{p}=0.08$ ) but not for females ( $\rho$ age 11-12 =-0.06, $\mathrm{p}=0.86, \rho$ age 17-18: $0.19, \rho=0.56$ ). 
Figure 7.5: Smoothed and predicted weekly systolic blood pressure values

\section{Males}
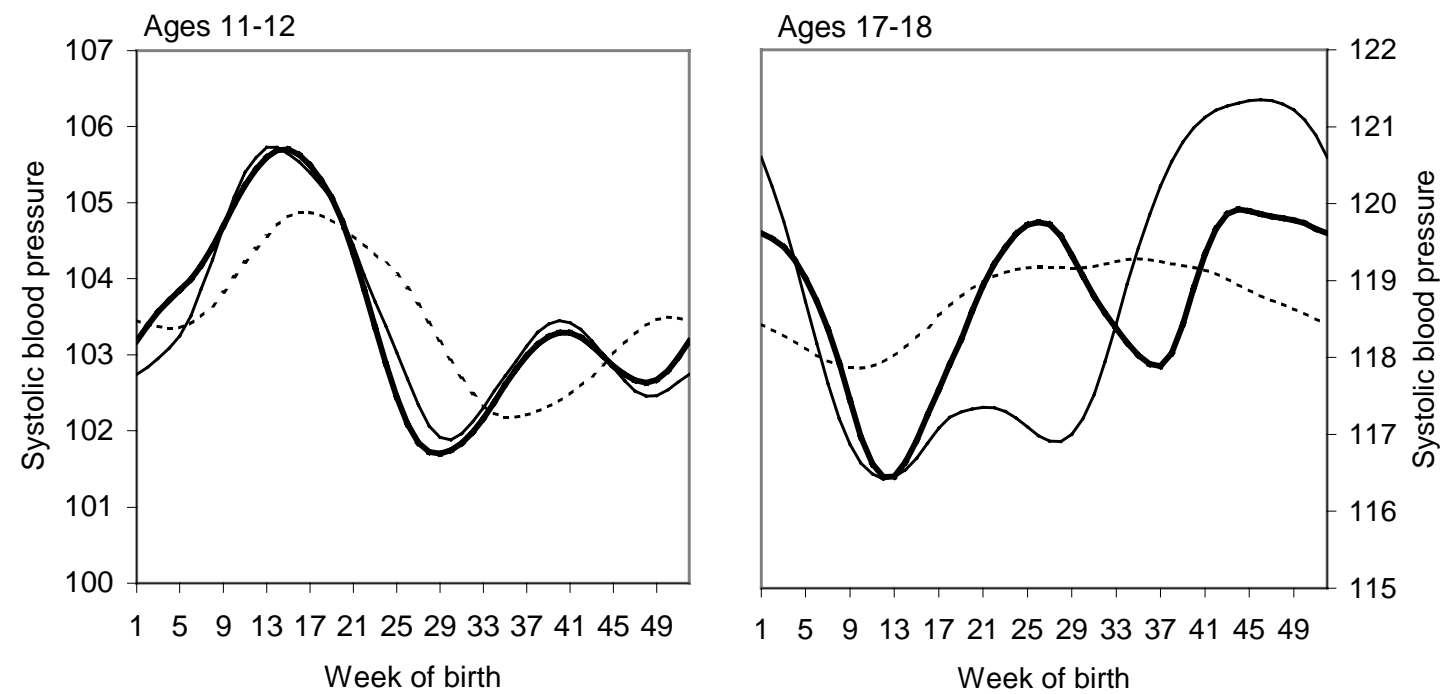

Females
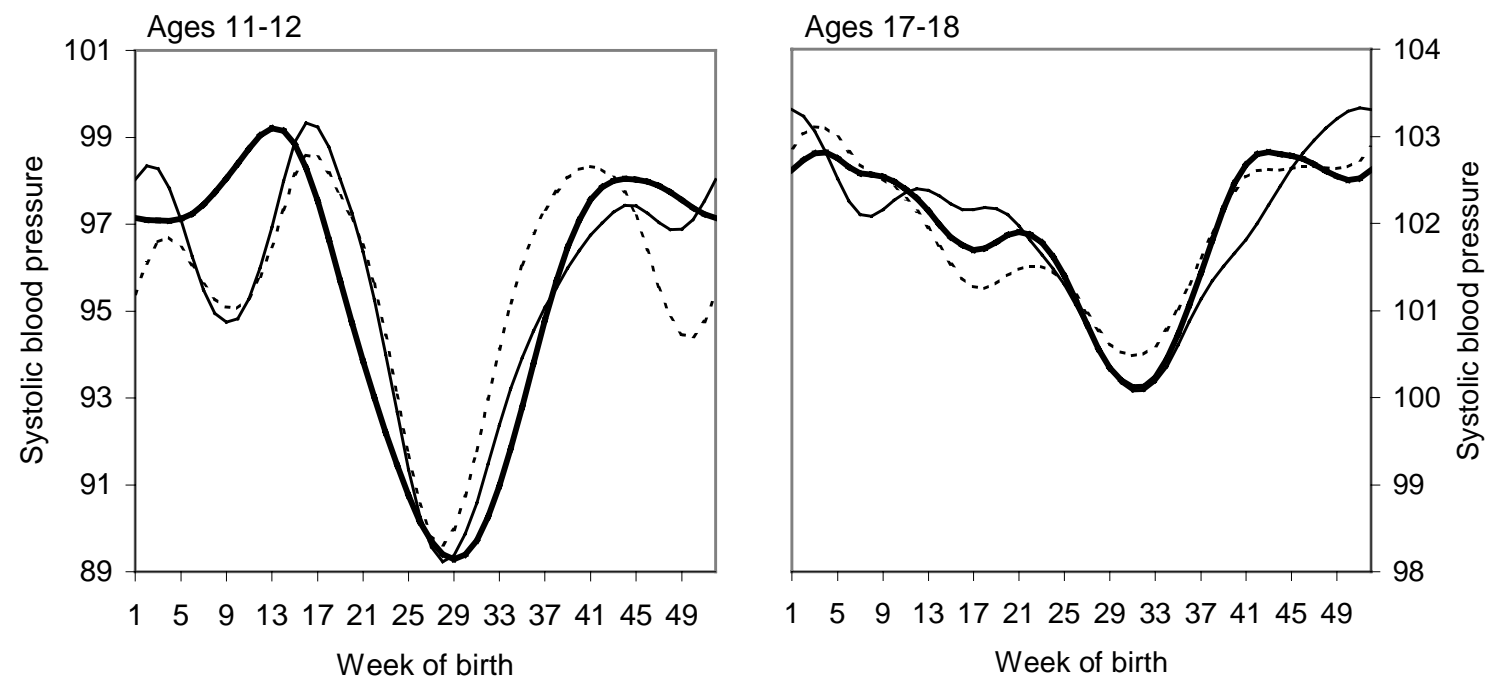

predicted with birthweight
predicted without birthweight 


\section{Conclusion}

In the Minnesota twin data the differences between the peaks and troughs in the four outcome measures birthweight, current weight, height and systolic blood pressure by week of birth are considerable. For birthweight two troughs and peaks exist. Since information about gestational age does not exist one cannot distinguish whether an increased risk of pre-term births or of growth-retardation in-utero is responsible for the two troughs.

There is a general consensus that seasonal differences in birth weight in developing countries are largely due to intrauterine growth retardation. In birth weight studies of developing countries mainly three seasonal factors of intrauterine growth retardation are discussed. First, energy intake during the cold and dry period, due to the availability of minor food crops, was about one-third greater than during the pre harvest monsoon (Brown et al. 1985). Second, during the hot and rainy period rainfall and hot temperature influence disease prevalence by affecting the infectious disease like

Table 7.4: Regression coefficients for the effect of the week-of-birth pattern in current weight, current height and birthweight on systolic blood pressure

\begin{tabular}{lllll} 
& Ages 11-12 & \multicolumn{3}{c}{ Ages 17-18 } \\
\hline Male twins & $\begin{array}{l}\text { Model 1 } \\
\text { Coefficient } \\
(\mathrm{p} \text {-value) }\end{array}$ & $\begin{array}{l}\text { Model 2 } \\
\text { Coefficient } \\
(\mathrm{p} \text {-value })\end{array}$ & $\begin{array}{l}\text { Model 1 } \\
\text { Coefficient } \\
(\mathrm{p} \text {-value })\end{array}$ & $\begin{array}{l}\text { Model 2 } \\
\text { Coefficient } \\
(\mathrm{p} \text {-value })\end{array}$ \\
\hline Birthweight & 22.122 & & -23.268 & \\
& $(0.000)$ & & $(0.000)$ & \\
Current height & 0.0204 & -.255 & -0.738 & -0.111 \\
& $(0.699)$ & $(0.088)$ & $(0.005)$ & $(0.646)$ \\
Current weight & 0.392 & 0.413 & 0.403 & 0.174 \\
Adj. R2 & $(0.000)$ & $(0.000)$ & $(0.029)$ & $(0.072)$ \\
\hline
\end{tabular}

Female twins

\begin{tabular}{lllll} 
Birthweight & -34.232 & & 5.164 & \\
& $(0.000)$ & & $(0.000)$ & \\
Current height & 3.112 & 3.764 & -1.094 & -1.156 \\
& $(0.000)$ & $(0.000)$ & $(0.000)$ & $(0.000)$ \\
Current weight & -2.463 & -2.895 & 0.085 & 0.0205 \\
& $(0.000)$ & $(0.000)$ & $(0.028)$ & $(0.000)$ \\
Adj. R2 & 0.753 & 0.558 & 0.796 & 0.274 \\
\hline
\end{tabular}


gastrointestinal infections (Chen et al. 1979, Datta 1978, Trowbridge and Newton 1979), tuberculosis, measles, and whooping cough (Gordon 1965, Chambers 1981). Third, most agricultural activities are concentrated in the wet season, and the amount of work that women invest in the field increases by two- or threefold (Brin 1984). The increase in work does not only affect energy expenditure but reduces the time for social activities including child rearing. There is an inverse relationship between the amount of time invested in farm work as compared to housework activities (Roberts et al. 1982).

There is no consensus, yet, whether the seasonal pattern in the birth weights of historic or contemporary western populations (including Japan) is due to differences in gestational age or due to intrauterine growth retardation. Matsuda's et al. (1993) study shows that the seasonal pattern is dampened but persists, even when corrected for gestational age.

Gestational age is not reported in the Minnesota twin family study, thus, it is not possible to control for gestational age. However, a study of over 400.000 white singleton live births and stillbirths in Minnesota in the years 1967-1973 by Keller and Nugent (1983) reports the seasonal pattern of preterm births (29-37 weeks gestational age). Like birthweight it reveals two troughs and two peaks. The risk of a preterm-birth is particularely high in December and February, reaches its mimimum in March and another peak in July and August. It is higher in fall than in spring. A highly significant correlation between the month-of-birth pattern in mean birth weight and the monthly probability of a preterm birth $(\rho=-0.73, p=0.007)$ exists among the older female twins and none among the younger female twins $(\rho=0.091, p=0.78)$. For males a nonsignificant negative correlation exists for the older age group $(\rho=-0.38, p=0.22)$, and a negative correlation of borderline significance, for the younger age group $(\rho=-0.54, p=0.07)$. The correlation coefficients, thus, suggest that the monthly differences in the birthweights of twins are only partly the results of differences in gestational age. Particularly the fallpeak in birthweight cannot be explained by gestational age.

A recent review (Huxley et al. 2002) questions the validity of the relationship between low birthweight and increased systolic blood pressure levels at adult ages. The authors show that the magnitude of the relationship depends on the size of the study population: the larger the population the smaller is the correlation between birth weight 
and blood pressure. Furthermore, they point out that most of the studies are adjusted for current weight, which might produce a spurious inverse relationship even if current blood pressure and weight are uncorrelated (Luca et al. 1999, Kramer 1987).

The results of the regression models that explain the week-of-birth pattern in systolic blood pressure by the week-of-birth pattern in current weight, height and birthweight demonstrate that at age 11-12 birthweight is an important factor, but current weight and height are of similar importance. This result implies that seasonal pre-natal or early natal influences on systolic blood pressure in childhood partly act through differences in birthweight. To an even larger extent, however, they affect systolic blood pressure through their direct influence on weight and height. The effect of the seasonal pattern in birthweight is larger among male twins than female twins. This is according to the expectation since male fetuses are more susceptible which is also shown by their higher spontaneous abortions rates.

Figure 5: Deviation of mean age at death (ages 50+) for people born in a specific month from average age at death among decedents born in Minnesota and difference in birtweight in the Minnesota Twin data (both age groups combined).
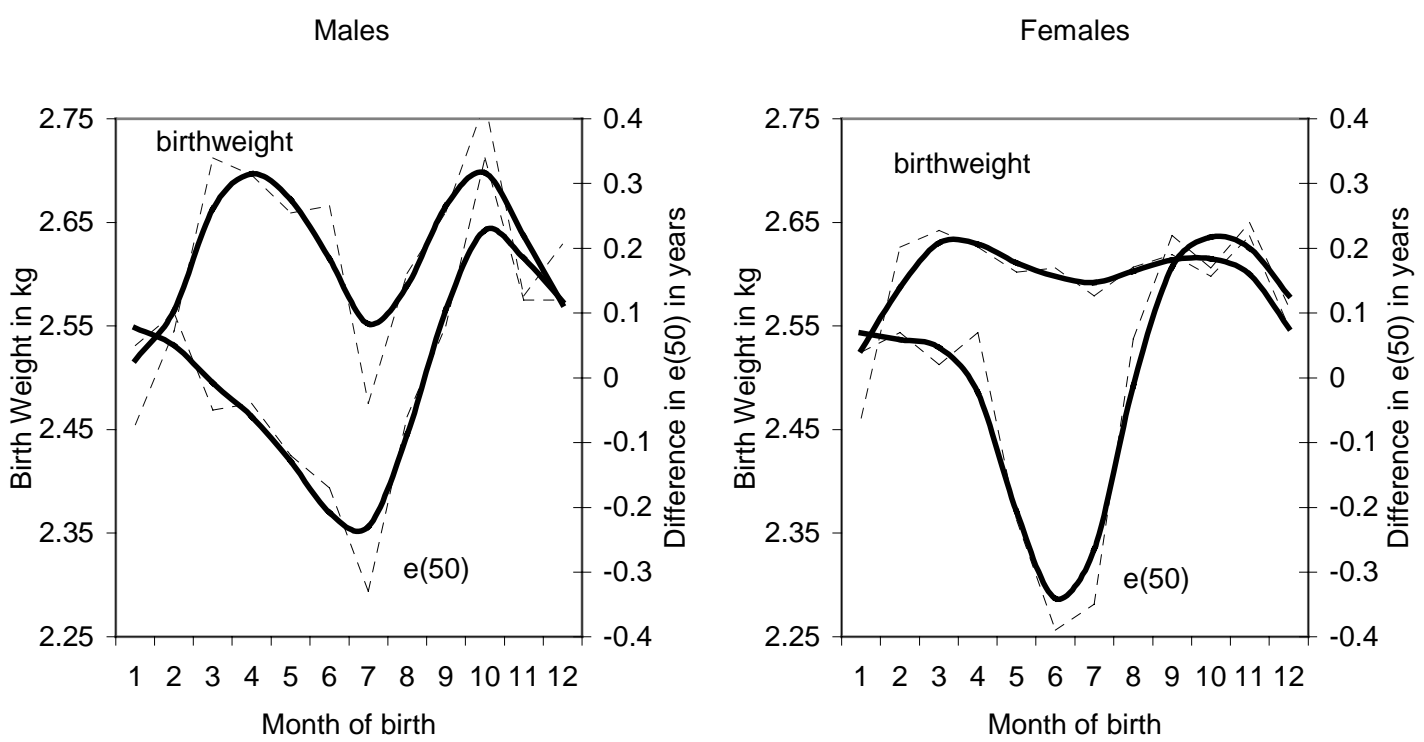

At ages 17-18 no relationship between the week-of birth patterns is found for males, which is not surprising since there are no significant differences in systolic blood by week of birth in the first place. Among the older female twins the pattern in systolic 
blood pressure is primarily the result of the patterns in current weight and height. In other words, if seasonal early life influences on systolic blood pressure do exist at all for young adults then they are primarily related to early-life factors that directly affect current weight and height independent of bithweight. Furthermore, from the sign of the regression coefficients it is not obvious that low birthweight is always related to high systolic blood pressure. For boys aged 11-12 and girls aged 17-18 there is a positive impact of the week-of-birth pattern in current weight and birthweight on systolic blood pressure: twins born in weeks with low birthweight and low current weight do also have low systolic blood pressure values. However, among female twins aged 11-12 the opposite result is found: Those born in weeks with low birthweight or low current weight do have higher blood pressure levels. The results of this chapter therefore support Huxley et al.'s (2002) conclusion that part of claimed relationship between low birthweight and systolic blood pressure later in life may be spurious. They rather suggest that early life factors influence systolic blood pressure through their effect on current weight and current height.

Among males the correlation between the month-of-birth pattern in birthweight and in life span after age 50 is positive and of borderline significance. Particularly in the summer trough and the fall peak there is a close resemblance. This could suggest that the factors that caused the summer trough and fall peak in the life spans of people born at the beginning of the $20^{\text {th }}$ century still cause differences in birthweights at the end of the $20^{\text {th }}$ century. 


\section{SUMMARY}

\section{Early life circumstances and adult mortality}

When mortality started to decline during the second part of the $19^{\text {th }}$ century the decline followed a cohort pattern. A cohort pattern in mortality decline is direct evidence for the effect of early life circumstances on adult mortality. The early studies from Kermack et al. in 1934 suggest that in terms of mortality up to the year 1925 the year of birth was more predictive than the year of death. This was reflected in the general view of public health policy at the beginning of the $20^{\text {th }}$ century. Mortality at adult ages was considered to be largely influenced by conditions that existed during childhood and in the earliest periods of life. After 1925 the year of birth as compared to the year of death lost much of its predictive power. Period factors became more important.

Today there is widespread evidence that during a mortality regime that is determined by infectious disease, early life conditions play a detrimental role for adult health and mortality. One major cause of death that during the last 100 years declined on a cohort basis rather than on a period basis is tuberculosis. Tuberculosis in late adulthood is believed to originate in infections during childhood. Other important causes of death that have experienced a cohort decline since the beginning of the $20^{\text {th }}$ century are stroke, stomach cancer and bronchitis. In the case of peptic ulcer-morbidity the cohort specific decline is traced back to cohort specific Heligopacter pylori infections in childhood. Heligobacter pylori infections in childhood caused by poor living circumstances before and during World Ware II seem responsible for the high rates of stomach cancer in Japan today. Adult mortality in Sweden during the $18^{\text {th }}$ and $19^{\text {th }}$ century was heavily influenced by the disease load during the first year of life: people born in years with extremely high infant mortality due to smallpox and whooping cough had increased mortality later in life.

Much controversy exists, however, whether cohort effects, and thus early life circumstances, are still important in a mortality regime that is determined by chronic disease. With the epidemiological transition from infectious to chronic disease cohort effects on mortality have largely lost their importance and period effects determine mortality. Coronary heart disease initially shows period-specific increase, the introduction of antibiotics influenced mortality in a period-specific way, medical therapeutics usually acts period specific. One counter example is lung cancer, which increased from cohort to cohort reflecting the increased uptake of smoking among the younger cohorts. Emphasis in research and public policy 
therefore shifted to life-course factors such as adult socioeconomic status and lifestyle factors such as diet physical exercise and smoking behavior.

In the 1970s Forsdahl, a medical doctor in Norway, observed that regional differences in adult lung cancer and heart disease were not related to contemporary differences in lifestyle, smoking behavior or socioeconomic status but rather to differences in regional infant mortality during childhood and youth of the studied cohorts. His study is now considered as the starting point of a large and productive area of research that tries to link early life conditions to the manifestation of chronic disease later in life. The discussion about early life effects on health at adult ages gained momentum with the studies of the Southampton group of Barker and colleagues. The group developed the fetal-origins hypothesis of adult disease (also known as the 'Barker hypothesis'), which suggests that coronary heart disease at adult ages results from poor condition in-utero caused by inadequate nutrition of the mother during pregnancy and infectious disease. Since inadequate nutrition of the fetus reflects itself in low birthweight the Barker hypothesis claims that growth retardation in-utero leads to low birthweight and to an increased risk of chronic disease later in life. The main pathway between birthweight and heart disease later in life is supposed to be systolic blood pressure with low birthweight infants experiencing increased systolic blood pressure at adult ages.

The fetal-origins hypothesis has stimulated a large output of research which generally comes to the conclusion that low birtweight is associated with an increased risk of heart disease at adult ages and that low birthweight infants suffer from increased systolic blood pressure later in life. The interpretation of these outcomes has, however, been repeatedly challenged. The main underlying idea of the fetal-origins hypothesis is that a critical time period exists early in life and that negative effects during this period cannot be reversed later in life. Critics of the hypothesis frequently bring forward the argument that birthweight is confounded with socioeconomic status. Negative social factors in the early life-environment may set people onto life-trajectories that negatively affect their health over the whole life course. Therefore the almost universally observed relationship between birthweight and the risk of chronic disease later in life may be rather an outcome of the whole life-course than of a critical period early in life.

This criticism leads to the question of an indicator for the prenatal and early postnatal environment that is not related to the life-course. Birthweight certainly does not fulfill this criterion and, in addition, is not widely available. Studies that use birthweight or other direct indicators of early life circumstances are usually based on hospital data, which are invariable subject to selection bias and their sample sizes tend to be modest. The fetal-origins hypothesis 
suggests that nutrition and infectious disease during pregnancy of the mother are responsible for growth retardation of the infant leading to an increased risk of heart disease at adult ages. Both nutrition and infectious disease are highly seasonal: Respiratory infections peak in fall and winter, gastrointestinal infections during warm periods of the summer months; the availability of fresh fruits and vegetables and therefore of micronutrients changes with the seasons of the year. An indicator that reflects the seasonally changing environment during the prenatal and early postnatal period is month of birth.

Month of birth can be used as an indicator for the seasonally changing environment around the time of birth if it is not confounded by social factors and if it does not have any life course interpretation. This monograph, therefore, tests a series of alternative hypotheses which all assume the existence of life-course factors or social factors that are related to the month of birth. Only after having rejected all the hypotheses a thorough analysis of the possible causal mechanisms is performed.

Epidemiological research about the underlying factors of schizophrenia has long used month of birth as an indicator for early life circumstances that affect the risk of schizophrenia later in life. This line of research dates back to Ellsworth Huntington who in 1938 published his book "Seasonality" in which he describes the relationship between the seasons of the year and social, psychological and demographic phenomena. By 1997 more than 250 studies about the month-of-birth effect in Schizophrenia have appeared and many more are still published. The most recent research links the relationship between the month of birth and the risk of Schizophrenia to influenza infection of the mother during pregnancy although results are not always conclusive. A month-of-birth effect has also been shown for other mental disorders such as mania and bipolar disorder, autistic disorder, Alzheimer disease or anorexia nervosa. Little research, however, has been done on the month-of-birth effect in chronic disease, which in contemporary populations determines life expectancy.

\section{How to study the effect of month of birth on life span?}

This monograph establishes the month-of-birth effect in life span on the basis of large and complete population data of over 17 million people. It mainly rests on the analysis of three populations of the Northern Hemisphere - Austria, Denmark and the United States - and one population of the Southern Hemisphere, namely Australia. The rational underlying the selection of the populations is that those of the Northern Hemisphere should reveal a similar month-of-birth pattern while in the Southern Hemisphere the pattern should be shifted by half a year. 
For Austria, Australia and the United States death records are the basis of the analysis. These death records contain the date of birth and the date of death. Since only deaths are known while the population at the risk is unknown mean age at death is used as a substitute for life expectancy. An advantage of using US data is that the US territory ranges over $\mathrm{xxx}$ degrees latitude and consists of six major climatic zones. Since the death records contain the state of birth of the decedents the data permit regional analysis. The Danish data come from the Danish population register. The register allows to follow each person alive in March 1968 until the present and records date of birth, date of death for those who have died, and date at the end of follow-up for those who survived. From these data both exposures (number of person months of people born in a specific month) and occurrences (number of deaths for people born in a specific month) are known. Therefore death rates and life expectancies based on life table techniques are estimated.

The advantage of studying Austria and Denmark is that they are geographically close and should therefore reveal similar month-of-birth patterns. While they are geographically close they belong to different climatic zones and have different histories of adult and infant mortality. At the beginning of the $20^{\text {th }}$ century infant mortality in Denmark was about half of the mortality in Austria where short periods or the complete absence of breastfeeding caused its high toll. Thus, despite their geographical closeness early life circumstances for example in terms of disease environment differed widely.

The data of all four populations are used to study mean age at death for ages 50+ (Austria, Australia and United States) and remaining life expectancy at age 50 (Denmark). Although age fifty certainly is an arbitrary cut-point there are several reasons why this age has been chosen. First, infant mortality is deliberately excluded in order to guarantee that differences in mean age at death are not caused by differences in survival during the first year of life but rather by differential survival later in life. Second, in contemporary populations mortality during childhood and young adulthood is so low that dividing populations according to their month of birth would result in even higher mortality fluctuations that may have distorted the general month-of-birth pattern. Third, mortality starts to accelerate around age 50 with the increasing incidence of chronic disease. Therefore the month-of-birth pattern in longevity is statistically primarily a function of the number of deaths at middle and old ages.

The cut-point at age 50, however, is disadvantageous in terms information about the month-of-birth pattern at younger ages. To overcome this limitation three additional data sources are studied. Aggregate data about infant mortality in the years 1911-1915 in Denmark by age and month of death are used to estimate infant mortality in the first year of life by 
month of birth. The Danish twin registry permits the study of all twins born between 1870 and 1930 who survived at least up to age 6. The twins are followed until present and for the deceased the date of death is recorded. Finally, the US census samples for the years 1960, 1970 and 1980 contain information about the quarter of birth. The comparison of the agespecific percentages of cohorts born in a specific quarter between two succeeding census rounds gives an indication of differential survival by quarter of birth. For example, one can compare the percentage of people born in the second quarter at ages 10 in the 1960-census with the respective percentage of the 20-year old in the 1970-census and the 30-year old in the 1980-census. If the percentage changes from one census to the next then the quarter on birth influences survival. The direction of the change indicates whether those born in the second quarter experience higher or lower mortality as compared to the total population.

There is an additional advantage of the US census data and the Danish twin data. Both datasets constitute a second independent source for the two populations that can be used to verify the month-of-birth patterns. Since the US results (together with the Austrian and Australian results) are based on death counts only it could be argued that the result is at worst an artifact and at best confounded because of the approximation of life expectancy by mean age at death. The use of repeated census rounds avoids the calculation of life expectancy and is therefore not subject to this criticism. Both the Danish register data and the Danish twin data are longitudinal data and provide therefore all the necessary information to calculate life expectancy. The advantage of the Danish twin register is that the month-of-birth pattern of the general population can be replicated in a very specific sub-population. Furthermore, one would expect that the peak-to-trough difference in life expectancy is larger among twins than among the general population because they experience harsher conditions early in life than singletons.

\section{The month-of-birth effect on lifespan is linked to the seasons of the year}

A significant effect of the season of birth on survival at adult ages exists in all studied populations. In the Northern Hemisphere mortality at ages 50+ peaks for the spring-born (April-June) and reaching a trough for the fall-born (Ocotber-December). In the Southern Hemisphere the pattern is shifted by half a year: mean age at death peaks for the spring-born and reaches a minimum for the fall-born. The difference in life span between the spring and the fall-born is 0.6 years in Austria and, thus, twice as large as in Denmark (0.3 years). For the total US the peak-to-trough difference is 0.4 years, however, large variability exists by region of birth. With 0.31 years the difference is lowest for people born in New England, followed by 
the Middle Atlantic region (0.36 years). It reaches a maximum for those born in East South Central (0.86 years) and West South Central region (0.69 years) while all other regions show differences around 0.44 years. The regional variability in the peak-to-trough differences persists when the results are corrected for the effects of race, education and marital status. With 0.6 years the maximum difference in Australia is comparable to that of Austria, although as noted above, the pattern is shifted by half a year.

Similar to the US death records the Australian death data contain state and territory of birth. In general the pattern is similar in all states and territories with high mortality for decedents born in the fourth quarter and low mortality for those born in the second quarter. Within Australia the peak in mortality of those born in the fourth quarter is highest for decedents born in Victoria ( 0.89 years), followed by those born in South Australia (0.61 years), Western Australia (0.49 years) and in New South Wales (0.39 years).

There are two exceptions: the first is Tasmania where due to the small numbers of death the peak-to-trough difference is not significant. The second exception is Queensland with a different pattern than in all the other states. In Queensland the trough in mean age at death exists for people born in the first four months, the peak for those born in April and May. Queensland belongs to tropical northern Australia and the trough in life expectancy coincides with the hot and wet summer season, the peak with the beginning of the more moderate and dry winter season. From its geographical location Hawaii is a mirror image of Queensland. Since the US death records also contain information about decedents born in Hawaii it is possible to compare these two patterns. It turns out that also in Hawaii the trough in life expectancy is linked to the hot summer period and the peak to the more moderate winter period.

The results for the United States and Denmark are supported by the analysis of the US census rounds and the Danish twin register. The three US census rounds show a significant disadvantage in survival of people born in the second quarter and an advantage of those born in fall. Up to age 40 the conditional survival probability of males surviving the next 20 years is about one percent higher for the fall-born than for the general population; between age 40 and 60, it is about 2.4 percent and it increases to 7.8 percent at ages $60-69$.

In general the Danish twins experience a similar month-of-birth pattern as the general Danish population. There are differences, however. The most important is that the peak-totrough difference in life expectancy is much larger among the twins than among the general population. On the basis of the Danish register data the difference in remaining life expectancy at age 50 between the fall- and the spring-born is 0,3 years; among the Danish 
twins it ranges from 0.58 years in the youngest cohort (1910-1930) to 0.88 years in the cohort 1890-1909. In other words, the difference is at least two to three times as high among twins than among the general population. This result is according to the initially formulated hypothesis that the harsher environmental circumstance in-utero and in the first year of life will result in larger differences in lifespan by month of birth. It has to be noted, however, that the mortality advantage of the fall-born is not as consistent among the male Danish twins as among the general male Danish population.

The results from Austria, Denmark, the United States, Australia and Hawaii suggest that the month-of-birth pattern in lifespan is linked to the seasons of the year. It appears that those born during periods of moderate climate, which coincides with fall in populations living at higher latitudes and winter in populations living close to the equator, experience higher life expectancy. Those born during spring and early summer show lower life expectancies; at lower latitude periods with high temperatures seem to be detrimental. At first sight it seems surprising that the month-of-birth pattern exists in regions close to the equator. Although it is often perceived that there are no seasonal changes at lower latitudes in realty this is not true. Differences in temperatures, humidity and precipitation define the seasons of the year in these areas their combination, however, may vary depending on the climate zone.

\section{The month-of-birth pattern of migrants}

A further test of whether the month-of-birth pattern depends on the seasonal environment early in life is to investigate the pattern of migrants. The Australian death records contain information about 43 thousand British-born immigrants to Australia who died at ages 50+. One would expect that these immigrants reveal the month-of-birth pattern of the Northern Hemisphere rather than that of the Southern Hemisphere. Since for the Novemberto January-born the peak in life expectancy is 0.36 years higher among the immigrants than among the Australian-born, while it is 0.26 years lower for the March- to May-born this seems indeed to be the case. However, contrary to the unimodal patterns of the populations of Northern Hemisphere the month-of-birth pattern of the migrants is bimodal. One possible explanation for the bimodal pattern is that the month-of-birth pattern of the total British population is bimodal. Another explanation is that migrants are not representative of the total British population. At present, no published information exists that would permit the test of the first explanation. An exploratory analysis of the month-of-birth effect on the basis of the genealogy of the British peerage did not yield any conclusive results. 
This monograph provides two examples on the basis of the US death records that migrants are both socially and health selected and therefore not representative of the total population. The first example shows that social status and race influence the month-of-birth pattern in life span. The peak-to-trough difference in mean age at death among US decedents with low education is with 0.62 years almost twice as large as among those with high education ( 0.38 years) while the basic pattern remains unchanged. This is different in the case of race. Among African-American decedents the peak-to trough difference is only slightly larger ( 0.57 years) than among white decedents ( 0.49 years), however, the shape of the pattern differs widely. Both for whites and African Americans those born in June and July show the lowest mean ages at death while the peak in life expectancy is shifted from fall to winter among African Americans. Those born in fall do not experience the same mortality advantage as the white population, although a secondary peak in mean age at death exists.

An indication that health status affects the month-of-birth pattern is the larger peak-totrough difference for never married decedents ( 0.62 years) as compared to the married $(0.40$ yeasr). It is now generally agreed upon that the beneficial effect of marriage on health and mortality results from two forces. On the one hand there exists a protective effect of marriage. On the other hand, individuals are selected into marriage according to their health status and frail individuals tend to remain unmarried. Thus, health status precedes marriage and up to a certain extend marital status can be regarded as an indicator of health.

The US death certificates, thus, provide evidence that social and health factors modulate the month-of-birth pattern in life span and that migrants who are both socially and health selected may therefore reveal a somewhat different pattern as that of their population of origin.

The second example applies to internal US migration. It shows that the month-of-birth pattern of migrants differs from that of their sending population. In the US large disparities by region of birth exist in the peak-to-trough difference in mean age at death. The lowest difference exists for decedents born in New England, and the largest for those born in the South East, which is each generally referred to as the South of the US. Due to the sizeable migration flows within the US it is possible to study migrants who are born in the North and who died in the South and vice versa. The two migration flows differ remarkably in their social composition as well as in their timing of migration. North to South migration is primarily retirement migration of healthy, married and comparably well-off Americans who moved to the American "sunbelt" . This migration flow became increasingly popular during the last few decades. South to North migration, however, was primarily labor migration 
caused by the economic upheavals of the first part of the $20^{\text {th }}$ century and peaked in the $1960 \mathrm{~s}$. These migrants were usually born in rural areas, and had lost their land or their status as sharecroppers because of the increasing industrialization of the southern agricultural system.

It appears that the South to North migration of the retirees is consistent with the expectation that migrants reveal the month-of-birth pattern of their birth region rather than that of their residence region. The peak-to-trough difference of the migrants born in the North is smaller than the difference of those who were born and who died in the South. This is not generally true for labor migrants from the South to the North. Although most of the southern migrants stem from rural areas they are by no means a homogenous group. The social class relations in the South were structured along the ownership of land and those who did not own their land were particularly poor off. The analysis of the month-of-birth pattern of farmers and farm workers shows that in the South the peak-to-trough difference of the farm workers is significantly larger than that of farmers. In other words, the labor migrants from the South to the North probably are less representative of the general southern population than the retirement migrants from the North to the South.

Three conclusions can be drawn from the analysis of the month-of-birth patterns of the Northern and Southern Hemisphere and of the migrants between the hemispheres: First, the differences in lifespan by season of birth are linked to seasonal factors around the time of birth. Since the seasons in the Northern and the Southern Hemisphere are shifted by half a year also the month-of-birth pattern is shifted by half a year. Second, at higher latitudes with four distinct seasons those born during spring have a lower life expectancy than those born during fall. At lower latitudes close to the equator those born during the hot season of the year experience a lower life expectancy than those born during the moderate winter season. Third, the peak-to-trough difference in the month-of-birth pattern varies for different social groups: the higher the social status the lower is the difference in life span. There are two alternative implications of this result. Since education of the deceased is closely linked to the social status at the time of birth the educational gradient in the peak-to-trough difference may reveal the impact of social status. Alternatively, educational status later in life may modify the effect of the early life environment. This explanation implies that the early life is a critical period in terms of adult health and mortality, however, its effect may be partly reversed by life-course factors.

Alternative hypotheses for the month-of-birth effect 
Before proceeding further with the analysis of the month-of-birth effect on lifespan it is worthwhile to consider whether other explanations exist than those that are related to the beginning of life. One frequently raised concern is that the month-of-birth effect rather reflects the seasonal distribution of deaths than the seasonal changes in the early life environment. More specifically, the concern is that the interaction between the seasonal distribution of deaths and the monthly increase in adult mortality causes a month-of-birth pattern. This hypothesis has been already widely discussed in the research about the monthof-birth effect in schizophrenia whose incidence is seasonal and whose risk increases with age.

The Danish register data used in this study permit explicitly the test of this hypothesis because of the longitudinal nature of the dataset. The result is that although month of birth, age and month of death influence mortality simultaneously they are independent of each other. This is consistent with the outcomes of the tests that were developed in the area of schizophrenia.

A second frequently raised concern is that the month-of-birth effect is caused by socioeconomic differences in the seasonal distribution of births. The number of births is distributed seasonally over the year with the exception of only a few populations. If the seasonality in births is partly driven by the preference of couples for giving birth in certain seasons of the year, then this preference may differ between social groups. In schizophrenia research this explanation is generally known as the procreational habits theory. Indviduals with schizophrenia may have a different procreational pattern than the non-schizophrenic population. Since schizophrenia is heritable to a large degree this would result in a seasonal distribution of births of individuals at increased risk of developing schizophrenia that differs from the seasonal distribution in the general population. Two predictions of this theory have already been falsified: First, it is not the case that individuals with schizophrenia who have a family history of schizophrenia reveal a larger peak-to-trough difference in their seasonality of births than those who do not have a family history. Second, schizophrenic individuals and their siblings have different seasonal birth distributions.

In this study education is used as an indicator for social groups and the seasonal birth distribution at age $50+$ on the basis of the 1981 census for Austria is analyzed. It turns out that proportionally more people with high education are born in spring than in fall, while proportionally more people with basic education have their birthdays in fall. Since among the analyzed cohorts own education is closely linked with education of the parents this result indicates that social differences in the seasonal distribution of births cannot explain the 
month-of-birth pattern in lifespan. On the contrary it appears that they even tend to reduce the differences in lifespan by month of birth.

Another prominent hypothesis in social and psychological research is the deadline hypothesis. Starting school is usually tied to reaching a certain age before a certain deadline. Children who are born shortly after the deadline have to wait an additional year before the can start school and will therefore be among the oldest of their classmates. This may pose a special advantage compared to those who are born shortly before the deadline and who will always be among the youngest. However, there is a second interpretation of the deadline hypothesis. Children born shortly after the school attendance deadline will be older when they start school and will attain the legal drop-out rate earlier in their educational year than those born shortly before the deadline. This may result into a fewer years of school enrollment. Being born after the deadline is therefore considered as disadvantageous in terms of the educational career and research suggests that this is reflected in later earnings.

The seasonal distribution of the month of birth of Austrians aged 50+ points towards the second interpretation of the deadline hypothesis. In Austria school started at 1 October and children who had not turned six by that date had to wait another year before they could start school. Since the fall-born belong to a larger percentage to the group with basic education only, the deadline effect would be detrimental rather than beneficial for those born shortly after the deadline of October 1st. However, since mean age at death of the fall-born is higher than that of the spring-born the deadline hypothesis cannot explain the month-of-birth effect in lifespan.

\section{The causal mechanisms}

What are the mechanisms that cause the month of birth pattern in lifespan? It is possible to rule out that month of birth has any major life-course interpretation in terms of longevity. Therefore, any month of birth pattern relates back to the very first period of life. It is also possible to rule out that month of birth is confounded by socioeconomic status and that the differences in lifespan by month of birth are simply differences in socioeconomic status.

The study of the month of birth pattern in infant mortality at the beginning of the $20^{\text {th }}$ century alllows to rule out a third alternative. If fall-born infants suffer higher mortality in their first year of life than spring-born infants then the increased life expectancy of the fallborn may simply be the result of selective survival. Among the fall-born only the more robust individuals would survive the first year of life, who would then have lower mortality later in life. Danish data on historical infant mortality between the years 1911 and 1915, however, 
show that not the fall- but the spring-born experience higher mortality in their first year of life. The standardized death rate of the June-born infants is 30 percent higher than the death rate of the December-born. It therefore appears that selective survival cannot explain the month-ofbirth pattern in life span.

The month-of-birth pattern in infant mortality rather points to another explanation. For Denmark the correlation between infant mortality in the first year of life and adult mortality after age 50 is 0.87 and highly significant. This result indicates that the causal mechanism of the month-of-birth pattern is related to debilitating factors in-utero or in the first year of life. In other words those factors that contributed to the high infant mortality of the past are also the factors that cause the differences in lifespan by month of birth. The contemporary view of the public health experts at the beginning of the $20^{\text {th }}$ century was that mothers' health status and whether the mothers breastfed their babies were the two most important factors, in addition to housing, sanitation and general poverty, that were closely linked with the survival of the infants. The health status of pregnant women depends largely on their diet and on the general disease load. Breastfeeding the infant is primarily related to a lower incidence of infectious disease of the gastrointestinal tract, which historically is the major cause of infant mortality.

Both nutrition and infectious disease are highly seasonal. Diet at the beginning of the $20^{\text {th }}$ century did not much resemble contemporary dietary patterns. People ate less meat, fruits and vegetables and more starchy staple food. The first vitamins were only discovered in 1911 and in the early 1900s nutritionists were even opposed to greens, which were considered to require more bodily energy for digestion that they provided. Although severe malnourishment was not widespread people had inadequate nutrition particularly during the winter and early spring. Peak growth of the fetus in-utero happens during the third trimester. For infants born in spring the third trimester coincides with a period of largely inadequate nutrition; for those born in fall, with a period of plenty.

The incidence of infectious disease depends on the climate and on the seasons of the year. The incidence of waterborne infectious disease, which mainly affects the gastrointestinal tract, is correlated with warmer temperatures and flooding. Peak climatological temperatures coincide with the incidence of foodborne diseases. Many childhood diseases are highly seasonal; airborne diseases that affect the respiratory tract usually peak in fall and winter.

The effect of nutrition of the mother during pregnancy on health of the child at adult ages is highly contested. Nutrition is considered to be the central causal mechanism in the fetal-origins hypothesis, which claims that inadequate nutrition of the mother during 
pregnancy leads to growth retardation in-utero and to an increased risk of heart disease later in life. Studies that looked at old-age mortality of cohorts born shortly after periods of famine and that supposedly were affected by severe malnutrition of the mother during their gestational period did not find any difference. In other words, those born shortly before, during or after a famine had similar mortality rates at older ages. On the other hand, the study of the social composition of births during and shortly after the Dutch Famine in 1945 has shown that this composition has changed. Primarily women of higher social background continued to give birth while women of lower background stopped having babies. Unobserved differences in the social composition might therefore be the reason that cohorts born during and shortly after a famine do not have higher mortality later in life than those unaffected by the famine. Still the evidence is weak concerning the effect of nutrition during gestational age on mortality later in life.

The situation is different concerning the effect of infectious disease. There exists ample evidence that infectious disease early in life affects later life health and mortality. Historically, people born in years with extremely high infant mortality primarily caused by whooping cough and smallpox tend to have higher mortality later in life. Tuberculosis in late adulthood is believed to originate in infections during childhood. $\mathrm{H}$ pylori infections in childhood are responsible for peptic ulcer-morbidity later in life. Increased $\mathrm{H}$ pylori infections in childhood caused by poor living circumstances before and during World Ware II seem to be responsible for the high rates of stomach cancer in Japan today. Chronic respiratory disease later in life seems to be related to lower respiratory tract infection in childhood.

The indicator month of birth does not permit the distinction between the period inutero and the first year of life. It therefore does not tell whether nutrition of the mother during pregnancy or infectious disease in the first year of life is of crucial importance. The investigation of causes of death reveals that the month-of-birth effect exists for all major groups of causes of death. The pattern is particularly strong and consistent for heart disease, it is less strong but consistent for many types of cancer. Significant month-of-birth patterns exist for causes of death such as stroke, stomach cancer and bronchitis that declined between the mid $19^{\text {th }}$ century and today following a birth cohort pattern. There are two possible explanations: First, since the etiology of all the different causes of death differs there may be more than one causal mechanism and some of them may be related to the period in-utero, others to the first year of life. The research of Barker and colleagues who formulated the fetalorigins hypothesis links the increased risk of heart disease later in life to nutrition in-utero. A 
large body of literature investigates the month-of-birth effect in the prevalence of schizophrenia and discusses the effect of influenza infection of the mother during pregnancy on the risk of the child to develop schizophrenia. Historically, children born in years with extremely infant mortality caused by smallpox experience higher mortality later in life. A second explanation is that the spring-born are generally weaker as compared to the fall born and that their rate of aging is higher.

Also other explanations than nutrition and infectious disease have been brought forward to explain the month-of-birth effect. One of the first who studied the influence of month of birth on lifespan is Elsworth Huntington who in 1936 formulated the hypothesis that high temperature at the time of conception weakens the "germ plasma" of the parents with negative effects on the development of the fetus. Recent research has shown that indeed the sperm quality of male outside workers decreases during periods of high temperature. A related hypothesis is that hot summers are the cause of protein deficiencies at the time of conception. This hypothesis is clearly ruled out on the basis of the US death data. The United States consists of six major climatic zones with very different climatic conditions. Since the US death data contain state of birth it is possible to correlate the peak-to-trough difference in lifespan by month of birth for people born in a specific state with maximum and minimum temperature and with the maximum difference in temperature. It appears that no correlation exists between the peak-to-trough difference and the temperature variables, neither for total mortality, nor for major causes of death.

Another explanation is that seasonal changes in the hours of daylight influence the human endocrine functions and that the month-of-birth effect might be caused by variations in the internal chemistry or neural development brought about by the seasonal variations in light. This hypothesis implies that the peak-to-trough differences are larger at higher than at lower altitudes. Again, the hypothesis can be refuted on the basis of the US death data since there is no correlation between latitude and the peak-to-trough difference in lifespan by month of birth.

\section{Does the month of birth effect exist in cohorts born today?}

All the observed differences in lifespan by month of birth pertain to individuals who are born during the first part of the $20^{\text {th }}$ century. The Danish results are based on the birth cohorts 1868 to 1918 , the Austrian, on births between 1888 and 1946, the Australian, on births between 1893 and 1947, and the US results, on births between 1889 and 1947. The question whether the differences in lifespan by month of birth still exist in infants born today cannot be 
answered on the basis of mortality data since one does not know anything about the future mortality of contemporary cohorts. Other measures have to be applied.

The fetal-origins hypothesis of adult disease states that growth retardation in-utero leads to low birth weight and causes an increased susceptibility to chronic disease at adult ages. According to Barker and colleagues the main reason of growth retardation in-utero is deficient nutrition. Since nutrition is seasonal one would expect that growth retardation is seasonal and that this is reflected in a seasonal pattern in birthweight. Evidence for seasonal growth retardation in-utero exists from less developed countries. A positive correlation between the seasonal pattern in birthweight and the month-of-birth pattern in life span after age 50 of cohorts born earlier in time would suggest that the differences in lifespan still exist in contemporary cohorts.

This hypothesis is tested on twin data from the Minnesota twin registry. The seasonal pattern in birthweight of twins born in the 70s and 90s is compared with the month-of-birth pattern in mean age at death of decedents aged 50+ who were born in Minnesota. Twin data are used because in contemporary populations twins belong to the most vulnerable group early in life. They have higher spontaneous abortion rates, and higher infant and child mortality up to age 6. At adult ages, however, their mortality does not differ from the mortality of singletons. This is also true for the month-of-birth pattern in lifespan as has been shown in this monograph by the Danish twins and the Danish general population. There is, however, one difference between the Danish twin and general population. The peak-to-trough difference in the month-of-birth pattern is two to three times as large among the twins.

Since twins face much tougher conditions early in life than singletons a seasonal pattern in birthweight due to growth retardation may be more readily detectable among twins than among singletons. Results suggest that the seasonal pattern in birthweight is bimodal with birthweight reaching its maximum in spring and fall and its minimum in winter and summer. This result is consistent with earlier findings that the risk of pre-term births in Minnesota is bimodal with peaks in summer and in winter.

A positive correlation of 0.52 of borderline significance exists between the life span pattern and the birthweight pattern for male twins, for female twins the results are not conclusive. This result may be a first indication that the differences in lifespan by month of birth still exist in cohorts born today.

Although the presented evidence is weak one has to keep in mind that birtweight is only an imperfect measure of growth retardation because it does not take gestational age into account. For example, preterm infants may have just the right birthweight for their gestational 
age. Even if their birthweight is low as compared to that of term babies they may not have suffered from growth retardation. A better measure would be birthweight corrected for gestational age but information about gestational time is not available for the Minnesota twins. An earlier study about seasonal differences in the risk of preterm births in Minnesota shows that the risk is elevated during winter and summer. Thus, the seasonal pattern in birthweight of the Minnesota twins does not only reflect seasonal growth retardation but also seasonal differences in gestational age. Further studies should therefore examine the correlation between the seasonal pattern in birtweight corrected for gestational age and the month-of-birth pattern after age 50 .

The second "cornerstone" of the fetal-origins hypothesis is the claimed negative correlation between low birthweight and increased systolic blood pressure later in life. Growth retardation caused by deficient nutrition in-utero is reflected in low birthweight and leads to increased systolic blood pressure later in life and therefore to an increased risk of chronic disease. The negative relationship between birthweight and systolic blood pressure has been found in a large series of studies but has also been repeatedly challenged. In terms of seasonal differences in nutrition this hypothesis implies a) that a month-of-birth pattern exists in systolic blood pressure, and b) that the pattern is correlated with the seasonal pattern in birth weight. The Minnesota twin data also permit testing this hypothesis.

In adolescence and young adulthood significant month-of-birth patterns exist for height, weight and systolic blood pressure, particularly among males. In adolescence about half of the week-of-birth pattern in systolic blood pressure is explained by the week-of-birth pattern in height and weight and the other half by the week-of-birth pattern in birthweight. This implies that in adolescence about half of the seasonal early life effects on systolic blood pressure are related to factors in-utero that simultaneously affect birthweight and later systolic blood pressure. The other half affect systolic blood pressure through weight and height. The effect of birthweight is larger for males than for females.

With increasing age the month-of-birth patterns in systolic blood pressure, weight and height become less distinct and birthweight only contributes marginally to the explanation of the season-of-birth pattern in systolic blood pressure. At that age most of the explanatory power comes from the season-of-birth patterns in weight and height. This suggests that at young adult ages the season-of-birth differences in systolic blood pressure are primarily related to early life factors that affect height and weight rather than birthweight. 


\section{Summary of Accomplishments and Outlook}

This monograph achieved six major accomplishments:

- First, it demonstrates the widespread existence of the differences in life span by month of birth in the elderly population of contemporary societies.

- Second, it provides evidence that the pattern is linked to the seasons of the year by comparing the Northern and the Southern Hemisphere.

- Third, it formulates and tests a series of explanations for the month of birth effect and rejects many of the most frequently raised. In particular it rejects those that attribute the month-of-birth effect to social or statistical confounding.

- Fourth, in the case of Denmark it establishes a link between the month-of-birth pattern in life span and the month-of-birth pattern in survival during the first year of life. The major determinants of infant mortality at the beginning of the $20^{\text {th }}$ century are health status of the mother and whether or not the mother breastfed the infant. The first is related to the nutritional and disease environment of the mother during pregnancy, the latter to the risk of the infant to suffer from infectious disease in the first year of life. The positive correlation between the month-of-birth pattern in lifespan after age 50 and infant survival during the first year of life is therefore direct evidence that nutrition and infectious disease early in life play an important role for adult health and survival later in life.

- Fifth, it provides preliminary evidence that the differences in life span by month of birth do still exist in cohorts born today.

- Finally, it contributes to the ongoing debate about the pathway that links growth retardation in-utero and the increased risk of chronic disease later in life by presenting evidence that the pathway must not necessarily be systolic blood pressure.

Although month of birth has been used for a long time in research about mental disorders it was never tested systematically whether a month-of-birth pattern exists in different populations and for different causes of death. Research was mainly confined to specific diseases, historically diseases of mental disorder, more recently diseases like diabetes, and multiple sclerosis, or lung and breast cancer. Since the interest in the month-of-birth effect primarily arouse from an epidemiological point of view more emphasis was given to the specific disease rather than to the phenomenon of the month-of-birth effect itself. Usually the datasets are rather small and the results subject to random fluctuations. With some notable exceptions in the research about schizophrenia, anorexia nervosa, etc. the intention of most of 
the studies was to show that a month-of-birth effect exists rather than to test hypotheses regarding the underlying factors of the month-of-birth effect.

Some first steps to uncover the causal mechanisms behind the month-of birth effect in life span are presented in this monograph. The next steps will have to consider the following topics. The indicator month of birth does not permit the distinction whether the critical period early in life is in-utero or in the first year of life. It also does not provide an answer to the question whether infectious disease or nutrition causes the differences. One way to address this question is to study the effect of food shortage, and in its severest stage the effect of famine, on the differences in lifespan by month of birth. Peak growth in-utero takes place during the third trimester. Infants born in spring experience worse nutritional conditions during the last trimester than infants born in fall. This is consistent with the result that the spring-born have a lower life expectancy than the fall-born. The hypothesis therefore is that fetuses affected by famine during their last trimester of gestation should experience higher mortality risks later in life.

Based on current research findings, however, this line of research does not seem to be very promising. Studies of cohorts born during or shortly after famine do no find increased old-age mortality. Twins have similar old-age mortality as singletons, although they usually have much lower birthweights.

The study of infectious disease, on the other hand, shows more potential. There is ample evidence that infectious disease during infancy and childhood affects late life mortality. In historical Sweden, cohorts with exceptionally high infant mortality also have higher oldage mortality. In Denmark, the month-of-birth pattern in infant mortality at the beginning of the $20^{\text {th }}$ century is positively correlated with the month-of-birth pattern in lifespan at ages 50+ at the end of the $20^{\text {th }}$ century.

To test whether infectious disease plays an important role the seasonal pattern of major outbreaks of infectious disease can be utilized. One example is the Spanish flu pandemic in 1918. Another possibility is the use of seasonal indices for the incidence of respiratory disease, gastrointestinal disease, and common childhood diseases like smallpox, whooping cough or rubella. One could test whether there is a positive correlation between these indices and the month-of-birth patterns for specific causes of death. Unfortunately, these indices are not readily available for the beginning of the $20^{\text {th }}$ century, thus, contemporary indices would have to suffice under the assumption that the seasonality did not change over time. These indices are also not available on an individual basis for the elderly population and one therefore would have to use an ecological study design. A third possibility is to use seasonal 
infant mortality as an indicator of infectious disease environment in the first three months, the second three months and the second half-year. The three time periods should reflect the developmental stages of the infants regarding the development of the immune system and the likelihood of weaning. A similar approach could be applied using seasonal adult mortality during childbearing ages to account for the disease environment of the mother during the three trimesters of pregnancy.

Future research on the month-of-birth effect in lifespan and in causes of death will have to proceed from the description of the phenomenon to finding the underlying causal mechanisms. Probably they will differ for different causes of death. Some first steps to unravel the mechanisms have been done in this monograph but much remains to be done. 


\section{APPENDIX \\ THREE METHODS OF SMOOTHING SEASONAL DATA}

How to smooth seasonal data is of crucial importance in reasearch about the month-ofbirth effect. This appendix explores three methods in order to detect whether a seasonal periodicity exists in the season-of-birth pattern in lifespan.

The first method is cosinor analysis which has been widely used in the analysis of biological rhythms generally known as chronobiology. The method was developed by Halberg and colleagues (Nelson et al. 1979) and fits a cosine function of known periodicity to the data. The second model, proposed by Jim W. Vaupel, fits cubic splines with an a-priori defined number of knots that are located at the minima/maxima. The third method fits cubic smoothing splines using a penalty function that represents the trade-off between minimizing residual error and smoothness of the curve (Reinsch 1967).

The three methods represent three approaches of detecting seasonal variation. Cosinor analysis assumes that the seasonal variation follows a functional form, namely a cosine wave with a known period. The method of fitting cubic splines with unknown position of knots is more flexible in terms of the functional form, however, similar to cosinor analysis it assumes a certain number of minima and maxima in a given period. Fitting cubic splines using a penalty function does not generate any a-prior hypothesis concerning the property of the rhythm. The trade-off between smoothness and minimizing error makes it sometimes difficult, however, to distinguish between clear fluctuations in the rhythm and imprecision of the estimation.

Cosinor Analysis

Cosinor analysis estimates function [A.1]

$$
y=\alpha_{0}+\beta \cos (t-\gamma)+\varepsilon
$$




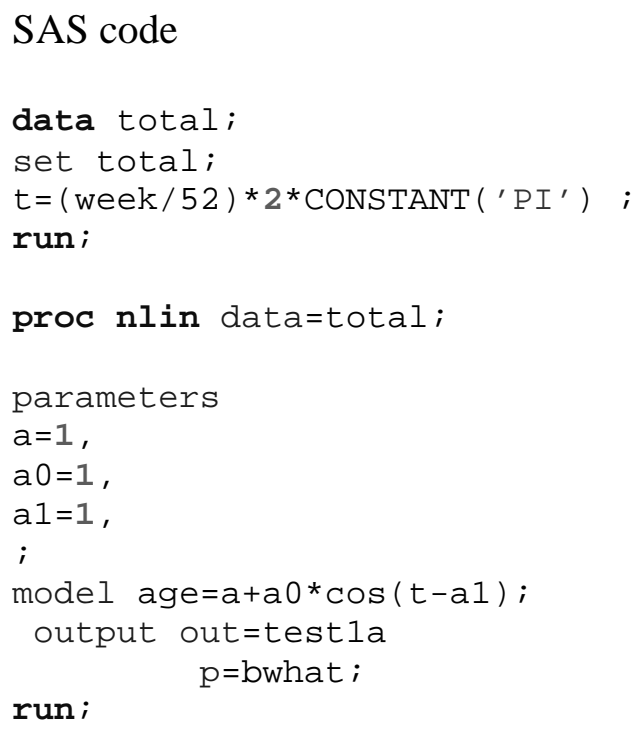

The function is implemented in SAS using proc nlin. F-test based on the sum of squares is used to test whether the sinusoidal pattern is statistically significant. Bimodal cosine functions can be implemented by defining a period of 6 months for monthly data and 26 weeks for weekly data.

\section{Cubic splines with knots located at the minima/maxima.}

Let time be denoted by $x$, with $x=0$ in week 1 and $x=1$ in week 52 . Suppose one wants to fit a smooth curve $f(x)$ with a single minimum and a single maximum and with $f(0)=f(1)$. Suppose that the minimum (or maximum) of this curve is at $X^{o}, Y^{o}$ and that the maximum (or minimum $)$ is at a subsequent point $X^{*}, Y^{*}$. Let $X=\left(x-X^{o}\right) /\left(X^{*}-X^{o}\right)$, so $X=0$ at the minimum (maximum) and $X=1$ at the maximum (minimum). Let $y=f(X)=a+b X+c X^{2}+d X^{3}$. Because $f(0)=Y^{o}$, it follows that $a=Y^{o}$. Because the derivative of $f$ with respect to $X$ evaluated at $X=0$ must be zero, it follows that $b=0$. Because $f(1)=Y^{*}$, it follows that $c+d=Y^{*}-Y^{o}$. Because the derivative of $\mathrm{f}$ with respect to $\mathrm{X}$ evaluated at $X=1$ must be zero, it follows that $2 c+3 d=0$. Solving these two formulas for $c$ and d yields $c=3\left(Y^{*}-Y^{o}\right)$ and $d=-2\left(Y^{*}-Y^{o}\right)$.

These values of $\mathrm{a}, \mathrm{b}, \mathrm{c}$ and $\mathrm{d}$ can be used to plot a cubic for $\mathrm{x}$ between $X^{o}$ and $X^{*}$. A similar procedure can be used between $X^{*}$ and $X^{o}+1$. To get values of $\mathrm{f}(\mathrm{x})$ for $x<X^{o}$, use $f(x)=f(x+1)$.

Thus, values of $X^{o}, Y^{o}$ and $X^{*}, Y^{*}$ can be used to fit two cubics that join smoothly. To find the optimal values of these four parameters, one can minimize the sum of the squared deviations between the estimated curve and the actual data.

Suppose the alternative hypothesis is that there are two minima and two maxima. Then one would have eight parameters: $X_{1}^{o}, Y_{1}^{o}, X_{2}^{o}, Y_{2}^{o}, X_{1}^{*}, Y_{1}^{*}$ and $X_{2}^{*}, Y_{2}^{*}$. One can fit four cubic splines using the method described above and estimate the eight parameters by least squares. 
This procedure is implemented using proc nlin in SAS. The Akaike information criteria, which minimizes the RSS $+2 p$ (residual sum of squares panelized by 2 times the number of parameters used in the model) is used to test informally whether the unimodal or bi-modal model fits the data best.

\section{Cubic smoothing splines}

A cubic spline with knots at $x_{i},(i=1, \ldots, n)$ is defined by

$$
f(x)=a_{i}+b_{i} x+c_{i} x^{2}+d_{i} x^{3}
$$

and subject to the restrictions that the function and the first two derivatives are continuos at the knots and at the two endpoints. The last restriction results into a periodic cubic spline. As a measure of roughness the integrated squared second derivative $\int\left(f^{\prime \prime}(x)^{2}\right) d x$ is used with smooth or slowly varying curves giving small values. A straight line, for example, gives the value of 0 . Using this measure as a roughness penalty the weighted sum

$$
S_{\lambda}(f)=\sum_{i=1}^{n}\left(y_{i}-f\left(x_{i}\right)\right)^{2}+\lambda \int\left(f^{\prime \prime}(x)^{2}\right) d x
$$

is minimized where $\lambda$ denotes the user defined smoothness parameter and controls the trade off between minimizing the residual error and minimizing local variation. A large value of $\lambda$ gives more weight to the smoothness of the function while a $\lambda$ value of 0 minimizes the residual error and results into the interpolating spline. The procedure is implemented by using the SAS IML function splinec and the type option 'periodic'.

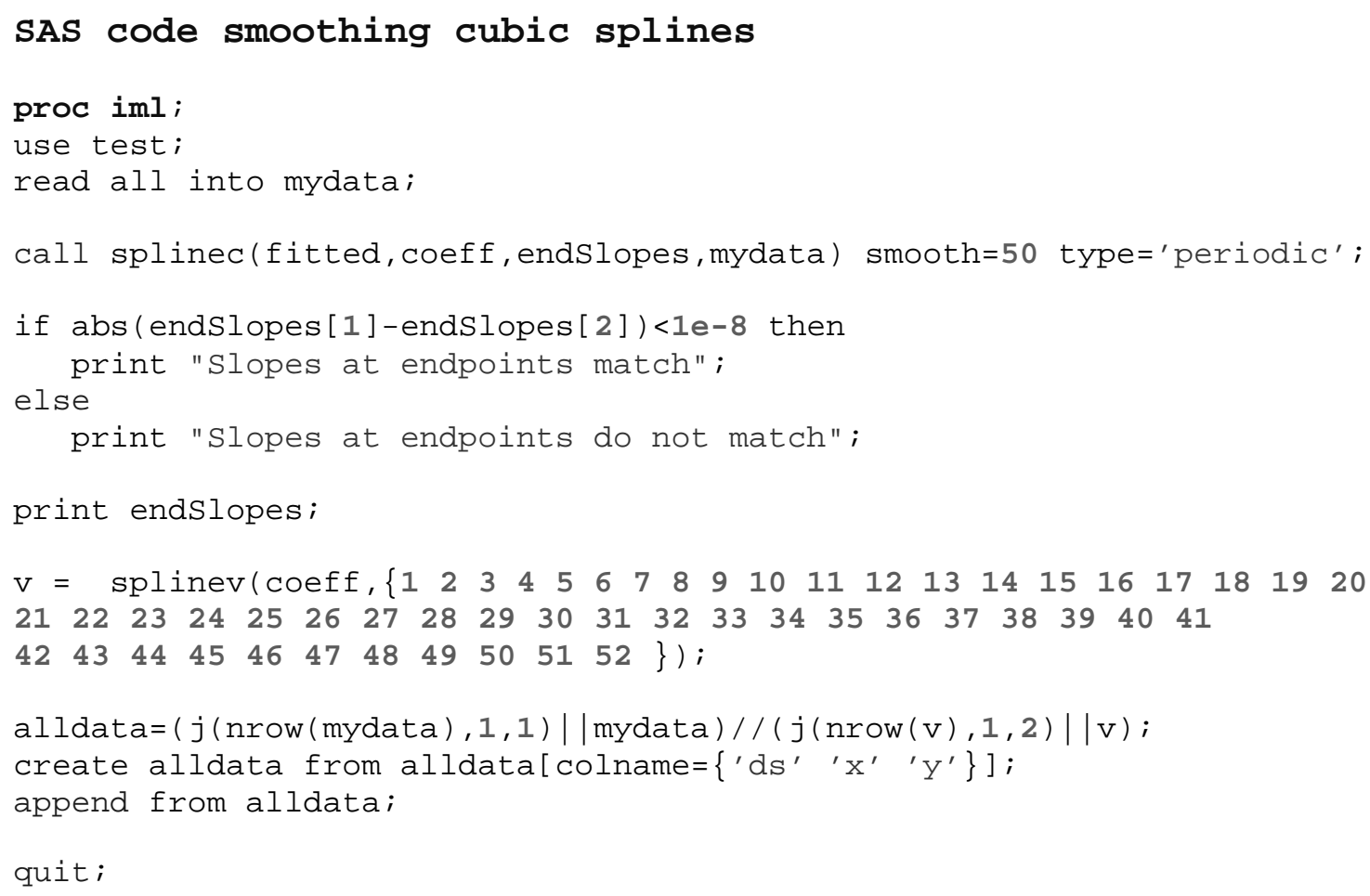




\begin{tabular}{|c|c|}
\hline \multicolumn{2}{|c|}{ Cubic splines with unknown position of knots } \\
\hline SAS code 2 knots & SAS code 4 knots \\
\hline 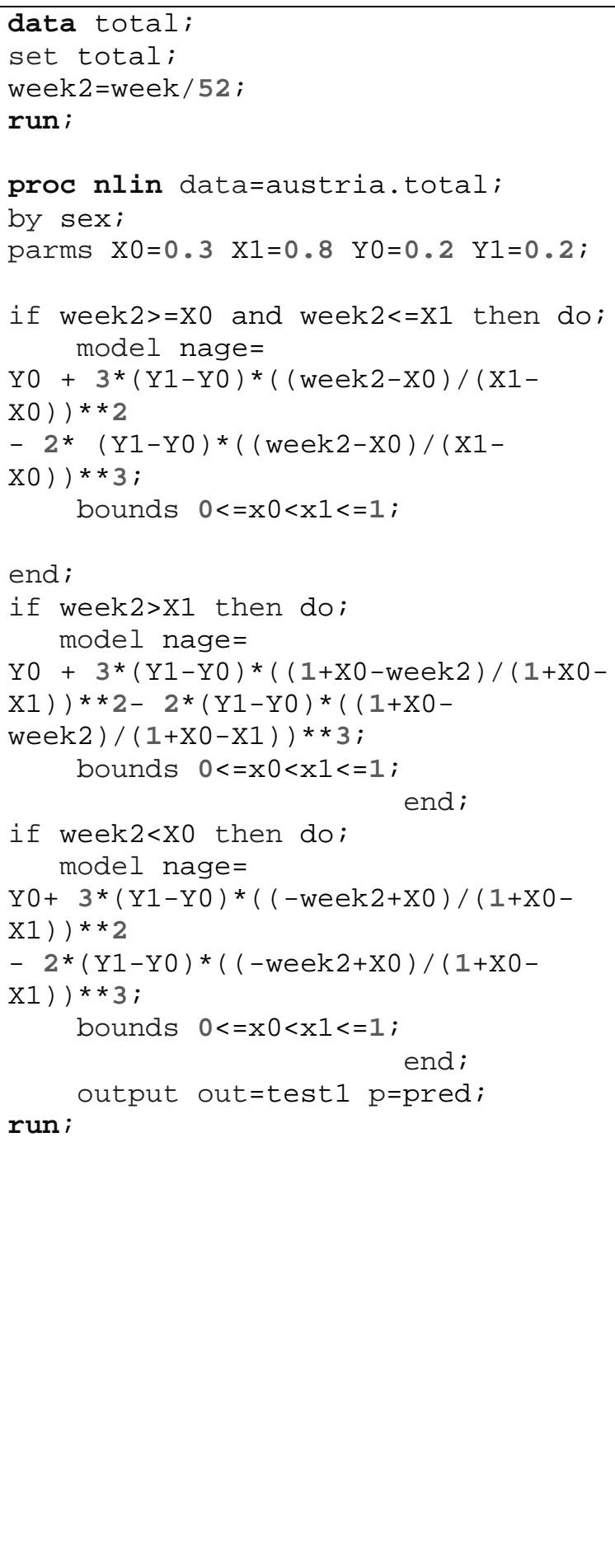 & 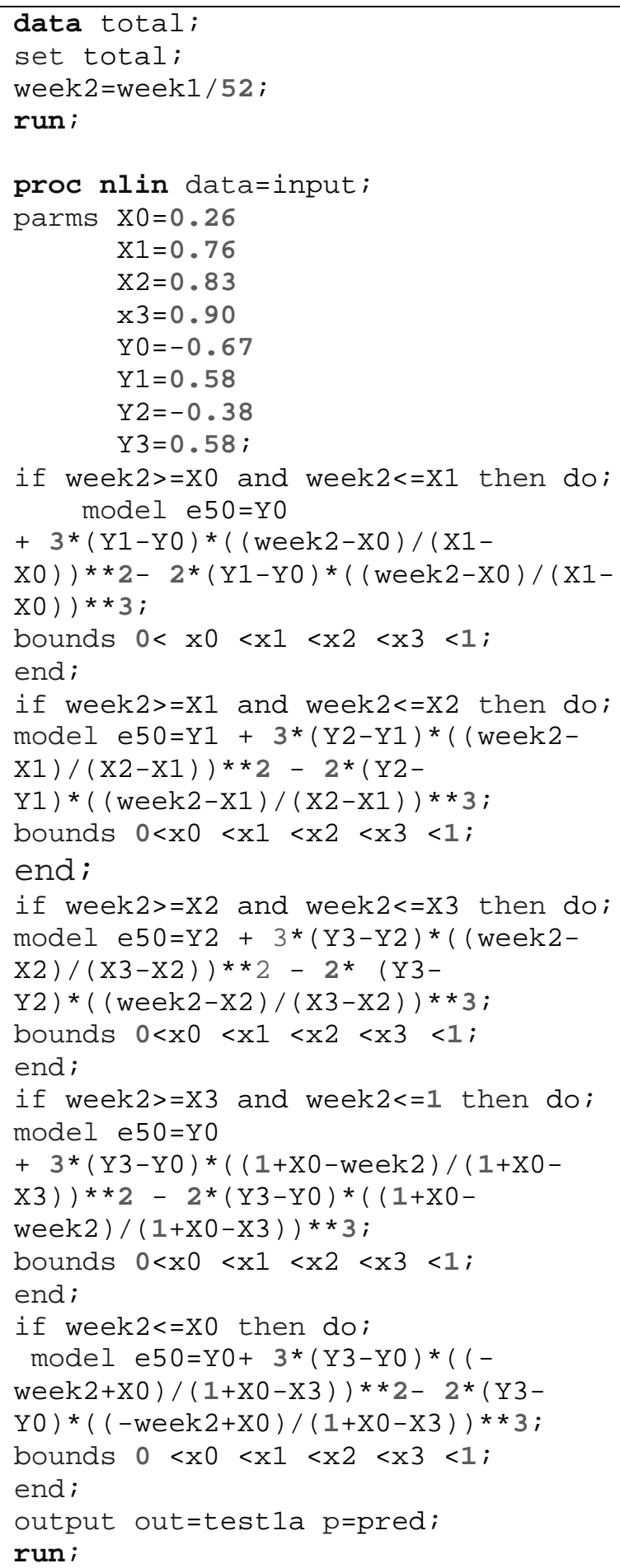 \\
\hline
\end{tabular}




\section{Results}

All three methods are used to estimate smoothed functions of week of birth on individual ages at death for Austria and Australia, and of month of birth on individual ages at death for Hawaii. In other words, the results are based on individual death records of 681,677 Austrians, 219,820 native-born Australians, and 42,969 decedents born in Hawaii. For the Danish register and twin data remaining life expectancy at age 50 by week of birth is calculated and the resulting 52 values are smoothed by applying the three different methods. Table A.1 contains the resulting maxima/minima of the three estimation procedures, together with the maximum difference in mean age at death and the Akaike information critera for the first two methods, and the R2.

Figure A.1: Austria: Cosinor analysis (black), cubic splines with 2 knots (red), and smoothing cubic splines (light blue). Differences in mean age at death from average age at death by week of birth
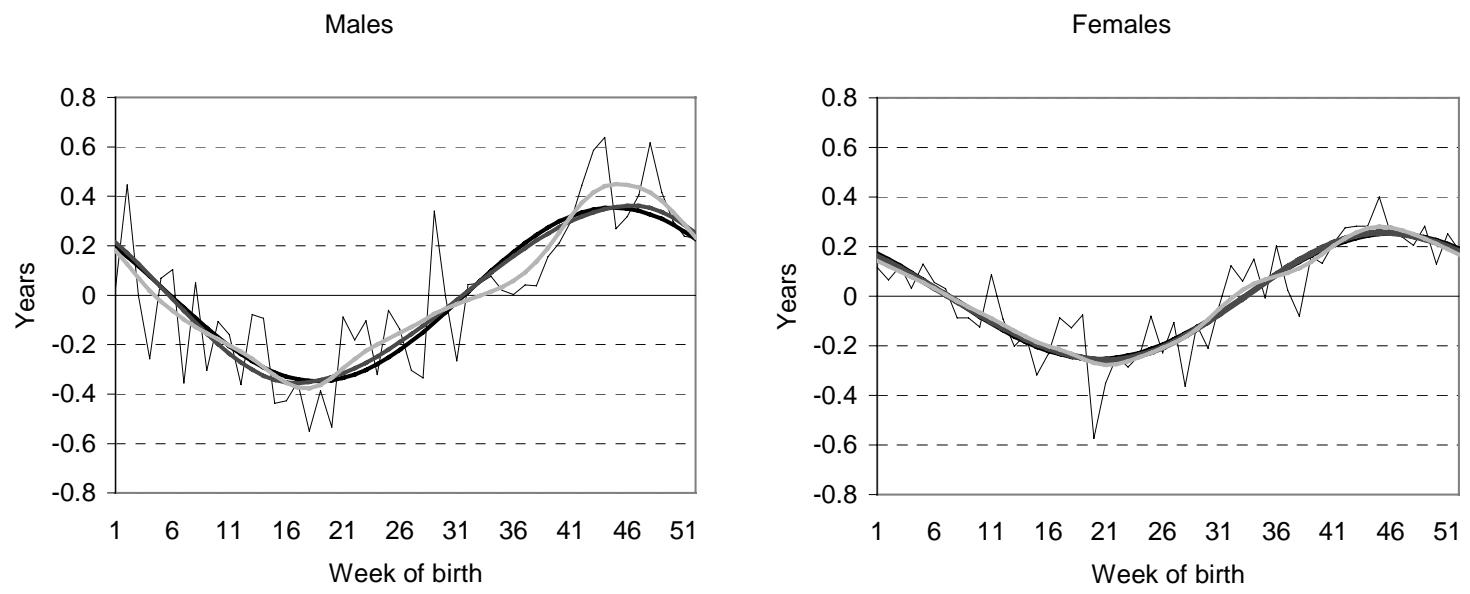

Austria

All three methods come to very similar results with the minimum and maximum only differing by one to two weeks. The closeness of the three smoothed trajectories indicates that the underlying week-of-birth pattern is well described by a sinusoidal wave, particularly for females. For males the smoothing cubic splines estimate a slightly higher mean age at death for the fall-born, which results into a maximum difference of 0.83 years as compared to 0.7 years (cosinor analysis and cubic splines). 
Table A.1: Results of the three estimation procedures

\begin{tabular}{|c|c|c|c|c|c|c|c|c|c|c|}
\hline & \multirow{2}{*}{\multicolumn{2}{|c|}{$\begin{array}{l}\text { Cubic splines with } 2 \\
\text { knots } \\
95 \% \mathrm{CF}\end{array}$}} & \multicolumn{4}{|c|}{ Cubic splines with 4 knots } & \multicolumn{2}{|c|}{ Cosinor analysis } & \multicolumn{2}{|c|}{ Cubic smoothing splines } \\
\hline & & & $\begin{array}{l}\text { Primary } \\
\text { minimum/ } \\
\text { maximum }\end{array}$ & $95 \% \mathrm{CF}$ & $\begin{array}{l}\text { Secondary } \\
\text { minimum/ } \\
\text { maximum }\end{array}$ & $95 \% \mathrm{CF}$ & & $95 \% \mathrm{CF}$ & $\begin{array}{l}\text { Primary } \\
\text { minimum/ } \\
\text { maximum }\end{array}$ & $\begin{array}{l}\text { Secondary } \\
\text { minimum/ } \\
\text { maximum }\end{array}$ \\
\hline \multicolumn{11}{|l|}{ Austria males } \\
\hline min week & 17 & $(13-20)$ & & & & & 19 & $(17-20)$ & 18 & \\
\hline max week & 46 & $(43-50)$ & & & & & 45 & $(43-46)$ & 45 & \\
\hline $\max$ dif & 0.7 & & & & & & 0.70 & & 0.83 & \\
\hline $\mathrm{R}^{2}$ & 0.00053 & & & & & & 0.00052 & & & \\
\hline AIC & 35390634 & & & & & & 35390984 & & & \\
\hline \multicolumn{11}{|l|}{ Austria females } \\
\hline min week & 21 & $(17-25)$ & & & & & 20 & $(19-22)$ & 21 & \\
\hline max week & 45 & $(41-49)$ & & & & & 46 & $(45-48)$ & 45 & \\
\hline $\max$ dif & 0.5 & & & & & & 0.51 & & 0.56 & \\
\hline $\mathrm{R}^{2}$ & 0.00033 & & & & & & 0.00033 & & & \\
\hline AIC & 36132302 & & & & & & 36132349 & & & \\
\hline \multicolumn{11}{|l|}{ Australia males } \\
\hline min week & 49 & $(42-4)$ & & & & & 45 & $(43-47)$ & 25 & \\
\hline max week & 11 & $(3-18)$ & & & & & 19 & $(17-21)$ & 45 & \\
\hline $\max$ dif & 0.5 & & & & & & 0.54 & & 0.6 & \\
\hline $\mathrm{R}^{2}$ & 0.00028 & & & & & & 0.00038 & & & \\
\hline AIC & 10666475 & & & & & & 10692366 & & & \\
\hline \multicolumn{11}{|l|}{ Australia females } \\
\hline min week & 3 & $(49-9)$ & & & & & 45 & $(42-49)$ & 44 & \\
\hline max week & 6 & $(52-12)$ & & & & & 19 & $(16-23)$ & 20 & \\
\hline max dif & 0.4 & & & & & & 0.40 & & 0.5 & \\
\hline $\mathrm{R}^{2}$ & 0.00015 & & & & & & 0.00018 & & & \\
\hline AIC & 11487292 & & & & & & 11757810 & & & \\
\hline \multicolumn{11}{|l|}{ Hawaii males } \\
\hline min month & 9 & $(6-12)$ & & & & & 10 & $(11-8)$ & 9 & \\
\hline max month & 2 & $(11-5)$ & & & & & 2 & $(1-4)$ & 2 & \\
\hline $\max \operatorname{dif}$ & 0.7 & & & & & & 0.66 & & 0.6 & \\
\hline
\end{tabular}




\begin{tabular}{|c|c|c|c|c|c|c|c|c|c|c|}
\hline $\mathrm{R}^{2}$ & 0.00051 & & & & & & 0.00049 & & & \\
\hline AIC & 2640067 & & & & & & 2640116 & & & \\
\hline \multicolumn{11}{|c|}{ Hawaii females } \\
\hline min month & 10 & $(8-13)$ & & & & & 9 & $(10-7)$ & 10 & \\
\hline max month & 3 & $(2-5)$ & & & & & 3 & $(2-5)$ & 3 & \\
\hline $\max$ dif & 0.7 & & & & & & 0.72 & & 0.7 & \\
\hline $\mathrm{R}^{2}$ & 0.00055 & & & & & & 0.00052 & & & \\
\hline AIC & 2366658 & & & & & & 2366716 & & & \\
\hline \multicolumn{11}{|c|}{ Denmark males register } \\
\hline min week & 13 & $(8-19)$ & No conversior & & & & 18 & $(16-20)$ & 13 & 44 \\
\hline max week & 50 & $(45-3)$ & & & & & 44 & $(42-46)$ & 38 & 50 \\
\hline $\max$ dif & 0.4 & & & & & & 0.40 & & 0.4 & 0.1 \\
\hline $\mathrm{R}^{2}$ & 0.51 & & & & & & 0.65 & & & \\
\hline AIC & 16.71 & & & & & & 4.49 & & & \\
\hline \multicolumn{11}{|c|}{ Denmark females register } \\
\hline min week & 12 & $(9-16)$ & & & & & 21 & $(19-23)$ & 16 & \\
\hline max week & 3 & $(52-7)$ & & & & & 47 & $(45-49)$ & 51 & \\
\hline $\max$ dif & 0.4 & & & & & & 0.38 & & 0.4 & \\
\hline $\mathrm{R}^{2}$ & 0.74 & & & & & & 0.62 & & & \\
\hline AIC & 16.45 & & & & & & 4.62 & & & \\
\hline \multicolumn{11}{|c|}{ Denmark male twins } \\
\hline min week & 3 & $(50-7)$ & 14 & $(7-20)$ & 43 & $(39-47)$ & 17 & $(12-21)$ & 12 & 42 \\
\hline max week & 5 & $(2-7)$ & 40 & $(34-45)$ & 47 & $(43-51)$ & 43 & $(38-47)$ & 34 & 50 \\
\hline $\max$ dif & 1.25 & & 1.25 & & 1.24 & & 1.1 & & 0.8 & 0.52 \\
\hline $\mathrm{R}^{2}$ & 0.31 & & 0.37 & & & & 0.25 & & & \\
\hline AIC & 29.79 & & 35.89 & & & & 27.74 & & & \\
\hline \multicolumn{11}{|c|}{ Denmark female twins } \\
\hline min week & 5 & $(3-7)$ & & & & & 24 & $(24-25)$ & 19 & \\
\hline max week & 10 & $(7-12)$ & & & & & 50 & $(50-51)$ & 52 & \\
\hline $\max$ dif & 0.42 & & & & & & 0.39 & & 0.4 & \\
\hline $\mathrm{R}^{2}$ & 0.95 & & & & & & 0.68 & & 0.4 & \\
\hline AIC & 8.38 & & & & & & 4.47 & & & \\
\hline
\end{tabular}




\section{Australia}

Australia is one example where the three different methods estimate three very distinct maxima. For males the maximum ranges from week 11 (cubic spline) to week 21 (cubic smoothing spline); the minimum differs only by 4 weeks. The reason for the divergence of the four methods is that the maximum is a plateau stretching over most of the fist half-year rather than a single peak. The cosinor analysis positions the maximum in the middle of the plateau, the cubic spline at the beginning and the smoothing spline at the end of the plateau. For females there is a sharp discontinuity in mean ages at death around week six. While both the cosinor analysis and the smoothing spline smooth the discontinuity, the cubic spline method locates the minimum and maximum at the beginning and the end of the discontinuity. Although the same value for the smoothing parameter is used for the smoothing splines of males and females the female trajectory is less smooth. This raises the question of how to define the optimal smoothing value.

Figure A.2: Australia: Cosinor analysis (black), cubic splines with 2 knots (red), and smoothing cubic splines (light blue). Differences in mean age at death from average age at death by week of birth
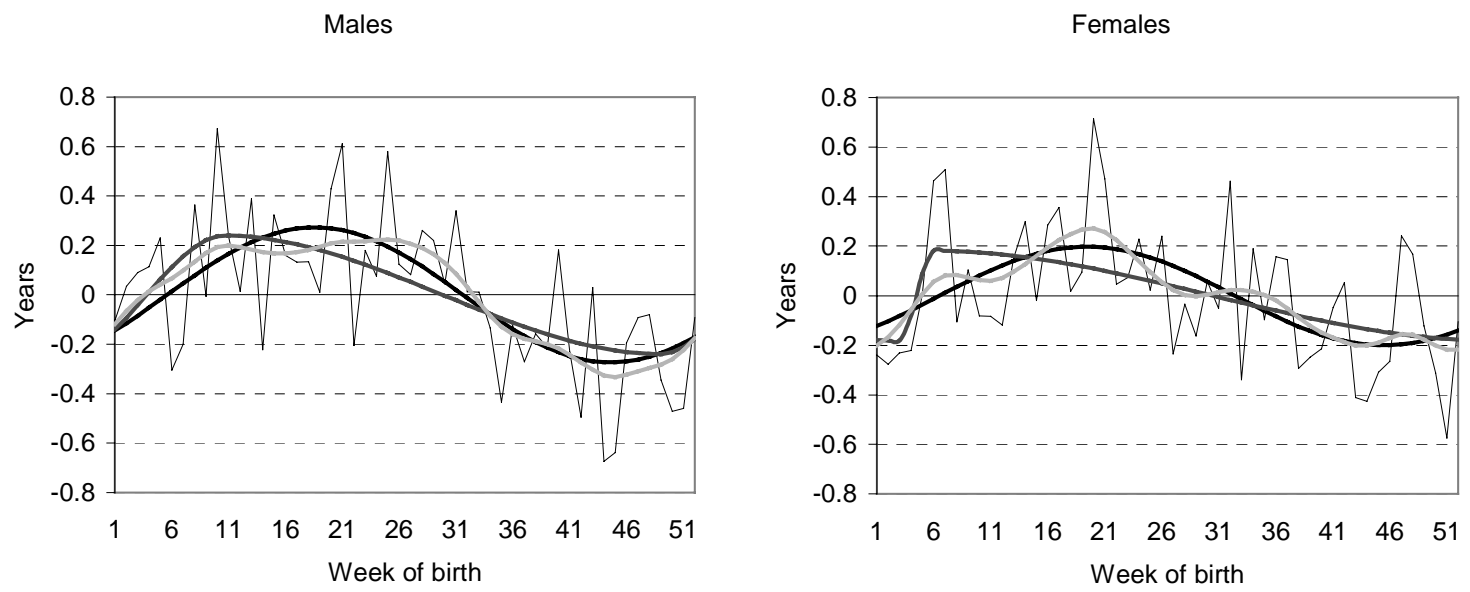
Denmark register population

Similar to Australia, the minimum and the maximum are two plateaus rather than two peaks. Again the cosinor analysis tends to put the acrophase in the middle of the plateau while the cubic spline method puts it at the end or the beginning. Sharp discontinuities in the data influence the estimation of the position of the minimum/maximum when using the cubic spline method. The smoothing cubic splines tend to model the plateaus more appropriately. For males this method indicates a secondary trough for the fall born which is overseen when using the other two methods. A similar secondary trough exists in the Danish twin register. In order to account for the secondary trough among the male fall-born using the cubic spline method, a model with two peaks and two troughs was estimated. This model, however, failed to converge.

Figure A.3: Denmark register population: Cosinor analysis (black), cubic splines with 2 knots (red), and smoothing cubic splines (light blue). Differences in remaining life expectancy at age 50 from average remaining life expectancy at age 50 by week of birth.
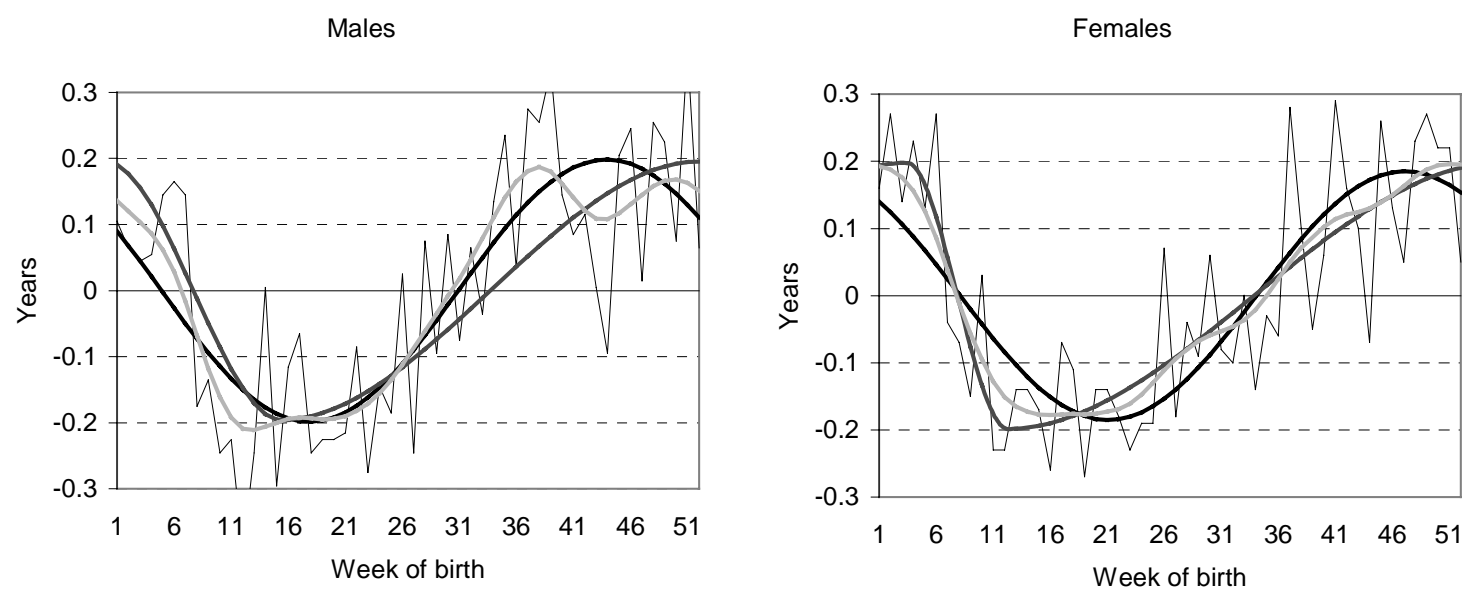

Danish twin registry

The differences in life expectancy by week of birth very much resemble the pattern of the total population. In both populations, therefore, the three methods come to very similar results. The cosinor analysis positions the minimum and the maximum in the middle of the plateaus, the cubic spline method with one peak and one trough is heavily influenced by the 
strong discontinuity in the data at the beginning of the year. The smoothing cubic splines are more appropriate in modeling the plateaus and find a secondary trough among the fall-born males. Contrary to the model for the total Danish population, the cubic spline model with two troughs and two peaks converges and indicates a secondary trough for the fall-born.

Figure A.4: Danish twins: Cosinor analysis (black), cubic splines with 2 knots (red dahed), cubic splines with 4 knots (red solid) and smoothing cubic splines (light blue). Differences in remaining life expectancy at age 6 from average remaining life expectancy at age 6 by week of birth.
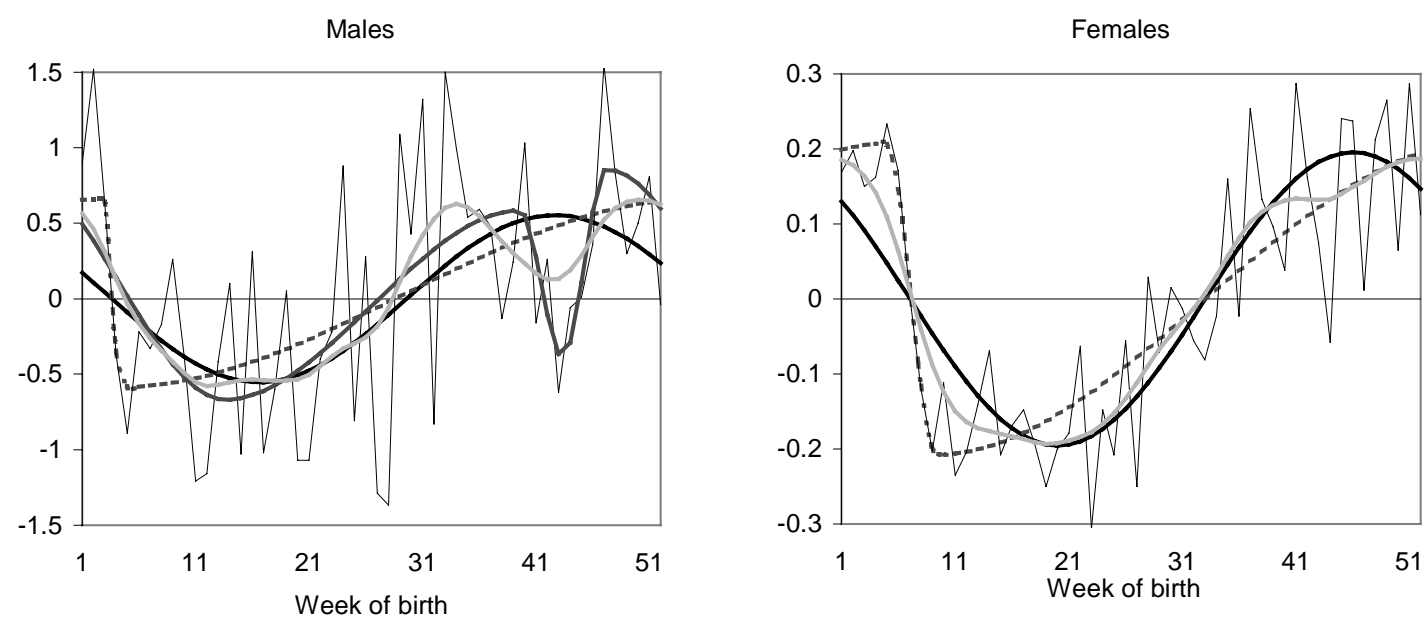

Hawaii:

Contrary to the other data ages at death for Hawaii are only given by month of birth. The cosinor analysis and the cubic splines give very similar results. Since a distinct maximum exists all three methods position the maximum in the same month, namely February. Again the three methods give diverging result when it comes to the minimum. Only the smoothing cubic splines position the minimum in the month with the minimum observed value. 
Figure A.5: Hawaii: Cosinor analysis (black), cubic splines with 2 knots (red dahed), and smoothing cubic splines (light blue). Differences in mean age at death from average age at death by week of birth.
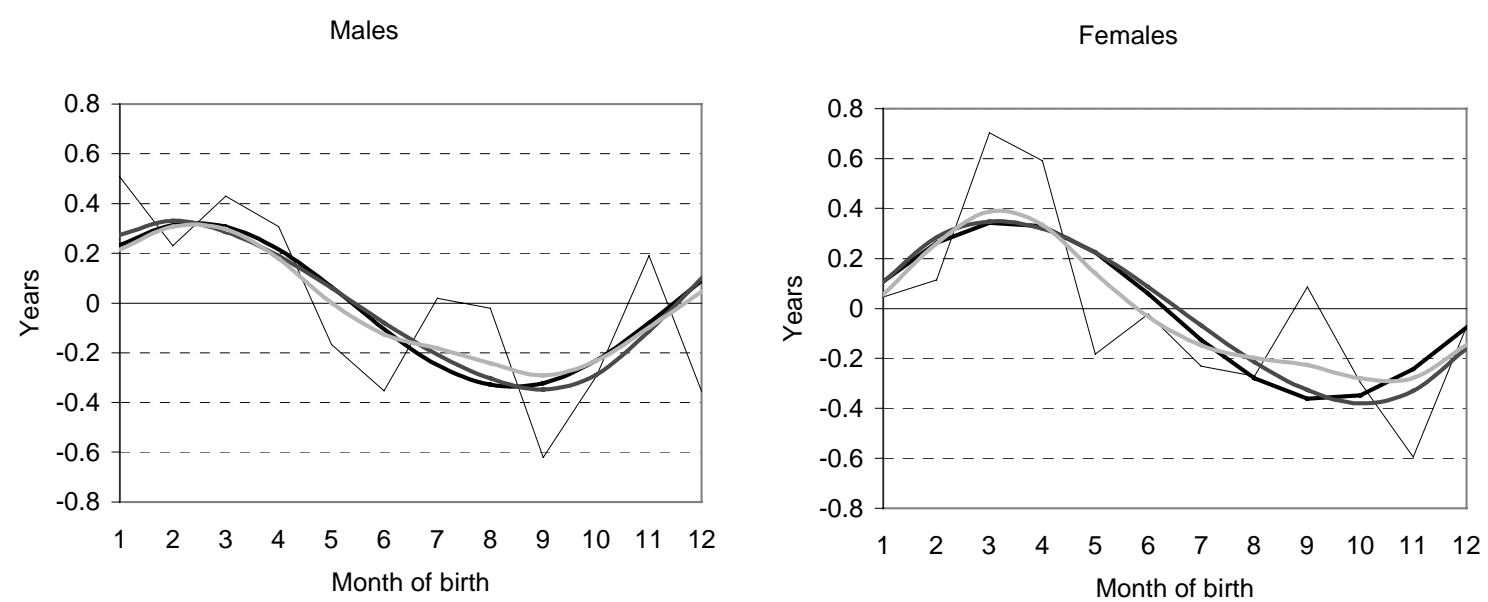

Discussion and conclusion:

In the case of a sinusoidal wave all three methods perform equally well. If the underlying function, however, departs from a sinusoidal form the three methods have different advantages and disadvantages. In terms of the exact location of the minimum/maximum the smoothing cubic splines seem to perform best. They are purely descriptive and are not based on assumptions concerning the underlying form. In particular they perform better if there is not a distinct minimum/maximum but rather a plateau. However, the smoothness of the curve depends on the smoothing factor, which is chosen by the user and there is no optimal criteria for choosing the smoothing factor. Large smoothing factors result in a smoother function but have the disadvantage that the spline approaches the mean of the data. This implies that the maximal difference may be underestimated/overestimated depending on the smoothness of the function.

The cosinor analysis and the cubic spline method with two knots give very similar results concerning the maximum difference in lifespan but different results for the location of the maximum/minimum. In terms of a plateau rather than a single peak/trough the cosinor analysis puts the acrophase in the middle of the plateau, the cubic spline method tends to put the knots at the beginning or end of the plateau. With the latter method strong discontinuities in the data tend to influence the estimation of the location of the knots. 
One can conclude that the latter two methods are preferable if the emphasis is on the statistical test of whether a seasonal pattern exists. If the emphasis is on describing the pattern most accurately then the cubic smoothing splines perform best. The monograph follows the approach that in the analysis of total mortality on population level the emphasis is more on the statistical test of whether a seasonal pattern exists. Therefore cosinor analysis is the method of choice. In the analysis of the month-of-birth pattern of specific causes of death more emphasis is put on the exact description of the pattern and therefore smoothing cubic splines are chosen. In this case the test whether the differences in mean age at death by month of birth are statistically significant is based on a generalized linear model. 


\section{REFERENCES}

Aalberse, R C, Nieuwnhuys, E J, Hey, M, Stapel, S O. 1992. Horoscope effect not only for seasonal but also for non-seasonal allergens, Clinical and experimental Allergy 22(11):10031006.

Adair, LS and Pollit, E, 1983, Seasonal variation in pre- and postpartum maternal body measurements and infant birthweights, Am J. Phys. Anthropol. 62: 325-331.

Adair, LS and Pollit, E, 1985, Outcome of maternal nutritional supplementation: A comprhensive review of the Bacon Chow Study, Am. J. Clin. Nutr. 41: 948-978.

Alton, A, Massey, A. 1998, Date of birth and achievement in GCSE and GCE A-Level, Educational Research 40(1):105-109

Angrist JD, Krueger, AB, 1991, Does Compulsory school Attendance affect Schooling and Earnings?, The Quarterly Journal of Economics 106(4):979-1014

Bantje, H, and Niemeyer, R, 1984, Rainfall and birthweight distribution in rural Tanzania, J. Biosoc. Sci 16:375-384

Barak, Y., Ring, A., Sulkes, J., Gabbay, U., and Elizur, A. 1995. Season of birth and autistic disorder in Israel . American Journal of Psychiatry 152(5):798-800.

Barker DJP ,2002, Commentary: Components in the interpretation of the high mortality in the county of Finnmark , Int. J. Epidemiol. 31: 309-310.

Barker DJP, Osmond C ,1986a, Infant mortality, childhood nutrition, and ischemic heart disease in England and Wales, Lancet 10(1):77-81

Barker DJP, Osmond C ,1986b, Childhood respiratory infection and adult chronic bronchitis in England and Wales, British Medical Journal 293(6557): 1271-5

Barker DJP, Osmond C ,1987, Death rates from stroke in England and Wales predicted from past maternal mortality , British Medical Journal 295 (6590):83-6

Barker DJP, Osmond C, Golding J, Kuh, D, Wadsworth MEJ,1989a, Growth in-utero, blood pressure in childhood and adult life, and mortality from cardiovascular disease, British Medical Journal 298(6673):564-567

Barker DJP, Osmond, C, Golding J,1990, Height and mortality in the countries of England and Wales, Annals of Human Biology 17(1):1-6

Barker, D.J.P. 1995. Fetal origins of coronary heart disease. BMJ 311, 171-174

Barker, D.J.P. 1994. Mothers, babies and diseases in later life (London: BMJ Publishing Group). 
Bengtsson T, Lindstrom M,2001, Childhood misery and disease in later life: The effects on mortality in old age of hazards experienced in early life,southern Sweden, 1760-

1894,Population Studies (3): 263-277

Ben-Shlomo Y, Kuh D ,2002, A life course approach to chronic disease epidemiology: conceptual models, empirical challenges and interdisciplinary perspectives, Int. J. Epidemiol. 31: 285-293.

Ben-Shlomo Y, Davey Smith G,1991, Deprivation in infancy or in adult life: which is more important for mortality risk?, Lancet 2: 530-534

Bernstein L, Chilvers, C, Murrels, T, et al. 1986. Month of birth of men with malignant germ cell tumors of the testis. Journal of Epidemiology and Community Health 40: 214-217.

Biggar, JC, 1980, Who moved among the elderly, 1965-1970: A comperison of types of older movers, Research on Aging 2: 73-91.

Bleuler, M., 1991, Seasonality of births of future schizophrenics and seasonality of depressive episodes (letter) Schizophr. Bull 17, 191-192

Block, T., Pedersen, C. R., Volund, A., Pallesen. C., and Buschard, K. 1994. Perinatal determinants among children who later develop IDDM. Diabetis Care 17:1154-1157.

Bobak M, \& Gjonca A. 2001. The seasonality of live birth is strongly influenced by sociodemographic factors, Hum Reprod 16 (7): 1512-1517.

Bolton, P., Pickles, A., Harrington, R., Mcdonald, H, and Rutter, M. 1992. Season of birth: issues approaches and findings for autism. Journal of Child Psychological Psychiatry 33:509530.

Bound, J, Jaeger, DA, 1996, On the validity of season of birth as an instrument in wage equations: a comment on Angrist and Krueger's "Does compulsory school attendance affect schooling and earnings, NBER working paper 5835, Cambridge, Ma.

Bradbury, J. H. and Miller, G. A. 1985. Season of birth in schizophrenia: a review of evidence, methodology, and etiology. Psychological Bulletin 98:569-594.

Breitinger, FE, 1966, Advances in the Biology of Human Populations 139-148, Hungarian Academy of Sciences, Budapest.

Breschi, M. \& Bacci, M.L. 1996 Month of birth as a factor in children's survival. in Infant and child mortality in the past, eds. Desjardins, B. \& Brignoli, P. (Oxford, Clarendon Press, 1996), pp. 157-173.

Brown KH, Black RE, and Becker S 1982 Seasonal changes in nutritional status and the prevaence of malnutrition in longitudinal study of young children in rural Bangladesh. American Journal of Clinical Nutrition 36:303-313. 
Brown, KH, Black, RE, Robertson, AD, and Becker, S, 1985, Effects of season and illness on the dietary intake of weanlings during longitudinal studies in rural Bangladesh, Am. J. Clin. Nutr. 41: 343-355.

Brownlee J,1916, Certain considerations regarding the epidmiology of phthisis pulmonalis, Public Health 29:130-145

Brun, T, 1984, Physiological measurement of activity among adults under free living conditions, in Pollit, E, Amante, P (eds.), Energy intake and Activity, New York: Alan T. Liss, Inc pp131-156

Carroll, R. E. and Haddon, W. jr. 1964. Birth characteristics of persons dying of cerebral aneurysms. Journal of Chronic Diseases 17:705-711.

Caselli G, Vallin J, Vaupel JW, et al. 1987. Age-specific mortality trends in France and Italy since 1900 - period and cohort effects, European J Popul 3 (1): 33-60.

Caselli G, Capocaccia R, 1989, Age-period-cohort and early mortality: an analysis of adult mortality in Italy, Population Studies 43:133-153

Caselli G., 1990, The influence of Cohort effects on differentials and trends in mortality. In (Vallin, JS, D'Souza S, Palloni A eds): Measurement and Analysis of Mortality: New Approaches,Oxford, England, Clarendon Press, p 229-249

Centola G., \& Eberley S., 1999. Seasonal variations and age-related changes in human sperm count, motility, motion parameters, morphology, and white blood cell concentration. Fertility and Sterility 72:803-808

Chambers, R, Longhurst, R, and Pacey, A (eds.) 1981, Seasonal Dimensions to rural poverty, London: Frances Pinter Publishers

Chen, L.C., Chowdhury, AKMA, Huffman, SL 1979, Seasonal dimensions of energy protein malnutrition in rural Bangladesh: the role of agriculture, dietary malnutrition, and infection, Ecol Food Nutr 8: 175-87.

Chenoweth LB and Canning RG 1941 Relation of season of birth to certain attributes of students. Human Biology 13:533-540.

Chew, F T, Goh, D Y T, Teo, J, Quak, S H, Lee, B W. 1998. Month of birth and childhood atopic disease in the tropics. Allergy 53(10): 962-968.

Chotai, J., Salander Renberg, E., and Jacobsson, L. 1999. Season of birth associated with the age and method of suicide. Archive of Suicide Research 5:245-254.

Christensen K., Orstavik K.H., Vaupel, J.W ,2001: The x-chromosome and the female survival advantage: an example of the intersection between genetics, epidemiology and demography, Ann N Y Acad Sci.:954:175-83

Christensen, K, Stovring, H, and McGue, M, 2001, Do genetic factors contribute to the association between birthweight and blood pressure, J Epidmiol Comm Health 55: 583-587. 
Christensen, K.; Wienke, A.; Skytthe, A.; Holm, N.V.; Vaupel, J.W.; Yashin, A.I., 2001, Cardiovascular mortality in twins and the fetal origins hypothesis, Twin Research, 4:3, 344349.

Clark R. 1993. Water: The International Crisis. Cambridge: MIT Press.

Coale, AJ \& Kisker EE. 1990. Defects in Data on Old Age Mortality in the United States, Asian and Pacific Population Forum 4(1).

Cole, TJ, 1993, Seasonal effect on physical growth and development, in Ulijaszek, SJ, and Strickland, SS, (eds.), Soasonality and Human Ecology, Society for the S tudy of Human Biology Symposium Series: 35, Cambridge: Cambridge University Press .

Colwell R.R. 1996. Global climate and infectious disease: the cholera paradigm. Science 274:2025-31.

Dahlquist, G. G. and Källen, B. A. J. 1996. Time-spacing clustering of date birth in childhood-onset diabetis. Diabetis Care 19:328-332.

Dalen, P. 1975. Season of birth: A study of Schizophrenia and other mental disorders. Amsterdam.

Datta, BND, 1978, Epidemiology of gastroenteritis of preschool children in slum areas in New Delhi with special reference to helminth and parasitic infection. Indian J. Pediatr. 45: 305-309.

Davey Smith G, Kuh D ,2001, Commentary: William Ogilvy Kermack and the childhood origins of adult health and disease, Int. J. Epidemiol. 30: 696-703.

Davey Smith, G., Harding, S. \& Rosato, M. 2000. Relation between infant's birthweight and mothers' mortality: prospective observational study. Brit Med J 320, 839-840.

Davey Smith, G., Hart, C., Ferrell, C., et al. 1997. Birthweight of offspring and mortality in the Renfrew and Paisley study: prospective observational study. Brit Med J 315, 1189-1193.

de Montis, G. 1998. Circannual rhythm for IgE-dependent hypersensitivity to house dust mites according to birthdate. Interpretation and practical consequences for prevention, Bulletin del Academie Nationale de Medicine 182(8):1697-1707.

Derrick, VPA,1927, Observations on (1) errrors in Age in the Population Statistics of England and Wales and (2) the changes in mortality indicated by the National Records ,Journal of the Institute of Actuaries 58:117-159

Dirks, R.T., \& Duran, N. 2001. African American dietary patterns at the beginning of the 20th century, Journal of Nutrition 131 (7): 1881-1889.

Doblhammer G., \& Vaupel J.W. 2001. Lifespan depends on month of birth. Proceedings of the National Academy of Sciences of the United States of America, 98:5, 2934-2939. 
Doblhammer, G, Rodgers, J, Rau, R,. 2000, Seasonality of birth in Nineteenth and Twentieth Century Austria", Social Biology 47 (3): 201-217.

Dorling D, Mitchell R, Shaw M, et al.,2000, The Ghost of Christmas Past: health effects of poverty in London in 1896 and 1991,British Medical Journal 321 (7276): 1547-1551

Dudink, A., 1994, Birth date and sporting success, Nature 368:592.

Duffy, D. L. and Mitchell, C. A. 1991. Respiratory symptoms in Queensland and Australia schoolchildren - an association between month of birth and respiratory illness. Clinical \& Experimental Allergy 21(2):231-234.

Dyson, L.K. 2000. American Cuisine in the 20th Century, FoodReview 23(1),2-7.

Eagles, J. M., Andrew, J. E., Johnston, M. I., Easton, E. A., and Millar, H. R. 2001. Season of birth in females with Anorexia nervosa in Northeast Scotland. The International Journal of Eating Disorders 30(2):167-175.

Ekbom, A, Daszak, P, Kraaz, W, Wakefield, AJ, 1996. Crohn's disease after in-utero measles virus exposure, Lancet, 348: 515-517.

Elford J, Shaper AG, Whincup P,1992, Early Life Experience and Cardiovascular-Disease Ecologocal Studies,J Epidemiol Commun H 46 (1): 1-8

Elo, I. T. \& Preston, S. H. 1992. Effects if Early-Life conditions on adult mortality: a review. Population Index 58(2):186-212.

Elo, I. T. \& Preston, S.H. 1996. Educational differentials in mortality: United States, 1979-85. Social Science\& Medicine, 42(1):47-57

Eriksson JG, Forsen T, Tuomilehto J, Osmond C, Barker DJP,2000,Fetal and childhood growth and hypertension in adult life,Hypertension 36:790-794

Eriksson JG, Forsen T, Tuomilehto J, Osmond C, Barker DJP,2001,Early growth and coronary heart disease in later life: longitudinal study, British Medical Journal 322:949-953

Eriksson JG, Forsen T, Tuomilehto J, Winter PD, Osmond C, Barker DJP,1999,Catch-up growth in childhood and death from coronary heart disease: longitudinal study, British Medical Journal 318:427-31

Eriksson, NE, \& Holmen, A. 1996. Skin prick tests with standardized extracts of inhalant allergenens in 7099 adult patients woth asthma or rhinitis: Cross-sensatizations and relationships to age, sex, month of birth and year of testing, Journal of investigational Allergology \& Clinical Immunology 6(1): 36-46.

Erel, F, Karaayvaz, M, Caliskaner, Z, Ozanguc, N. 1998. The allergen spectrum in Turkey and the relationship between allergens and age, sex, birth month, birthplace, blood groups and family history of atopy, Journal of Investigattional Allergology and Clinical Immunology 8(4):226-233. 
Eysenck HJ, Nias DKB (1982) Astrology. Science or Superstition? London: Gloucester Mansions, Cambridge Circus.

Fallis G and Hidditch J (1989) A comparison of seasonal variation in birthweights between rural Zaire and Ontario. Canadian Journal of Public Health 80 (3):205-208.

Feltbower, R, Pearce, M S, Dickinson, H O, Parker, L, McKinney, P A.2001. Seasonality of birth for cancer in Northern England, UK, Paedriatric and Perinatal Epidemiology 15:338345.

Fichera, G., Arpi, M. L. Squatrito S., Purello, F, Ashkenazi, I., and Laron, Z. 2001.

Seasonality of birth in children (0-14 years) with diabetis mellitus type 1 in the District of Catania. The Journal of Pediatric Endocrinology \& Metabolism14:95-96.

Fitt, A. B., 1955, The Heights and Weights of Men according to Month of Birth, Human Biology 27:138-142.

Fitt, AB, 1941, Seasonal Influence on Growth, Function and Inheritance, New Zealand Council for Educational Research, Oxford University Press.

Fligstein N, 1981, Going North. Migration of Blacks and Whites from the South, 1900-1950, New York, Academic Press

Floud, R., Wachter K. \& Gregory A. 1990. Height, health and history (Cambridge: Cambridge University Press).

Flynn JM, Rahbar, MH, Bernstein, AJ, 1996, Is there an association between season of birth and reading disability? Journal of Developmental and Behavioral Pediatrics 17(1): 22-26.

Fogel, R.W. 1994. Economic growth, population theory, and physiology: the bearing of longterm processes on the making of economic policy. Am Econ Rev 84, 369-395.

Forsdahl A ,2002,Observations throwing light on the high mortality in the county of Finnmark.: Is the high mortality today a late effect of very poor living conditions in childhood and adolescence?, Int. J. Epidemiol. 31: 302-308.

Forsdahl A ,2002a, Commentary: Childhood deprivation and adult mortality, Int. J. Epidemiol. 31: 308.

Forsdahl A, 1973, Momenter til belysning ar den høye dødelighet, Finnmark Fylke.,Tidsskr Nor Lægeforen 93: 661-667

Forsdahl A,1977,Living conditions in childhood and subsequent development of risk factors for ateriosclerotic heart disease,J Epidemiology Community Health 32:34-37

Forsdahl A,1978,Are poor living conditions in childhood and adolescence an important risk factor for arteriosclerotic heart disease,British Journal of Preventive and Social Medicine 31: 91-95 
Forsen T, Eriksson JG, Tuomilehto J, Osmond C, Barker DJP,1999, Growth in-utero and during childhood among women who develop coronary heart disease: longitudinal study,British Medical Journal 319:1403-1407

Forsen T, Eriksson JG, Tuomilehto J, Reunanen A, Osmond C, Barker DJP,2000, The fetal and childhood growth of perons who develop type 2 diabetes,Ann Intern Med 133: 176-182

Fossey, E. and Shapiro, C. M. 1992. Seasonality in psychiatry - A review. Canadian Journal Psychaiatry 37:299-308.

Frost WH,1939, The age selection of mortality from tuberculosis in successive decades,American Journal of Hygiene 20:91-96

Gavrilova N.S., Gavrilov L.A., Evdokuskina, G.N., Semyonova V.G. (2002) Early life conditions and later sex differences in adult life, paper presented at the PAA 2002, Atlanta.

Goldberg, A. E., Newlin, D. B. 2000. Season of birth and substance abuse: Findings from a large national sample. Alcoholism: Clinical and Enviromental Research 24(6):774-780.

Goldman, N., Hu, Y. 1993. Excess mortality among the unmarried: a case study of Japan. Social Science and Medicine 36(4): 533-59

Goldman, N., Lord, G., Hu, Y. 1993. Marriage selection and age patterns of mortality: a mathematical investigation. Mathematical Population Studies 4(1): 51-73.

Greenwood M,1936,English death-rates: past, present and future. A valedictory address,Journal of the Royal Statistical Society 99:674-713

Greville, T.N.E. (1943) Rec. Am. Inst. Actuar. 32,29-43.

Gueri , M., Gonzalea, C., and Morin V. 1986. The effect of the floods caused by 'El Nino' on health. Disasters 10: 118-124.

Hafner, H., Haas, S., Pfeifer-Kurda, M., Eichhorn, S, Michitsuji, S, 1987, Abnormal seasonality of schizophrenic births. A specific finding? Eur. Arch. Psycjiatry Neurol. Sci. 236: 333-342.

Hare E.H., 1975, Season of birth in Schizophrenia and Neurosis, Am J. Psychiatry 132, 11681171

Hare, E., Moran, P. 1981. A relation between seasonal temperature and the birth rate of schizophrenic patients. Acta Psychiatr. Scand. 63, 396-405.

Harris B,2001, Commentary: 'The child is father of the man.' The relationship between child health and adult mortality in the 19th and 20th century, Int. J. Epidemiol. 30: 688-696.

Haslam, N, Mayberry, JF, Hawthorne, AB, Newcombe, RG, Holmes, GKT, Probert, CSJ. 2000: Measles, month of birth and Crohn's disease, Gut47:801-803. 
Hellmuth, K, and Wnoroski, 1923, Variationsstatistischer Beitraf zur Frage des Einflusses der Jahreszeit auf das Koepergewicht der Neugeborenen, Klinischfe Wochenschrift 2: 75-78.

Helgasson, T, Jonasson, M R. 1981. Evidence for a food additive as a case of ketosis-prone diabetes, Lancet ii:716-720.

Helsen, W.F., Starkes J L, van Winckel, J, 1998, The influence of relative age on success and dropout in male soccer player, American Journal of Human Biology 10(6): 791-798.

Henderson, A. S., Korten, A. E., Jorm, A. F., McCusker, E., Creasy, H., and Broe, G. A. 1991. Season of birth in Alzheimer's disease in the Southern hemisphere. Psychological Medicine 21:371-374.

Higgins, C. D. Dos-Santos-Silva, I.; Stiller, C. A. Swerdlow AJ. 2001. Season of birth and diagnosis of children with leukaemia : an analysis of over 15000 UK cases occurring from 1953-95. British Journal of Cancer. 84(3):406-412.

Hillman RW and Conway HC (1972) Season of birth and relative body weight. American Journal of Clinical Nutrition 25:279-281.

Hillman, RW, Slaterand, P, Nelson, MJ, 1970, Season of birth, parental age and body form. Some Interrelationships in young women, Human Biology 42: 570.

Horiuchi, S. 1983. The long-term impact of war on mortality: old-age mortality of the First World War survivors in the Federal Republic of Germany Population Bulletin of the United Nations 15:80.

Hu, Y. H., Kurioshi, T., Matsushita, Y., Nagata, C., and Shimizu, H. 1996. Birth season and breast cancer risk in Japan. Breast Cancer Research \& Treatment 39( 3):315-319

Hummel, M.; Ziegler, A. G.; Lewy, H.; Ashkenazi, I;. Laron, Z.; 2001. IAA/GAD-positive offspring of diabetic parents have a different seasonality in month of birth than antibodynegative offspring. Diabetes Care. 24(11).

Huntington, E. (1938) Season of birth (New York: J. Wiley \& Sons, Inc.) Huxley R, Neil A, Collins R,2002,Unravelling the fetal origins hypothesis: if there really an inverse relationship between birthweight and subsequent blood pressure,Lancet 360: 659-65

Ivarsson, A.; Hernell, O.; Nystrom, L.; Persson, L. A. 2003. Children born in the summer have increased risk for coeliac disease. Journal of Epidemiology and Community Health 57(1):36-39

James, W H, 1978, Seasonality in Schizophrenia (letter), Lancet, March:664.

Jansson, B. and Malahy, M. A. 1981. Cancer risk, Age at diagnosis, and Age at death as functions of season of birth. Cancer Detection and Prevention 4:291-194.

Jongbloet P.H. 1975. The effects of pre-ovulatory overripness of human eggs on development. In Blandau, R.J. (ed.), Aging Gametes, S. Karger. Basel, Switzerland, 300-329. 
Jongbloet, P. H., Greonewould, H. M. M., and Hirasing, R. A. Vaan Buuren S. 1998. Seasonality of birth in patients with childhood diabetis in the Netherlands. Diabetis Care 21:190-191.

Joseph, KS, Kramer MS,1996,Review of the Evidence of Fetal and Early Childhood Antecedents if Adult Chronic Disease,Epidemiol Rev 18(2): 158-174

Kannisto V, Christensen K, Vaupel JW.,1997,No increased mortality in later life for cohorts born during famine.,Am J Epidemiol. 1,145(11):987-94.

Karl, T.R. \& Koss W.J., 1984: "Regional and National Monthly, Seasonal, and Annual Temperature Weighted by Area, 1895-1983." Historical Climatology Series 4-3, National Climatic Data Center, Asheville, NC, 38 pp.

Keller CA and Nugent RP (1983) Seasonal patterns in perinatal mortalityand preterm delivery. American Journal of Epidemiology 118 (5):689-698.

Kermack WO, McKendrick AG, McKinlay PL,1934, Death-rates in Great Britain and Sweden. Some general regularities and their significance ,Lancet 226:698-703

Kermack WO, McKendrick AG, McKinlay PL,2001, Death-rates in Great Britain and Sweden. Some general regularities and their significance, Int. J. Epidemiol. 30: 678-683.

Kettl, P. A. Collins T. Sredy M. \& Bixle E. O. 1997. Seasonal differences in suicide birth rates in Alaska Natives compared to other populations. American Indian and Alaska Native Mental Health Research 8:1-10.

Kida, K., Mimura, G., Ito, T., Murakami, K., Ashkenazi, I., Laron, Z. 2000. Incidence of type 1 diabetis (IDDM) in children (0-14 years) in Japan (1986-1990) including an analysis for seasonality of onset and month of birth. Diabetic Medicine 17:59-63.

Kinabo J (1993) Seasonal variation of birthweight distribution in Morogoro, Tanzania. East African Medical Journal 70 (12):752-755.

Kinlen LJ, \& Willows, AN. 1987. Cancer of the testis and month of birth, British Journal of cancer 55: 579-581.

Kitagawa EM \& Hauser PM 1973. Differential Mortality in the United States: A study in socioeconomic epidemiology. Cambridge, MA: Harvard University Press.

Kliewer E, 1992, Epidemiology of dieseases among migrants, International migration141-64.

Knox AG \& Cummins, C. 1985. Birth dates of men with cancer of the testis. Journal of Epidemiology and Community Health 39:237-243.

Köppen, W. 1936: Das geographische System der Klimate. In: KÖPPEN, W., u. R. GEIGER: Handbuch der Klimatologie. Band 1, Teil C. Berlin. 
Kordonouri, O, Shuga, N, Lewy, H, Ashkenazi, I, Laron, Z, 2002, Seasonality of month of birth of children and adolescents with type 1 diabetes mellitus in Berlin differs from the general population, European Journal of Pediatrics 161: 291-292.

Korlath JA, Osterholm MT, Judy LA, Forfang JC, Robinson RA. 1985. A point-source outbreak of campylobacteriosis associated with consumption of raw milk. J Infect Dis 152:592-6.

Koziel, S and Jankowska, EA, 2002, Birtweight and stature, body mass index and fat distribution of 14-year-old Polish adolescents, J. of paedriatrics and Child Health 38(1): 5558 .

Kramer MS,2000,Invited commentary: Association between restricted fetal growth and adult chronic disease: Is it causal? Is it important?, Am J Epidemiol 152 (7): 605-608

Kramer, MS, 1987, Determinants of low birthweight: methodological assessment and metaanalysis, Bull World Health Organ 65: 663-737.

Kuh, D. \& Davey Smith, G. 1993. When is mortality risk determined? Historical insights into a current debate. Social History of Medicine 6(1), 101-123.

Kunugi, H., Watanabe, H., Sekiba, K., and Kazamatsuri, H.1998. Season of birth of chronic alcoholics. Journal of Psychiatric Research 32:321-323.

Lam, D.A. \& Miron, J.A. 1996. The effects of temperature on human fertility. Demography 33, 291-306.

Langlois, B., Blouin, C., 1998, Effect of a horse's month birth on its future sport performance. II. Effect on annual earnings per start., Annales de Zootechnie 47(1): 67-74

Laron, Z., Shamis, I., Nitzan-Kaluski, D., and Ashkenazi, I. Month of birth and subsequent developmentof type 1 diabetis (IDDM). 1999. The Journal of Pediatric Endocrinology \& Metabolism 12:397-402.

Lau, Y. I. and Karlberg, J. 1998. Prevalence and risk factors of childhood asthma, rhinitis and eczema in Hong. J Paediatr Child H 34(1):47-52.

Lechner I, Mielck A. 1998, Die Verkleinerung des "Healthy Migrant Effects": Entwicklung der Morbidität von ausländischen und deutschen Befragten im Sozio-Ökonomischen Panel 1984-1992. Gesundheitswesen60: 715-20.

Leon DA, Davey Smith G,2000,Infant mortality, stomach cancer, stroke, and coronary heart disease: ecological analysis ,British Medical Journal , 320 (7251): 1705-1706

Leon DA, Johansson M, Rasmussen F,2000, Gestational Age and Growth Rate of Fetal Mass Are Inversely Associated with Systolic Blood Pressure in Young Adults: An Epidemiologic Study of 165,136 Swedish Men Aged 18 Years, Am. J. Epidemiol.152: 597604. 
Lester, D. 1987. Month of birth of suicides, homicides and natural deaths. Psychological Reports 60: 1310.

Lester, D., Reeve, C. L., and Priebe, K. 1970. Completed suicide and month of birth. Psychological Reports 27:210.

Levenstein, H. 1988. Revolution at the Table: The transformation of the American Diet. New York, Oxford, University Press.

Levenstein, H. 1993. Paradox of Plenty: a Social History of Eating in Modern America. New York. Oxford, University Press.

Levine, M. E. and Wojcik, B. E. 1999. Alcoholic typology and season of birth. Journal of Addictive Disorders 18:41-52.

Lewis M S, Griffin P A, 1981, An explanation for the season of birth effect in schizophrenia and other diseases, Psychol. Bull 89, 589-596.

Lillard L.A. \& Panis C.W.A. 1996. Marital Status and Mortality: The Role of Health (in Mortality), Demography 33(3): 313-327.

Liang, K. -Y \& Zeger, S.L. (1986) "Longitudinal data Analysis Unsing Generalized Linear Models", Biometrika, 13-22.

London, W. P. 1998. Alcoholism: Theoretical consideration of season of birth and geographic latitude. Alcohol. 4:127-129.

Lucas, A, Fewtrell, MS, Cole, TJ, 1999, Fetal origins of adult disease: the hypothesis revisited, British Medical Journal 319: 245-249.

Lummaa V, Lemmetyinen R, Haukioja, E, Pikkola, M. 1998. Seasonality of births in Homo sapiens in preindustrial Finland: maximisation of offspring survivorship? Journal of Evolutionary Biology 11: 147-157.

Madico, G., McDonald J., Gilman R.H., Cabrera, L., Sterling, C.R. 1997. Epidemiology and treatment of Cyclospora cayetanenis infection in Perucian children. Clin. Infect. Dis. 24:977981.

Maheswaran R, Strachan DP, Dodgeon B, et al.,2002,A population-based case-control study for examining early life influences on geographical variation in adult mortality in England and Wales using stomach cancer and stroke as examples,Int J Epidemiol 31 (2): 375-382 APR

Mason WM, Smith HL,1985,Age-period-cohort analysis and the study of deaths from pulmonary tuberculosis. In (Mason WM, Fienberg SE eds) Cohort Analysis in Social Research: Beyond the Identification Problem,New York, NY:Springer-Verlag,pp151-227

Matsuada S et al (1993) Seasonality of mean birthweight and mean gestational period in Japan. Human Biology 65 (3):481-501. 
Mattock, C., Marmot, M., and Stern, G. 1988. Could Parkinson's disease follow intra-uterine influenza? A speculative hypothesis. Journal of Neurology, Neurosurgery and Psychiatry 35:753-756.

McNeil, T., Dalen, P., Dzierzykray-Rogalska, M., Kaij, L., 1975. Birth rates of schizophrenics following relatively warm versus relatively cool summers. Arch Psychiatr. Nervenkr. 221,110 .

Mills, CA, 1941, Mental and Physical Development as influenced by season of conception, Human Biology 13: 378-389.

Miura T, 1987 Seasonality of birth: The Hague, SPB Academic Publishing.

Miura, T., Shimura, M., and Kimura, T. 1987. Season of birth in parkinsonism. In Miura T. (ed) Seasonality of birth: Progress in biometeorology . Hague, Netherlands. 157-162.

Modestin, J., Ammann, R., and Wurmle, O. 1995. Season of birth: Comparison of patients with schizophrenia, affective disorders, and alcoholism. Acta Psychatrica Scandinavia 91:140143.

Moore S.E. 1998. Nutrition, immunity and the fetal and infant origins of disease hypothesis in developing countries. Proceedings of the Nutrition Society 57, 241-247.

Moore, S.E., Cole, T.J., Poskitt EME, Sonko, B.J., Whitehead R.G., McGregor I.A. \& Prentice A.M. 1997. Season of birth predicts mortality in rural Gambia. Nature 338,434.

Morgan, R., 1978. Seasonality in Schizophrenia (letter). Lancet, 830.

Nakao, H, 1988. Season of birth breast cancer patients and its relation to patient's reproductive history in Tokyo, Japan. Acta Med Okayama 42(4):231-241.

Nelson W, Tong YL, Lee J-K, Halberg F. Methods for cosinor rhythmometry. Chronobiologia 1979; 6: 305-23.

Neu, A., Kehrer, M., Ashkenazi, I., and Laron, Z. 2000. Seasonality of birth in children (0-14 years) with diabetis mellitus type 1 in Baden-Württemberg, Germany. The Journal of Pediatric Endocrinology \& Metabolism 13:1081-1085.

Nielsen, S. 1992. Seasonal variation in anorexia nervosa? Some preliminary findings from a neglected area of research. The International Journal of Eating Disorders 11:25-35.

Nielsen, LL, Nielsen NM, Melbye M, Sodermann, M, Jacobsen M, Aaby, P. 1998. Exposure to measles in utero and Crohn's disease: Danish register study, British Medical Journal 316: 196-197.

Nilsson, L, Bjorksten, B, Hattevig, G, Kjellman, B, Sigurs, N, Kjellman, N I M, 1997. Season of birth as predictor of atopic manifestations, Archives of Disease in Childhood 76(4): 341344. 
Nonaka, K. and Imaizumi, Y. 200x. Deaths from cerebrovascular diseases correlated to month of birth: elevated risk of death from subarachnoid hemorrhage among summer born. International Journal of Biometeorology 44:182-185.

Norjavaara E, de Verdier MG, Lindmark B. 2001. Adult height in women with childhood asthma - a population-based study. PHARMACOEPIDEM DR S 10 (2): 121-125.

Orford S, Dorling D, Mitchell R, et al.,2002,Life and death of the people of London: a historical GIS of Charles Booth's inquiry,Health Place 8 (1): 25-35

Osmond C, Barker DJP, Slattery JM,1990,Risk of death from cardiovascular disease and chronic bronchitis determined by the place of birth in England and Wales,Journal of Epidemiology and Comm Health 44(2):139-141

Otto, W and Glaass, R, 196x, Inwieweit sind Tragezeit, Koerperlaenge und Koerpergewicht der Neugeborenen von jahreszeitlichfen Einfluessen abhaengig?, Deutsches Gesundheitswesen 14(35): 1625-1628.

Otto, W, and Noack, H, 1957, Jahreszeitliche Schwankungen der Koerpermasse bei 100000 neugeborenen Berliner und Leipziger Kindern, Zur menschlcihen Vererbungs und Konstitutionslehre 34: 250-260.

Pallast, E.G.M., Jongbloet, P.H., Straatman, H.M., Zielhuis, G.A. 1994. Excess seasonality of births among patients with schizophrenia and sesonal ovopathy, Schizophrenia Bull. 129, 355361.

Pasamanick, B., 1986. Seasonality of schizophrenia births (letter) Am. J. of Orthopsychiatry 56, 168-169.

Pflug, E. J. S., 2001, Season of birth, schooling and earnings, Journal of Economic

Phillips DIW (1993) Twin-studies in medical research - can they tell us whether diseases are genetically determined, Lancet 341: 1008-1009.

Philips DIW and Young JB (2000) Birthweight, climate at birth and the risk of obesity in adult life. International Journal of Obesity 24:281-287.

Philpot, M., Rottenstein, M., and Burns, A. 1989. Season of birth in Alzheimer's disease . The British Journal of Psychiatry 155:662-666.

Pokorny, A. D. 1960. Characteristics of 44 patients who subsequently committed suicide. Archives of General Psychiatry2 :314-323.

Pollitt EAJ (1989) Seasonality and weight gain during the first year of life. American Journal of Human Biology 1:747-756.

Prener, A \& Carstensen, B. 1990. Month of birth and Testicular cancer risk in Denmark. American Journal of Epidemiology 131(1): 15-19. 
Prentice, AM, Whitehead, RG, Roberst, SB, and Paul AA, 1981, Long term energy balance in childbearing Gambian women, Am. J. Clin. Nutr 34: 2790-2799.

Preston, S.H. \& Haines, M.R. 1991 Fatal years. Child mortality in late nineteenth-century in America (Princton University Press, Princton).

Preston, S.H., Hill, M.E., Drevenstedt, G.L. 1998. Childhood conditions that predict survival to advanced ages among African Americans. Social Science and Medicine 47 (9):1231-1246.

Preston, SH and van de Walle, E. 1978. Urban French Mortality in the Nineteenth Century, Population Studies 32 (2):275-297.

Pringle DG,1998,Hypothesized foetal and early life influences on adult heart disease mortality: An ecological analysis of data for the Republic of Ireland,Soc Sci Med 46 (6): 683693 MAR

Procopio, M. and Marriott, P. K. 1998. Seasonality of birth in epilepsy: A danish study. Acta Neurologica Scandinavica 98:297-301.

Quested, D.J. 1991. Incidence rates of schizophrenia (letter). Br. J. Psychiatry 159, 587-588.

Razum, O, Zeeb, H, Akgün HS, Yilmaz S. 1998, Low mortality of Turkish residents in Germany persits and extends into to second generation: merely a healthy migrant effect? Trop Med Int Health 3: 297-303

Regidor E, Gutierrez-Fisac JL, Calle ME, et al.,2002,Infant mortality at time of birth and cause-specific adult mortality among residents of the region of Madrid born, INT J EPIDEMIOL 31 (2): 368-374

Reinsch, H. (1967), Smoothing by spline functions, Numerische Mathematik 10: 177-83.

Rezaul, I., Persaud, R., Takei, N., and Treasure, J. 1996. Season of birth and eating disorders. The International Journal of Eating Disorders 19:53-61.

Ringbäck W, Gullberg A, Hjern A, Rosén M, Mortality statistics in immigration research: method for adjusting underestimation of mortality, International Journal of Epidemiology 28: 756-763.

Roberts S, Paul A A, Cole, T J and Whitehead, RG, 1982, Seasonal changes in activity, birthweight, and lactational performance in rural Gambian women, Trans. R. Soc. Trop. Med. Hygiene 76: 668-678

Roseboom TJ, van der Meulen JHP, Osmond C, et al.,2001,Adult survival after prenatal exposure to the Dutch famine 1944-45,PAEDIATR PERINAT EP 15 (3): 220-225

Rothwell, P. M., Gutnikow, S. A., McKinney, P. A., Schober, E., and Ionescu- 
Rousham EK and Gracey M (1998) Seasonality of low birthweight in indigenous Australians: an increase in pre-term birth or intrauterine growth retardation? Australian \& New Zealand Journal of Public Health 22 (6):669-672.

Sadovnick, A. D. Yee, I. M. L. 1994. Season of birth in Multiple sclerosis. Acta Neurologica Scandinavia 89:190-191.

Salemi, G., Ragonese, P., Aridon, P., Reggio, A., Nicoletti, A., Buffa, D., Conte, S., and

Salib, E. 2002. Month of birth and suicide: An exploratory study, International Journal of Psychiatry in Clinical Practice 6(1):39-44.

Samuelsson, U., Johansson, C. \& Ludvigsson, J. 1999. Month of birth and risk of developing insulin dependent diabetes in southeast Sweden Arch Dis Child 81,143-146.

Sanborn, D. E. and Sanborn, C. J.1974. Suicide and month of birth. Psychological Reports 34:950.

Savettieri, G. 2000. Is season of birth associated with multiple sclerosis? Acta

Schaefer, T, Przybilla, B, Ring, J, Kunz, B, Greif, A, Ueberla, K. 1993. Manifestation of Atopy is not related to patiemt's month of birth, Allergy 48(4):291-294.

Schneider D, Greenberg M, Lu L,1997a,Early life experiences linked to diabetes mellitus: A study of African-American migration,J NATL MED ASSOC 89 (1): 29-34

Schneider D, Greenberg MR, Lu LL,1997b, Region of birth and mortality from circulatory diseases among black Americans,AM J PUBLIC HEALTH 87 (5): 800-804

Shears, P. \& Wright, A., 1995. Community-acquired infections among children in an urban environment: a-2-year prospective study in Liverpool, U.K. J Infect 1995 30(2): 173-177.

Shimura, M., Kimura, T., and Miura, T. 1987 Season of birth in some neurological disorders Multiple sclerosis, amyotrphic lateral sclerosis, senole dementia. In Miura, T. (ed.)

Seasonality of birth: Progress in biometeorology . Hague, Netherlands. 163-168.

Smithers, A.G. \& Cooper, H.J. (1984) Social class and season of birth J Soc Psychol 124, 7984.

Songini, M., Casu, A., Ashkenazi, I., and Laron, Z. 2001. Seasonality of birth in children (014 years) and young adults (0-29 years)with type 1 Diabetes Mellitus in Sardinia differs from that in the general population . The Journal of Pediatric Endocrinology \& Metabolism 14(6):781-783.

Sonnenberg A, Mueller H, Pace F,1985, Birth-cohort analysis of peptic ulcer mortality in Europe,J Chron Dis 38: 309-317

Sonnenberg A,1987,Causative factors in the etiology of peptic ulcer disease become effective before the age of 15 years,J Chron Dis 40: 193-202 
Sorensen HT. Pedersen L. Olsen JH. Rothman KJ. 2001. Seasonal variation in month of birth and diagnosis of early childhood acute lymphoblastic leukemia., Journal of the American Medical Association. 285(2):168-169.

Speare, A, Meyer, JW, 1988, Types of elderly residential mobility and their determinants, Journal of Gerontology Social Sciences 43: S71-S74.

Strachan DP, Leon DA, Dodgeon B,1995,Mortality from cardiovascular disease among interregional migrants in England and Wales,British Medical Journal 310 (6977): 423-427

Strachan, D. P., Seagroatt, V., and Cook, D G. 1994. Chest illness in infancy and chronic respiratory disease in later life: An analysis by month of birth . INT J EPIDEMIOL 23(5):1060-1068.

Susser M, Stein Z,1962,Civilication and Peptic ulcer,Lancet 1:115-119

Susser M,2001,The longitudinal perspective and cohort analysis,Int J Epidemiol 30: 684-87

Swerdlow AJ. 1991, Mortality and cancer incidence in Vietnamese refugees in England and Wales: a follow-up study. International Journal of Epidemiology 20:13-19.

Templer DI, Trent NH, Spencer DA, Trent A, Corgiat MD, Mortensen PB, Gorton M 1992. Season of birth in multiple sclerosis. Acta Neurologica Scandinavica 85 (2): 107-109.

Thors H, Svanes C, Thjodleifsson B,2002,Trends in peptic ulcer morbidity and mortality in Iceland,J Clin Epidemiol 55 (7): 681-686

Ticher, A., Ring, A., Barak, Y., Elizur, A., and Weizman. A. 1996. Circannual pattern of autistic births: Reanalysis in three ethnic groups. Human Biology 68:585-592.

Tirgoviste, C. 1999. Seasonality of birth in children with diabetis in Europe: multicentre cohort study. BMJ. 319:887-888.

Toft-Sorensen, H, Pedersen, L, Norgard, B, Fonager, K, Rothmann, KJ. 2001, Does monthof birth affect risk of Crohn's disease in childhood and adolescence?, British Medical Journal 323:907.

Torrey, E.F., Bowler, A.F., Rawlings, R. 1991. An influenza epidemic and the seasonality of schizophrenic births. In: Kurstak, E. (Ed), Psychiatry and Biological Factors. Plenum Medical Book Company, New York:109-116.

Torrey, E.F., Miller, J., Rawlings, R. \& Yolken, R.H. 1997. Seasonality of births in schizophrenia and bipolar disorders: a review of the literature. Schizophr Res 28,1-38.

Torrey, E.F., Torrey, B.B., Peterson, M.R. 1977. Seasonality of schizophrenic births in the United States. Arch. Gen. Psychiatry 34: 1065-1070.

Townbridge, FL and Newton, LH 1979, Seasonal changes in malnutrition and diarrheal disease among preschool schildren in El Salvador. Am. J. Trop. Med. Hygiene 28: 135-141. 
Turnquist, K. 1993. Second-trimester markers of fetal size in schizophrenian(letter) Am. J. Psychiatry 150, 1571-1572.

Ursic-Bratina, N., Battelino, T. Krzisnik C., Laron-Kenet, T., Ashkenazi, I., and Laron, Z. 2001. Seasonality of birth in children (0-14 years) with diabetis mellitus type 1 in Slovenia. The Journal of Pediatric Endocrinology \& Metabolism 14:47-52

Vaiserman, A.M, Collinson, AC, Koshel, NM, Belaja, II, Voitenko, VP, . 2002. Seasonal programming of adult longevity in Ukraine, International Journal of Biometeorology 47:4952.

Valkonen, T. 1989. Adult mortality and level of education: a comparison of six countries. In: Fox J (ed.), Health Inequalities in European Countries. Aldershot: Gower Publishing, 142162.

Vaupel JW, Gambill BA, Yashin AI. 1987. Thousands of data at a glance - shaded contour maps of demographic surfaces, Popul Index 53 (3): 376-376.

Vaupel, JW, Wang, Z, Andreev, KF, Yashin, AI.1997. Population Data at a Glance: Shaded Contour Maps of Demographic Surfaces over Age and Time, Odense Monographs on Population Aging, 4, Odense: Odense University Press.

Vezina, H, Houde, L., Charbonneau, H., Beaudry, M., Cholette, A., Daoud, N., Mathieu, J., Robitaille, Y., Veilleux, F., and Gauvreau, D. 1996. Season of birth and Alzheimer's disease : a poulation-based study in Saguenay-Lac-St-Jean/Quebec (IMAGE-Project). Psychological Medicine 26(1):143-149.

Vitiello, B., Hill, J. L., Molchan, S. E., Martinez, R. A., Martinson, H. J., and Sunderland, T. 1991. Lack of seasonal variation in the birth of patients with dementia of the Alzheimer's type. Psychiatry Research 39:21-24.

Waaler H.F. 1984. Height, Weight and Mortality - The Norwegian Experience. Acta Med Scand 1-\&Suppl 679.

Ward WP (1987) Weight at birth in Vienna, Austria, 1865 - 1930. Annals of Human Biology 14 (6):495-506.

Watson, C. G.,Kucala, T., Tilleskjor, C., and Jacobs, L. 1984. The birth effect in nonschizophrenic psychiatric patients. Journal of Clinical Psychology 40:884-888.

Watson, C.G., Kucala, T., Tilleskjor, C., Jacobs, L. 1984. Schizophrenic birth seasonality in relation to the incidence of infectious diseases and temperature extremes. Arch. Gen.

Psychiatry 41, 85-90.

Weber, GH, Prossinger, H, Seidler, H, 1998, Height depends on month of birth, Nature 391: 754-755. 
Wehr, T. 1998. Effect of seasonal Changes in Daylength on Human Neuroendocrine Function, Horm Res 49: 118-124.

Wendl-Richter HU (1997) Birthweight distribution in rural north-west Burkina Faso. Trop Med Int Health 2 (4):404-408.

Wiberg, M. and Templer, D. I. 1994. Season of birth in multiple sclerosis in Sweden:

Replication. Journal of Orthomolecular Medicine 9(2):71-74.

Wilmoth,JR. 1986. Age-Period-Cohort Analysis of Mortality Data- An Exploratory Approach, Population Index 52 (3): 416-416.

Wilmoth J, Vallin J, Caselli G. 1989. Differences between observed and expected cohort mortality, Population 44 (2): 335-376.

Willis, J. A.; Scott, R. S.; Darlow, B. A.; Lewy, H.; Ashkenazi, I.; Laron, Z. 2002.

Seasonality of birth and onset of clinical disease in children and adolescents (0-19years) with type 1 diabetes mellitus in Canterbury, New Zealand, Journal of Pediatric Endocrinology \& Metabolism 15(5): 645-647

Wohlfahrt J et al (1998) Secular and seasonal variation of length and weight at birth. Lancet 352:1990.

$\mathrm{Xu} X$ et al (2001) Seasonality of growth in Shanghai infants $(\mathrm{n}=4128)$ born in 11 consecutive years. European Journal of Clinical Nutrition 55 (8):714-725.

Ye Chen, R.-G., Ashkenazi, I., and Laron, Z. 1998. Lack of seasonality in childhood IDDM (0,7 -15 years) in Shanghai, China. The Journal of Pediatric Endocrinology \& Metabolism 11:461-464

Young, CM, 1987, Migration and Mortality: The Experience of Birthplace Groups in Australia, International Migration Review 21 (3): 531-554.

Yuen, J., Ekbom, A., Trichopoulos, D., Hsieh, C.-C., and Adami, H.-O. 1994. Season of birth and breast cancer risk in Sweden. Br. J. Psychiatry 70 :564-568. 